\title{
Charakterisierung der Eaf 1-Funktion für die Biogenese der Aminopeptidase 1
}

\author{
Dissertation \\ zur Erlangung des mathematisch-naturwissenschaftlichen \\ Doktorgrades „Doctor rerum naturalium“ \\ der Georg-August-Universität zu Göttingen
}

vorgelegt von

Tanja Christine Benkert

aus Nürnberg

Göttingen 2008 
D7

Referent: Prof. Dr. K. von Figura

Institut für Biochemie II, Zentrum Biochemie und Molekulare Zellbiologie der Georg-August-Universität zu Göttingen

Korreferent: Prof. Dr. G. H. Braus

Institut für Mikrobiologie und Genetik

der Georg-August-Universität zu Göttingen

Tag der mündlichen Prüfung: 03.07.2008 




\section{Inhaltsverzeichnis}

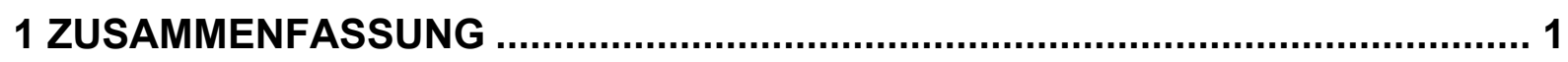

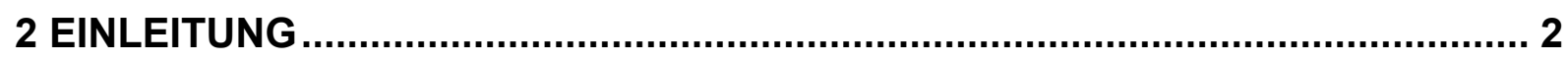

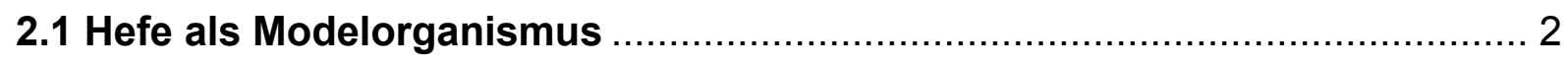

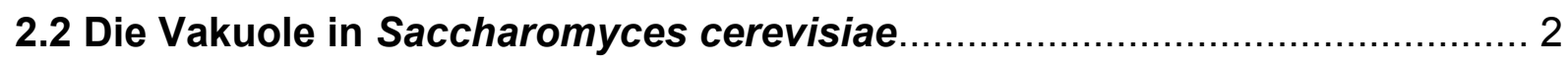

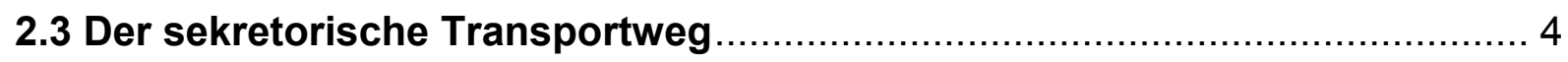

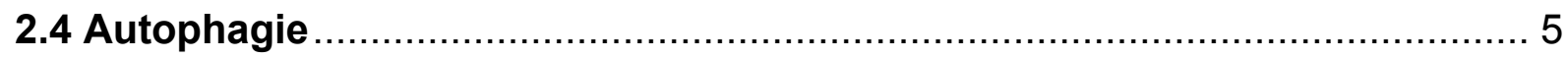

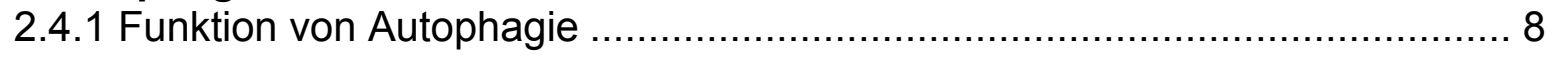

2.5 Cytoplasm to vacuole targeting (Cvt)-Transportweg …............................. 8

2.6 Vergleich von Autophagie und Cvt-Transportweg ….............................. 10

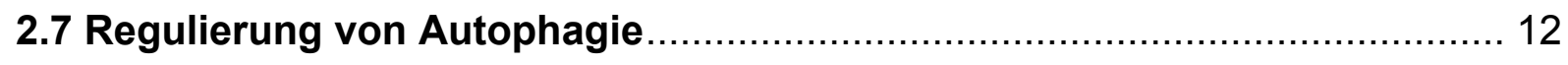

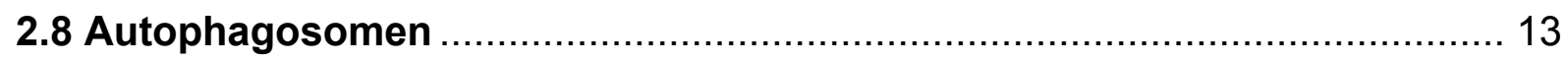

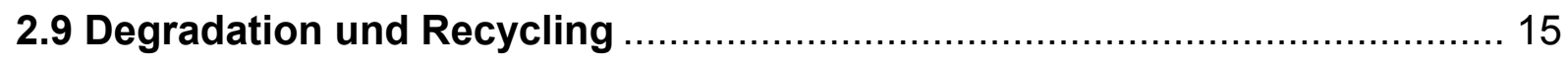

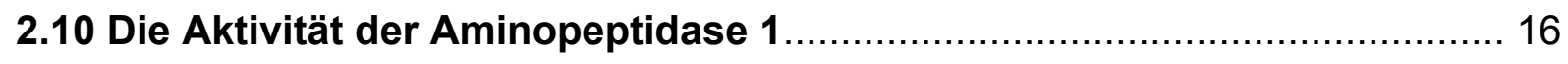

2.11 Charakterisierung von Mutanten ohne Aminopeptidase 1-Aktivität .......... 18

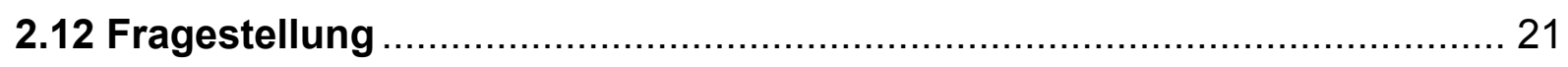

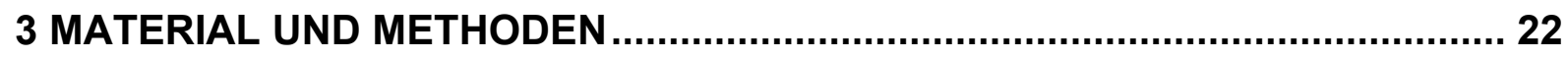

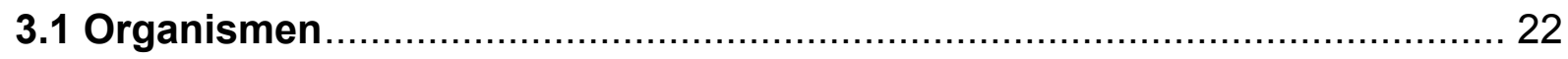

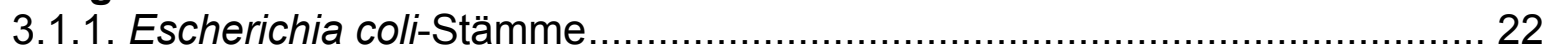

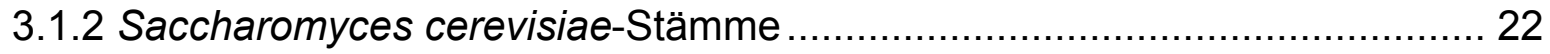

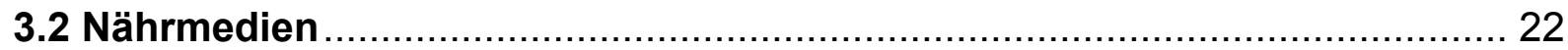

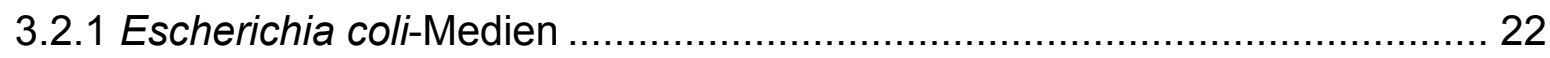

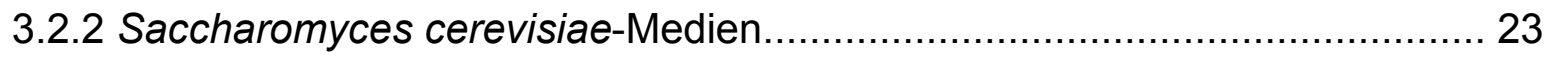

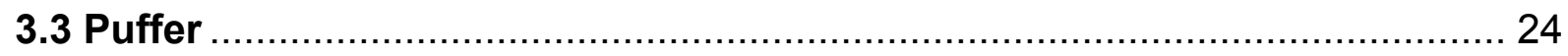

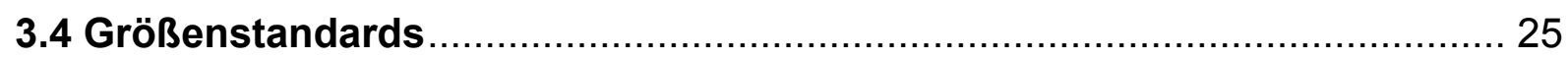

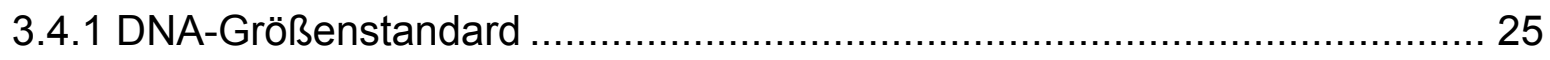

3.4.2 Protein-Größenstandards für SDS-Polyacrylamid-Gelelektrophorese ......... 25

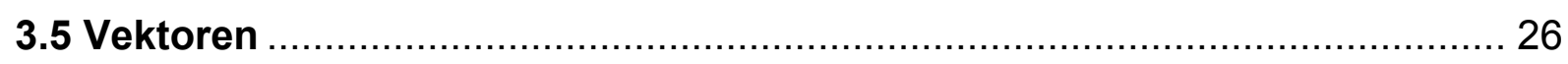

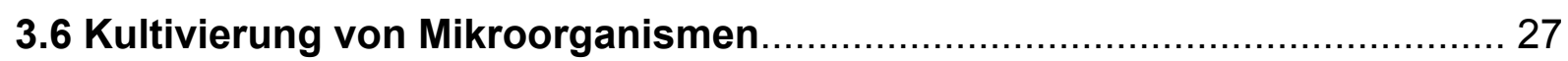

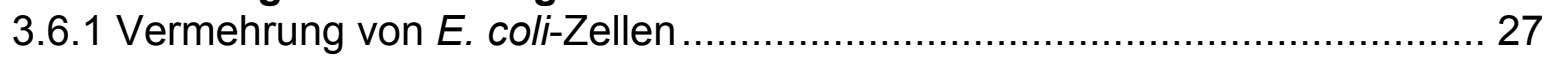

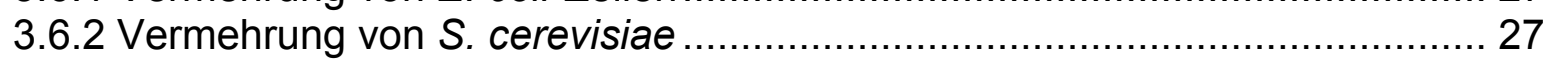

3.7 Bestimmung der Zelldichte in Flüssigkulturen ...................................... 27

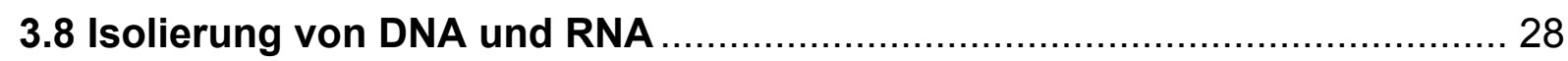

3.8.1 Isolierung von Plasmid-DNA aus E. coli über QIAprep Spin Plasmid Miniprep

Säulen. 
3.8.2 Isolierung von Plasmid-DNA aus E. coli über QIAprep Spin Plasmid Midiprep

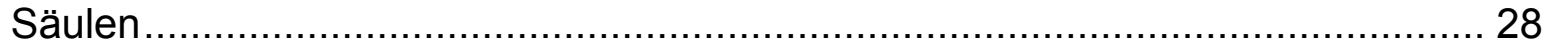

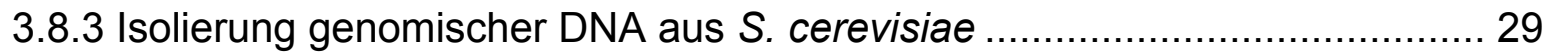

3.8.4 Isolierung von Plasmid-DNA aus S. cerevisiae .................................... 30

3.8.5 Isolierung von Gesamt-RNA aus S. cerevisiae ................................. 30

3.9 Photometrische Konzentrationsbestimmung von Nukleinsäuren .............. 32

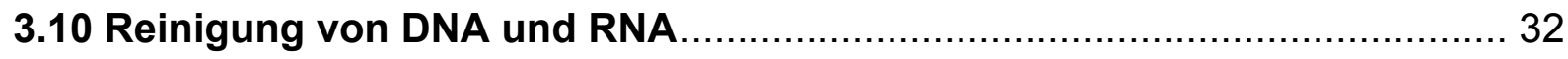

3.10.1 Fällung von DNA durch Ethanol ..................................................... 32

3.10.2 Phenol-Chloroform-Extraktion von DNA ......................................... 32

3.10.3 Aufreinigung DNase I behandelter RNA-Präperationen ........................ 33

3.11 Enzymatische Reaktionen mit DNA und RNA ................................. 33

3.11.1 In vitro Synthese spezifischer DNA-Fragmente mit Hilfe der Polymerase-

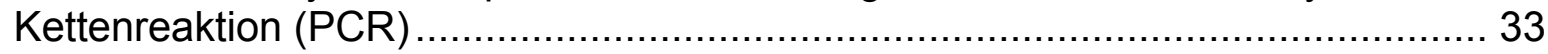

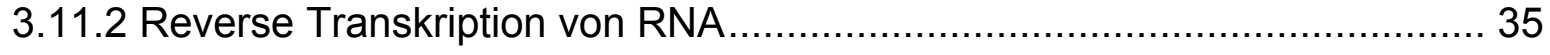

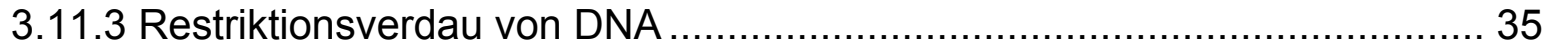

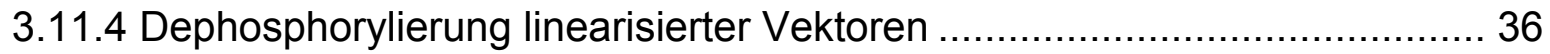

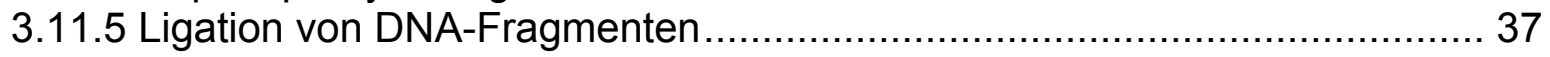

3.12 Agarose-Gelelektrophorese von DNA ....................................... 38

3.12.1 Isolierung von DNA-Fragmenten aus Agarosegelen mit dem QIAquick ${ }^{\mathrm{TM}}$

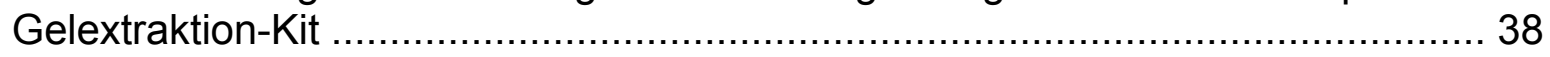

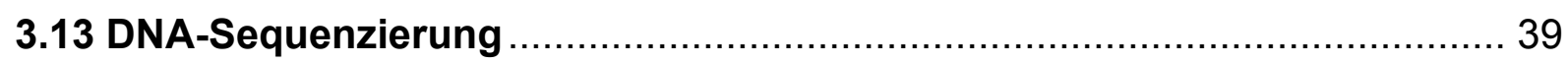

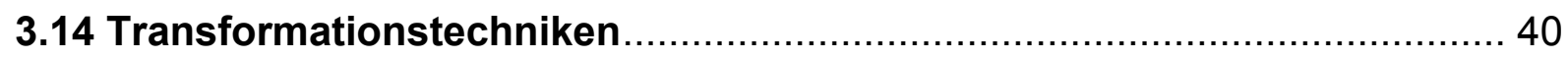

3.14.1 Transformation von E.coli Zellen über Elektroporation.......................... 40

3.14.2 Transformation von Hefe nach der Lithiumacetat-Methode .................... 41

3.15 Bestimmung des Paarungstyps ................................................. 42

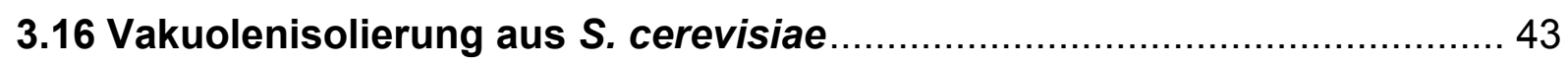

$3.17 \alpha$-Mannosidase-Aktivitäts-Assay .................................................. 44

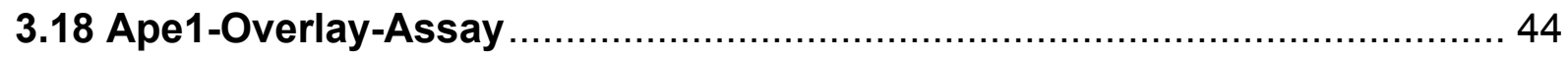

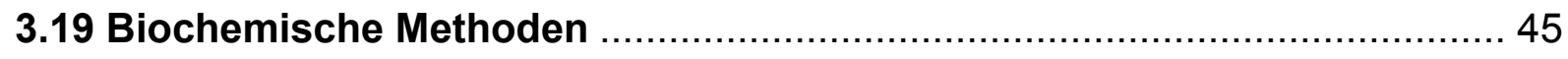

3.19.1 Ganzzellproteinextraktion aus Hefe ............................................ 45

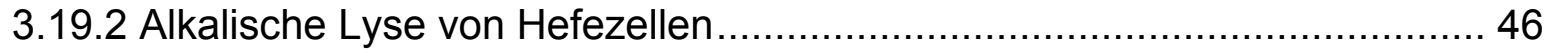

3.19.3 Zellaufschluß zum Nachweis von hyperacetyliertem Histon $\mathrm{H} 4$................ 47

3.19.4 Bestimmung der Proteinkonzentration ........................................ 47

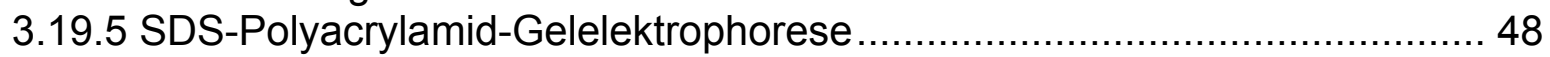

3.19.6 Gelfärbung mit Coomassie Blue.................................................... 49

3.19.7 Proteintransfer auf Membranen (Western Blot-Analyse) ....................... 49

3.19.8 Proteindetektion mit spezifischen Antikörpern und ECL (Enhanced

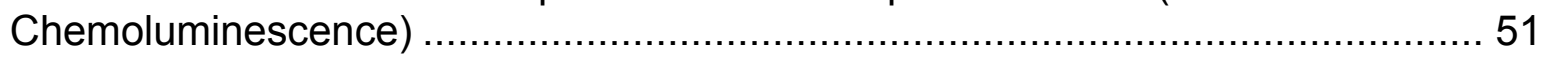

3.19.9 Entfernen membrangebundener Antikörper ..................................... 52

3.19.10 In situ Immunfluoreszenz ............................................................... 53

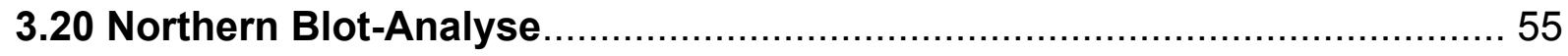

3.20.1 Gelelektrophoretische Auftrennung von RNA-Molekülen ........................ 55

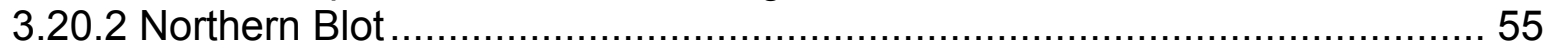

3.20.3 Prähybridisierung, Hybridisierung und Autoradiographie ...................... 56

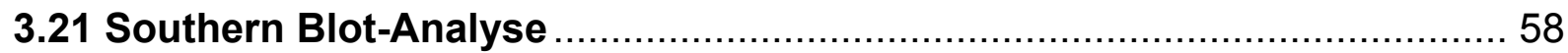

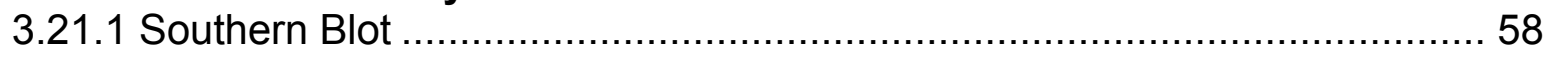


3.21.2 Entfernen von ${ }^{32} \mathrm{P}$-markierten Fragmenten von der Hybond ${ }^{+} \mathrm{N}-M e m b r a n$.. 59

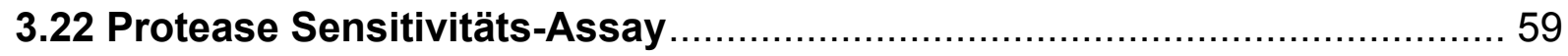

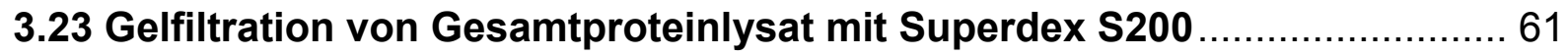

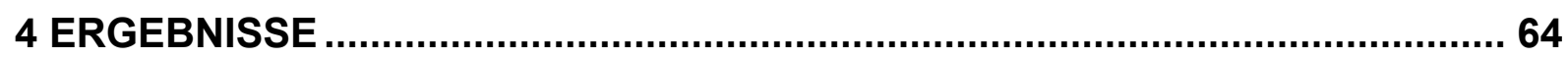

4.1 Genomische Integration der Aminopeptidase 1 in WT und via-Mutanten ... 64

4.2 Analyse des ORFs YDR360W ........................................................ 69

4.2.1 Der Einfluss von ORF YDR360W auf die Aktivität der Aminopeptidase 1... 69

4.2.2 Transkriptionsstudien der ORFs YDR360W und YDR359C ...................... 71

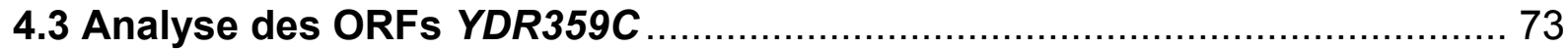

4.3.1 Der Einfluss des ORFs YDR359C auf die Aktivität der Aminopeptidase 1... 74

4.3.2 Herstellung von eaf1-Deletionsstämmen ........................................... 75

4.4 Charakterisierung von EAF1 in den Mutantenstämmen .......................... 78

4.5 Charakterisierung des Gens EAF1 .................................................... 81

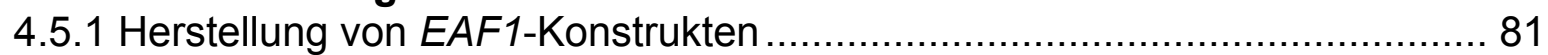

4.5.2. Der Einfluss von EAF1-Verkürzungen auf die Aktivität der Ape1 .............. 82

4.6 Der Einfluss von Eaf1 auf die Expressions- und Transkriptionsrate der

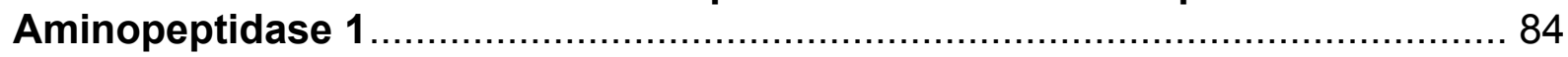

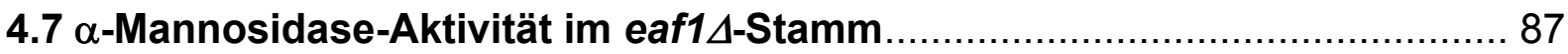

4.8 Eaf1 und seine Funktion innerhalb des NuA4-Komplexes ..................... 88

4.9 Herstellung weiterer Deletionsmutanten des NuA4-Komplexes ................ 91

4.10 Der Einfluss von Aminopeptidase 1-Überexpression auf die Wiederherstellung der Ape1-Aktivität in eaf1 $\Delta$-Stämmen ............................ 93

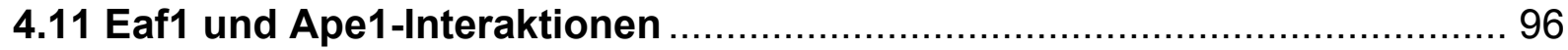

4.11.1 Lokalisationsstudien von Eaf1 und Ape1 …....................................... 96

4.11.2 „Yeast two Hybrid“-Interaktionsstudien von Eaf1 und Ape1 ...................... 98

4.12 Komplexassemblierung der Aminopeptidase $1 \mathrm{im}$ eaf1 $\Delta$-Stamm ........... 100

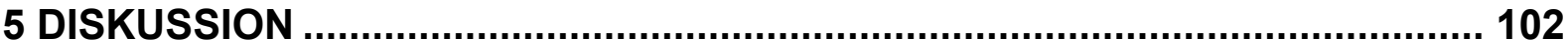

5.1 Suppression der Ape1-Aktivitätsdefizienz in den Mutanten via10 und via14

102

5.2 ORF YDR360W hat keinen Einfluss auf die Aminopeptidase 1-Aktivität... 104

5.3 ORF YDR359C beeinflusst die Aminopeptidase 1-Aktivität ..................... 106

5.3.1 Eaf1 suppremiert den Aktivitätsverlust im Mutantenstamm via14-2 ......... 106

5.3.2 Analyse von Eaf1-Domänen für die Induktion der Ape1-Aktivität............... 107

5.3.3 Der Einfluss von Eaf1 innerhalb des NuA4-Komplexes ........................... 108

5.3.4 Eaf1 induziert die Aminopeptidase 1-Transkription und -Expression ........ 109

5.3.5 Auswirkung einer Ape1-Überexpression auf die Ape1-Aktivität ................ 110

5.4 Weitere NuA4-Deletionsmutanten haben keinen Einfluss auf die Aktivität

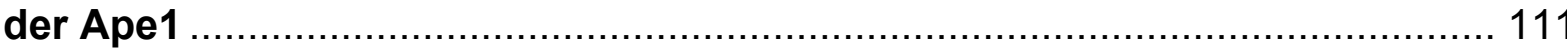

5.5 HA-Eaf1 co-lokalisiert mit der Ape1 im Zytoplasma ............................ 112 
5.6 Die Komplexassemblierung der Ape1 wird durch Deletion von EAF1 nicht

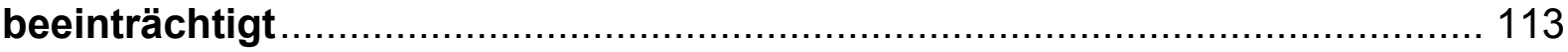

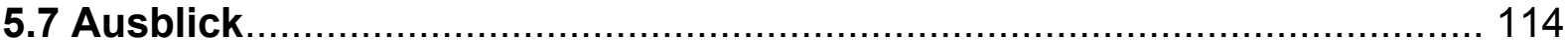

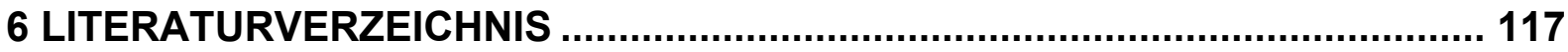

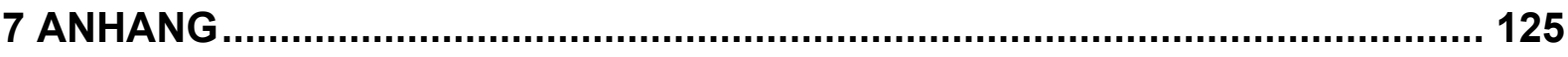

7.1 Saccharomyces cerevisiae-Stämme ………......................................... 125

7.2 Oligonukleotide ….......................................................................... 128

7.2.1 Oligonukleotide für Klonierungen in die Hefevektoren $p Y X 141,142,242$ und

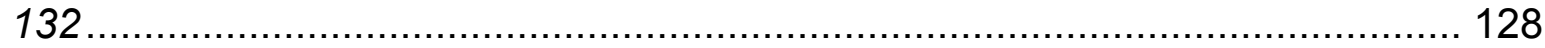

7.2.2 Oligonukleotide zur Klonierung der Hefevektoren pYX-HA141, 142 und 242

7.2.3 Oligonukleotide für Klonierungen in die Hefevektoren $p Y X-H A 141,142$ und

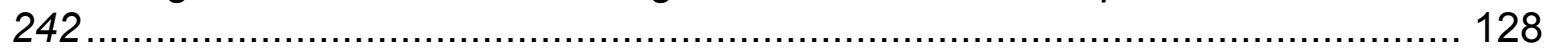

7.2.4 Oligonukleotide für Klonierungen in "Yeast two Hybrid“-Vektor pGADT7... 129

7.2.5 Oligonukleotide für Klonierungen in "Yeast two Hybrid“-Vektoren $p G B T 9$ und

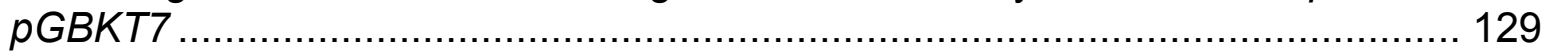

7.2.6 Oligonukleotide zur Verifizierung der Deletionsstämme........................ 129

7.2.7 Oligonukleotide für Sequenzierungen ................................................ 130

7.2.8 Oligonukleotide zur Amplifikation des HIS5 ${ }^{+}$-Gens aus pFA6a-HIS3MX6.. 130

7.2.9 Oligonukleotide zur Amplifikation von Sonden-DNA ............................... 131 


\section{Abkürzungen}

\begin{tabular}{|c|c|}
\hline Abb. & Abbildung \\
\hline $\begin{array}{l}\text { ad } \\
\alpha-\text { Maus-Ak }\end{array}$ & $\begin{array}{l}\text { „auf Endvolumen auffullen" } \\
\text { anti-Maus Antikörper }\end{array}$ \\
\hline Amp & Ampicillin \\
\hline APS & Amoniumpersulfat \\
\hline AS & Aminosäure \\
\hline ATP & Adenosintriphosphat \\
\hline bp & Basenpaar \\
\hline BSA & Rinderserumalbumin \\
\hline${ }^{\circ} \mathrm{C}$ & Grad Celsius \\
\hline cDNA & komplementäre DNA \\
\hline $\mathrm{Ci}$ & Curie $\left(2.22 \times 10^{6}\right.$ „counts per minute“) \\
\hline c-terminal & carboxyterminal \\
\hline $\mathrm{Da}$ & Dalton \\
\hline dCTP & Desoxycytidintriphosphat \\
\hline dNTP & Desoxyribonukleotid \\
\hline DMSO & Dimethylsulfoxid \\
\hline DNA & Desoxyribonukleinsäure \\
\hline DTT & Dithiothreitol \\
\hline E.coli & Escherichia coli \\
\hline EDTA & Ethylendiamintetraacetat \\
\hline ER & Endoplasmatisches Retikulum \\
\hline et al. & et alii (lat.: und andere) \\
\hline g & Gramm \\
\hline $\mathrm{h}$ & Stunde \\
\hline $\mathrm{HA}$ & Hämaglutinin \\
\hline $\mathrm{H} 2 \mathrm{O}$ & Wasser \\
\hline $\mathrm{dH} 2 \mathrm{O}$ & destilliertes Wasser \\
\hline HRP & Meerrettichperoxidase \\
\hline $\mathrm{k}$ & Kilo \\
\hline $\mathrm{kb}$ & Kilobasen \\
\hline I & Liter \\
\hline M & Molar \\
\hline $\mathrm{mA}$ & Milliampere \\
\hline $\mathrm{mg}$ & Milligramm \\
\hline $\min$. & Minute \\
\hline $\mathrm{ml}$ & Milliliter \\
\hline $\mathrm{mM}$ & Millimolar \\
\hline mRNA & „Messenger“ Ribonukleinsäure \\
\hline ms & Millisekunde \\
\hline MW & Molekulargewicht \\
\hline$\mu g$ & Microgramm \\
\hline$\mu l$ & Microliter \\
\hline $\mathrm{ng}$ & Nanogramm \\
\hline $\mathrm{nm}$ & Nanometer \\
\hline n-terminal & aminoterminal \\
\hline OD & optische Dichte \\
\hline ORF & „open reading frame” \\
\hline
\end{tabular}




$\begin{array}{ll}\text { PCR } & \text { Polymerasekettenreaktion } \\ \text { PEG } & \text { Polyethylenglykol } \\ \text { pH } & \text { negativer dekadischer Logarithmus der Protonenkonzentration } \\ \text { PMSF } & \text { Phenylmethylsulfonylfluorid } \\ \text { PVDF } & \text { Polyvinylidendifluorid } \\ \text { RNA } & \text { Ribonukleinsäure } \\ \text { RNAse } & \text { Ribonuklease } \\ \text { RT } & \text { Raumtemperatur } \\ \text { RT-PCR } & \text { Reverse Transkriptase-PCR } \\ \text { rpm } & \text { "rounds per minute“ } \\ \text { S. cerevisiae } & \text { Saccharomyces cerevisiae } \\ \text { SDS } & \text { Natriumdodecylsulfat } \\ \text { SSC } & \text { "Standard Saline Citrate“ } \\ \text { Sek. } & \text { Sekunde } \\ \text { Tab. } & \text { Tabelle } \\ \text { Taq } & \text { Thermophillus aquaticus } \\ \text { TE } & \text { Tris/HCl EDTA } \\ \text { TEMED } & \text { N, N, N', N'Tetramethyldiamin } \\ \text { TGN } & \text { Trans-Golgi-Netzwerk } \\ \text { transf. } & \text { Transformiert } \\ \text { Tris } & \text { Trishydroxymethylaminomethan } \\ \text { U } & \text { Enzymeinheit (Unit) } \\ \text { UTR } & \text { "untranslated region“ } \\ \text { UV } & \text { ultraviolettes Licht } \\ \text { V } & \text { Volt } \\ \text { Vol. } & \text { Volumen } \\ \text { WT } & \text { Wildtyp } \\ \text { w/v } & \text { Gewicht zu Volumen } \\ \text { v/v } & \text { Volumenverhältnis } \\ & \end{array}$




\section{Zusammenfassung}

In Saccharomyces cerevisiae wird die Leucin-Exopeptidase Aminopeptidase 1 (Ape1) als Vorläuferform im Zytoplasma synthetisiert, zu Homododecameren oligomerisiert, anschließend über den Cvt-Transportweg in die Vakuole transportiert und dort prozessiert.

Die Isolierung und Charakterisierung zweier Mutanten via10 und via14 (vacuole import and autophagocytosis) mit reduzierter, bzw. keiner Ape1-Aktivität, sollte weitere Details über die Biogenese des Proteins liefern. Mittels einer Komplementationsstudie wurde der ORF YDR359C identifiziert, der zum einen die Ape1-Aktivität in dem Mutantenstamm via14 wiederherstellte, und zum anderen nach dessen Deletion zu einem kompletten Verlust dieser führte. YDR359C kodiert für das verifizierte Protein Eaf1 (Esa1-associated factor) und ist neben der katalytischen Untereinheit Esa1 Bestandteil des aus dreizehn Proteinen zusammengesetzten Histon-Acetyltransferase-Komplexes NuA4.

Hier konnte gezeigt werden, dass die Expression von Eaf1 die Transkription, Expression und Aktivität der Ape1 erhöht und somit direkt beeinflusst. Interessanterweise ist dies nicht ausschließlich auf einen transkriptionellen Effekt zurückzuführen, da ein induzierter Anstieg der Ape1-Expression alleine nicht im selben Maße zur Restauration der Aktivität führte. Die Deletion weiterer nichtessentieller Untereinheiten des NuA4-Komplexes hatte ebenfalls keinen, bzw. nur minimalen Einfluss auf die Ape1-Aktivität. Des Weiteren konnte die Ape1-Aktivität sowohl durch amino- als auch carboxyterminal verkürzte Fragmente von Eaf1 wiederhergestellt werden. In in situ Immunfluoreszenzen konnte zwar eine CoLokalisation von Eaf1 und Ape1, bis jetzt jedoch keine direkte Interaktion der beiden Proteine gezeigt werden, was vermuten ließe, dass Eaf1 die Ape1-Aktivität unter Umständen nicht direkt, sondern in komplexgebundener Form beeinflusst. Der Verlust des EAF1-Gens beeinträchtigt weder die Prozessierung, noch die Komplexassemblierung der Ape1. Unsere Daten deuten daher auf eine neue Funktion des Proteins Eaf1, u.U. unter Beteiligung anderer Komponenten des NuA4Komplexes oder durch Interaktion mit noch nicht identifizierten Bindungspartnern hin. Zukünftige Experimente werden dazu beitragen, den Mechanismus der Eaf1abhängigen Biogenese der Aminopeptidase 1 aufzuklären. 


\section{Einleitung}

\subsection{Hefe als Modelorganismus}

Die Hefe Saccharomyces cerevisiae war der erste Eukaryot dessen komplette DNASequenz im Jahre 1996 veröffentlicht wurde: etwa 6000 potentiell kodierende Gene verteilen sich auf sechzehn Chromosomen (Goffeau et al., 1996). Hefe als Modelorganismus ist leicht zu manipulieren, während entsprechende Experimente, wie z.B. die Deletion eines Genes im Säugersystem langwieriger, teuerer und schwieriger durchzuführen sind. Da Hefe- und Säugergene oft für ähnliche Proteine kodieren (Botstein und Fink, 1988), können Untersuchungen in Hefe ihre biologische Funktionen erkennen lassen und selbst bei der Analyse von Krankheitsgenen erste Anhaltspunkte liefern.

Wie für alle eukaryotischen Zellen, ist auch für die Hefezelle ihre zelluläre Kompartimentierung für den reibungslosen Ablauf biologischer Prozesse entscheidend. Eine große physiologische Rolle spielt dabei die Vakuole.

\subsection{Die Vakuole in Saccharomyces cerevisiae}

Die Vakuole ist als saures Kompartiment das Pendant zu Lysosomen in Säugerzellen. Mit ihrer großen Vielzahl von Hydrolasen, Endo- und Exoproteinasen (Jones et al., 1997; van den Hazel et al., 1996) ist sie neben dem Proteasom zuständig für intrazelluläre Proteolyse (Thumm und Wolf, 1998). Vor allem unter Nährstoffmangelbedingungen werden $85 \%$ der intrazellulär abgebauten Proteine in der Vakuole degradiert.

Die Vakuole dient als Speicherkompartiment für Aminosäuren, Ionen (z.B. Kalzium) und Phosphate. Sie ist zudem an der $\mathrm{pH}$ - und Osmoregulation beteiligt. Das saure Milieu wird durch die aus mehreren Untereinheiten zusammengesetzte VakuolenATPase (V-ATPase) aufrechterhalten, die für die Translokation von Protonen durch die Vakuolenmembran verantwortlich ist (Powell et al., 2000). In Saccharomyces cerevisiae werden Proteine auf unterschiedlichen Wegen in die Vakuole transportiert (Abb.1): 
- Sekretorischer Weg via Endoplasmatischem Retikulum (ER) und GolgiApparat

- Endozytose

- „Cytoplasm-to-vacuole targeting“ (Cvt)-Transportweg und Autophagie

Um die unterschiedlichen Transportwege zu untersuchen, werden bestimmte Markerproteine wie z.B. Carboxypeptidase $\mathrm{Y}$ und Aminopeptidase 1 beobachtet. Vakuoläre Proteasen werden in der Regel als inaktive Zymogene synthetisiert, die erst nach proteolytischer Spaltung des Propeptids aktiviert werden. Die Prozessierung findet in der Vakuole vor allem durch die Proteinase A (PrA, Pep4) statt. Die daraus entstehende niedermolekulare Form des Proteins kann mittels Polyacrylamidgelelektrophorese überwacht werden (Ammerer et al., 1986).

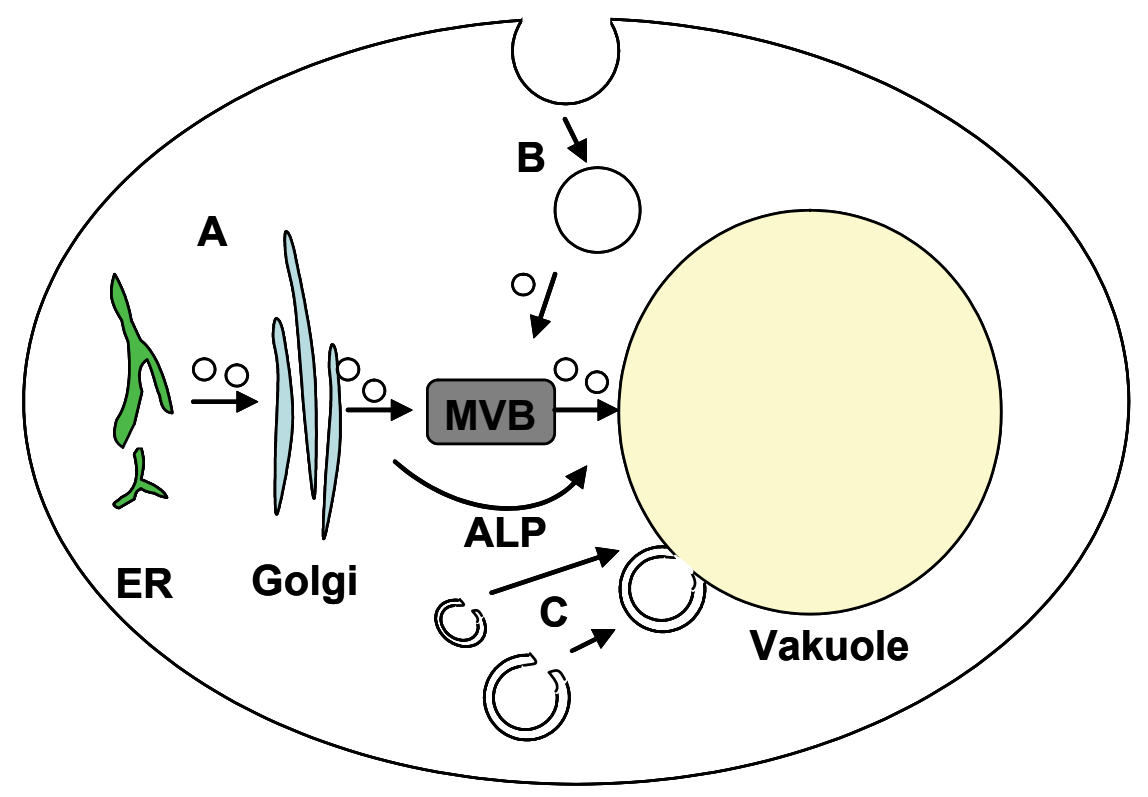

Abb.1: Proteintransport in die Vakuole.

A Sekretorischer Weg über ER und Golgi (CPY- und ALP-Transportweg), B Endozytose von Proteinen, C Autophagie oder Cvt-Weg. 


\subsection{Der sekretorische Transportweg}

Viele vakuoläre Hydrolasen wie z.B. die Carboxypeptidase $Y$ (CPY) oder Proteinase A (PrA) und vakuoläre Membranproteine wie beispielsweise eine Untereinheit der vakuolären ATPase (V-ATPase) Vph1 werden über den sekretorischen Weg in die Vakuole transportiert. CPY wird als inaktive Proform, Prepro-CPY synthetisiert und dann im Lumen des Endoplasmatischen Retikulums nach Spaltung der Signalsequenz N-glykosyliert und phosphoryliert (Hasilik und Tanner, 1978; Hashimoto et al., 1981). Das jetzt 67 kDa große Protein (p1) wird zusammen mit Proteinen, die segregiert oder in der Plasmamembran verankert werden, vom ER in den Golgi-Apparat transportiert, wo weitere Oligosaccharide zur Bildung der 69 kDa großen p2-CPY-Form angehängt werden. Im trans-GolgiNetzwerk (TGN) verlässt das Protein den sekretorischen Weg und wird durch einen rezeptorvermittelten Prozess in die Vakuole transportiert. Dabei enthalten die Aminosäurereste 24-27 der Prosequenz das Lokalisationssignal, d.h. ohne diese Aminosäuren kann das Protein nicht an seinen Rezeptor Vps10 binden und wird zu 90\% segregiert. Der Rezeptor/Liganden-Komplex wird unter Beteiligung von Clathrin und der Dynamin-ähnlichen GTPase Vps1 in sog. Golgi-Transport-Vesikel verpackt. Clathrin bildet das Gerüst der Vesikel, während Vps1 für die Abstoßung der Vesikel am TGN benötigt wird. Das Cargo wird zu dem späten Endosomen/multivesikulärenBody (MVB) transportiert, wo die Pro-CPY und Vps10 dissoziieren (Deloche et al., 2001). Vps10 gelangt zurück zum TGN, wo es weitere CPY-Proteine bindet (Cereghino et al., 1995; Cooper et al., 1996). Der Rezeptor erkennt neben CPY auch PrA und fehlgefaltete Proteine, die in der Vakuole degradiert werden (Hong et al., 1996). Pro-CPY wird weiter zur Vakuole transportiert, wo das Propeptid durch vakuoläre Proteasen gespalten wird. Die Masse der gereiften, aktiven Form der CPY (mCPY) beträgt $61 \mathrm{kDa}$ (Hemmings et al. 1981).

Einige Proteine, wie z.B. Vam3 werden in die Vakuole transportiert ohne das endosomale Netzwerk zu durchlaufen. Dieser Transportweg ist Clathrin unabhängig und ist nach seinem prominentesten Cargo-Protein, der Alkalischen Phosphatase (ALP) benannt (Piper et al., 1997; Cowles et al., 1997). Im TGN werden ALP und Vam3 in AP3 Adaptorprotein-Vesikel verpackt. Der AP3-Komplex besteht aus 4 Proteinen: Apl6 ( $\beta$-Adaptin Homolog), Apl5 ( $\delta$-Adaptin Homolog), Apm3 ( $\mu$ Untereinheit Homolog) und Aps3 ( $\sigma$-Untereinheit Homolog) und assoziiert mit Vps41, 
das bei der Fusion der Vesikel mit der Vakuolenmembran beteiligt sein könnte (Darsow et al., 2001).

\subsection{Autophagie}

Unter Autophagie (griech.: „auto“ sich selbst; „phagie“ essen) versteht man den Transport zytosolischen Materials bis hin zu ganzen Organellen, wie z.B. Mitochondrien, in die Vakuole. Dieser Prozess wird durch Stickstoffmangelbedingungen induziert. Innerhalb von 24 Stunden werden annähernd $50 \%$ der gesamten intrazellulären Proteine degradiert. Ein Großteil des Abbaus (ca. 80\%) findet dabei in der Vakuole statt, was eine Bereitstellung von Aminosäuren und weiteren Metaboliten für die hungernde Zelle gewährleistet (Teichert et al., 1989). Es werden drei Arten von Autophagie unterschieden: Mikroautophagie, Makroautophagie und Chaperon-induzierte Autophagie (Tab.1). Mikroautophagie ist die Aufnahme zytosolischen Materials, was auch große Moleküle wie Glykogen oder sogar Ribosomen beinhaltet. Die Substrate werden hierbei direkt durch Einschnürung der vakuolären Membran in Form von Einzelmembranvesikeln internalisiert (Mortimore et al., 1988).

Chaperon-induzierte Autophagie ist nur in höheren Eukaryoten beschrieben und umfasst die gerichtete Aufnahme von löslichen Proteinen mit entsprechenden „targeting“-Motiven, die entsprechende Rezeptoren der lysosomalen Membran binden. Die Substrate werden entfaltet und in das Lysosom aufgenommen (Cuervo und Dice, 1998; Dice 1990).

Makroautophagy wird meist nur mit Autophagie umschrieben, entsteht mit der Bildung von Autophagosomen, Doppelmembranvesikel mit einem Durchmesser von 300-900 nm. Die Bildung von Autophagosomen ist noch nicht abschließend geklärt. Als Entstehungsort wurde ein der Vakuole nahes Kompartiment, das sog. PAS (preautophagosomal structure) identifiziert (Suzuki et al., 2001; Kim et al., 2002). Kirisako et al. (1999) beschrieben die Formation der Vesikel als eine immer folgende Aneinanderreihung von Membranstrukturen am PAS. Nach Annäherung fusionieren die beiden Enden und schließen zytoplasmatisches Material als Doppelmembranvesikel ein. Große Autophagosomen könnten zum einen durch ein Aneinanderreihen von Vesikeln oder der Fusion kleiner Membranfragmente (Zisternen) gebildet werden (Reggiori und Klionsky, 2005). Der Ursprungsort der 
Autophagosomenmembranen wird kontrovers diskutiert. Atg9 und Atg27 sind transmembrane Proteine am PAS, die an der Bildung von Autophagosomen beteiligt sind (Lang et al., 2000; Yen et al., 2007). Atg9 pendelt zwischen PAS und Mitochondrien, somit könnten wenigstens Teile der autophagosomalen Lipide aus diesem Organell stammen (Reggiori et al., 2005). Später konnte Atg9 aus Säugerzellen (mAtg9) im Trans-Golgi-Netzwerk (TGN) und späten Endosomen nachgewiesen werden (Young et al., 2006). Demnach könnten autophagosomale Membranen sowohl aus den Mitochondrien (Reggiori et al., 2005), dem ER und Trans-Golgi-Netzwerk, den Endosomen oder vielleicht sogar aus der Vakuole selbst stammen.

Bei Ankunft an der Vakuole fusionieren die äußere Membran der Autophagosomen mit der Vakuolenmembran und das autophagische Vesikel wird in das Vakuolenlumen entlassen, wo die Vesikel aufgebrochen werden (Baba et al., 1994; Takeshige et al., 1992) (Abb.2). Dies unterscheidet Autophagie von dem bereits beschriebenen Vorgang des sekretorischen Transportweges, wo Proteine in Einzelmembranvesikel mit der Vakuolenmembran fusionieren und der Inhalt direkt ins Lumen freigegeben wird. Die autophagischen Vesikel hingegen werden von vakuolären Proteinasen und vor allem von der Endoproteinase $B$ unter Beteiligung des sauren Milieus degradiert. Wird die Endoproteinase B durch PMSF inhibiert oder deletiert, bzw. nach Deletion der VMA-Gene (Untereinheiten der V-ATPase), akkumulieren die autophagischen Vesikel im Lumen der Vakuole (Takeshige et al., 1992; Nakamura et al., 1997).

Tab.1: Zusammenfassung und Gegenüberstellung von Makro-, Mikroautophagie und Chaperoninduzierter Autophagie (chaperone-mediated autophagy,CMA):

\begin{tabular}{ccc}
\hline Makroautophagie & Mikroautophagie & $\begin{array}{c}\text { Chaperon-induzierte } \\
\text { Autophagie }\end{array}$ \\
\hline induzierbar (Nährstoffmangel) & konstitutiv & induzierbar (Nährstoffmangel) \\
Vesikel abhängig & Vesikel abhängig & direkt \\
Proteine/Organelle & Proteine/Organelle & Proteine \\
ungerichtet & ungerichtet & selektiv
\end{tabular}




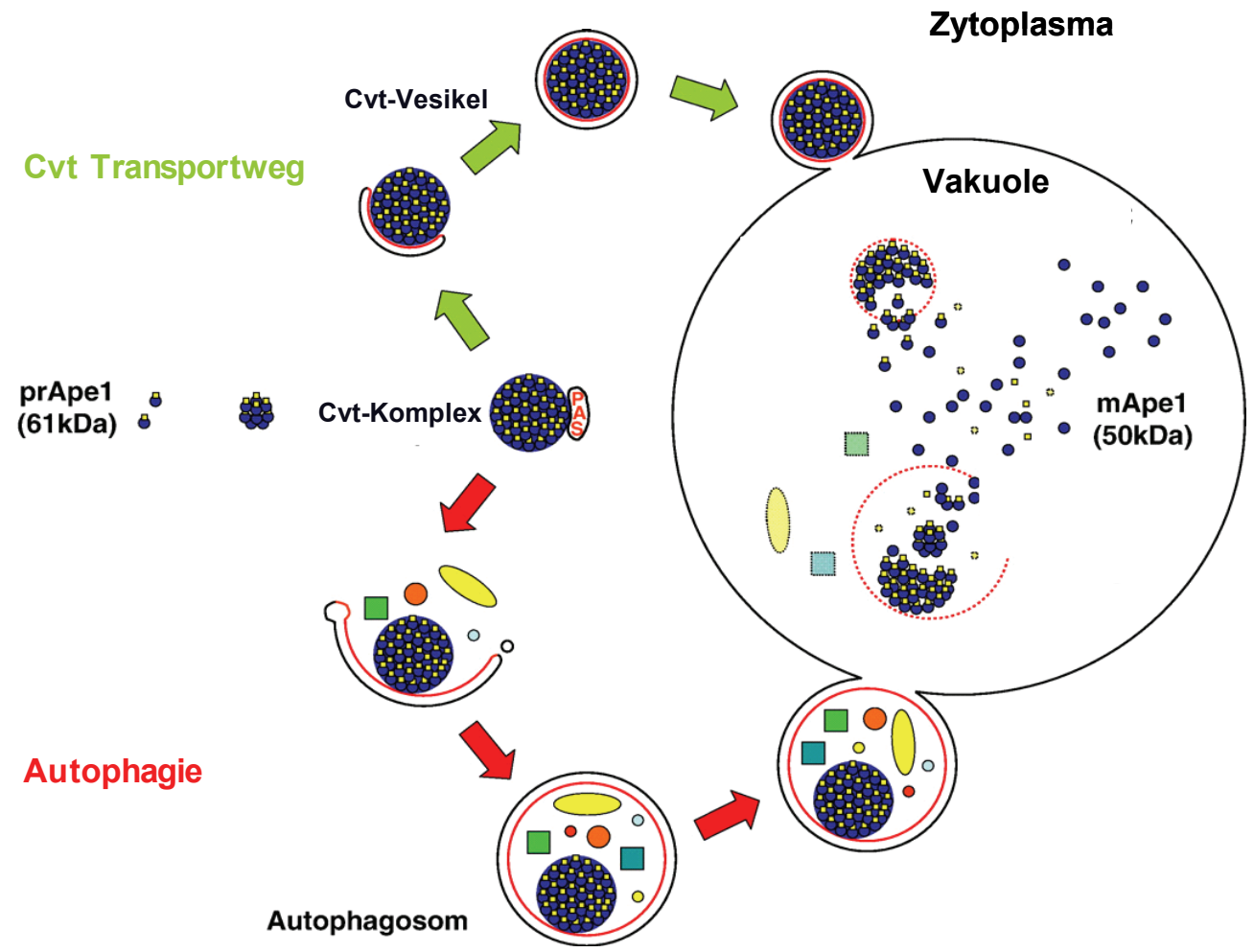

\section{Abb.2: Cvt (Cytoplasm to Vacuole Targeting)-Transportweg und Autophagie haben ähnliche Mechanismen.}

Aminopeptidase 1 (prApe1) wird im Zytoplasma synthetisiert, in Cvt-Vesikel verpackt und in die Vakuole transportiert. Unter Stickstoffmangelbedingungen wird Autophagie induziert. prApe1 wird zusammen mit intrazellulärem Material in Autophagosomen zur Vakuole transportiert, dort prozessiert (mApe1) und zytosolisches Material degradiert (nach Cebollero und Gonzalez, Review 2007). 


\subsubsection{Funktion von Autophagie}

Unter normalen Wachstumsbedingungen und kurzen Hungerintervallen wird der Aminosäurehaushalt durch Proteindegradation im Proteasom mittels spezifischen Abbaus von ubiquitinylierten Proteinen geregelt (Ciehanover et al., 1978). Beträgt die Hungerperiode mehrere Stunden, wird Autophagie induziert. Hefezellen reduzieren ihre Proteinsynthese unter Stickstoffmangelbedingungen, dieser Effekt wird in autophagiedefizienten Mutanten verstärkt. Zudem werden unter diesen Bedingungen bestimmte Proteine, wie z.B. das Hitzeschock-Protein Hsp26, die vakuoläre Aminopeptidase 1 (Ape1) und Carboxypeptidase $Y$ (CPY) verstärkt synthetisiert (Tsukada und Oshumi, 1993). Autophagie ist ein limitierender Prozess und kann das Überleben der Zelle nur für kurze Zeit garantieren.

Autophagie findet auch zur Beseitigung von überschüssigen, nicht benötigten Organellen statt. In $S$. cerevisiae werden Peroxisomen, ubiquitär vorkommende Zellorganellen, zuständig für die $\beta$-Oxidation von Fettsäuren (Kunau et al., 1988) nach Umsetzen von Ölsäurequelle auf Glucosemedium nicht mehr benötigt und daraufhin degradiert. Dieser Prozess wird auch als Pexophagie bezeichnet (Hutchins et al., 1999).

\subsection{Cytoplasm to vacuole targeting (Cvt)-Transportweg}

Erste Hinweise auf diesen Autophagie-ähnlichen Transportweg in S. cerevisiae erhielt man durch Studien der vakuolären Hydrolase $\alpha$-Mannosidase (Ams1; Yoshihisa und Anraku, 1990) und später mit der Erforschung des Proteins Aminopeptidase 1 (Ape1; Klionsky et al., 1992). Ape1 ist eine Leucin-Exopeptidase und in der Vakuole aktiv. Sie wird als $61 \mathrm{kDa}$ Vorläuferform prApe1 mit einem aminoterminalen Propeptid im Zytoplasma synthetisiert. Der ORF YKL103C (APE1, YSC1, API, LAP4) auf Chromosom XI kodiert für das aus 514 Aminosäuren bestehende Protein. Das aus 45 Aminosäuren bestehende Propeptid besitzt keine für den sekretorischen Transportweg typische Signalsequenz und ist nicht hydrophob (Cueva et al., 1989), wird allerdings für den Transport in die Vakuole benötigt. Bei Mutation des Propeptids akkumuliert das Protein im Zytoplasma (Oda et al., 1996). $\alpha$-Mannosidase (Ams1) ist das bis heute zweite identifizierte Protein, das wie die Ape1 direkt nach seiner Synthese im Zytoplasma in die Vakuole transportiert wird. 
Der ORF YGL156W auf Chromosom VII kodiert für 1083 Aminosäuren (Molekulargewicht (MW) 124.5 kDa). Ams1 wird aus drei Isoformen, d.h. einem 107 kDa Polypeptid und den durch proteolytische Spaltung resultierenden 73 und 31 kDa Polypeptiden zusammengesetzt (Yoshihisa und Anraku, 1989). Das native Protein ist $560 \mathrm{kDa}$ groß und hydrolysiert die Entfernung terminaler $\alpha$-D-Mannose-Reste in der Vakuole.

Die Aminopeptidase 1 und die $\alpha$-Mannosidase unterscheiden sich von Proteinen des sekretorischen Transportweges wie folgt: sie sind nicht glykosyliert und besitzen keine Standardsignalsequenz wie z.B. die der CPY, PrA oder PrB. Der Transport von Ape1 und Ams1 ist prozessierungsunabhängig von temperatursensitiven sec12- und sec23-Mutanten des sekretorischen Transportweges. Der vakuoläre Import und die Prozessierung der Ape1 erfolgen mit einer Halbwertszeit von ca. 30-45 Minuten (Klionsky et al., 1992) verglichen mit einer nur sechsminütigen HWZ der CPY, Proteinase A oder Alkalischen Phosphatase. Aufgrund dieser Beobachtungen wurde vermutet dass Ape1 und Ams1 über einen anderen als den sekretorischen Transportweg in die Vakuole transportiert werden.

Überexpression der Ams1 erhöht die Halbwertszeit der Prozessierung der Ape1, was auf einen gemeinsamen Transportmechanismus der beiden Proteine hinweist (Klionsky et al., 1992). Abbildung 3 zeigt ein Modell, wie die Proteine Ape1 und Ams1 in die Vakuole gelangen.

Nach Synthese oligomerisiert die Aminopeptidase 1 zügig mit einer Halbwertszeit von ca. zwei Minuten zu einem Homododecamer. Der Rezeptor Atg19 (Cvt19) interagiert mit den aus mehreren Homododecameren bestehenden Ape1Komplexen. $\mathrm{Zu}$ diesem Zeitpunkt oder zusammen mit Atg19 bindet die a-Mannosidase und bildet den sog. Cvt-Komplex. Dieser bindet nun an das Adaptorähnliche Protein Atg11 (Cvt9) und wird anschließend am PAS unter Beteiligung von unter anderem Atg8 (Aut7) in sog. Cvt-Vesikel verpackt und direkt, d.h. nicht über ER und Golgi-Apparat, zur Vakuole transportiert. Dort findet die Fusion mit der Vakuolenmembran statt. Der Innermembranvesikel wird ins Vakuolenlumen entlassen und anschließend von vakuolären Hydrolasen verdaut. In der Vakuole wird die prApe1 durch Proteinase A in ihre 50-51 kDa gereifte Form prozessiert (mApe1) (Trumbly and Bradley, 1983). Der Rezeptor Atg19 wird nach Ankunft in der Vakuole degradiert. Atg19 und somit auch die $\alpha$-Mannosidase benötigen die Interaktion mit 
Ape1, genauer den Cvt-Komplex, um in die Vakuole zu gelangen (Shintani et al., 2002)

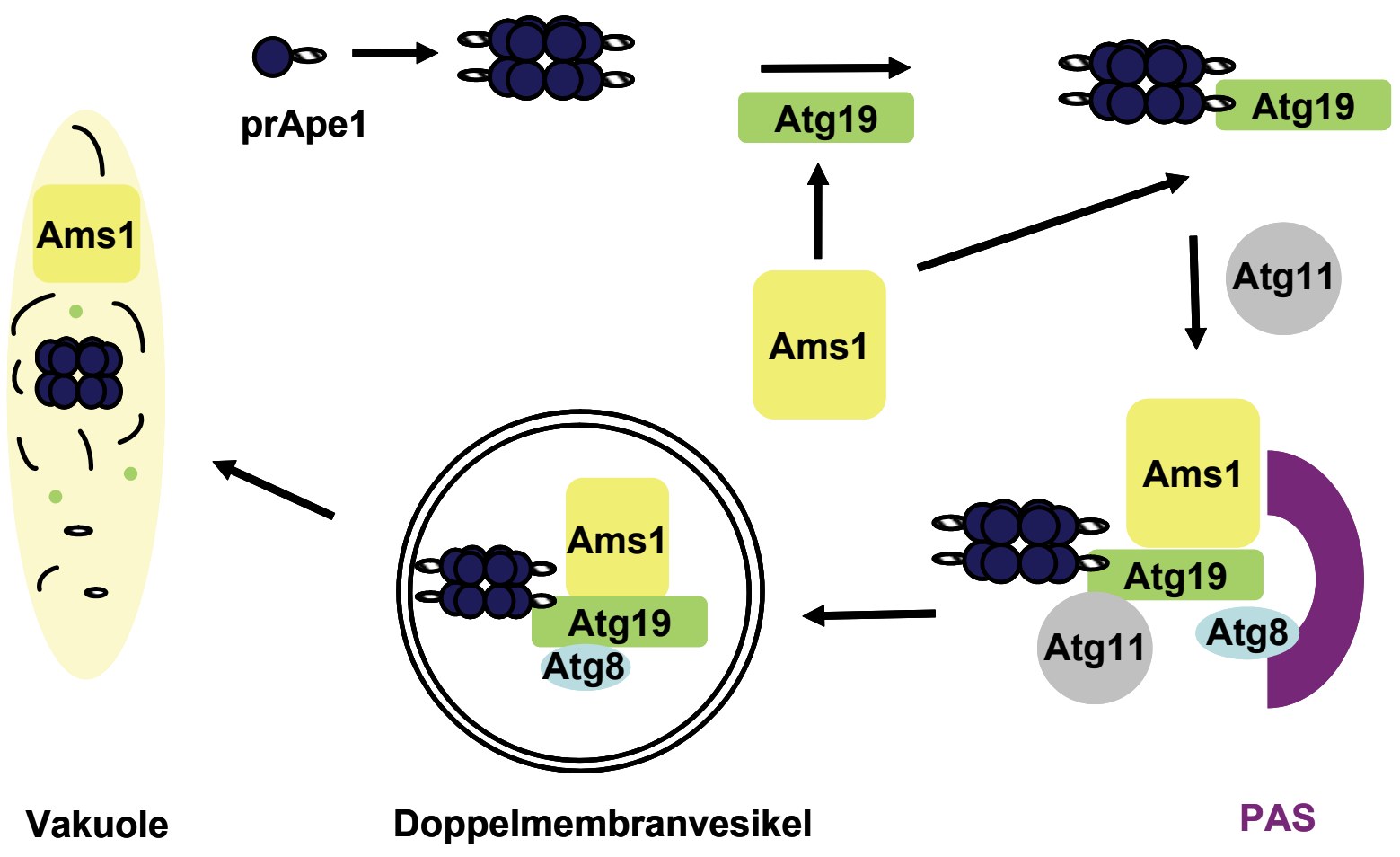

Abb.3: Modell für den Transport von Aminopeptidase 1 (Ape1) und a-Mannosidase (Ams1) in die Vakuole.

Ape1 homododecamerisiert im Zytoplasma und bildet große Komplexe (zur vereinfachten Darstellung wird hier nur ein Homododecamer gezeigt). Der Rezeptor Atg19 und a-Mannosidase binden. Der entstandene Cvt-Komplex wird am PAS in Doppelmembranvesikel verpackt und in die Vakuole transportiert.

\subsection{Vergleich von Autophagie und Cvt-Transportweg}

Autophagie ist ein ungerichteter, eher langsamer Prozess mit einer Halbwertszeit von mindestens zwölf Stunden (Scott et al., 1996). Der ausschließlich unter Nährstoffmangel induzierte Prozess führt zur Bildung von Autophagosomen mit einem Durchmesser von 300-900 nm (Takeshige et al., 1992). Nach Ankunft in der Vakuole, folgt die Degradation des transportierten Zellmaterials, d.h. der Proteine bis hin zu ganzen Organellen. Der Cvt-Transportweg ist dagegen auf zwei Proteine beschränkt (Ape1 und Ams1) und findet konstitutiv in logarithmisch wachsenden 
Zellen mit einer Halbwertszeit von 30 bis 45 Minuten statt (Klionsky et al., 1992, Scott et al., 1996). Cvt-Vesikel weisen einen Durchmesser von ca. $150 \mathrm{~nm}$ auf und sind somit wesentlich kleiner als Autophagosomen.

Zwei Arten von Mutanten halfen die molekularen Vorgänge von Autophagie besser zu verstehen. Elektronenmikroskopische Untersuchungen an Hefezellen mit Defekten vakuolärer Proteinasen zeigten unter Hungerbedingungen eine Anreicherung von kugelförmigen Membranstrukturen, sog. „Autophagic Bodies“ und führten zur Isolierung von sog. apg (autophagy)-Mutanten (Tsukada und Ohsumi, 1993). Aut (autophagy)-Mutanten wurden nach EMS-Mutagenese identifiziert. Hierbei wurden Hefestämme nach Degradationsdefekten der zytosolischen Fettsäuresynthase und dem Verlust zur Bildung autophagosomaler Vesikel unter Hungerbedingungen und Anwesenheit von PMSF (Inhibitor der Proteinase B) untersucht (Thumm et al., 1994).

Ein Jahr später wurden wieder durch EMS-Mutagenese sog. cvt (cytoplasm to vacuole targeting)-Mutanten anhand von Western Blot-Analysen isoliert. Dabei handelte es sich um Zellen mit Defekten in der Reifung der Aminopeptidase 1 und demzufolge einer Akkumulation der Vorläuferform im Zytoplasma (Harding et al., 1995).

Trotz morphologischer Unterschiede (Tab.2), konnten mit Hilfe von Komplementationsstudien an apg-, aut- und cvt-Mutanten (Scott et al., 1996) eine große Vielzahl von Gemeinsamkeiten der beiden Prozesse identifiziert werden. Für ein besseres Verständnis, wurde die Nomenklatur der AUT-, APG- und CVT-Gene auf ATG-Gene (Autophagy verwandte Gene) standardisiert (Klionsky et al., 2003). Bis heute sind 31 ATG-Gene identifiziert, wobei die Mehrzahl für Autophagie und Cvt-Transportweg relevant sind. Weiter gibt es auch Gene, die zwar für autophagozytotische Prozesse, wie die Fusion von Vesikeln und deren Abbau essentiell sind, allerdings nicht mit ATG bezeichnet werden. 
Tab.2: Morphologische Unterschiede und Gemeinsamkeiten von Autophagie und Cvt-Transportweg:

\begin{tabular}{cc}
\hline Autophagie & Cvt-Transportweg \\
\hline induzierbar (Nährstoffmangel) & konstitutiv (bei Nährstoffmangel: Autophagie) \\
Vesikel abhängig & Vesikel abhängig \\
nicht selektiv (Proteine, Organelle) & selektiv (Ape1, Ams1) \\
langsam (HWZ >12 Stunden) & schnell (HWZ 30-45 Minuten) \\
Vesikelgröße 300-900 nm & Vesikelgröße 140-160 nm
\end{tabular}

\subsection{Regulierung von Autophagie}

Einer der Hauptregulatoren von Autophagie ist die Serin-Threonin Kinase Tor. Wie in Abbildung 4 illustriert, ist die Kinase unter normalen Wachstumsbedingungen aktiv. Gerät die Zelle unter Hungerstress, führt die Inaktivierung der Tor-Kinase zu einer teilweisen Dephosphorylierung des Proteins Atg13, was dessen Interaktion mit Atg17 und der Serin-Threonin Kinase Atg1 erhöht (Noda und Ohsumi, 1998; Kamada et al., 2000; Kabeya et al., 2005). Die Auswirkungen auf Atg1 werden hierbei kontrovers diskutiert, in vivo Studien haben allerdings gezeigt, dass eine Mutation der Kinase weniger den Prozess der Autophagie beeinflusst, als den Cvt-Transportweg inhibiert (Abeliovich et al., 2003). Das Phosphoprotein Atg13 ist mit Vac8, einem vakuolären Membranprotein assoziiert und an der Vesikelbildung und damit dem Transport der Ape1 zur Vakuole beteiligt. Atg1 scheint außerdem mit den Proteinen Atg11, Atg20 und Atg24 einen Komplex zu bilden, der an dem Wechsel von Cvt-Weg zu Autophagie unter wechselnden Nährstoffbedingungen beteiligt sein könnte (Scott et al., 2000). Atg17 ist maßgeblich an der Organisation des PAS beteiligt, vermutlich im Komplex mit den erst kürzlich identifizierten Proteinen Atg29 und Atg31 (Kawamata et al., 2005; Kabeya et al., 2007). 
Nahrung nicht limitierend

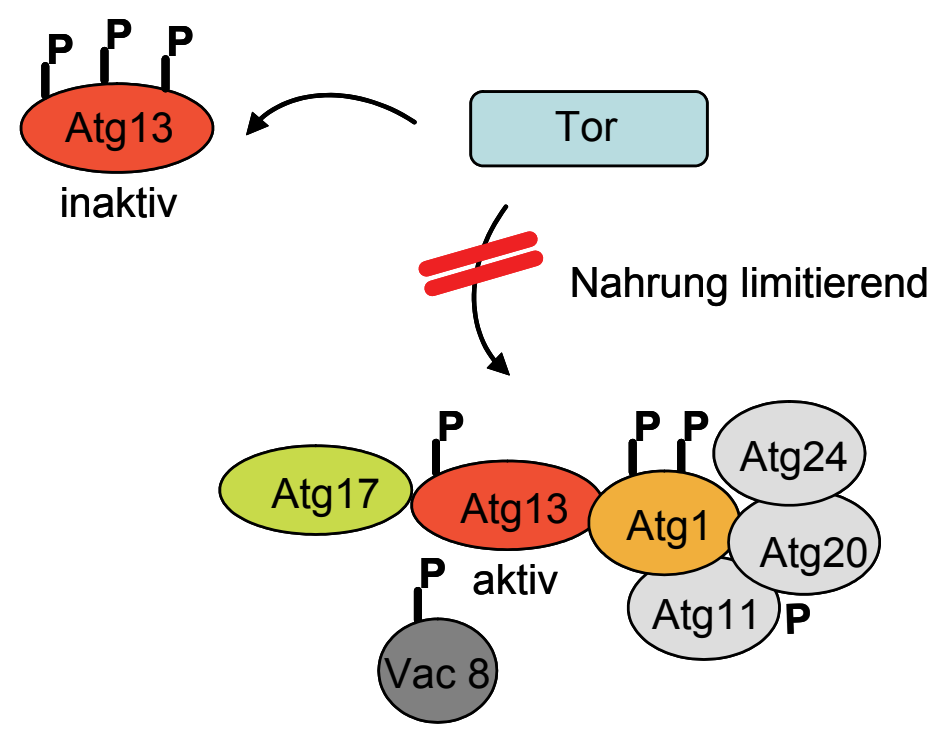

\section{Abb.4: Regulation von Autophagie.}

Hungerstress führt zur Inaktivierung der Tor-Kinase, die Dephosphorylierung von Atg13 führt zu dessen Aktivierung. Komplexbildung mit den Proteinen Vac8, bzw. Atg1 und Atg17 beeinflussen eine Vielzahl autophagozytotischer Prozesse, wie beispielsweise die Bildung von Vesikeln (Abbildung abgeändert nach Levine und Kroemer, 2008).

\subsection{Autophagosomen}

Atg8 ist, wie bereits erwähnt, am Transport der Aminopeptidase 1 und der $\alpha$-Mannosidase in die Vakuole beteiligt. In atg8-Mutantenstämmen sind die Vesikel in der Regel kleiner und in geringerer Anzahl nachweisbar, der Transport der Ape1 in die Vakuole findet allerdings statt. Es ist daher anzunehmen, dass Atg8 eher an der Ausdehnung, bzw. Erweiterung der Autophagosomen involviert ist (Kirisako et al., 1999; Abeliovich et al., 2000).

Die Funktion von Atg8 ist an eine kovalente Bindung des Proteins mit Phosphatidylethanolamin (PE) geknüpft. Die Bildung des Atg8-PE-Komplexes erinnert an das Ubiquitinierungssystem. Zuerst wird Atg8 carboxyterminal modifiziert. Die Cysteinprotease Atg4 entfernt dabei ein Arginin und hinterlässt C-terminal ein Glycin. Das E1-verwandte Protein Atg7 und das E2-verwandte Protein Atg3 katalysieren dann die Bindung von Atg8 mit PE (Schlumpberger et al., 1997; Kim et al., 2001) und die damit unter Beteiligung des Phosphatidylinositol 3-Kinase-Komplex 
I, Atg9 und weiteren Proteinen (Atg12-Atg5 Komplex, Mae1/Atg21) verbundene Lokalisation am PAS. Die dynamische Interaktion von Atg8-PE wird erneut von Atg4 gespalten. Dieser Vorgang und die damit verbundene Loslösung von Atg8 vom PAS ist einer der essentiellen Schritte der Autophagie (Kirisako et al., 2000).

Atg12 ist ein weiteres Protein, das in einem Ubiquitin-ähnlichen System wirkt. Das carboxyterminale Glycin ist hier kovalent mit Lysin 149 des Proteins Atg5 verbunden. Diese Verbindung wird durch Atg7 (E1-verwandtes Enzym zur Atg12 Aktivierung) und Atg10 (E2-verwandtes Enzym zur Atg12 Konjugation) katalysiert (Tanida et al., 1999). Ein weiteres Protein Atg16 oligomerisiert und interagiert mit der aminoterminalen Region von Atg5, was zur Bildung eines ca. $350 \mathrm{kDa}$ multimeren Atg12-Atg5·Atg16-Komplexes führt (Kuma et al., 2002). Nach bisherigem Wissensstand ist dieser Komplex am Wachstum der Membranen beteiligt. Atg12Atg5 begünstigen die Assoziation von Atg8 an PE. Es liegt deshalb die Vermutung nahe, dass dieser Komplex als E3-Enzym agiert (Abb.5).

Die Phosphatidylinositol 3-Kinase (Vps34) ist Teil zweier Komplexe, I und II, die am vesikulären Transport beteiligt sind. Phosphatidylinositol 3-Kinase-Komplex I (Ptdlns 3-Kinase-Komplex I) besteht außerdem aus den Proteinen Vps15, Atg6 und Atg14 und ist essentiell für den Cvt-Transportweg und Autophagie. Seine molekulare Funktion ist noch nicht abschließend geklärt. Komplex I scheint jedoch während der Entstehung von Autophagosomen, d.h. im Rekrutieren verschiedener Atg-Proteine (u.a. Atg18, Atg20, Atg21 und Atg24) an den PAS eine zentrale Rolle zu spielen (Nice et al., 2002; Stromhaug et al., 2004). Im Ptdlns 3-Kinase-Komplex II wird Atg14 durch Vps38 ersetzt. Komplex II wird für den Transport von Carboxypeptidase Y vom Golgi-Apparat zur Vakuole benötigt, hat allerdings keinen Einfluss auf Autophagie (Kihara et al., 2001). 


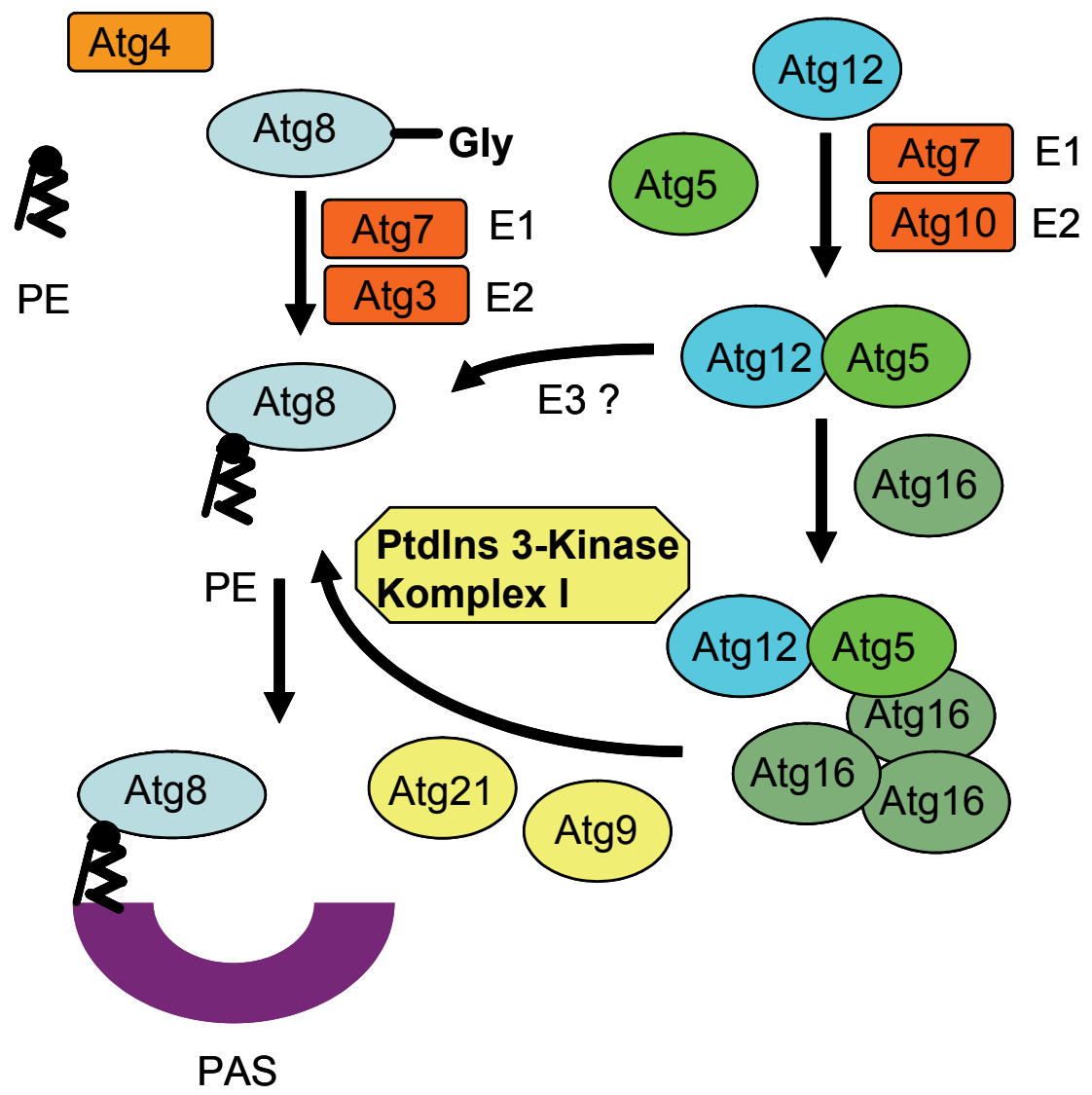

Abb.5: Atg8-PE und Atg12-Atg5-Atg16-Komplex sind entscheidend an der Bildung des Autophagosoms beteiligt.

Weitere Atg Proteine, wie Atg7, Atg3 und Atg10 agieren als, dem Ubiquitinierungssystem verwandte E1-, bzw. E2- Enzyme und katalysieren die Bildung des Atg12-Atg5-Komplexes, wie die Assoziation von Phosphatidylethanolamin (PE) an Atg8 (Abbildung abgeändert nach Levine und Kroemer, 2008).

\subsection{Degradation und Recycling}

Nach Fusion der Autophagosomen mit der Vakuole, werden die Einzelmembranvesikel und ihr zytosolischer Inhalt von vakuolären Hydrolasen degradiert. Proteinase B und höchstwahrscheinlich die putative Lipase Atg15 sind maßgeblich an der Lyse der Vesikel beteiligt (Epple et al., 2001; Teter et al., 2001). Nach dem Verdau der Makromoleküle werden die Einzelkomponenten, wie z.B. Aminosäuren zur Wiederverwertung ins Zytoplasma exportiert. Das Membranprotein Atg22 und die zur selben Proteinfamilie gehörenden Proteine Avt3 und Avt4 vermitteln hierbei den Rücktransport von Aminosäuren aus der Vakuole. Dieser Aminosäurepool garantiert den Fortbestand der Proteinsynthese und damit der ganzen Zelle unter Stickstoffmangelbedingungen. 


\subsection{Die Aktivität der Aminopeptidase 1}

In S. cerevisiae wurden bislang vier Aminopeptidasen identifiziert (Trumbly und Bradley, 1983). Die Zink-bindende Aminopeptidase 1 (Ape1, früher Lap4) ist als einzige in der Vakuole lokalisiert (Matile et al., 1971; Frey und Röhm, 1978). Wie bereits erwähnt, kodiert der ORF YKL103C (APE1, YSC1, API, LAP4) auf Chromosom XI für das aus 514 Aminosäuren bestehende Protein mit vier potentiellen N-Glykosylierungsstellen (Cueva et al., 1989; Chang und Smith, 1989). Die Aminopeptidase 1 wird als $61 \mathrm{kDa}$ Vorläuferform (prApe1) im Zytoplasma synthetisiert. Das aus 45 Aminosäuren bestehende Propeptid ist nicht hydrophob und weist stattdessen $\mathrm{N}$-terminal die Charakteristiken einer amphiphilen $\alpha$-Helix auf. Das Propeptid besitzt keine für den sekretorischen Transportweg typische Signalsequenz (Cueva et al., 1989), wird allerdings für den Transport in die Vakuole benötigt (Oda et al., 1996). Das Protein wird unter normalen Wachstumsbedingungen direkt nach Synthese über den Cvt-Transportweg (HWZ ca. 45 Minuten), unter Stickstoffmangelbedingungen über Autophagie (Abb.2) in die Vakuole transportiert (Klionsky et al., 1992). Die Prozessierung der Ape1 erfolgt durch einen zweistufigen Prozess in der Vakuole. Die $61 \mathrm{kDa}$ prApe1 wird unter Bildung einer $55 \mathrm{kDa}$ intermediären Form (iApe1) zu einem 50 kDa Protein gereift (mApe1, mature Ape1) (Segui-Real et al., 1995). Das berechnete Molekulargewicht der mApe1 liegt bei $45 \mathrm{kDa}$ und somit ist das gelelektrophoretische Laufverhalten etwas langsamer als erwartet. Metz und Röhm (1976) erklärten diese Beobachtung mit einer Modifikation durch Oligosaccharide, Klionsky et al. (1992) konnten allerdings zeigen, dass das Protein nicht glykosyliert ist. Die Reifung des Proteins ist abhängig von Proteinase A und B. In Proteinase A (pep44)-Deletionsstämmen ist nur die Vorläuferform (prApe1) nachweisbar und nach Klionsky et al. (1992) ist dieses Protein nicht aktiv, was auf den Verlust der Reifung von Proteinase B, die Proteinase A abhängig ist, zurückzuführen ist (Hemmings et al., 1981; Moehle et al., 1989). Diese Daten sind widersprüchlich mit Arbeiten unserer Arbeitsgruppe, wo pep4-Deletionstämme eine vergleichbare Wildtyp-Aktivität aufweisen (Andrei-Selmer et al., 2001). Proteinase B prozessiert dann die intermediäre Form (iApe1) zu der stabilen, reifen mApe1 (Seguí-Real et al., 1995).

Nach Synthese der prApe1 oligomerisiert das Protein mit einer Halbwertzeit von zwei Minuten zu einem Homododecamer. In der Vakuole wird die Prosequenz unter Erhalt 
des oligomerisierten Proteins gespalten, das Molekulargewicht der prozessierten Form entspricht dann ca. $600 \mathrm{kDa}$ (Kim et al., 1997). 2007 wurden Kristalle der Aminopeptidase 1 generiert (Adachi et al., 2007), die Bildung eines Dodecamers wurde dabei verifiziert. Bis jetzt wurde noch keine Kristallstruktur der Ape1 in Hefe veröffentlicht. Abbildung 6 zeigt die Kristallstruktur der Ape2 des Bakteriums Pseudomonas aeruginosa, das $48 \%$ Sequenzhomologie zur Ape1 in Hefe aufweist. Die Assemblierung zum Homododecamer ist für die Aktivität der Aminopeptidase 1 unerlässlich.

Die Aminopeptidase 1 ist eine Leucin-Exopeptidase, die die Spaltung $\mathrm{N}$-terminaler Leucine von Polypeptiden in der Vakuole katalysiert. Methodisch lässt sich die Aktivität der Ape1 durch Spaltung des Substrats H-Leucin- $\beta$-Naphtylamid photometrisch bestimmen (Trumbly und Bradley, 1983; Andrei-Selmer et al., 2001; 3.18). H-Leucin- $\beta$-Naphtylamid wird von allen in $S$. cereviesiae vorkommenden Aminopeptidasen katalytisch gespalten, die Ape1 besitzt jedoch die höchste Spezifität. 
A

$\begin{array}{ccccccccc}5 & 10 & 15 & 20 & 25 & 30 & 35 & 40 & 45 \\ 1 & 1 & 1 & 1 & 1 & 1 & 1 & 1 & 1 \\ \mathrm{NH}_{3}^{*} \text { MEEQREILEQLKKTLQMLTVEPSKNNQIANEEKEKKENENSWCIL-COO } & \end{array}$

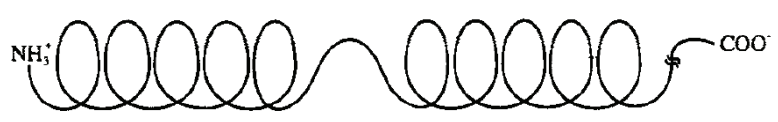

B

C
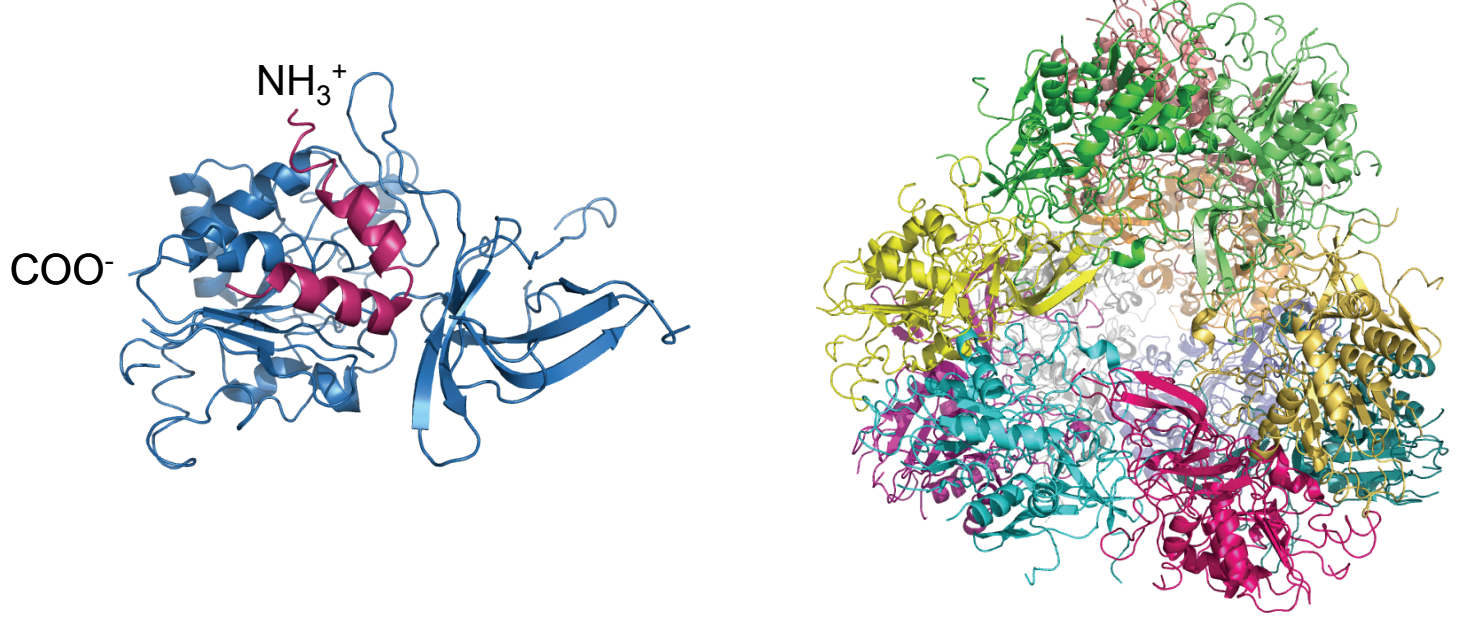

Abb.6: Sequenz des Ape1-Propeptids (S. cerevisiae) und Kristallstruktur der Ape2 aus Pseudomonas aeruginosa.

A Aminosäuresequenz und vorhergesagte Sekundärstruktur des Propeptids aus S. cerevisiae. Die ersten 18 Aminosäuren bilden eine amphipatische $\alpha$-Helix, Aminosäuren 20-24 ein $\beta$-Faltblatt, gefolgt von einer zweiten $\alpha$-Helix der letzten 20 Aminosäuren (Oda et al., 1996). B Tertiärstruktur der Ape2 von Pseudomonas aeruginosa, das N-terminale Propeptid ist in violett dargestellt. C Homododacamerer-Komplex der Ape2 aus Pseudomonas aeruginosa (Min et al.).

\subsection{Charakterisierung von Mutanten ohne Aminopeptidase 1-}

\section{Aktivität}

EMS-Mutagenese an Hefestämmen, defizient in allen vier Leucinaminopeptidasen, und anschließender Bestimmung der Ape1-Aktivität führte zur Isolierung von zwei Mutanten mit geringer (20\%), bzw. keiner messbaren Aminopeptidase 1-Aktivität unter logarithmischen und hungerinduzierten Wachstumsbedingungen (AndreiSelmer et al., 2001). Die Mutanten wurden mit via10 und via14 für „vacuolar import and autophagocytosis" bezeichnet. APE1 wurde dabei als "single copy“-Plasmid ( $p R S 314-A P E 1$ oder $p R S 313-A P E 1)$ in die Hefestämme transformiert. Die zwei 
Mutanten zeigten eine geringere Expressionshöhe der Ape1 und eine Akkumulation der zytosolischen prApe1 im Vergleich zum Wildtyp (WT) in Western Blot-Analysen. Nach Induktion von Autophagie wurde ein Anstieg des prApe1-Imports in die Vakuole beobachtet, d.h. die Akkumulation von prApe1 in den Mutanten ist auf einen Defekt des Cvt-Transportweges zurückzuführen.

Zudem reagierte die prApe1 in beiden Mutanten sensitiver auf Proteasen wie Trypsin und Proteinase K. Des Weiteren wurde mit Glycerolgradienten die Assemblierung der prApe1 näher untersucht. In WT-Zellen akkumulieren $90 \%$ der pr- und mApe1 als Dodecamer, die Mutanten via10 und via14 zeigten hingegen Defekte in der Aggregation von prApe1-Komplexen, mApe1 akkumulierte weiterhin in Dodecameren. Die erhöhte Sensitivität auf Proteasen und die fehlerhafte Komplexassemblierung deuten auf eine nicht native Konformation der Ape1 in den Mutanten via10 und via14 hin.

Die Identifikation der VIA10- und VIA14-Gene könnte zur Charakterisierung neuer, evtl. Chaperon-ähnlicher Faktoren führen, die an der Formation nativer Ape1 Komplexe und der Ausbildung der Cvt-Vesikel beteiligt sind (Andrei-Selmer et al., 2001). In zu diesem Zweck durchgeführten Komplementationsstudien wurden die Mutantenstämme mit einer „single copy“ genomischen DNA-Bank transformiert. Die DNA-Bank wurde aus dem parentalen WT-Stamm C6C (Kreuzung aus SEY6211 (Robinson et al., 1988) mit II-17 (D.H. Wolf) transformiert mit pRS313-APE1) hergestellt. Genomische DNA wurde mit dem Restriktionsenzym Sau3A I verdaut und auf ein 1\%-iges Agarosegel geladen. Banden von einer Größe zwischen 2000 und $5000 \mathrm{bp}$ wurden aus dem Gel isoliert, aufgereinigt und in den mit BamH I verdauten Vektor $p R S 316$ kloniert und danach in E.coli $(D H 5 \alpha)$ transformiert. Die aus den E. coli-Klonen isolierte DNA wurde in die Mutantenstämme via10 und via14 transformiert. Die Hefeklone wurden mit Ape1-Overlay-Assays in Hinblick auf eine Wiederherstellung der Ape1-Aktivität untersucht. Bei diesem Screen wurde ein ca. 1.3 kb großer Genabschnitt auf Chromosom IV (Koordinatoren: 1195168-1195325) isoliert. Dieser beinhaltete auf dem Watson-Strang einen kompletten ORF (YDR360W) und gegenüberliegend auf dem Crick-Strang den N-Terminus eines zweiten ORFs (YDR359C) (Abb.7), die sich mit 286 bp überlappen. YDR360W (435 bp) war bis dato ein hypothetischer ORF, wohingegen YDR359C (2949 bp) für ein beschriebenes Protein kodiert. 


\section{Chromosom IV}

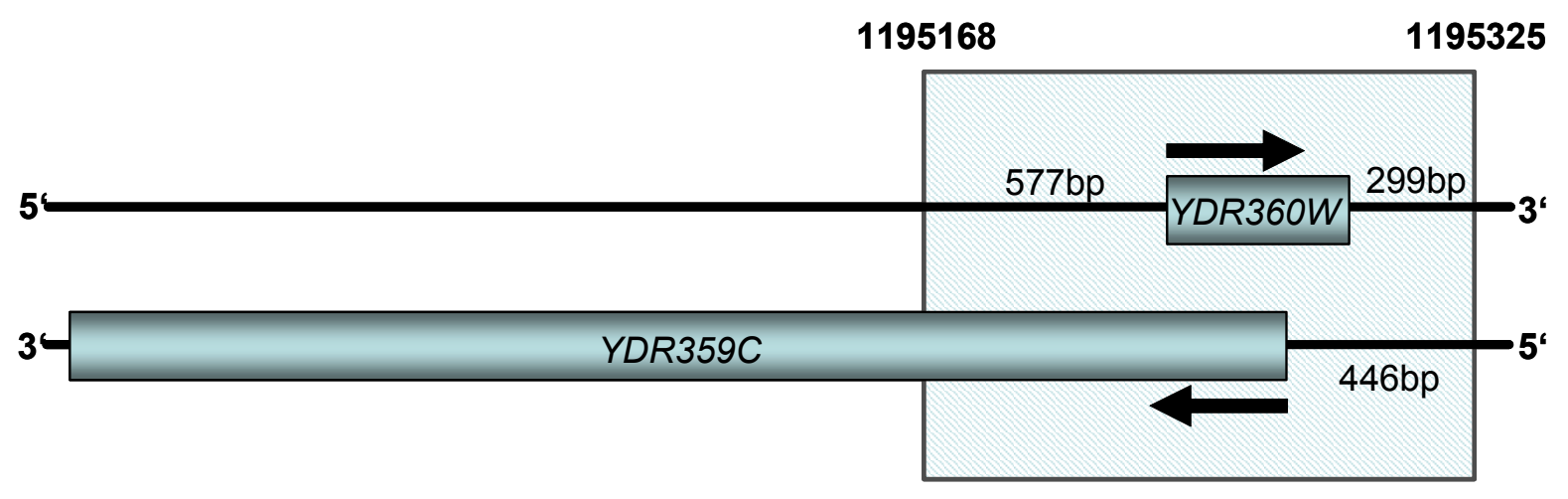

Abb.7: Genabschnitt auf Chromosom IV.

Durch Transformation einer "single copy“-DNA Bank wurde ein ca. 1.3 kb langer Genabschnitt (blau unterlegt) des Chromosoms IV mit den Koordinaten 1195168 bis 1195325 identifiziert, der eine Aktivierung der Ape1 in den via Mutanten bewirkt. Die beiden ORFs überlappen um 286 bp, entsprechend 95 Aminosäuren.

In der Dissertation von Pasupuleti Naga Rekha (2004) wurde der ORF YDR360W näher charakterisiert. Sequenzvergleiche des WT-Stammes mit den beiden Mutanten via10 und via14 zeigten, dass es auf diesem Genabschnitt keine Mutationen gab, die den Defekt erklären konnten. Deshalb wurde angenommen, dass YDR360W als Suppressor der Ape1-Aktivität fungiert. Das zu keiner klassifizierten Proteinfamilie gehörende Protein wurde Suvia1 für "suppressor of via" genannt. Deletion des ORFs YDR360W (ydr360wA) führte zu einem Verlust der Aminopeptidase 1-Aktivität, während die Expression von Suvia1 die Aktivität sowohl im ydr360w $\Delta$ Stamm, als auch in den beiden Mutanten wiederherstellte. Suvia1 schien dabei die Ape1Expression zu stabilisieren. Zudem war ein geringer Anstieg der Ape1-Expression zu beobachten. In der Studie wurde Suvia1 zur Expressionskontrolle mit caboxyterminalem HA-,tag“ exprimiert. Das elektrophoretische Laufverhalten des Proteins entsprach nicht dem berechneten Molekulargewicht von $16 \mathrm{kDa}$, sondern lief langsamer bei ca. $48 \mathrm{kDa}$. Suvia1-HA wurde als zytoplasmatisches Protein beschrieben, das in mikroskopischen Untersuchungen in der Nähe des PAS lokalisierte. Eine Co-Lokalisation mit GFP-Atg8 konnte allerdings nicht bestätigt werden.

Zytosolisches Suvia1-HA eluiert von einer S200 Gelfiltrationssäule unter nicht denaturierenden Bedingungen bei ca. 200 kDa. Suvia1-HA könnte somit Teil eines 
200 kDa Komplexes sein, der entscheidend die Konformation und damit die Aktivität der Ape1 beeinflusst.

\subsection{Fragestellung}

Die Aminopeptidase 1 (Ape1) ist eine Leucin-Exopeptidase, die die Spaltung Nterminaler Leucine von Polypeptiden in der Vakuole katalysiert. Ihre Aktivität kann mit der Spaltung des Substrats H-Leucin- $\beta$-Naphtylamid photometrisch verfolgt werden. Ape1 wird im Zytoplasma synthetisiert. Das Protein oligomerisiert zu einem sog. CvtKomplex, bestehend aus mehreren zu Homododecameren assemblierten Ape1Molekülen, dem Ape1-Rezeptor Atg19 und dem Protein Ams1. Dieser wird in CvtVesikeln verpackt in die Vakuole transportiert, wo das Protein unter Erhalt des Dodecamers prozessiert wird. Die komplizierten Vorgänge der Komplexassemblierung und Prozessierung sind noch weitgehend unerforscht.

Ein Komplementationsscreen an zwei Mutanten via10 und via14 führte zur Isolation eines bis dato zu keiner klassifizierten Proteinfamilie gehörenden Suppressorgens, SUVIA1 (YDR360W) und dem 5'-Fragmentes des ORFs YDR359C. Dieser ORF kodiert für das verifizierte Protein Eaf1/ Vid21. Der Name Vid21 (vacuole import and degradation) steht für eine potentielle Beteiligung des Proteins an dem Transport und der Degradation der Fruktose-1,6-bisphosphatase (FBPase) in der Vakuole (Hoffman und Chiang, 1996). Mit dem Namen Eaf1 (Esa1-associated factor) wurde das Protein 2004 als eine von dreizehn Untereinheiten des Histon Acetyltransferase Komplexes NuA4 (nucleosome acetyltransferase of H4) identifiziert (Krogan et al., 2004).

In dieser Arbeit sollte die Bedeutung der Proteine Suvia1 und Eaf1 für die Biogenese der Ape1 näher charakterisiert werden. 


\section{Material und Methoden}

\subsection{Organismen}

\subsubsection{Escherichia coli-Stämme}

Tab.3: Genotyp der verwendeten E.coli Stämme

\begin{tabular}{|c|c|}
\hline Stamm & Genotyp \\
\hline XL1blue & endA1, gyrA96, hsdR17 ( $\left.\mathrm{rk}^{-} \mathrm{mk}^{-}\right)$, lac, recA1, relA1, supE44, thi-1, F' [proAB, laclaZM15, TN10(Tet')] \\
\hline DH5a & f- Ф 80d lacZM15(lacZya-argF), U169, recA1, endA1, hsdR17 ( $\left.\mathrm{r}^{-} \mathrm{mk}^{-}\right)$ \\
\hline BL21 & F-, ompT, hsdS(r-B, m-B), gal, dcm \\
\hline
\end{tabular}

\subsubsection{Saccharomyces cerevisiae-Stämme}

\section{Siehe Anhang}

\subsection{Nährmedien}

Alle Mengenangaben beziehen sich auf ein Endvolumen von einem Liter. Die Reagenzien wurden in deionisiertem Wasser $\left(\mathrm{dH}_{2} \mathrm{O}\right)$ gelöst und 20 bis 40 Minuten bei $120^{\circ} \mathrm{C}$ autoklaviert.

\subsubsection{Escherichia coli-Medien}

Lyysogeny Broth-Medium (LB) $10 \mathrm{~g}$ Trypton, $5 \mathrm{~g}$ Hefeextrakt, $10 \mathrm{~g} \mathrm{NaCl}$

SOC-Medium $20 \mathrm{~g}$ Trypton, $5 \mathrm{~g}$ Hefeextrakt, $0.58 \mathrm{~g} \mathrm{NaCl}, 2.46 \mathrm{~g} \mathrm{MgSO}_{4}, 4 \mathrm{~g}$ Glucose

Zur Herstellung ampicillin- oder kanamycinhaltigen Selektionsmedien wurde sterile Ampicillin-, bzw. Kanamycinlösung zu einer Endkonzentration von jeweils 50 g/ml nach dem Autoklavieren zugegeben. 
Agarplatten enthalten zusätzlich zu den oben genannten Inhaltsstoffen $20 \mathrm{~g}$ Agar.

\subsubsection{Saccharomyces cerevisiae-Medien}

YP-Medium $\quad 20 \mathrm{~g}$ Pepton, $10 \mathrm{~g} \mathrm{Hefeextrakt}$

Geneticin-Medium YP Medium versetzt mit Geneticin (G418, PAA), 200 mg/ml Endkonzentration

Benomyl-Medium YP Medium versetzt mit in DMSO gelöstem Benomyl (Sigma), 5 oder $15 \mu \mathrm{g} / \mathrm{ml}$ Endkonzentration

SD-Leu-Medium

$6.7 \mathrm{~g}$ Yeast Nitrogen Base ohne Aminosäuren, $1.205 \mathrm{~g}$ Aminosäurecocktail, $10 \mathrm{ml}$ 100xAdenin, 100xUracil, 100xHistidin, nach dem Autoklavieren wurde $10 \mathrm{ml}$ 100xTryptophan zugegeben

SD-His-Medium

$6.7 \mathrm{~g}$ Yeast Nitrogen Base ohne Aminosäuren, $1.205 \mathrm{~g}$ Aminosäurecocktail, $10 \mathrm{ml}$ 100xAdenin, 100xUracil, 100xLeucin, nach dem Autoklavieren wurde $10 \mathrm{ml}$ 100xTryptophan zugegeben

SD-Ura-Medium $\quad 6.7 \mathrm{~g}$ Yeast Nitrogen Base ohne Aminosäuren, $1.205 \mathrm{~g}$ Aminosäurecocktail, $10 \mathrm{ml}$ 100xAdenin, 100xHistidin, 100xLeucin, nach dem Autoklavieren wurde $10 \mathrm{ml}$ 100xTryptophan zugegeben

100xAminosäure-Lösungen 600 mg L-Leucin, 400 mg Adenin Hemisulfatsalz, $400 \mathrm{mg}$ Uracil, $400 \mathrm{mg}$ L-Histidin-HCL, jeweils in $200 \mathrm{ml}$ deionisiertem Wasser gelöst und autoklaviert.

100xTrp $400 \mathrm{mg} \mathrm{L-Tryptophan,} \mathrm{gelöst} \mathrm{in} 200 \mathrm{ml}$ deionisiertem Wasser und steril filtriert 
Aminosäure-Cocktail $900 \mathrm{mg}$ Lysin-HCL, $4500 \mathrm{mg} \mathrm{L-Valin,} 900 \mathrm{mg}$ L-Isoleucin, $600 \mathrm{mg}$ L-Arginin-HCL, $600 \mathrm{mg}$ L-Methionin, $900 \mathrm{mg} \mathrm{L-}$ Tyrosin, $1500 \mathrm{mg}$ L-Phenylalanin, $3000 \mathrm{mg}$ LGlutaminsäure, $11.25 \mathrm{~g} \mathrm{L-Serin,} 12 \mathrm{~g}$ L-Threonin

Die Aminosäuren wurden gemörsert und $1.205 \mathrm{~g}$ pro Liter eingesetzt.

Agarplatten enthalten zusätzlich $20 \mathrm{~g}$ Agar pro Liter. Nach dem Abkühlen auf ca. $60^{\circ} \mathrm{C}$ wurde den Medien 2\% Glucose oder 2\% Galaktose aus einer $20 \%$ Glucose-, bzw. Galaktoselösung zugesetzt.

\subsection{Puffer}

10xTE-Puffer $100 \mathrm{mM}$ Tris/HCl (pH7.5), $10 \mathrm{mM}$ EDTA, mit $\mathrm{H}_{2} \mathrm{O}$ ad 1 Liter

10xTAE-Puffer $\quad 48.4 \mathrm{~g}$ Tris, $11.42 \mathrm{ml}$ Essigsäure (98\%), $10 \mathrm{mM}$ EDTA, mit $\mathrm{H}_{2} \mathrm{O}$ ad 1 Liter

10xPBS-Puffer $\quad 14.4 \mathrm{~g} \mathrm{Na}_{2} \mathrm{HPO}_{4} \times 2 \mathrm{H}_{2} \mathrm{O}, 2.4 \mathrm{~g} \mathrm{KH}_{2} \mathrm{PO}_{4}, 2 \mathrm{~g} \mathrm{KCl}, 80 \mathrm{~g} \mathrm{NaCl}$ mit $\mathrm{H}_{2} \mathrm{O}$ ad 1 Liter

20xTBS-Puffer $\quad 150 \mathrm{mM}(175.32 \mathrm{~g}) \mathrm{NaCl}, 25 \mathrm{mM}(60.57 \mathrm{~g})$ Tris mit $\mathrm{H}_{2} \mathrm{O}$ ad 1 Liter, $\mathrm{pH} 7.4$

20xSSC-Puffer $\quad 175.32 \mathrm{~g} \mathrm{NaCl}, 88.22 \mathrm{~g}$ Trinatriumcitrat-2-hydrat mit $\mathrm{H}_{2} \mathrm{O}$ ad 1 Liter, $\mathrm{pH} 7.0$

20xSCP-Puffer $\quad 2 \mathrm{M}$ Natriumchlorid, 0.6 M Dinatrium-Hydrogen-Phosphat, $0.02 \mathrm{M}$ EDTA, pH6.2

Weitere Puffer sind direkt zu den Methoden angegeben. 


\subsection{Größenstandards}

\subsubsection{DNA-Größenstandard}

Hartley and Gregori et al. (1981)

$1 \mathrm{~Kb}$ DNA-Leiter $1.0 \mathrm{mg} / \mathrm{ml}$ (Invitrogen) (Abb.8)

Von diesem Größenstandard wurden je $10 \mu \mathrm{l}$ auf ein Agarosegel aufgetragen.

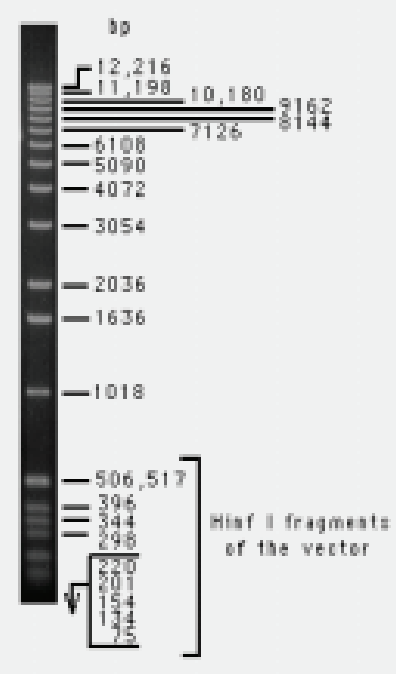

Abb.8: $1 \mathrm{~Kb}$ DNA-Leiter aufgetrennt auf einem 1\%-igen Agarosegel.

\subsubsection{Protein-Größenstandards für SDS-Polyacrylamid-Gelelektrophorese}

Prestained Precision Plus Protein Marker All Blue (BioRad): 10 kDa, $15 \mathrm{kDa}, 20 \mathrm{kDa}$, $25 \mathrm{kDa}, 37 \mathrm{kDa}, 50 \mathrm{kDa}, 75 \mathrm{kDa}, 100 \mathrm{kDa}, 150 \mathrm{kDa}, 250 \mathrm{kDa}$

Auftragsvolumen:

Mini-Gel: $6 \mu \mathrm{l}$

Großes-Gel: $15 \mu \mathrm{l}$ 


\subsection{Vektoren}

Tab.4: In dieser Arbeit verwendete Vektoren.

\begin{tabular}{|c|c|c|c|}
\hline Vektor & Funktion & Selektion & Referenz \\
\hline YEp13 & $\begin{array}{l}\text { Proteinexpression in } \\
\text { Hefe, "genomic library } \\
\text { vector" }\end{array}$ & $A m p^{r}, L E U 2$ & $\begin{array}{l}\text { Broach et al., 1979: } \\
\text { Nasmyth und Tatchell, } \\
1980\end{array}$ \\
\hline $\begin{array}{l}\text { pFA6a- } \\
\text { HIS3MX6 }\end{array}$ & $\begin{array}{l}\text { Generation von } \\
\text { Deletionsstämmen in } \\
\text { Hefe }\end{array}$ & $\mathrm{Amp}^{r}, \mathrm{HIS} 3$ & Wach et al., 1994 \\
\hline pGBT9 & $\begin{array}{l}\text { GAL4-DNA-Bindevektor } \\
\text { in Hefe }(\mathrm{Y} 2 \mathrm{H})\end{array}$ & $A m p^{r}, T R P 1$ & $\begin{array}{l}\text { Clontech Laboratories, } \\
\text { Inc. }\end{array}$ \\
\hline pGBKT7 & $\begin{array}{l}\text { GAL4-DNA-Bindevektor } \\
\text { in Hefe }(\mathrm{Y} 2 \mathrm{H})\end{array}$ & $A m p^{r}, T R P 1$ & $\begin{array}{l}\text { Clontech Laboratories, } \\
\text { Inc. }\end{array}$ \\
\hline$p G A D T 7$ & $\begin{array}{l}\text { GAL4- } \\
\text { Aktivierungsdomäne in } \\
\text { Hefe }(Y 2 H)\end{array}$ & $A m p^{r}, L E U 2$ & $\begin{array}{l}\text { Clontech Laboratories, } \\
\text { Inc. }\end{array}$ \\
\hline pRS313-316 & $\begin{array}{l}\text { Proteinexpression in } \\
\text { Hefe }\end{array}$ & $\begin{array}{l}\text { Amp }{ }^{r}, H I S 3, \\
\text { TRP1, } \\
\text { LEU2, bzw. } \\
\text { URA3 }\end{array}$ & $\begin{array}{l}\text { Sikorski und Hieter et al., } \\
1989\end{array}$ \\
\hline pRS303-306 & $\begin{array}{l}\text { integrierende Vektoren } \\
\text { zur Proteinexpression } \\
\text { in Hefe }\end{array}$ & $\begin{array}{l}\text { Amp }{ }^{r}, H I S 3, \\
\text { TRP1, } \\
\text { LEU2, bzw. } \\
\text { URA3 }\end{array}$ & $\begin{array}{l}\text { Sikorski und Hieter et al., } \\
1989\end{array}$ \\
\hline $\begin{array}{l}p Y X 141,142 \\
242 \text { und } 132\end{array}$ & $\begin{array}{l}\text { Proteinexpression in } \\
\text { Hefe, C-terminaler HA- } \\
\text { tag }\end{array}$ & $\begin{array}{l}\text { Amp }^{r}, \\
\text { LEU2, } \\
\text { bzw.TRP1 }\end{array}$ & $\begin{array}{l}\text { Foreman und Davis, 1994; } \\
\text { Hans-Dieter Schmitt, MPI } \\
\text { Göttingen }\end{array}$ \\
\hline $\begin{array}{l}p Y X 141 \text { und } \\
242-3 \times H A\end{array}$ & $\begin{array}{l}\text { Proteinexpression in } \\
\text { Hefe, C-terminaler } \\
\text { 3xHA-tag }\end{array}$ & $A m p^{r}, L E U 2$ & diese Arbeit \\
\hline $\begin{array}{l}p Y X 141-, 142- \\
\text { und } 242-H A\end{array}$ & $\begin{array}{l}\text { Proteinexpression in } \\
\text { Hefe, N-terminaler HA- } \\
\text { tag }\end{array}$ & $A m p^{r}, L E U 2$ & diese Arbeit \\
\hline
\end{tabular}




\subsection{Kultivierung von Mikroorganismen}

\subsubsection{Vermehrung von E. coli-Zellen}

E.coli Zellen wurden auf LB-Ampicillin oder Kanamycin-Platten bei $37^{\circ} \mathrm{C}$ im Brutschrank vermehrt. Flüssigkulturen von E.coli wurden in LB-Ampicillin oder Kanamycin-Medium bei $37^{\circ} \mathrm{C}$ in Reagenzgläsern (2-3 $\mathrm{ml}$ ) oder in Erlenmeyerkolben $(50-500 \mathrm{ml})$ auf einer Schüttelplattform bei 250 rpm angezogen.

\subsubsection{Vermehrung von S. cerevisiae}

Das Wachstum von Hefezellen auf Festmedium erfolgte bei $30^{\circ} \mathrm{C}$ im Brutraum oder Brutschrank. Anzuchten in Flüssigmedium wurden bei $30^{\circ} \mathrm{C}$ in Reagenzgläsern oder Erlenmeyerkolben bei $220 \mathrm{rpm}$ im Brutraum oder Brutschrank geschüttelt. Eine frische Übernachtkultur wurde in der Regel 1:20 in YPD-Medium auf eine $O_{600}$ 0.30.4 verdünnt und bis zum Erreichen der logarithmischen Phase $\left(O D_{600}\right.$ von ca. 1.0) inkubiert.

\subsection{Bestimmung der Zelldichte in Flüssigkulturen}

Die Zelldichte von Flüssigkulturen wurde durch photometrische Messungen bei einer Wellenlänge von $600 \mathrm{~nm}$ bestimmt. Als Nullwert diente das Medium, in dem die Zellen angezogen wurden. Dabei entspricht einer optischen Dichte von $\mathrm{OD}_{600}=1$, ca. $2 \times 10^{7}$ Zellen/ml (Hefe), bzw. ca. $3 \times 10^{8}$ Zellen/ml (E.coli). 


\subsection{Isolierung von DNA und RNA}

\subsubsection{Isolierung von Plasmid-DNA aus E. coli über QIAprep Spin Plasmid Miniprep Säulen}

QIAprep Spin Säulen, Puffer aus QIAprep Spin Plasmid Miniprep Set (Qiagen). Genaue Angaben zu Puffern und Säulenmaterial sind dem QIAprep Spin Plasmid Miniprep Kit zu entnehmen.

2-3 ml einer E. coli-Übernachtkultur in LB-Ampicillin oder -Kanamycin Medium.

Die E.coli-Übernachtkulturen wurden abzentrifugiert und in $250 \mu \mathrm{l}$ gekühltem P1 Puffer resuspendiert. Nach Zugabe von $250 \mu \mathrm{l}$ P2 Lysepuffer und anschließend 350 ul N3 Neutralisationspuffer wurde das Zelllysat bei 13000 rpm 10 Minuten sedimentiert, der klare Überstand auf eine QIAprep Minisäule aufgetragen und wieder 1 Minute zentrifugiert. Die an die Säulenmembran gebundene Plasmid-DNA wurde mit $750 \mu \mathrm{l}$ PB Puffer und gewaschen und die DNA am Ende durch Zugabe von 30-50 $\mu \mathrm{l} \mathrm{H}_{2} \mathrm{O}$ eluiert.

\subsubsection{Isolierung von Plasmid-DNA aus E. coli über QIAprep Spin Plasmid Midiprep Säulen}

QIAprep Spin Säulen, Puffer aus HiSpeed Plasmid Midi Kit (Qiagen)

Genaue Angaben zu Puffern, Säulenmaterial und Vorgehensweise sind dem HiSpeed Plasmid Midi Kit zu entnehmen

50-100 ml einer E. coli-Übernachtkultur in LB-Ampicillin- oder -Kanamycin-Medium. 


\subsubsection{Isolierung genomischer DNA aus S. cerevisiae}

SCE-Puffer: $1 \mathrm{M}$ Sorbitol, 0.1 M Natriumcitrat, 0.06 M EDTA pH7.0

Sphäroblastierungspuffer: $2 \mathrm{mg}$ Zymolyase 5000 (T20) und $0.8 \mu \mathrm{l}$ 2-Mercaptoethanol in $1 \mathrm{ml} \mathrm{SCE}-P$ uffer

SDS-Lösung: 2\% SDS, $0.1 \mathrm{M}$ Tris/HCl pH9.0, $0.05 \mathrm{M}$ EDTA

Ammoniumacetat-Lösung: $5 \mathrm{M}$ Ammoniumacetat

Kaliumacetat-Lösung: $5 \mathrm{M}$ Kaliumacetat

1xTE-Puffer

$5 \mathrm{ml}$ einer Übernachtkultur von S. cerevisiae in YPD-Medium wurden zwei Minuten bei $3000 \mathrm{rpm}$ zentrifugiert, der Überstand verworfen und die Hefezellen in $1 \mathrm{ml} \mathrm{H}_{2} \mathrm{O}$ gewaschen. Die Zellen wurden anschließend in $0.2 \mathrm{ml}$ Sphäroblastierungspuffer resuspendiert und $30-60$ Minuten bei $37^{\circ} \mathrm{C}$ inkubiert.

Die Proben wurden zwischenzeitlich 2-3 kurz geschüttelt. Der Abbau der Zellwände durch Zymolyase wurde anhand der Zellen vermengt mit einem Tropfen 0.1\% SDS mikroskopisch verfolgt.

Nach Zugabe von $0.2 \mathrm{ml}$ SDS-Lösung wurde die lysierte Probe gemischt und fünf Minuten bei $65^{\circ} \mathrm{C}$ erhitzt. Nach Hinzufügen von $0.2 \mathrm{ml} 5 \mathrm{M}$ Kaliumacetat folgte ein Kälteschritt für 20 Minuten bei $0^{\circ} \mathrm{C}$. Die Probe wurde anschließend fünf Minuten bei $14000 \mathrm{rpm}$ zentrifugiert, 400-500 $\mu \mathrm{l}$ des Überstands in ein neues Reaktionsgefäß überführt, mit $0.2 \mathrm{ml} 5 \mathrm{M}$ Ammoniumacetat gemischt, $1 \mathrm{ml}$ Isopropanol zugegeben und bei 3000 rpm 15-30 Sekunden zentrifugiert. Das Pellet wurde in $90 \mu \mathrm{l} 1 \mathrm{xTE}-$ Puffer gelöst.

Für den nächsten Reinigungsschritt wurde die gelöste DNA mit $10 \mu \mathrm{l} 5 \mathrm{M}$ Ammoniumacetat versetzt und mit $200 \mu \mathrm{l}$ 100\%-igem Ethanol gefällt. Nach einer kurzen Zentrifugation (30 Sekunden bei 3000 rpm) wurde der Überstand vorsichtig abgenommen und das verbleibende Pellet zweimal in $80 \%$ Ethanol gewaschen.

Das getrocknete Pellet wurde in $50 \mu \mathrm{l}$ 1xTE-Puffer gelöst. Für einen Restriktionsverdau wurden $5 \mu \mathrm{l}$ dieser Lösung in einem Gesamtvolumen von $30 \mu \mathrm{l}$ eingesetzt. 


\subsubsection{Isolierung von Plasmid-DNA aus S. cerevisiae}

Breaking Puffer: $100 \mathrm{mM} \mathrm{NaCl}, 10 \mathrm{mM}$ Tris/HCl pH 8.0, $1 \mathrm{mM}$ EDTA pH8.0, 1\% (w/v) SDS, $2 \%(v / v)$ Triton X-100

Glasperlen ( $\varnothing 0.45 \mathrm{~mm}$ )

Phenol/Chloroform: im Verhältnis 1:1, äquilibriert und überschichtet mit 1xTE-Puffer $100 \%$ Ethanol

$70 \%$ Ethanol

$3 \mathrm{M}$ Natriumacetat $\mathrm{pH} 5.2$

$1.5 \mathrm{ml}$ einer Übernachtkultur wurden geerntet (1 Minute, $13000 \mathrm{rpm}$ ). Die Zellen wurden einmal in Wasser gewaschen und in $200 \mu \mathrm{l}$ Breaking Puffer resuspendiert. Nach Zugabe von ca. $200 \mu \mathrm{l}$ Volumen Glasperlen und $200 \mu \mathrm{l}$ Phenol/Chloroform wurden die Zellen 5 Minuten bei $4^{\circ} \mathrm{C}$ auf dem IKA-Vibrax bei maximaler Geschwindigkeit aufgeschlossen und anschließend zentrifugiert (10 Minuten, 13000 rpm). $50 \mu \mathrm{l}$ der obersten Phase wurden in ein neues Eppendorfgefäß überführt und die DNA mit $5 \mu \mathrm{l}$ Natriumacetat und $140 \mu \mathrm{l}$ kaltem 100\%-igem Ethanol gefällt. Die Proben wurden 20 Minuten bei $-80^{\circ} \mathrm{C}$ inkubiert. Nach Zentrifugation (10 Minuten, 13000 rpm) wurde der Überstand verworfen, das Pellet einmal mit 70\%-igem Ethanol gewaschen und bei Raumtemperatur getrocknet. Die Plasmid-DNA wurde in $30 \mu \mathrm{l}$ $\mathrm{H}_{2} \mathrm{O}$ aufgenommen und bei $-20^{\circ} \mathrm{C}$ gelagert.

Je 1-2 $\mu \mathrm{l}$ der aufgereinigten DNA wurden bei einer Transformation in $E$. coli eingesetzt.

\subsubsection{Isolierung von Gesamt-RNA aus S. cerevisiae}

\section{1xTE-Puffer}

Glasperlen ( $\varnothing 0.45 \mathrm{~mm}$ )

Phenol/Chloroform: im Verhältnis 1:1, äquilibriert und überschichtet mit 1xTE-Puffer

Cross RNA-Puffer 1: $0.3 \mathrm{M} \mathrm{NaCl}, 10 \mathrm{mM}$ Tris pH7.5, $1 \mathrm{mM}$ EDTA, $0.2 \%$ SDS

(Lagerung bei $4^{\circ} \mathrm{C}$ )

Cross RNA-Puffer 2: 1xTE-Puffer, $0.2 \%$ SDS 
Eine frische Übernachtkultur von S. cerevisiae wurde auf eine ${ }^{O} D_{600}$ von 0.2 bis 0.3 in $20 \mathrm{ml}$ YPD Medium verdünnt und 4 bis 5 Stunden bei $30^{\circ} \mathrm{C}$ inkubiert. Die Zellen wurden bei einer $\mathrm{OD}_{600}$ 0.7- 0.8 durch Zentrifugation geerntet (3500 rpm, 3 Minuten, $4^{\circ} \mathrm{C}$ ), mit eisgekühltem 1xTE-Puffer gewaschen und dabei in ein $2 \mathrm{ml}$ EppendorfReagenzgefäß überführt. Die Pellets wurden in flüssigem Stickstoff schockgefroren und bei $-80^{\circ} \mathrm{C}$ gelagert. Für den Zellaufschluss wurden ca. $250 \mu \mathrm{l}$ Glasperlen, $350 \mu \mathrm{l}$ Phenol/Chloroform und $350 \mu \mathrm{l}$ Cross RNA Puffer I auf das gefrorene Pellet gegeben. Die Eppendorf-Reagenzgefäße wurden 15 Minuten im Kühlraum auf dem IKA-Vibrax bei maximaler Geschwindigkeit geschüttelt. Nach anschließender Zentrifugation (14000 rpm, 10 Minuten, $4^{\circ} \mathrm{C}$ ) wurde die obere wässrige Phase in einem $2 \mathrm{ml}$ Eppendorfgefäß mit $1.5 \mathrm{ml}$ gekühltem $\left(-20^{\circ} \mathrm{C}\right)$ Ethanol gemischt und für $10 \mathrm{Min}$. bei $20^{\circ} \mathrm{C}$ gefällt. Das Präzipitat wurde durch Zentrifugation (10 Minuten, $14000 \mathrm{rpm}$ ) sedimentiert. Das Pellet wurde in Cross RNA Puffer II durch fünfminütige Inkubation bei $65^{\circ} \mathrm{C}$ unter leichtem Schütteln gelöst. Zur Konzentrationsbestimmung wurden die RNA-Proben 1:300 in 1xTE-Puffer verdünnt und die Absorption bei $260 \mathrm{~nm}$ im Spektralphotometer bestimmt. RNA-Lösungen wurden bei $-20^{\circ} \mathrm{C}$ gelagert.

\section{DNase I Verdau gereinigter Gesamt-RNA}

Mit einem DNase I Verdau wurden DNA-Kontaminationen aus RNA Proben entfernt.

DNase I Verdau:

$40 \mu$ RNA-Probe

$2.5 \mu \mathrm{l} 1 \mathrm{M}$ Tris/ $\mathrm{HCl}$ pH7.5 (in DEPC- $\mathrm{H}_{2} \mathrm{O}$ )

$0.5 \mu \mathrm{l} 1 \mathrm{M} \mathrm{MgCl}_{2}$ (in DEPC- $\mathrm{H}_{2} \mathrm{O}$ )

$0.1 \mu \mathrm{l}$ DNase I (Invitrogen, $151 \mathrm{U} / \mu \mathrm{l}$ )

$0.25 \mu \mathrm{l}$ RNaseOUT Ribonuclease (Invitrogen, $40 \mathrm{U} / \mu \mathrm{l}$ )

ad $50 \mu \mathrm{l}$ DEPC- $\mathrm{H}_{2} \mathrm{O}$

Der enzymatische Verdau wurde bei $37^{\circ} \mathrm{C}$ für mindestens 20 Minuten inkubiert. Die Aufreinigung erfolgte wie in Methode 3.12 .1 beschrieben. 


\subsection{Photometrische Konzentrationsbestimmung von Nukleinsäuren}

Die Konzentration von Nukleinsäuren wurde in Quarzküvetten photometrisch bei einer Wellenlänge von $260 \mathrm{~nm}$ bestimmt. Dabei entspricht der Absorptionswert von $\mathrm{OD}_{260}=1$ einer Konzentration von $50 \mu \mathrm{g} / \mathrm{ml}$ doppelsträngiger DNA, $33 \mu \mathrm{g} / \mathrm{ml}$ einzelsträngiger DNA oder $40 \mu \mathrm{g} / \mathrm{ml}$ RNA.

\subsection{Reinigung von DNA und RNA}

\subsubsection{Fällung von DNA durch Ethanol}

Natriumacetat-Lösung: $3 \mathrm{M}$ Natriumacetat pH5.5

$100 \%$ und $70 \%$ Ethanol

1xTE-Puffer

Die Reinigung und Konzentrierung von Nukleinsäuren aus wässriger Lösung erfolgte durch Fällung. Dazu wurde die DNA-Lösung mit 0.1 Volumen $3 \mathrm{M}$ Natriumacetat pH5.5 gemischt und anschließend 2 Volumen 100\%-igen Ethanol zugegeben, gut gemischt und für 10 Minuten bei $-20^{\circ} \mathrm{C}$ inkubiert. Die präzipitierte DNA wurde durch zehnminütiges Zentrifugation bei $13000 \mathrm{rpm}$ sedimentiert. Der Niederschlag wurde zweimal mit 70\%-igem Ethanol gewaschen, bei Raumtemperatur oder in der Speed Vac Concentrator (Bachofer, Reutlingen) getrocknet und in einem kleinen Volumen (z.B. 20-50 $\mu$ l) 1xTE-Puffer oder $\mathrm{H}_{2} \mathrm{O}$ gelöst.

\subsubsection{Phenol-Chloroform-Extraktion von DNA}

P/C/TE: Phenol/Chloroform im Verhältnis 1:1, mit 1xTE-Puffer äquilibriert und überschichtet.

Proteine und andere Verunreinigungen wurden aus einer wässrigen DNA-Lösung durch Extraktion mit Phenol/Chloroform entfernt. Dazu wurde die Probe mit gleichem Volumen Phenol/Chloroform/TE gut gemischt (Vortex) und anschließend zur Phasentrennung 5 Minuten bei 13000 rpm zentrifugiert. Die obere wässrige, DNA- 
haltige Phase wurde in ein neues Reagenzgefäß überführt. Die extrahierte DNA wurde mit Natriumacetat und Ethanol präzipitiert (siehe 3.10.1).

\subsubsection{Aufreinigung DNase I behandelter RNA-Präperationen}

Phenol/Chloroform/lsopropanol im Verhältnis 25:24:1

Isopropanol

$3 \mathrm{M}$ Natriumacetat $\mathrm{pH} 4.8$

$70 \%$ Ethanol (in DEPC- $\mathrm{H}_{2} \mathrm{O}$ )

DEPC- $\mathrm{H}_{2} \mathrm{O}$

$\mathrm{Zu}$ der mit DNase I behandelten RNA-Probe wurde 1 Volumen Phenol/Chloroform/Isopropanol gegeben und 2 Minuten bei $13000 \mathrm{rpm}$ zentrifugiert. Die oberste, wässrige Phase wurde in ein neues Eppendorfgefäß überführt. Durch Zugabe von 0.1 Volumen $3 \mathrm{M}$ Natriumacetat und 1 Volumen Isopropanol wurde die RNA gefällt und anschließend 15 Minuten bei $13000 \mathrm{rpm}\left(4^{\circ} \mathrm{C}\right)$ abzentrifugiert. Das Pellet wurde zweimal in $70 \%$-igem Ethanol gewaschen und bei $37^{\circ} \mathrm{C}$ getrocknet. Die RNA wurde in $20-50 \mathrm{ml}$ DEPC- $\mathrm{H}_{2} \mathrm{O}$ bei $42^{\circ} \mathrm{C}$ für 10 Minuten gelöst und bei $-80^{\circ} \mathrm{C}$ gelagert. Die RNA-Konzentration wurde bei $\mathrm{OD}_{260}$ bestimmt.

\subsection{Enzymatische Reaktionen mit DNA und RNA}

\subsubsection{In vitro Synthese spezifischer DNA-Fragmente mit Hilfe der Polymerase- Kettenreaktion (PCR)}

Bei diesem Verfahren erfolgt eine in vitro Amplifikation von linearen DNAFragmenten. Für diese enzymatische Reaktion werden zwei spezifische Primer benötigt, die das zu amplifizierende Fragment flankieren und deren Sequenz zu jeweils einem der beiden DNA-Stränge komplementär ist. Als Matrize kann sowohl Plasmid-DNA, cDNA als auch chromosomale DNA dienen.

Der PCR-Zyklus beginnt mit der Auftrennung des DNA-Doppelstranges, danach erfolgt eine Anlagerungsphase, in der sich Hybridmoleküle aus den DNAEinzelsträngen und den Oligonukleotiden bilden. Während der Synthesephase bei ca. $72^{\circ} \mathrm{C}$ dienen die $3^{\prime}$-Enden der Primer als Ansatzstelle für die DNA-Polymerase. 
Für analytische Zwecke wurde Taq-Polymerase (Roche) und für Klonierungen wurde aufgrund ihrer „proofreading“-Aktivität High Fidelity Polymerase (Roche) verwendet. Für eine sog. „Whole Cell“-PCR wurden Zellen einer durchschnittlichen großen Zellkolonie fünf Minuten in $10 \mathrm{ml}$ Zymolyase Lösung $(2.5 \mathrm{mg} / \mathrm{ml}$ Zymolyase T100 (Seikagaku), 1.2 M Sorbitol, 0.1 M di-Natriumhydrogenphosphat Dihydrat $\mathrm{pH} 7.4$ ) bei $37^{\circ} \mathrm{C}$ inkubiert. $2 \mu \mathrm{l}$ dieser sphäroblastierten Zellen wurden in einem PCR-Ansatz eingesetzt.

Ein Standard-PCR-Ansatz für ein Gesamtvolumen von $50 \mu$ enthielt:

ca. 10 ng Plasmid-DNA, $2 \mu$ sphäroblastierte Zellen oder $1 \mu$ l chromosomale DNA je 100 pmol Primer

0.1 Volumen 10xPCR Reaction Buffer $+\mathrm{MgCl}_{2}$ (Roche) oder 10xExpand High Fidelity Buffer $+\mathrm{MgCl}_{2}$ (Roche)

$2 \mu \mathrm{l} 10$ mM dNTP-Mix (aus je 10 mM dATP, dCTP, dGTP und dTTP, Roche)

$1 \mu \mathrm{l}$ Taq- oder High Fidelity Polymerase (Roche)

Programme der PCR Maschine (Eppendorf, Mastercycler gradient)

\begin{tabular}{lll} 
Zustand & Temperatur & Zeit \\
\hline Denaturierung & $95^{\circ} \mathrm{C}$ & 4 Minuten \\
& $94^{\circ} \mathrm{C}$ & 1 Minute \\
Anlagerung & $53^{\circ} \mathrm{C}$ & 1 Minute \\
Extension & $72^{\circ} \mathrm{C}$ & 1 Minute $/ 1 \mathrm{~kb}$ \\
Anzahl der Zyklen & & $29 x$ \\
Ende & $4^{\circ} \mathrm{C}$ & unendlich
\end{tabular}

Nach Beendigung der PCR Reaktion wurde das Produkt auf ein Agarosegel geladen.

Die präperative Aufreinigung aus dem Gel erfolgte wie in Methode 3.12.1 beschrieben. 


\subsubsection{Reverse Transkription von RNA}

Puffer, dNTPs, RNAse-freies $\mathrm{H}_{2} \mathrm{O}$ und Enzym stammten aus dem Omniscript ${ }^{\mathrm{R}} \mathrm{RT}$ Kit (200) von Qiagen. Für die Reverse Transkription von RNA wurden eingesetzt:

2-5 $\mu \mathrm{g}$ RNA

$2 \mu$ poly-T18 Oligo (5'-TTTTTTTTTTTTTTTTTTGCGGCCGC-3')

$2 \mu l$ 10xPuffer RT

$2 \mu \mathrm{d}$ dNTP Mix (5 mM/dNTP)

$1 \mu$ Omniscript Reverse Transcriptase

ad $20 \mu \mathrm{l}$ RNase-freies Wasser

Der Ansatz wurde eine Stunde bei $37^{\circ} \mathrm{C}$ inkubiert und danach 10 Minuten bei $72^{\circ} \mathrm{C}$ abgestoppt. Für die anschließende PCR wurden $2.5 \mu \mathrm{l}$ des RT-PCR Ansatzes und der mit DNase I behandelten Ausgangs-RNA als Kontrolle eingesetzt.

\subsubsection{Restriktionsverdau von DNA}

10xReaktionspuffer (NEBuffer 1,2,3,4 von New England BioLabs)

10xBSA (10 mg/ml)

Restriktionsenzyme (New England BioLabs)

6xDNA-Auftragspuffer: $30 \%$ Glycerin, 0,25 \% Bromphenolblau in 1xTE-Puffer (steril filtriert)

Standard-Restriktionsansatz:

0.5-1 $\mu \mathrm{g}$ DNA

0.1 Volumen 10x Reaktionspuffer

50-100 $\mu$ g BSA (falls empfohlen)

2-4 U Restriktionsenzym

ad $20 \mu \mathrm{l} \mathrm{H}_{2} \mathrm{O}$

Meist wurde 1-2 Stunden bei der für die jeweiligen Enzyme optimalen Temperatur inkubiert. Danach wurde der Ansatz mit $5 \mu$ DNA-Auftragspuffer versetzt und über Agarose-Gelelektrophorese analysiert. 
Restriktionsverdau für PCR-Produkte:

$30 \mu \mathrm{l}$ gereinigtes PCR-Produkt

0.1 Volumen NEBuffer

$1 \mu \mathrm{l}$ 10xBSA

$10 \cup$ Restriktionsenzym

ad $40-50 \mu \mathrm{l} \mathrm{H}_{2} \mathrm{O}$

$2-3 \mathrm{~h}$ bei $37^{\circ} \mathrm{C}$

Die verdauten PCR-Produkte wurden mit 3 Volumen QG-Puffer versetzt und erneut mit dem QIAquick ${ }^{\mathrm{TM}}$ Gelextraktionskit (Methode 3.12.1) aufgereinigt. Das Elutionsvolumen betrug ca. 30-40 $\mu$ l.

Restriktionsverdau für Vektor-DNA:

$10 \mu \mathrm{l}$ Vektor-DNA (ca. 5-10 $\mu \mathrm{g}$ )

0.1 Volumen NEBuffer

$1 \mu \mathrm{l} 10 \mathrm{xBSA}$

10 U Restriktionsenzym

ad $30-50 \mu \mathrm{l} \mathrm{H}_{2} \mathrm{O}$

$2-4 \mathrm{~h}$ bei $37^{\circ} \mathrm{C}$

Die verdauten Vektoren wurden anschließend auf ein Agarosegel geladen und

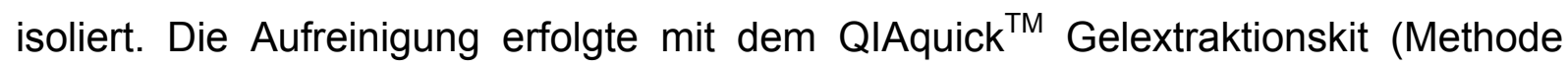
3.12.1).

\subsubsection{Dephosphorylierung linearisierter Vektoren}

10xDephosphorylierungspuffer (Roche)

Alkalische Phosphatase (Roche)

125 mM EDTA

Um an den freien 5'-Enden der linearisierten Vektoren die Phosphatgruppen zu entfernen und somit Religationen nach Vektorverdauen mit nur einem Enzym zu vermeiden, bzw. reduzieren wurden diese dephosphoryliert.

Der verdaute Vektor wurde mit 0.1 Volumen 10xDephosphorylierungspuffer und $1 \mathrm{U}$ alkalische Phosphatase (Roche) versetzt und 15 Minuten bei $37^{\circ} \mathrm{C}$ inkubiert. Zum 
Abstoppen der Reaktion wurde 5 mM EDTA zugeben und der Ansatz 10 Minuten auf $65-75^{\circ} \mathrm{C}$ erhitzt.

\subsubsection{Ligation von DNA-Fragmenten}

10xLigasepuffer (NewEngland BioLabs)

T4-DNA-Ligase (NewEngland BioLabs)

Die Ligation doppelsträngiger linearer DNA-Fragmente ist Ausbildung einer Phosphodiester Bindung der 3'-Hydroxylgruppe eines Nukleotids mit der 5'Phosphatgruppe eines anderen. Die T4-DNA-Ligase ist für diese kovalente Verknüpfung verantwortlich.

Standard Ligationsansatz:

$2 \mu$ linearisierte Vektor-DNA

$4 \mu \mathrm{l} \mathrm{PCR}-$ Fragment

0.1 Volumen 10xLigasepuffer

$2 \cup$ T4-DNA-Ligase

ad $10 \mu \mathrm{l} \mathrm{H}_{2} \mathrm{O}$

Der Ligationsansatz wurde $2 \mathrm{~h}$ bei Raumtemperatur oder über Nacht bei $15^{\circ} \mathrm{C}$ inkubiert. Für die anschließende Transformation in kompetente E. coli-Zellen wurden 2-5 $\mu$ l des Ligationsansatzes eingesetzt. 


\subsection{Agarose-Gelelektrophorese von DNA}

6xDNA-Auftragspuffer: $30 \%$ Glycerin, $0.25 \%$ Bromphenolblau in 1x TE-Puffer 10xTAE-Puffer: $48.4 \mathrm{~g}$ Tris Base, $11.42 \mathrm{ml}$ Essigsäure (98\%), 20 ml 500 mM EDTA pH8.0, ad 1 Liter $\mathrm{H}_{2} \mathrm{O}$

Ethidiumbromid-Stammlösung $(10 \mathrm{mg} / \mathrm{ml})$

Agarose (Roth)

Aufgrund ihrer negativen Ladung können Nukleinsäuren in einem elektrischen Feld entsprechend ihrem Molekulargewicht aufgetrennt werden. In der Regel wurden Gele mit 1-2\% Agarose hergestellt. Dabei wurde die Agarose in 1xTAE-Puffer in der Mikrowelle aufgekocht und nach Abkühlen auf ca. $60^{\circ} \mathrm{C}$ Ethidiumbromid (Endkonzentration: $5 \mathrm{mg} / \mathrm{ml}$ ) zugegeben. Die Agaroselösung wurde in einen Elektrophoreseschlitten gegossen. Das erhärtete Gel wurde in eine mit 1xTAE-Puffer gefüllte Gelkammer gesetzt und die mit 6xDNA-Auftragpuffer versetzten DNA Proben konnten aufgetragen werden. Die elektrophoretische Auftrennung erfolgte bei konstanter Spannung (5-12 V/cm).

DNA-Banden wurden durch Anregung der Fluoreszenz der Ethidiumbromid-DNAKomplexe im UV-Licht nachgewiesen und photographiert oder für präperative Zwecke ausgeschnitten. Mit Hilfe eines Molekulargewichts-Standard (1Kb DNA-Leiter $1.0 \mathrm{mg} / \mathrm{ml}$ von Invitrogen) konnten die DNA-Fragmente zugeordnet werden.

\subsubsection{Isolierung von DNA-Fragmenten aus Agarosegelen mit dem QIAquick $^{\mathrm{TM}}$ Gelextraktion-Kit}

QG-Puffer: siehe QIAquick ${ }^{\text {TM }}$ Gelextraktion Kit

PE-Puffer: siehe QIAquick ${ }^{\mathrm{TM}}$ Gelextraktion Kit

Elutionspuffer: $10 \mathrm{mM}$ Tris/ $\mathrm{HCl}$ pH8.5 oder $\mathrm{H}_{2} \mathrm{O}$

Die Isolierung erfolgte gemäß der Anleitung für QIAquickspin-Säulen (QIAquick Spin Handbook). Nach Beendigung der Gelelektrophorese wurde das entsprechende DNA-Fragment unter langwelligem UV-Licht $(365 \mathrm{~nm})$ aus dem Agarosegel ausgeschnitten und das Gelstück gewogen. Dann wurden 3 Volumen QG-Puffer dazugegeben und die Agarose durch Erhitzen auf $50^{\circ} \mathrm{C}$ (10 Minuten) im 
Thermomixer unter Schütteln gelöst. Anschließend wurde die Probe auf eine QIAquickspin-Säule geladen. Nach Zentrifugation (14000 rpm, 1 Minute) wurde der Durchlauf verworfen und mit $750 \mu$ PE-Puffer gewaschen und erneut 1 Minute zentrifugiert. Nach Entfernen des Durchlaufes und einer weiteren Zentrifugation zur Entfernung aller Pufferreste wurde die Säule in ein $1.5 \mathrm{ml}$ Eppendorf-Reagenzgefäß überführt, zum Eluieren der DNA 30-40 $\mu$ l Elutionspuffer oder $\mathrm{H}_{2} \mathrm{O}$ auf das Gelbett pipettiert und erneut eine Minute zentrifugiert.

\subsection{DNA-Sequenzierung}

Plasmid-DNA wurde mit einem ABI PRISM 3100 Sequenzierautomat (Applied Biosystems) nach Sanger sequenziert. Der Sequenziermix beinhaltet ein Gemisch aus allen vier unmarkierten und Fluoreszenz-markierte Nukleotiden.

\section{Standard Sequenzieransatz:}

$1 \mu$ Plasmid-DNA (0.2-0.5 mg)

$1 \mu \mathrm{l}$ 5'- oder 3'- Primer (100 pmol/ ml)

$1.5 \mu$ S Sequenzierpuffer (ABI PRISM $\left.{ }^{R}\right)$

$1.5 \mu \mathrm{l}$ ABI PRISM Dye Terminator Cycle Sequencing Ready Reaction Premix ad $10 \mu \mathrm{HPLC}-\mathrm{H}_{2} \mathrm{O}$

Sequenzier-Programm:

\begin{tabular}{lll} 
Zustand & Temperatur & Zeit \\
\hline Denaturierung & $96^{\circ} \mathrm{C}$ & 10 Sekunden \\
Anlagerung & $50^{\circ} \mathrm{C}$ & 5 Sekunden \\
Extension & $60^{\circ} \mathrm{C}$ & 4 Minuten \\
Anzahl der Zyklen & & $25 x$ \\
Ende & $4^{\circ} \mathrm{C}$ & unendlich
\end{tabular}

Danach wurde die Sequenzierreaktion von überschüssigen, freien Fluoreszenzmarkierten dNTPs gereinigt. Das PCR-Produkt wurde mit $2 \mu \mathrm{l} 3 \mathrm{M}$ Natriumacetat (pH5.2) und $50 \mu \mathrm{l} 95 \%$ Ethanol für fünf Minuten bei Raumtemperatur gefällt. Das Präzipitat wurde bei 13000 rpm für 20 Minuten sedimentiert. Das Pellet wurde danach mit $250 \mu \mathrm{l} 75 \%$ Ethanol gewaschen und erneut zentrifugiert (13000 rpm, 10 Minuten), getrocknet und anschließend in $15 \mu \mathrm{l}$ Formamid gelöst. 


\title{
3.14 Transformationstechniken
}

\subsubsection{Transformation von E.coli Zellen über Elektroporation}

Beim Elektroporationsverfahren werden die Zellmembranen der in Suspension befindlichen Empfängerzellen durch kurze elektrische Pulse hoher Feldstärke für hochmolekulare Moleküle durchlässig gemacht. Die Plasmid-DNA-Lösung sollte für die Transformation einen niedrigen Salzgehalt aufweisen um einen Kurzschluss zu vermeiden.

\section{Herstellung elektrokompetenter E.coli-Zellen}

\author{
LB-Flüssigmedium \\ kaltes, steriles $\mathrm{H}_{2} \mathrm{O}$ \\ $10 \%$ Glycerol
}

Eine Übernachtkultur E.coli-Zellen wurde 1:100 in 1000 ml LB-Medium verdünnt und bei $37^{\circ} \mathrm{C}$ bis zu einer $\mathrm{OD}_{600}$ von $0.5-0.8$ vermehrt (logarithmische Phase). Die Zellen wurden für 15 Minuten auf Eis gekühlt und durch Zentrifugation geerntet $\left(4^{\circ} \mathrm{C}\right.$, 15 Minuten, $4000 \mathrm{~g}$ ). Das Pellet wurde zunächst zweimal mit kaltem Wasser (1 Liter

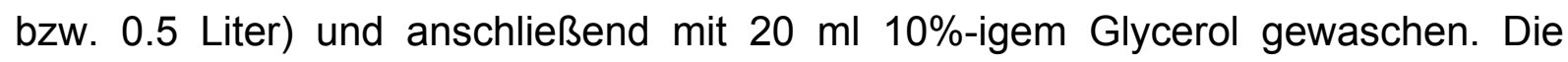
Zellen wurden schließlich in einem Endvolumen von 2-3 ml 10\%-igem Glycerol resuspendiert. Die Suspension wurde in Aliquots von je $100 \mu \mathrm{l}$ in flüssigem Stickstoff eingefroren und anschließend bei $-80^{\circ} \mathrm{C}$ gelagert.

\section{Elektroporation}

Für Transformationen wurden $50 \mu \mathrm{l}$ der kompetenten Zellen auf Eis aufgetaut, mit 0.3-0.5 $\mu$ l Plasmid-DNA oder 2-5 $\mu \mathrm{l}$ eines Ligationsansatzes versetzt. Der Transformationsansatz wurde dann in eine vorgekühlte $0.2 \mathrm{~cm}$ breite, UV-bestrahlte Elektroporationsküvette überführt. Die Elektroporation erfolgte mit Hilfe eines "Gene Pulsers" (Biorad), der bei einem Vorwiderstand von 200 W einen Puls der Spannung $1.8 \mathrm{kV}$ auslöste. Die gemessenen Zeitkonstanten lagen bei einer erfolgreichen Elektroporation bei 4.0-5.5 ms. Die Zellen wurden in $500 \mathrm{ml} \mathrm{LB}$ - oder SOC-Medium 
aufgenommen und zur Regeneration für ca. 45 Minuten bei $37^{\circ} \mathrm{C}$ inkubiert. $50-100 \mathrm{ml}$ bei Re-Transformationen oder der gesamte Ansatz bei Ligationen, wurden auf mit Antibiotika versetzten LB-Platten ausgestrichen und über Nacht bei $37^{\circ} \mathrm{C}$ inkubiert.

\subsubsection{Transformation von Hefe nach der Lithiumacetat-Methode}

Waschpuffer: 0.1 M Lithiumacetat in 1x TE-Puffer, steril filtriert

PEG/LiAcetat-Puffer: 40\% Polyethylenglycol und 0.1 M Lithiumacetat in 1x TE-Puffer, steril filtriert

Heringssperma-DNA (11 mg/ml, Sigma), 10 Minuten auf $95^{\circ} \mathrm{C}$ erhitzt

2-5 ml einer Hefe-Übernachtkultur wurden in $50-100 \mathrm{ml}$ YPD-Medium auf eine $\mathrm{OD}_{600}$ von 0.2-0.4 angeimpft und bei $30^{\circ} \mathrm{C}$ 4-5 Stunden bis zu einer von $\mathrm{OD}_{600}$ 0.6-1.0 schüttelnd inkubiert. Die Zellen wurden geerntet (3 Minuten, $2800 \mathrm{rpm}$ ), mit $10 \mathrm{ml}$ Wasser und anschließend mit $10 \mathrm{ml}$ Waschpuffer gewaschen, danach in $0.2 \mathrm{ml}$ Waschpuffer resuspendiert und auf Eis gelagert. Für die Transformation wurden $5 \mu \mathrm{l}$ Heringsperma-DNA und $5 \mu \mathrm{l}$ der $z u$ transformierenden DNA in einem $2.2 \mathrm{ml}$ Eppendorf-Gefäß gemischt und mit $50 \mu \mathrm{l}$ der Zellsuspension versetzt. Nach Zugabe von $300 \mu \mathrm{PEG} / \mathrm{LiAcetat-Puffer} \mathrm{wurden} \mathrm{die} \mathrm{Ansätze} \mathrm{erst} \mathrm{für} 30$ Minuten bei $30^{\circ} \mathrm{C}$ und dann für 15 Minuten bei $45^{\circ} \mathrm{C}$ inkubiert. Der gesamte Ansatz wurde dann auf Selektionsplatten (SD-Platten) ausplattiert und 2-5 Tage bei $30^{\circ} \mathrm{C}$ inkubiert. $4-8$ Einzelklone wurden dann erneut auf Selektionsplatten vereinzelt und nach weiteren 2-3 Tagen getestet.

\section{Integrative Tansformation von Plasmiden oder PCR-Produkten}

Bei Integration des transformierten Plasmids in das Hefegenom, wurde die PlasmidDNA vor der Transformation enzymatisch geschnitten. Der Verdau wurde mit 20 mM EDTA gestoppt und 5 Minuten bei $65^{\circ} \mathrm{C}$ inkubiert. Danach wurde das DNA-Gemisch präzipitiert (Methode 3.10.1) und in einem Endvolumen von $20 \mu \mathrm{l} \mathrm{H}_{2} \mathrm{O}$ gelöst. $5 \mu \mathrm{l}$ des linearisierten Plasmids wurden für eine Transformation eingesetzt.

Bei Integration von PCR-Produkten wurde das PCR-Produkt auf ein Agarosegel aufgetragen, die DNA ausgeschnitten und aufgereinigt (Methode 3.12.1). 5-10 $\mu \mathrm{l}$ der PCR wurden für die Transformation verwendet. Die Hefezellen wurden nach einem 
Hitzeschritt kurz abzentrifugiert, mit $2 \mathrm{ml}$ YPD-Medium versetzt und 2-3 Stunden bei $30^{\circ} \mathrm{C}$ schüttelnd $(220 \mathrm{rpm})$ inkubiert. Nach der Regenerationsphase wurden die Zellen erneut kurz zentrifugiert und in $200 \mu \mathrm{l} \mathrm{H}_{2} \mathrm{O}$ aufgenommen und auf entsprechenden Mangelmediumplatten selektioniert.

\subsection{Bestimmung des Paarungstyps}

Zur Bestimmung des Paarungstyps wurden die Testerstämme y93 (Mata) und y94 (Mata) verwendet. Diese beiden Stämme tragen das seltene Allel his1. Die zu testenden Stämme (A-D) wurden mit den Testerstämmen kreuzweise auf HistidinSelektionsplatten ausgestrichen und 2-4 Tage bei $30^{\circ} \mathrm{C}$ inkubiert. Stämme mit unterschiedlichen Paarungstypen konnten sind paaren und wuchsen (Abb.9).

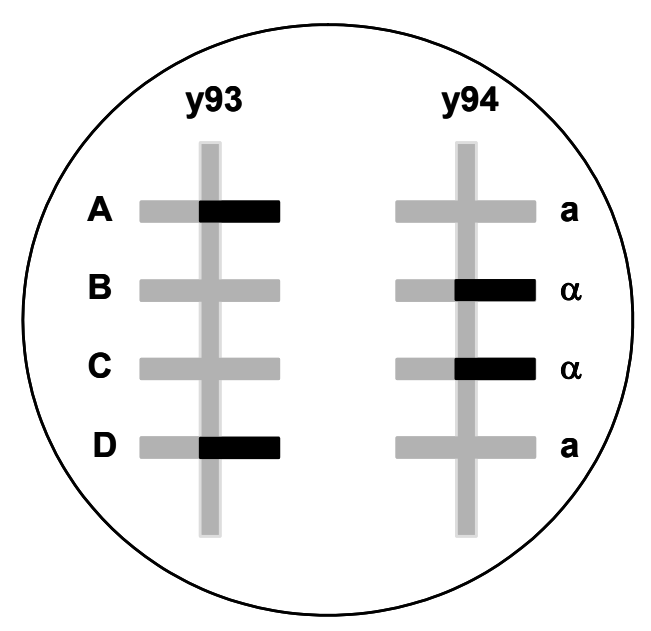

Abb.9: Beispiel zum Ausstrich einer Paarungstyp-Testerplatte.

Graue Balken - kein Wachstum, Schwarze Balken - Wachstum auf Histidin-Mangelmedium. 


\subsection{Vakuolenisolierung aus S. cerevisiae}

(nach Bankaitis et al., 1986)

$10 \mathrm{mM}$ Tris/SO $/ \mathrm{SH}_{4}$, $10 \mathrm{mM}$ DTT

0.6 M Sorbitol, 0.2 M Imidazol, pH6.5

0.2 M Sorbitol, $0.2 \mathrm{M}$ Imidazol, pH6.5

Zymolyase T100 (Seikagaku) (1 mg/ml Endkonzentration in 0.6 M Sorbitol, 0.2 M

Imidazol, $\mathrm{pH} 6.5)$

DEAE-Dextran (Sigma) (4 mg/ml 15\% Ficoll)

$15 \%, 8 \%$ und 4\% Ficoll in 0.2 M Sorbitol, $0.2 \mathrm{M}$ Imidazol, pH6.5

Ultra-Clear $^{\mathrm{TM}}$ Tubes (14x89 mm, Beckmann)

500 OD Hefezellen wurden einmal in $\mathrm{dH}_{2} \mathrm{O}$ gewaschen und anschließend in $20 \mathrm{ml} 10$ $\mathrm{mM}$ Tris $/ \mathrm{SO}_{4}, \mathrm{p} 9.4,10 \mathrm{mM}$ DTT resuspendiert und 20 Minuten bei $30^{\circ} \mathrm{C}$ schüttelnd (100 rpm) inkubiert. Nach Zentrifugation (3 Minuten, $4000 \mathrm{rpm}$ ) wurden die Zellen in $25 \mathrm{ml} 0.6 \mathrm{M}$ Sorbitol, 0.2 M Imidazol, pH6.5 mit $5 \mathrm{mg}$ Zymolyase T100 für mindestens 30 Minuten bei $30^{\circ} \mathrm{C}$ (80 rpm) sphäroblastiert. Der Verlauf des Verdaus der Zellwände wurde photometrisch überprüft. Eine 1:10 Verdünnung sollte eine um mindestens $60-70 \%$ geringere $\mathrm{OD}_{600}$ aufweisen als das ebenso verdünnte Ausgangsmaterial. Danach wurden die Proben 5 Minuten auf Eis gekühlt und anschließend zentrifugiert (3 Minuten, $3000 \mathrm{rpm}$ bei $4^{\circ} \mathrm{C}$ ). Das Pellet wurde in $1.5 \mathrm{ml}$ $15 \%$ Ficoll langsam resuspendiert. Die Zellen wurden durch Titration von $450 \mu \mathrm{l}$ DEAE-Dextran lysiert, 1 Minute auf Eis und anschließend 5 Minuten bei $30^{\circ} \mathrm{C}$ im Wasserbad inkubiert. $150 \mu \mathrm{l}$ der Ansätze wurden für einen späteren $\alpha$-Mannosidase Aktivitäts-Assay zurückgehalten. Für den Gradienten wurde das restliche Zellmaterial auf den Boden eines Ultra-Clear ${ }^{T M}$ Tubes pipettiert und mit $2 \mathrm{ml} 8 \%$, dann mit $4 \mathrm{ml}$ $4 \%$ Ficoll überschichtet. Abschließend wurden noch $2 \mathrm{ml} 0.2 \mathrm{M}$ Sorbitol, $0.2 \mathrm{M}$ Imidazol, pH6.5 pipettiert. Die Vakuolen konnten nach 90 minütiger Zentrifugation bei 30000 rpm (SW-41 Rotor) in der Ultrazentrifuge aus der Interphase zwischen 4 und 0\% Ficoll isoliert werden. Zur Untersuchung der $\alpha$-Mannosidaseaktivität wurde die Proteinkonzentration der Vakuolen anhand der Bradford-Methode (3.19.4) bestimmt. 


\section{$3.17 \alpha-M a n n o s i d a s e-A k t i v i t a ̈ t s-A s s a y$}

(nach Yoshihisa et al., 1988)

$20 \%$ Triton $X-100$

4 mM 4-Nitrophenyl- $\alpha-D-M a n n o p y r a n o s i d ~(N 2127$, Sigma) in 200 mM Natriumacetat, $\mathrm{pH} 6.5$

$10 \mathrm{mM} \mathrm{CuSO}_{4}$

$0.2 \mathrm{M}$ Sorbitol, $0.2 \mathrm{M}$ Imidazol, pH6.5

$10 \%$ TCA

1 M Glycin, $\mathrm{pH} 10.4$

6-12 $\mu \mathrm{g}$ isolierte Vakuolen oder $100 \mu \mathrm{g}$ lysiertes Zellmaterial wurden mit $12.5 \mu \mathrm{l}$ Triton X-100, $9.75 \mu \mathrm{CuSO}_{4}$ und $100 \mu \mathrm{l} 4 \mathrm{mM}$ Substrat auf ein Gesamtvolumen von $500 \mu \mathrm{l}$ gebracht. Als Hintergrund dienten Vakuolen, bzw. Iysierten Zellen mit Puffer, ohne Substrat. Die Ansätze wurden 2 bis 4 Stunden bei $30^{\circ} \mathrm{C}$ inkubiert. Die enzymatische Reaktion wurde durch Zugabe von $200 \mu$ 10\% TCA gestoppt. Nach Zentrifugation (10 Minuten, 13000rpm) wurden $500 \mu \mathrm{l}$ in ein neues Reaktionsgefäß überführt und $500 \mu \mathrm{l} 1 \mathrm{M}$ Glycin zupipettiert. Die photometrische Auswertung erfolgte bei $400 \mathrm{nM}$.

\subsection{Ape1-Overlay-Assay}

Rundfilter $\varnothing 80 \mathrm{~mm}$ (Schleicher\&Schüll)

Chloroform

$75 \mathrm{mM}$ Tris/HCl pH7.5, 3 mM EDTA

$200 \mathrm{mM}$ H-Leucin- $\beta$-Naphtylamid in $1 \mathrm{ml}$ Methanol

$3 \%$ Agarose in $\mathrm{H}_{2} \mathrm{O}$

Glaspetrischalen $\varnothing 90 \mathrm{~mm}$

Einzelklone wurden auf Vollmedium- oder entsprechenden Selektionsplatten ausgestrichen. Nach 2 bis 3 Tagen Wachstum bei $30^{\circ} \mathrm{C}$ wurden die Zellen auf sterile Rundfilter gestempelt und mit der Kolonieseite nach oben zeigend, über Nacht auf neuen Mediumplatten inkubiert. 
Die Filter wurden mit der Kolonieseite nach unten zeigend in einer Wanne gefüllt mit Chloroform für 50 Sekunden geschwenkt. Nach Abdampfen des Chloroforms wurden die lysierten Zellen in einer Glaspetrischale platziert. Für fünf Ansätze wurde $14 \mathrm{ml}$ $75 \mathrm{mM}$ Tris/ $\mathrm{HCl}$ pH7.5, $3 \mathrm{mM}$ EDTA und $6 \mathrm{ml} \mathrm{3 \%}$ Agarose getrennt voneinander aufgekocht und anschließend vereinigt. Nach Abkühlen auf ca. $60^{\circ} \mathrm{C}$ konnte das Substrat $(200 \mathrm{mM})$ dazupipettiert und alles gleichmäßig über die Filter verteilt werden. Die Hefestämme wurden hinsichtlich ihrer Aminopeptidase 1-Aktivität durch die Spaltung des Naphtylamids photometrisch bei 365 nm nach 5 und 20 Minuten getestet.

\subsection{Biochemische Methoden}

\subsubsection{Ganzzellproteinextraktion aus Hefe}

Aufschlusspuffer l: $50 \mathrm{mM}$ Tris pH7.5, $1 \mathrm{mM}$ EDTA

Aufschlusspuffer II: $10 \mu \mathrm{l} / \mathrm{ml} 0.1 \mathrm{M}$ DTT und $10 \mu \mathrm{l} / \mathrm{ml}$ Pefablock $(20 \mathrm{mg} / \mathrm{ml})$ in Aufschlusspuffer I

Glasperlen ( $\varnothing 0.45 \mathrm{~mm})$

6xSDS-Lämmli Ladepuffer: 350 mM TrisHCl pH6.8, 10\% SDS, 30\% Glycerol, $0.12 \mathrm{mg} / \mathrm{ml}$ Bromphenolblau, $20 \% \beta$-Mercaptoethanol

$50 \mathrm{ml}$ einer exponentiell wachsenden Hefekultur $\left(\mathrm{OD}_{600}\right.$ 0.8-1.5) wurde 2 Minuten bei $2800 \mathrm{rpm}$ zentrifugiert und in 3 bis $10 \mathrm{ml}$ Aufschlusspuffer I gewaschen. Alle folgenden Schritte wurden auf Eis oder im Kühlraum bei $4^{\circ} \mathrm{C}$ durchgeführt. Die Zellen wurden in 200 bis $300 \mu \mathrm{l}$ Aufschlusspuffer II aufgenommen und in ein $2.2 \mathrm{ml}$ Eppendorfgefäß überführt. Zu der Zellsuspension wurden ca. $300 \mu \mathrm{l}$ Glasperlen gegeben und zum Zellaufschluss 5 bis 10 Minuten im KIA-Vibrax geschüttelt. Nach fünfminütiger Zentrifugation bei $13000 \mathrm{rpm}$ wurde das Zelllysat geklärt. Der proteinhaltige Überstand wurde in ein neues Eppendorfgefäß überführt. Nach der Konzentrationsbestimmung nach Bradford wurde der Proteinextrakt mit 0.6 Volumen 6xSDS-Lämmli-Ladepuffer versetzt. Die Proteine wurden durch fünfminütiges Erhitzen auf $95^{\circ} \mathrm{C}$ denaturiert. Die Proteinextrakte wurden bei $-20^{\circ} \mathrm{C}$ gelagert. 


\subsubsection{Alkalische Lyse von Hefezellen}

Lyse-Lösung: $1.85 \mathrm{M} \mathrm{NaOH}, 7.5 \%$ (v/v) $\beta$-Mercaptoethanol

1000xInhibitor-Mix: $20 \mu \mathrm{g} / \mathrm{ml}$ Leupeptin, $20 \mu \mathrm{g} / \mathrm{ml}$ Benzamidin, $10 \mu \mathrm{g} / \mathrm{ml}$ Pepstatin A,

$40 \mu \mathrm{g} / \mathrm{ml}$ Aprotinin

Protease Inhibitor Complete EDTAfree (Roche)

$100 \mathrm{mM}$ PMSF in $100 \%$ Ethanol

$50 \%(w / v)$ TCA

$100 \%$ Aceton

1xSDS-Lämmli Ladepuffer

$1 \mathrm{M}$ Tris/HCl pH9.0

Für den Zellaufschluss durch alkalische Lyse wurden $1 \mathrm{OD}_{600}$ Zellen eingesetzt. Dazu wurden die Zellen abzentrifugiert (4 Minuten, $4000 \mathrm{rpm}$ ) und anschließend in 1 $\mathrm{ml} \mathrm{H}_{2} \mathrm{O}$ resuspendiert. Nach Zugabe der Proteaseinhibitoren wurden die Zellen mit $150 \mu \mathrm{l}$ Lyse-Lösung versetzt und unter mehrmaligem Vortexen 10 Minuten auf Eis lysiert. Danach wurden $150 \mu$ l kaltes 50\%-iges TCA zupipettiert, die Proben gevortext und mindestens 10 Minuten auf Eis inkubiert. Anschließend wurde das Präzipitat 10 Minuten bei $13000 \mathrm{rpm}\left(4^{\circ} \mathrm{C}\right)$ sedimentiert, der Überstand verworfen und das Pellet zweimal mit Aceton gewaschen. Das Präzipitat wurde in 1xSDS-Lämmli Ladepuffer bei $30^{\circ} \mathrm{C}$ gelöst und danach sonifiziert. Bei Gelbfärbung wurde der pH mit $1 \mathrm{M}$ Tris/ $\mathrm{HCl}$ nachgestellt. Die Proben konnten bei $-20^{\circ} \mathrm{C}$ gelagert werden. 


\subsubsection{Zellaufschluß zum Nachweis von hyperacetyliertem Histon H4}

HSB Puffer: 45 mM HEPES-KOH pH7.4, 150 mM NaCl, 10\% Glycerol, 1 mM EDTA, $0.5 \%$ NP-40

1000xInhibitor-Mix: $20 \mu \mathrm{g} / \mathrm{ml}$ Leupeptin, $20 \mu \mathrm{g} / \mathrm{ml}$ Benzamidin, $10 \mu \mathrm{g} / \mathrm{ml}$ Pepstatin A, $40 \mu \mathrm{g} / \mathrm{ml}$ Aprotinin

Protease Inhibitor Complete EDTAfree (Roche)

$100 \mathrm{mM}$ PMSF in $100 \%$ Ethanol

Glasperlen ( $\varnothing 0.45 \mathrm{~mm})$

$15 \mathrm{ml}$ einer exponentiell wachsenden Hefekultur wurden geerntet (2 Minuten, 2800 rpm) und einmal mit Wasser gewaschen. Die Zellen wurden in $300 \mu$ HSB Puffer resuspensiert und mit ca. $250 \mu$ l Glassperlen versetzt. Zum Zellaufschluss wurde die Suspension 5 Minuten bei $4^{\circ} \mathrm{C}$ im KIA-Vibrax geschüttelt. Nach zehnminütiger Zentrifugation bei $13000 \mathrm{rpm}\left(4^{\circ} \mathrm{C}\right)$ wurde der Überstand in ein neues Eppendorfgefäß überführt und die Proteinkonzentration mit dem $\mathbf{D}_{\mathbf{c}}$-Proteinassay von BIORAD bestimmt.

\subsubsection{Bestimmung der Proteinkonzentration}

\section{Proteinbestimmung nach Bradford}

Bovine Serum Albumin (BSA) Stock Lösung: $1 \mathrm{mg} / \mathrm{ml}$

Bradford Reagenz (BIORAD)

Mit BSA wurde eine Verdünnungsreihe von 2-16 $\mu \mathrm{g} / \mathrm{ml}$ Proteinkonzentration hergestellt. Für die Proteinbestimmung wurden 2-10 $\mu \mathrm{l}$ der Proteinlösungen eingesetzt. Das Probengesamtvolumen wurde mit Wasser auf $800 \mu$ l aufgefüllt. Danach wurden $200 \mu$ Bradford Reagenz zupipettiert, gevortext und 5 Minuten bei Raumtemperatur inkubiert. $200 \mu$ jedes Ansatzes wurden in Doppelwerten auf eine 96-Well-Platte pipettiert und die optische Dichte bei $595 \mathrm{~nm}$ im ELISA-Reader bestimmt. 


\section{Proteinbestimmung mit $D_{c}-$ Proteinassay}

Bovine Serum Albumin (BSA) Stock Lösung: $1 \mathrm{mg} / \mathrm{ml}$

Dc-Reagenz A, S und B (BIORAD)

Mit BSA wurde eine Verdünnungsreihe von 2-16 $\mu \mathrm{g} / \mathrm{ml}$ Proteinkonzentration hergestellt. Für die Proteinbestimmung wurden 2-10 $\mu \mathrm{l}$ der Proteinlösungen eingesetzt. Das Probengesamtvolumen wurde mit Wasser auf $100 \mu$ l aufgefüllt. Auch hier wurden Doppelbestimmungen durchgeführt. $\mathbf{D}_{\mathbf{c}}$-Reagenz $\mathbf{S}$ wurde 1:500 mit Reagenz A verdünnt und $25 \mu \mathrm{l}$ zu den Proteinproben pipettiert. Danach wurden zügig $200 \mu \mathrm{l}$ Reagenz B hinzugegeben. Die 96-Well-Platte wurde 15 Minuten bei Raumtemperatur inkubiert. Die optische Dichte der Proben wurde anschließend bei $690 \mathrm{~nm}$ im ELISA-Reader bestimmt.

\subsubsection{SDS-Polyacrylamid-Gelelektrophorese}

4xTrenngel-Puffer: $1.5 \mathrm{M}$ Tris/HCl pH8.8, 0.4\% SDS

4xSammelgel-Puffer: 0.5 M Tris/HCl pH6.8, 0.4\% SDS

5xLaufpuffer: $150 \mathrm{~g}$ Glycin, $30 \mathrm{~g}$ Tris, $5 \mathrm{~g}$ SDS, $0.5 \mathrm{ml}$ 0.1\% Bromphenolblau auf 1 Liter auffüllen

$30 \%$ Polyacrylamid

TEMED (N,N,N',N'-Tetramethylethylendiamin)

10\% Ammoniumperoxodisulfat (APS)

$10 \%$ Trenngel $(8 \mathrm{ml})$ :

$2 \mathrm{ml} 4 x$ Trenngelpuffer

$2.67 \mathrm{ml} \mathrm{30 \%} \mathrm{Polyacrylamid}$

$3.2 \mathrm{ml} \mathrm{H}_{2} \mathrm{O}$

$80 \mu \mathrm{l} 10 \%$ APS

$8 \mu \mathrm{I}$ TEMED $\mathbf{5 \%}$ Sammelgel $(3 \mathrm{ml})$

$0.75 \mathrm{ml} 2 \times$ Sammelgelpuffer

$0.45 \mathrm{ml} \mathrm{30 \%} \mathrm{Polyacrylamid}$

$1.77 \mathrm{ml} \mathrm{H}_{2} \mathrm{O}$

$30 \mu \mathrm{l} 10 \%$ APS

$3 \mu \mathrm{l}$ TEMED

Für die gelelektrophoretische Analyse von Proteinen wurden diskontinuierliche SDSPolyacrylamid-Gele (Laemmli, 1970) verwendet, d.h. zuerst wurde zwischen zwei vertikalen Glasplatten (Minigel System von BIORAD oder eigens hergestellte grosse Gele) ein Trenngel gegossen und mit ca. $1 \mathrm{ml}$ Isopropanol überschichtet. Nach erfolgter Polymerisierung wurde das Isopropanol vollständig entfernt, das Trenngel 
mit weitmaschigerem Sammelgel überschichtet und ein Teflonkamm eingesetzt. Nach dessen Polymerisation wurden die Glasplatten in eine Gellaufkammer (BIORAD) mit 1xLaufpuffer gespannt, der Kamm gezogen und mit Proteinproben beladen. Die Auftrennung erfolgte bei 20-40 mA für 2-3 Stunden.

\subsubsection{Gelfärbung mit Coomassie Blue}

Coomassie Färbelösung: 10\% Essigsäure, 25\% Isopropanol, 0.025\% Coomassie Blue (G250)

Entfärbelösung: 10\% Essigsäure

Nach der elektrophoretischen Auftrennung der Proteine auf einem Polyacrylamidgel, wird dieses für 2-3 Stunden in Coomassie Färbelösung schüttelnd inkubiert. Die Entfärbung erfolgte wieder 2-5 Stunden bis die gewünschte Intensität erreicht wurde. Mit dieser Methode lassen sich Signale von 50-100 ng Protein sichtbar machen.

\subsubsection{Proteintransfer auf Membranen (Western Blot-Analyse)}

Über SDS-Polyacrylamidgelelektrophorese aufgetrennte Proteine wurden durch ein elektrisches Feld aus dem Gel auf eine PVDF- oder Nitrozellulose-Membran übertragen.

\section{„Semi Dry“-Verfahren nach BIORAD}

2xAnodenpuffer: $75 \mathrm{mM}$ Tris/HCl pH7.4, 20\% Methanol

2xKathodenpuffer: 20 mM Tris/HCl pH9.0, 40 mM ع-Aminocapronsäure, 20\%

Methanol

Nitrozellulose-Membran (Whatman, Schleicher und Schüll)

PVDF-Membran (Whatman, Schleicher und Schüll)

Filterpapier (Whatman)

Ponceau S-Lösung (Sigma): 0.5\% PonceauS-Konzentrat in 1\% Essigsäure TBS-Tween-Milch: 5\% Magermilchpulver, 150 mM NaCl, 25 mM Tris pH7.4, 0.05\% Tween 20 
Blotaufbau:

\section{Anode (+)}

2 Lagen Filterpapier, getränkt in 1xAnodenpuffer

PVDF- (mit Methanol befeuchtet) oder Nitrozellulose-Membran

Polyacrylamidgel

2 Lagen Filterpapier, getränkt in 1xKathodenpuffer

\section{Kathode (-)}

Der elektrische Transfer der Proteine erfolgte bei $1 \mathrm{~mA} / \mathrm{cm}^{2}$ Gelfläche für 75 Minuten.

Der Erfolg des Transfers wurde durch ca. zweiminütiges Färben der Membran in Ponceau S-Lösung überprüft.

\section{Nassblot (,Wet Blot“)-Verfahren nach BIORAD}

Nassblotpuffer: 192 mM Glycin, 25 mM Tris, 20\% Methanol (Methanol nach dem

Verdünnen zugeben)

Nitrozellulose-Membran (Whatman, Schleicher und Schüll)

PVDF-Membran (Whatman, Schleicher und Schüll)

Filterpapier (Whatman)

Blotaufbau:

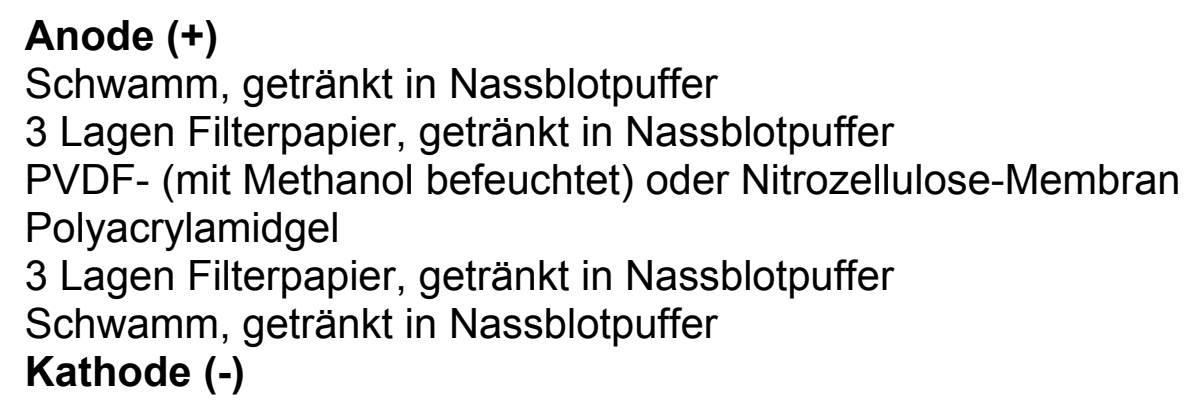

Der elektrische Transfer der Proteine erfolgte bei 250 mA für 3 Stunden oder 200 mA über Nacht.

Die Membran wurde zur Blockierung unspezifischer Bindestellen eine Stunde bei Raumtemperatur oder über Nacht bei $4^{\circ} \mathrm{C}$ in TBS-Tween-Milch inkubiert. 


\subsubsection{Proteindetektion mit spezifischen Antikörpern und ECL (Enhanced Chemoluminescence)}

Tab.5: Antikörper für Western Blot-Analysen

\begin{tabular}{|c|c|c|}
\hline Antikörper & Funktion & $\begin{array}{l}\text { Verdünnung in TBS- } \\
\text { Tween-Milch }\end{array}$ \\
\hline $\begin{array}{l}\text { Hyperacetyliertes Histon } \\
\text { H4 Penta (Upstate) }\end{array}$ & $\begin{array}{l}\text { Kaninchen- } \alpha- \\
\text { hyperacetyl. H4 (prim. } \\
\text { Ak) }\end{array}$ & $1: 1000$ \\
\hline $\begin{array}{l}\text { Ape1 Antiserum (aa 168- } \\
182 \text { und aa191-210, } \\
\text { Andrei-Selmer et al., } \\
\text { 2003) }\end{array}$ & $\begin{array}{l}\text { Kaninchen- } \alpha-A p e 1 \\
\text { (prim. Ak) }\end{array}$ & $1: 1000$ bis $1: 2000$ \\
\hline Anti-HA 4C14 (Abcam) & Maus- $\alpha-\mathrm{HA}$ (prim. Ak) & $1: 1000$ \\
\hline Anti-HA 3F10 (Roche) & Ratte- $\alpha-H A$ (prim. Ak) & $1: 1000$ \\
\hline $\begin{array}{l}\text { Anti-HA.11 16B12 } \\
\text { (Convance) }\end{array}$ & Maus- $\alpha-\mathrm{HA}$ (prim. Ak) & $1: 1000$ \\
\hline $\begin{array}{l}\text { 3-Phosphoglycerate } \\
\text { Kinase (Molecular Probes) }\end{array}$ & Maus- $\alpha-P G K$ (prim. Ak) & $1: 1000$ \\
\hline $\begin{array}{l}\text { Carboxypeptidase Y } \\
\text { (Molecular Probes) }\end{array}$ & Maus- $\alpha-C P Y$ (prim. Ak) & $1: 1000$ \\
\hline $\begin{array}{l}\text { Anti-Maus-Meerettich } \\
\text { Peroxidase-Konjugat } \\
\text { (Dianova, Hamburg) }\end{array}$ & Ziege- $\alpha$-Maus (sek. Ak) & $1: 10000$ \\
\hline $\begin{array}{l}\text { Anti-Ratte-Meerettich } \\
\text { Peroxidase-Konjugat } \\
\text { (Dianova, Hamburg) }\end{array}$ & Ziege- $\alpha$-Ratte (sek. Ak) & $1: 10000$ \\
\hline $\begin{array}{l}\text { Anti-Kaninchen-Meerettich } \\
\text { Peroxidase-Konjugat } \\
\text { (Dianova, Hamburg) }\end{array}$ & $\begin{array}{l}\text { Ziege- } \alpha \text {-Kaninchen } \\
\text { (sek. Ak) }\end{array}$ & $1: 10000$ \\
\hline
\end{tabular}


TBS-Tween-Milch: 5\% Magermilchpulver, $150 \mathrm{mM} \mathrm{NaCl}, 25 \mathrm{mM}$ Tris $\mathrm{pH} 7.4,0.05 \%$ Tween 20

TBS-Tween: $150 \mathrm{mM} \mathrm{NaCl}, 25 \mathrm{mM}$ Tris pH7.4, 0.05\% Tween 20

SuperSignal ${ }^{R}$ West Pico Chemiluminescent Substrat (Pierce)

SuperSignal ${ }^{R}$ West Femto Maximum Sensitivity Substrat (Pierce), wurde 1:10 mit

Pico Chemiluminescent Substrat verdünnt

Um unspezifische Bindungsstellen abzusättigen, wurde die PVDF- oder Nitrozellulosemembran mit TBS-Tween-Milch für mindestens 30 Minuten bei Raumtemperatur schüttelnd blockiert. Danach wurde ein bis zwei Stunden mit dem primären Antikörper inkubiert. Um das Volumen so gering wie möglich zu halten, wurde der Filter in einen Plastikbeutel eingeschweißt. Anschließend wurde die Membran kurz mit TBS-Tween gespült und dreimal 10 Minuten gewaschen. Danach wurde mit dem sekundären Antikörper 30 bis 60 Minuten schwenkend inkubiert. Der Filter wurde wieder dreimal 10 Minuten in TBS-Tween gewaschen, danach kurz mit Wasser gespült.

Zur Detektion der gebundenen Antikörper wurde die Membran fünf Minuten mit SuperSignal $^{R}$ West Pico Chemiluminescent Substrat (Pierce) inkubiert. Das Prinzip der Nachweismethode beruht auf der Chemilumineszenz, die durch Meerrettichperoxidase ausgelöst wird. Dieses Enzym katalysiert die Oxidation von Luminol. Bei der Reaktion wird Licht der Wellenlänge $420 \mathrm{~nm}$ emittiert, das über einen Detektor (Fuji LAS-1000) ausgewertet wird. Die Belichtungszeit lag in der Regel zwischen 10 Sekunden und 5 Minuten.

\subsubsection{Entfernen membrangebundener Antikörper}

„Stripping“-Puffer: $62.5 \mathrm{mM}$ Tris/HCl pH6.8, 2\% SDS, $100 \mathrm{mM} \beta$-Mercaptoethanol TBS-Tween: $150 \mathrm{mM} \mathrm{NaCl}, 25 \mathrm{mM}$ Tris pH7.4, 0.05\% Tween 20

$0.2 \mathrm{M} \mathrm{NaOH}$

Die mit Antikörper gebundene Membran wurde mit $50 \mathrm{ml}$ "Stripping"-Puffer 15 Minuten auf $50^{\circ} \mathrm{C}$ und danach weitere 15 Minuten unter dem Abzug abgekühlt. Die gelösten Antikörper wurden durch Waschen mit Wasser und TBS-Tween entfernt. 
Eine weniger stringente Methode war die Inkubation der Membran mit 0.2 M NaOH (zwei Mal, mindestens 5 Minuten). Danach wurde der Filter gründlich mit Wasser und TBS-Tween gewaschen. Es wurde wie in Methode 3.19.8 beschrieben fortgefahren.

\subsubsection{In situ Immunfluoreszenz}

Bei der in situ Immunfluoreszenz wurde die zelluläre Lokalisation von Proteinen mit Hilfe von fluoreszenzmarkierten Antikörpern untersucht.

Tab.6: Verwendete Antikörper bei In situ Immunfluoreszenz

\begin{tabular}{|l|l|l|}
\hline Antikörper & Funktion & Verdünnung in BSA/PBS \\
\hline anti-HA 3F10 (Roche) & Ratte- $\alpha$-HA (prim. Ak) & $1: 200$ \\
\hline Alexa Fluor 488 (Molecular Probes) & Esel- $\alpha$-Ratte (sek. Ak) & $1: 400$ \\
\hline
\end{tabular}

$37 \%$ Formaldehyd

0.1 M Kaliumphosphat-Puffer pH6.4 (27.8 $\mathrm{ml} 1 \mathrm{M} \mathrm{K}_{2} \mathrm{HPO}_{4}$ und $72.2 \mathrm{ml} 1 \mathrm{M} \mathrm{KH}_{2} \mathrm{PO}_{4}$, ad 1 Liter $\mathrm{H}_{2} \mathrm{O}$ )

Formaldehydpuffer: 0.1 M Kaliumphosphatpuffer, 3.7\% Formaldehyd

Sorbitolpuffer: 1.2 M Sorbitol, 0.1 M Phosphat-Citrat pH5.9 (1.74 g K $\mathrm{HPO}_{4}$ und $0.7 \mathrm{~g}$ Zitronensäure)

Monohydrat, ad $100 \mathrm{ml} \mathrm{H}_{2} \mathrm{O}$ )

Zymolyase T100 (Seikagaku): $3 \mathrm{mg} / \mathrm{ml}$ Zymolyase in $10 \%$ Glucose, bei $-20^{\circ} \mathrm{C}$ gelagert

Glusulase (Dupont de Nemours)

Methanol- und Aceton-Bad

$0.1 \%$ Polylysin (400K, Sigma P-1524)

BSA-PBS: 1\% BSA in 1x PBS (0.04 $\left.\mathrm{M} \mathrm{K}_{2} \mathrm{HPO}_{4}, 0.01 \mathrm{M} \mathrm{KH}_{2} \mathrm{PO}_{4}, 0.15 \mathrm{M} \mathrm{NaCl}\right)$ pd-DAPI: $100 \mathrm{mg}$ p-Phenylendiamin in $10 \mathrm{ml}$ PBS, pH8.0, $90 \mathrm{ml}$ Glycerin und 0.05 $\mu \mathrm{g} / \mathrm{ml}$ DAPI

farbloser Nagellack

Eine logarithmisch wachsende Hefekultur $\left(\mathrm{OD}_{600}=1\right)$ wurde mit 0.1 Volumen $37 \%$ Formaldehyd 15 bis 20 Minuten bei Raumtemperatur schüttelnd fixiert. $2 \mathrm{ml}$ dieses Ansatzes wurden zentrifugiert (1 Minute, $4000 \mathrm{rpm}$ ), in $1 \mathrm{ml}$ Formaldehyd-Puffer resuspendiert. Hierbei werden vorwiegend Aminogruppen quervernetzt. Die 
Inkubationszeit bei $4^{\circ} \mathrm{C}$ betrug, abhängig vom Antikörper 2 bis 12 Stunden. Nach dreimaligem Waschen mit 0.1 M Kaliumphosphatpuffer und einmal mit Sorbitolpuffer wurden die Zellen in $0.2 \mathrm{ml}$ Sorbitolpuffer resuspendiert und die Zellwände durch Zugabe von $5 \mu \mathrm{l}$ Zymolyase T100 und $1 \mu \mathrm{l}$ Glusulase verdaut (15-30 Min. bei $30^{\circ} \mathrm{C}$ ). Der Verdau ist vollständig, wenn die Zellen unter dem Mikroskop schwarz erscheinen.

Die Zellen wurden nach Zentrifugation (2 Minuten, $4000 \mathrm{rpm}$ ) vorsichtig in Sorbitolpuffer gewaschen und anschließend in 100-200 $\mu \mathrm{l}$ Sorbitolpuffer resuspendiert. Die Probe konnte so bei $+4^{\circ} \mathrm{C}$ gelagert werden.

In die Einbuchtungen eines Multiwell-Objektträgers wurden jeweils $5 \mu \mathrm{l} \quad 0.1 \%$ Polylysin pipettiert. Nach einer zweiminütigen Einwirkzeit wurde die Platte mit destilliertem Wasser gespült und getrocknet. Danach wurden je $2 \mu \mathrm{l}$ Zellen auf die Einbuchtungen gegeben und der Objektträger zum Fixieren für 3 Minuten in ein $-20^{\circ} \mathrm{C}$ kaltes Methanol- und 10 Sekunden in ein $-20^{\circ} \mathrm{C}$ kaltes Aceton-Bad gestellt. Nach dem Verdampfen des Acetons folgte eine 1- bis 2-stündige Inkubation mit dem ersten Antikörper (verdünnt in BSA-PBS), wobei jeweils $5 \mu$ Antikörperlösung auf die Zellen gegeben wurden. Die Platte wurde in dieser Zeit feucht und dunkel gelagert. Nach dreimaligem Waschen mit BSA-PBS wurde mit dem sekundären Antikörper wieder 1-2 Stunden unter gleichen Bedingungen inkubiert. Danach wurde viermal mit BSA-PBS gewaschen und die Platte getrocknet. Jeweils $2 \mu \mathrm{l}$ pd-DAPI wurden auf die behandelten Einbuchtungen gegeben. Das Deckglas wurde auf dem Objektträger mit farblosem Nagellack fixiert. Die Präparate wurden mit dem Fluoreszenzmikroskop von Zeiss Axioskop 2 mot plus (Objektiv: 100x1.45 Oil $\alpha$ Plan-Fluar) analysiert und mit der Software Axiovision 4.3 ausgewertet. 


\subsection{Northern Blot-Analyse}

\subsubsection{Gelelektrophoretische Auftrennung von RNA-Molekülen}

Agarose (Roth)

DEPC- $\mathrm{H}_{2} \mathrm{O}$ : im Verhältnis 1:1000, autoklaviert

10xMOPS-Puffer: $48.1 \mathrm{~g}$ MOPS, $16.6 \mathrm{ml} 3 \mathrm{M} \mathrm{NaAc}, 20 \mathrm{ml} 0.5 \mathrm{M}$ EDTA pH8.0, ad 1

Liter DEPC- $\mathrm{H}_{2} \mathrm{O}$ (steril filtriert, Flasche mit Alufolie verkleidet)

$37 \%$ Formaldehyd

RNA-Probenpuffer: $10 \mathrm{ml}$ Formamid, $3.5 \mathrm{ml}$ 37\% Formaldehyd, $2 \mathrm{ml}$ 10x MOPS-

Puffer, $3.8 \mathrm{mg}$

Xylencyanol, $3.8 \mathrm{mg}$ Bromphenolblau (steril filtriert)

Für ein Agarose-Formaldehydgel (100 ml Ansatz) wurden $1.23 \mathrm{~g}$ Agarose in $87.5 \mathrm{ml}$ DEPC- $\mathrm{H}_{2} \mathrm{O}$ in der Mikrowelle aufgekocht. Nach Abkühlen auf ca. $65^{\circ} \mathrm{C}$ wurden $9.6 \mathrm{ml}$ 10xMOPS-Puffer und $2.9 \mathrm{ml} \mathrm{37 \%} \mathrm{Formaldehyd} \mathrm{zugegeben.} \mathrm{Die} \mathrm{Lösung} \mathrm{wurde} \mathrm{in}$ einen vorbereiteten Gelschlitten gegossen. 15-20 $\mu$ g RNA wurden vor dem Beladen mit je $15 \mu$ RNA-Probenpuffer vermischt und zur Denaturierung 15 Minuten bei $65^{\circ} \mathrm{C}$ inkubiert. Die Elektrophorese wurde bei einer Spannung von 60 bis $100 \mathrm{~V}$ durchgeführt.

\subsubsection{Northern Blot}

20xSSC-Puffer

50 mM Natrium-Phosphat-Puffer, pH7.0

RNA-Färbelösung: 0.04\% Methylenblau in $0.5 \mathrm{M}$ Natriumacetat pH5.5 (steril filtriert)

Filterpapier (Whatman, GB002)

Papiertücher

Parafilm

Hybond $^{+} \mathrm{N}-$ Membran (Amersham Pharmacia)

Der Northern Blot beruht auf Kapillarkräfte, die die elektrophoretisch aufgetrennte RNA vom Gel auf eine Membran transferieren. Dazu wurde auf ein mit 10xSSC gefülltes Gefäß eine Glasplatte mit zwei dünnen, übereinander liegenden Filterpapiere gelegt, so dass diese an beiden Seiten in das Gefäß ragten. Das Gel 
wurde mit der Beladungsseite nach unten auf die Filterpapiere gelegt und mit Parafilm seitlich begrenzt. Dann folgte die Hybond ${ }^{+} \mathrm{N}-M e m b r a n$, auf die 4 bis 5 in 10xSSC getränkte, Whatman-Papiere folgten. Um die Kapillarwirkung zu verstärken wurden noch trockene Papiertücher aufgelegt, die durch ein Gewicht beschwert wurden. Nach 12 Stunden wurde der Blot abgebaut. Die Membran wurde kurz in 50 $\mathrm{mM}$ Natrium-Phosphat gewaschen, getrocknet und die RNA durch Bestrahlung eine 30-sekundige mit UV-Licht (312 nm) fixiert. Um die Qualität der RNA-Präperation und des Blots zu überprüfen, wurde die Membran für 2-3 Minuten in RNA-Färbepuffer geund in $\mathrm{H}_{2} \mathrm{O}$ entfärbt.

\subsubsection{Prähybridisierung, Hybridisierung und Autoradiographie}

\section{Herstellung von ${ }^{32} \mathrm{P}$-markierten Sonden}

Rediprime II Random Prime Labelling System (Amersham Pharmacia, GE Healthcare)

${ }^{32} \mathrm{P}$-dCTP $(50 \mu \mathrm{Ci} / 5 \mu \mathrm{l}$, Hartmann Analytic, Braunschweig)

Quick Spin S300 (Amersham Pharmacia)

1xTE-Puffer

Heringssperma-DNA (11 mg/ml, Sigma)

In dieser Arbeit wurden Sonden gegen das HIS5 ${ }^{+}$, YDR360W-, URA3-, ACT1-, EAF1- und APE1-Gen eingesetzt.

Das APE1-Fragment wurde durch Restriktionsenzymverdau (Kpn I/Pst I) des Plasmids pRS313-APE1 isoliert. Die HIS5 ${ }^{-}$, YDR360W-, URA3-, ACT1- und EAF1Fragmente wurden mittels PCR aus den Plasmiden pRS316 (URA3), oder pFA6aHIS3MX6 (HIS5 $\left.{ }^{+}\right)$, bzw. chromosomaler DNA amplifiziert.

100 ng der Matrizen-DNA wurden in $\mathrm{H}_{2} \mathrm{O}$ (Gesamtvolumen: $45 \mu \mathrm{l}$ ) aufgenommen und 5-10 Minuten bei $95^{\circ} \mathrm{C}$ denaturiert und anschließend auf Eis gestellt. Die DNA wurde im Isotopenlabor mit Rediprime II Random Prime Labelling System gemischt und mit $50 \mu \mathrm{Ci}{ }^{32} \mathrm{P}$-dCTP, 15 Minuten bei $37^{\circ} \mathrm{C}$ inkubiert. Die ${ }^{32} \mathrm{P}$-markierten Fragmente wurden mit Hilfe einer Sephadex-Säule (Quick Spin S300, Amersham Pharmacia) von überschüssigen Nukleotiden gereinigt. Dazu wurde die DNA mit $150 \mu \mathrm{l}$ 1xTEPuffer versetzt und die Sephadex-Säule zur Entfernung des Puffers 1 Minute bei 
3000 rpm zentrifugiert und in ein neues Reaktionsgefäß mit Schraubverschluss gestellt. Die radioaktiven Fragmente wurden genau auf die Schräge der Säule pipettiert und die Säule 2 Minuten bei 3000 rpm zentrifugiert. Die radioaktiv markierte DNA wurde mit Heringssperma-DNA versetzt und 5 Minuten bei $95^{\circ} \mathrm{C}$ inkubiert. Die Sonde wurde in einem Bleibehälter bei $+4^{\circ} \mathrm{C}$ gelagert.

\section{Prähybridisierung und Hybridisierung}

Rapid-hyb Buffer (GE Healthcare)

Zur Prähybridisierung wurde die Membran mit Rapid-hyb Buffer für mindestens 15 Minuten bei $65^{\circ} \mathrm{C}$ im Hybridisierungsofen vorbehandelt. Die radioaktiv markierte DNA wurde mit $3 \mathrm{ml}$ Rapid-hyb Buffer gemischt und auf die Membran gegeben. Die Hybridisierung erfolgte über Nacht bei $65^{\circ} \mathrm{C}$ unter Rotation.

Waschen der hybridisierten Membran

2xSCP-Puffer, $0.2 \%$ SDS

$0.2 \times S C P-P u f f e r, 0.2 \%$ SDS

Die Hybridisierungslösung wurde in einem $50 \mathrm{ml}$ Reaktionsgefäß (Falcon) in einem Plexiglasbehälter bei $+4^{\circ} \mathrm{C}$ gelagert. Die Membran wurde in der Hybridisierungsröhre zunächst kurz mit 2xSCP-Puffer, $0.2 \%$ SDS gespült und dann dreimal 10 Minuten bei Raumtemperatur gewaschen. Anschließend wurde sie zwei- bis dreimal 10 Minuten $0.2 \times S C P-P u f f e r, 0.2 \%$ SDS inkubiert. Southern Blots wurden stringenter mit auf $50^{\circ} \mathrm{C}$ vorgewärmten Puffer bei $65^{\circ} \mathrm{C}$ gewaschen. Das Ende des Waschvorgangs wurde mit dem Geigerzähler überprüft, die Membran sollte noch ca. 100 IPS aufweisen. Anschließend wurde die Membran auf einem Filterpapier getrocknet und eingeschweißt. Danach wurde eine Phosphoimager-Platte (BAS-MP 2025P, Fuji) aufgelegt. Die Inkubation hing von der Intensität der vorhandenen Signale ab und lag in der Regel zwischen 4 Stunden und 3 Tagen. Die Platte wurde in einem Phosphoimager (PMI ${ }^{\mathrm{TM}}$ System, Biorad) ausgelesen. 


\subsection{Southern Blot-Analyse}

Um die Integration von Plasmid-DNA oder PCR-Fragmenten mit homologen, flankierenden Enden in S. cerevisiae zu überprüfen, wurden Southern Blot Analysen durchgeführt. Im Vergleich zum Northern Blot, werden hier DNA-Fragmente elektrophoretisch aufgetrennt und auf eine Membran transferiert. Die Hybridisierung der Membran (Hybond ${ }^{+} \mathrm{N}$, Amersham Pharmacia) erfolgte wie in Methode 3.20.3 beschrieben.

\section{Verdau genomischer DNA aus S. cerevisiae}

$5 \mu \mathrm{l}$ genomische DNA

$3 \mu \mathrm{l}$ 10xNEBuffer (BioLabs)

$1 \mu \mathrm{l}$ RNAse (1 mg/ml, in $\mathrm{H} 2 \mathrm{O}, 10$ Minuten gekocht)

$1 \mu \mathrm{l}$ Enzym

ad $30 \mu \mathrm{l} \mathrm{H}_{2} \mathrm{O}$

bei $37^{\circ} \mathrm{C}$ über Nacht verdaut

Die verdaute DNA wurde mit $5 \mu$ l 6xDNA-Auftragspuffer versetzt und auf ein $0.8 \%$ iges Agarosegel zusammen mit dem DNA-Standard aufgetragen. Die Elektrophorese erfolgte bei ca. $40 \mathrm{~V}$. Das Gel wurde anschließend unter UV-Licht (312 nm) mit einem anliegenden Lineal photographiert.

\subsubsection{Southern Blot}

\subsection{Salzsäure}

Denaturierungspuffer: $0.5 \mathrm{M} \mathrm{NaOH}, 1.5 \mathrm{M} \mathrm{NaCl}$

20xSSC-Puffer: $175.32 \mathrm{~g} \mathrm{NaCl}, 88.22 \mathrm{~g}$ Trinatriumcitrat-2-hydrat in $1 \mathrm{I} \mathrm{H}_{2} \mathrm{O}, \mathrm{pH} 7.0$

$50 \mathrm{mM}$ Natrium-Phosphat-Puffer, pH7.0

Hybond $^{+} \mathrm{N}-$ Membran (Amersham Pharmacia)

Filterpapier (Whatman, GB002)

Um die DNA partiell zu depurinieren wurde das Gel 20 Minuten in 0.25 M Salzsäure geschwenkt. Zur Denaturierung der DNA wurde das Gel anschließend zweimal 20 
Minuten in $0.5 \mathrm{M} \mathrm{NaOH}, 1.5 \mathrm{M} \mathrm{NaCl}$ gewaschen. Der Blotaufbau erfolgte wie unter Methode 3.20.2 beschrieben. Allerdings wurde beim Southern Blot Denaturierungspuffer, anstatt 10xSSC-Puffer (Northern Blot) für den Transfer der DNA auf die Membran eingesetzt. Der Kapillarblot erfolgte wiederum über Nacht. Die Membran wurde kurz in $50 \mathrm{mM}$ Natrium-Phosphat-Puffer geschwenkt und getrocknet. Die DNA wurde auf der Membran durch UV-Licht (312 nm) fixiert.

\subsubsection{Entfernen von ${ }^{32} \mathrm{P}$-markierten Fragmenten von der Hybond ${ }^{+} \mathrm{N}-\mathrm{Membran}$}

Die radioaktiv markierte Hybond ${ }^{+} \mathrm{N}$-Membran wurde in kochendes $0.1 \%$-iges SDS gelegt und darin für mindestens 30 Minuten unter Abkühlung der Flüssigkeit schüttelnd inkubiert. Danach wurde die Membran mit dem Geigerzähler gemessen, dabei sollte die Membran nicht mehr als 30 IPS ausweisen. Um SDS-Reste zu entfernen, wurde diese anschließend intensiv mit Wasser gewaschen und konnte danach erneut prähybridisiert werden.

\subsection{Protease Sensitivitäts-Assay}

$0.1 \mathrm{M} \mathrm{Tris} / \mathrm{SO}_{4} \mathrm{pH} 9.4,10 \mathrm{mM}$ DTT

Sphäroblastierungspuffer: $0.6 \mathrm{M}$ Sorbitol

$50 \mathrm{mM} \mathrm{KH}_{2} \mathrm{PO}_{4} \mathrm{pH} 7.5$

$10 \mathrm{mM}$ DTT

$0.2 \%$ Glucose

Alles gelöst in YP-Medium

Zymolyase T20, 0.5-1 mg/50OD Zellen in Sphäroblastierungspuffer

Sorbitol/Pipes-Puffer: 200 mM Sorbitol, 20 mM Pipes pH6.8

$4 \mathrm{mg} / \mathrm{ml}$ DEAE-Dextran in Sorbitol/Pipes-Puffer

$100 \mathrm{mM} P M S F$ in EtOH

Triton X-100

$1 \mathrm{mg} / \mathrm{ml}$ Trypsin (SERVA) in Sorbitol/Pipes-Puffer

$1 \mathrm{mg} / \mathrm{ml}$ Proteinase $\mathrm{K}$ (Roth) in Sorbitol/Pipes-Puffer

TCA/Aceton: 20\%TCA und 80\% Aceton

$100 \%$ Aceton

1xSDS-Laufpuffer, $3 \% \beta$-Mercaptoethanol 
100OD einer logarithmisch wachsende Hefekultur $\left(\mathrm{OD}_{600}\right.$ 0.6-1.1) wurden bei 2800 rpm für zwei min zentrifugiert und einmal mit $\mathrm{dH}_{2} \mathrm{O}$ gewaschen. Das Zellpellet wurde in $10 \mathrm{ml} 0.1 \mathrm{M} \mathrm{Tris} / \mathrm{SO}_{4} \mathrm{pH} 9.4,10 \mathrm{mM}$ DTT resuspendiert und $15 \mathrm{~min}$, bei $30^{\circ} \mathrm{C}$ schüttelnd $(200 \mathrm{rpm})$ inkubiert. Nach dreiminütiger Zentrifugation bei $3000 \mathrm{rpm}\left(4^{\circ} \mathrm{C}\right)$, wurden die Zellen in $16.6 \mathrm{ml}$ Sphäroblastierungspuffer resuspendiert und weitere 15$30 \mathrm{~min}$ bei $30^{\circ} \mathrm{C}$ und $60 \mathrm{rpm}$ sphäroblastiert. Danach wurde bei $2000 \mathrm{rpm}$, für zwei Minuten bei $4^{\circ} \mathrm{C}$ zentrifugiert. Das Pellet wurde sehr vorsichtig in ca. $1400 \mu \mathrm{l}$ Sorbitol/Pipes-Puffer resuspendiert und die Zellen mit 120-180 $\mu \mathrm{g}$ DEAE-Dextran lysiert. Die Zellen wurden danach fünf Minuten bei $30^{\circ} \mathrm{C}$ und anschließend eine Minute auf Eis inkubiert.

Für die Lyse Kontrolle, wurden $144 \mu \mathrm{l}$ der lysierten Sphäroblasten mit $0.7 \mu \mathrm{l}$ PMSF bei $6000 \mathrm{~g}$ für $5 \mathrm{~min}\left(4^{\circ} \mathrm{C}\right)$ zentrifugiert. Pellet und Überstand wurden auf ein $10 \%$ iges SDS-Polyacrylamidgel geladen.

Für den Protease Sensitivitäts-Assay wurde pipettiert:

Detergenz (D) Triton X-100

Enzym (E) Trypsin oder Proteinase $K$

\begin{tabular}{|ccc|l|}
\hline$-D$ & $-D$ & $+D$ & \\
$-E$ & $+E$ & $+E$ & \\
\hline 144 & 144 & 144 & $\mu l$ lysierte Sphäroblasten \\
56 & 46 & 42 & $\mu l$ Sorbitol/Pipes-Puffer \\
- & - & 4 & $\mu l$ Triton X-100 (Endkonzentration 0.2\%) \\
- & 10 & 10 & $\mu l$ Trypsin oder Proteinase K (Endkonzentration $50 \mu \mathrm{g} / \mathrm{ml}$ ) \\
\hline
\end{tabular}

Die Assay-Ansätze wurden $30 \mathrm{~min}$ auf Eis inkubiert, danach wurde $1 \mu \mathrm{l}$ PMSF zugegeben und weitere 10 Minuten auf Eis inkubiert. Die Proben wurden 1:1 mit TCA/Aceton gefällt. Die mit Aceton gewaschenen Pellets wurden zügig mit $200 \mu \mathrm{l}$ 1xSDS-Ladepuffer versetzt und resuspendiert. $50 \mu$ wurden auf ein $10 \%$-iges SDSPolyacrylamidgel geladen. 


\subsection{Gelfiltration von Gesamtproteinlysat mit Superdex S200}

$50 \mathrm{mM}$ di-Natriumhydrogenphosphat Dihydrat pH7.0, $150 \mathrm{mM} \mathrm{NaCl}$ (mit $\mathrm{HPLC}-\mathrm{H}_{2} \mathrm{O}$ und filtriert)

1000xInhibitor-Mix: $20 \mu \mathrm{g} / \mathrm{ml}$ Leupeptin, $20 \mu \mathrm{g} / \mathrm{ml}$ Benzamidin, $10 \mu \mathrm{g} / \mathrm{ml}$ Pepstatin A, $40 \mu \mathrm{g} / \mathrm{ml}$ Aprotinin

Protease Inhibitor Complete EDTAfree (Roche)

$100 \mathrm{mM}$ PMSF in $100 \%$ Ethanol

Standard: $5 \mu \mathrm{l}$ Tyroglobulin $(50 \mathrm{mg} / \mathrm{ml})-669 \mathrm{kDa}-$

$3 \mu \mathrm{l}$ Ferretin $(50 \mathrm{mg} / \mathrm{ml})-440 \mathrm{kDa}-$

$3 \mu \mathrm{l} \mathrm{Myosin} \mathrm{HC}(4.3 \mathrm{mg} / \mathrm{ml})-205 \mathrm{kDa}-$

$10 \mu \mathrm{l}$ Transferrin $(50 \mathrm{mg} / \mathrm{ml})-81 \mathrm{kDa}-$

$7 \mu \mathrm{l}$ Ovalbumin $(50 \mathrm{mg} / \mathrm{ml})-43 \mathrm{kDa}-$

$4 \mu \mathrm{l}$ Ribonuclease A $(50 \mathrm{mg} / \mathrm{ml})-13.7 \mathrm{kDa}-$

Der Standardansatz wurde mit 50 mM di-Natriumhydrogenphosphat Dihydrat pH7.0, $150 \mathrm{mM} \mathrm{NaCl}$ auf $100 \mu \mathrm{l}$ aufgefüllt. Davon wurden $3 \mu \mathrm{l}$ mit $47 \mu \mathrm{l}$ Puffer auf eine Superdex S200 PC 3.2/3.0 (Pharmacia Biotech) geladen. Bei einer Superdex S200 liegt die optimale Trennung zwischen 10 und $600 \mathrm{kDa}$.

$100 \mathrm{ml}$ einer exponentiell wachsenden Hefekultur $\left(\mathrm{OD}_{600}\right.$ 0.8-1.5) wurden zwei Minuten bei $2800 \mathrm{rpm}$ zentrifugiert, $2 \mathrm{Mal}$ mit Wasser gewaschen und in $300 \mu \mathrm{l} 50$ $\mathrm{mM}$ di-Natriumhydrogenphosphat Dihydrat $\mathrm{pH} 7.0,150 \mathrm{mM} \mathrm{NaCl}$ zusammen mit Protease Inhibitoren resuspendiert. Alle folgenden Schritte wurden auf Eis oder im Kühlraum bei $4^{\circ} \mathrm{C}$ durchgeführt. Zu der Zellsuspension wurden ca. $300 \mu$ l Glasperlen gegeben und zum Zellaufschluss 5 bis 10 Minuten im KIA-Vibrax geschüttelt. Nach zehnminütiger Zentrifugation bei $13000 \mathrm{rpm}$ wurde das Zelllysat geklärt. Der proteinhaltige Überstand wurde in $1.5 \mathrm{ml}(9.5 \times 38 \mathrm{~mm})$ Microfuge $^{R}$ Tubes Polyallomer (Beckman) überführt und 30 Minuten bei 40000 rpm (TLA-55) zentrifugiert. Nach Bestimmung der Proteinkonzentration nach Bradford (Methode 3.19.4) wurden $50 \mu \mathrm{l}$ der Probe auf eine Superdex S200 Säule geladen und mit der SMART ( $\mu$ Separation Unit, Pharmacia Biotech) analysiert. 
Dabei wurden Fraktionen zu $30 \mu$ lautomatisch gesammelt und anschließend mit $6 \mu \mathrm{l}$ $50 \%$ TCA gefällt, zweimal mit 100\% Aceton gewaschen und anschließend in 1xSDSLämmli Ladepuffer gelöst. Die Proteine wurden durch fünfminütiges Erhitzen auf $95^{\circ} \mathrm{C}$ denaturiert, über eine SDS-Polyacrylamidgelelektrophorese aufgetrennt und mittels Western Blot-Analyse untersucht. 


\section{Ergebnisse}

\subsection{Genomische Integration der Aminopeptidase 1 in $W T$ und via- Mutanten}

In den Arbeiten von Cornelia Andrei-Selmer (Dissertation von 1999, Andrei-Selmer et al., 2001) und Pasupuleti Naga Rekha (Dissertation von 2004) wurden Untersuchungen zur Aktivität der Aminopeptidase 1 mit Hefestämmen durchgeführt, die das APE1-Gen transformiert auf "single copy“-Plasmiden trugen ( $p R S 313$ und pRS314). Die episomale Expression der Ape1 erlaubte es zwischen verschiedenen Auxotrophiemarkern zu wählen, jedoch erforderte die Charakterisierung weiterer Gene Doppeltransformationen und Wachstum der Hefen auf Medien mit zwei Selektionsmarkern. Dieses System zeigte sich anfällig für Schwankungen in der Ape1-Aktivität und der gezeigte Einfluss des Gens YDR360W konnte in dieser Arbeit nicht bestätigt werden (Daten nicht gezeigt). Deshalb wurden Plasmide hergestellt, die durch Integration in das Hefegenom eine Überexpression der Proteine verhindern. Da nach erfolgter Integration alle Zellen einer Kultur genetisch identisch sind, wird die Reproduzierbarkeit der Ergebnisse verbessert und gleichzeitig ein stabiles System geschaffen, das es erlaubt die zu testenden Stämme auf Vollmedium, ohne Selektion auf das transformierte Gen, zu kultivieren.

Um das Gen APE1 in den URA3-Locus des Hefegenoms zu integrieren, wurde das Plasmid pRS313-APE1 mit dem Restriktionsenzym Sall verdaut. Das dadurch isolierte APE1-Gen mit endogener 5'-Promotor- und 3'-Terminator-Sequenzen von insgesamt ca. $5 \mathrm{~kb}$ Länge wurde anschließend in den ebenfalls mit Sal I geschnittenen integrativen Vektor $p R S 306$ kloniert. Die richtige Orientierung des eingefügten Konstrukts wurde durch Restriktionsenzymverdau überprüft. Das mit Stu I linearisierte Plasmid wurde in die Hefestämme y25 (C6C ohne pRS313-APE1), y27 (via10 ohne pRS313-APE1) und y28 (via14 ohne pRS313-APE1) mittels homologer Rekombination am genomischen URA3-Locus integriert (Abb.10 und verwendete Hefestämme siehe Anhang). Erfolgreiche Integration wurde durch Selektion auf Uracil-Prototrophie erzielt und durch Southern Blot-Analysen verifiziert. 


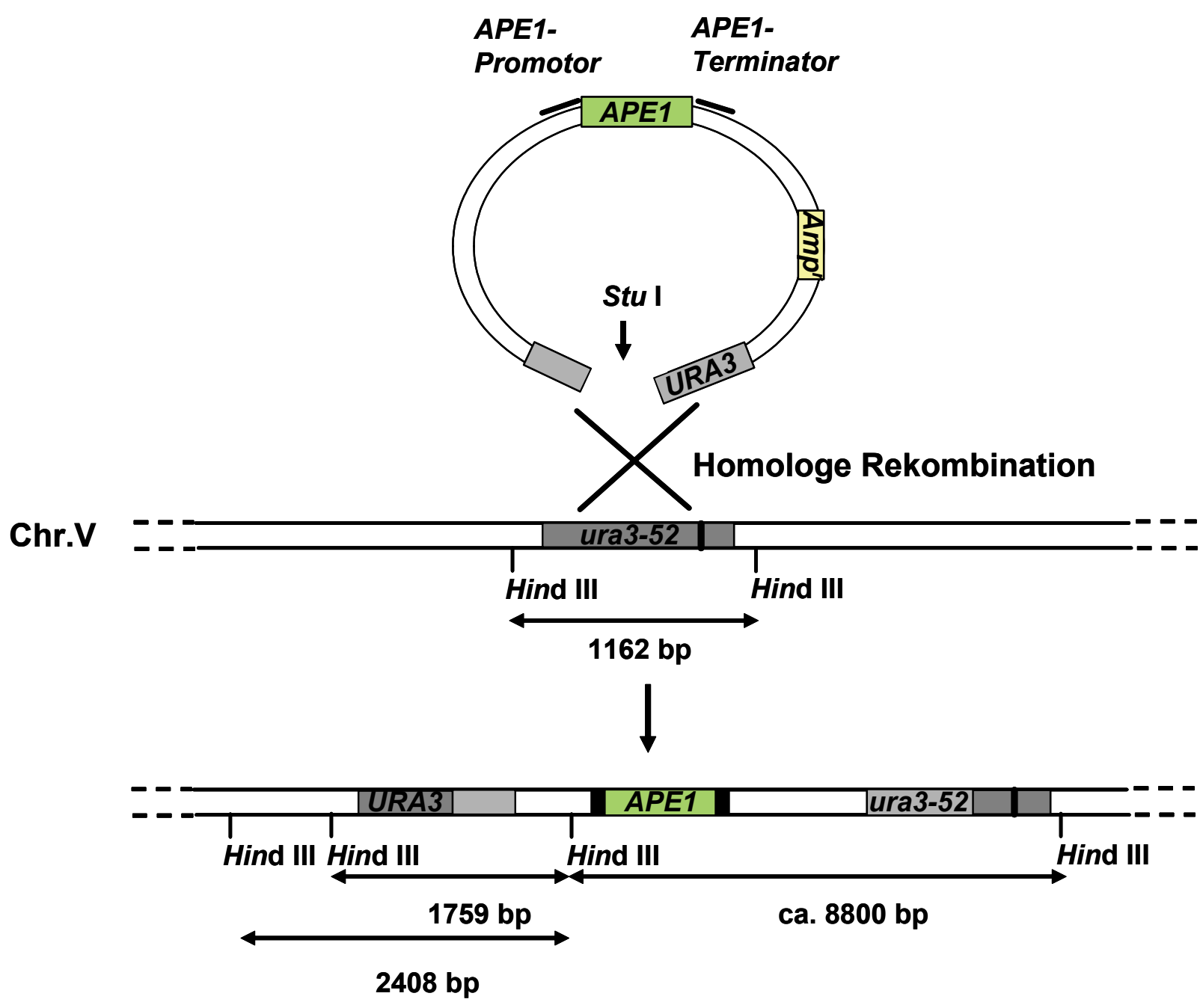

Abb.10: Schematische Darstellung der homologen Rekombination des integrativen Hefeplasmids $p R S 306-A P E 1$.

Die Mutation des endogenen ura3-52-Allels ist durch einen schwarzen Balken angedeutet. Nach homologer Rekombination des Plasmids werden die Hefezellen Uracil-prototroph. 
Dazu wurde die chromosomale DNA des Wildtypstammes y25 und von je zwei ausgewählten Transformanden mit dem Restriktionsenzym Hind III geschnitten, über ein 0.8\%-iges Agarosegel elektrophoretisch aufgetrennt und auf eine Nylonmembran transferiert. Die Membran wurde anschließend mit einem ${ }^{32} \mathrm{P}$-markierten DNAFragment des URA3-Gens hybridisiert. Wie in Abb.10 illustriert, entstehen bei einer korrekten Integration der APE1 zwei, bzw. drei Fragmente mit ca. 8800 bp und 1759 bp, bzw. 2408 bp. Dies konnte in Southern Blot-Analysen bestätigt werden (Abb.11). Integrationen in den URA3-Locus der Stämme y25 und y28 ergaben zwei Signale von 8800 bp und 2408 bp Länge, wohingegen die Integration in y27 in drei Signalen von 8800 bp, 2408 bp und 1759 bp Länge resultierte, was entweder auf einen unvollständigen Verdau der ersten beiden Transformanden oder auf Verlust der dem URA3-Locus sehr nahen Schnittstelle (Abb.10) zurückzuführen ist. Die so generierten Stämme aus y25, y27 und y28 werden in dieser Arbeit mit WT (y96), via10-2 (y43) und via14-2 (y46) bezeichnet. Der Stamm ydr360w $\Delta$ (y26) konnte nicht für die homologe Rekombination der APE1 in den URA3-Locus verwendet werden, da hier der URA3-Locus komplett deletiert war (ura3 $\triangle 0$ ).

Die erfolgreiche Expression des integrierten APE1-Gens wurde mit Western BlotAnalysen überprüft (Abb.12). Die Ausgangsstämme y25, y27 und y28 zeigten ein schwaches prApe1-Signal. In diesen Stämmen ist das APE1-Gen mutiert und wird auch schwach exprimiert, die prApe1 kann aber nicht mehr prozessiert werden (parentaler Stamm II-17, H. D. Wolf). Der WT-Stamm mit integrierter APE1 exprimiert ca. 50\% weniger Ape1 als der Ursprungsstamm C6C, der das APE1-Gen auf dem „single copy“-Plasmid pRS313 trägt (Andrei-Selmer et al., 2001). Im Vergleich zu C6C zeigt der WT-Stamm eine um ca. $20 \%$ verminderte Aktivität des Proteins im Ape1-Overlay-Assay (Daten nicht gezeigt). Dieser Unterschied lässt sich durch die zwei- bis fünffach höhere Kopienzahl des Plasmids in C6C im Vergleich zum nur einfach integrierten APE1-Gen im WT-Stamm erklären. Die Mutantenstämme via10-2 und via10 zeigten ähnliche Ape1-Expressionshöhen, allerdings akkumuliert via10 etwas mehr prApe1. Auch hier lässt sich der Unterschied in der Expressionsrate durch die erhöhte Kopienzahl des Plasmids erklären. Der Mutantenstamm via14-2 mit integrierter APE1 zeigte eine leicht erhöhte Ape1-Expression im Vergleich zur Ursprungsmutante via14, transformiert mit pRS313-APE1. Via14 besitzt eine um zehnmal geringere Transformationsrate als der WT-Stamm und die Isolation transformierter Plasmide (3.8.4) aus via14 erwies sich als sehr schwierig. Damit ist 
bei diesem Stamm eine verstärkte Tendenz zum Plasmidverlust wahrscheinlich. Jedoch besitzt auch via14-2 eine niedrigere Expressionsrate als der WT-Stamm.

Mit der Integration der APE1 in das Hefegenom wurde ein System geschaffen, das es erlaubt, die Ape1-Expression und -Aktivität verlässlich und kontinuierlich, d.h. beispielsweise ohne Plasmidverlust oder variable mRNA-Mengen, zu bestimmen.

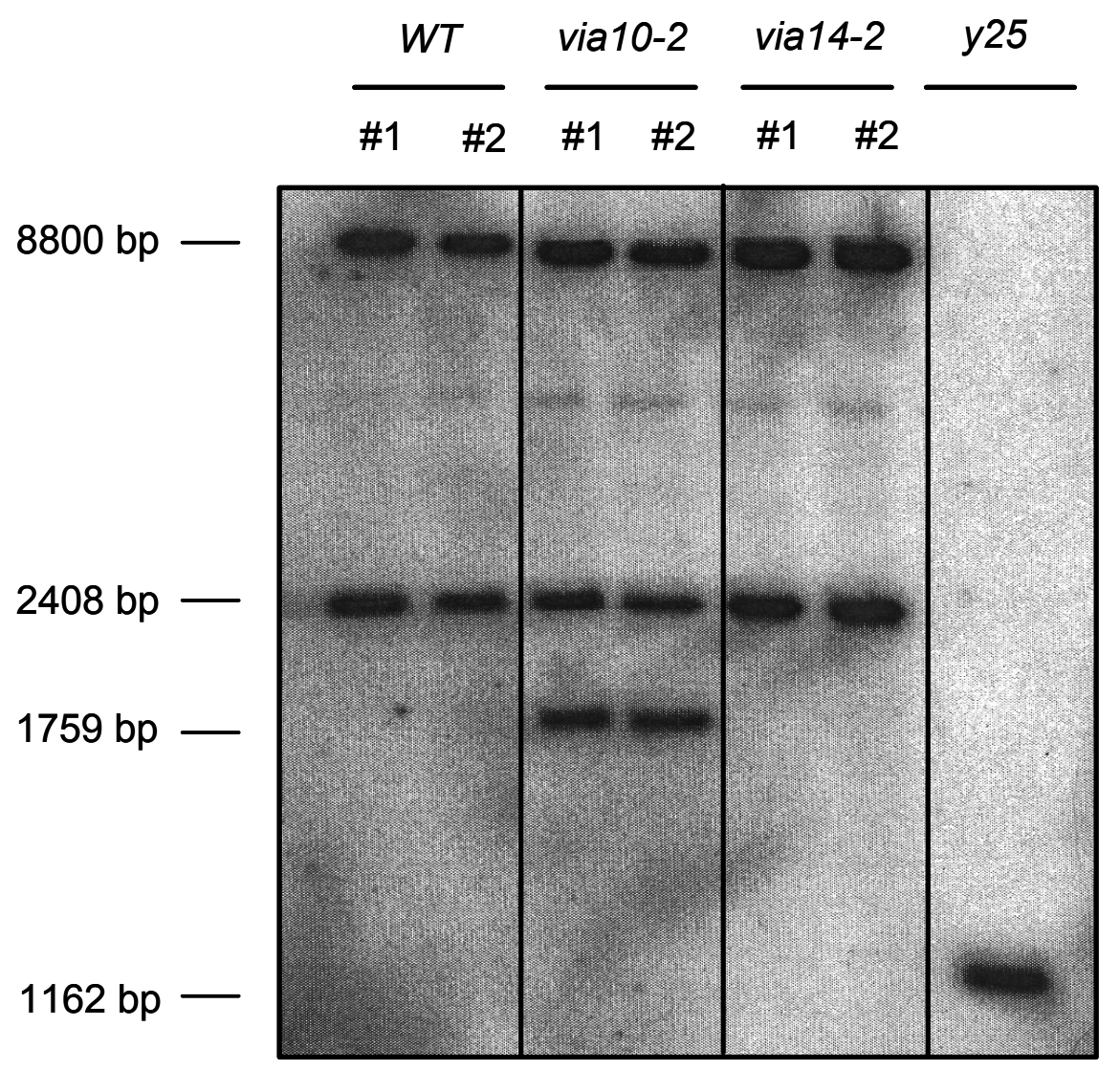

Abb.11: Southern Blot-Analyse zum Integrationsnachweis des Plasmids pRS306-APE1 in den URA3-Locus der Hefestämme y25, y27 und y28.

Genomische DNA der Stämme y25, WT (y25 ura3::pRS306 APE1), via10-2 (y27 ura3::pRS306 APE1) und via14-2 (y28 ura3::pRS306 APE1) wurde isoliert und mit dem Restriktionsenzym Hind III verdaut. Nach elektrophoretischer Auftrennung über ein 0.8\%-iges Agarosegel, wurde die DNA auf eine NylonMembran transferiert. Die Hybridisierung erfolgte mit einem ${ }^{32} \mathrm{P}$-markierten DNA-Fragment des URA3Gens aus S. cerevisiae. 


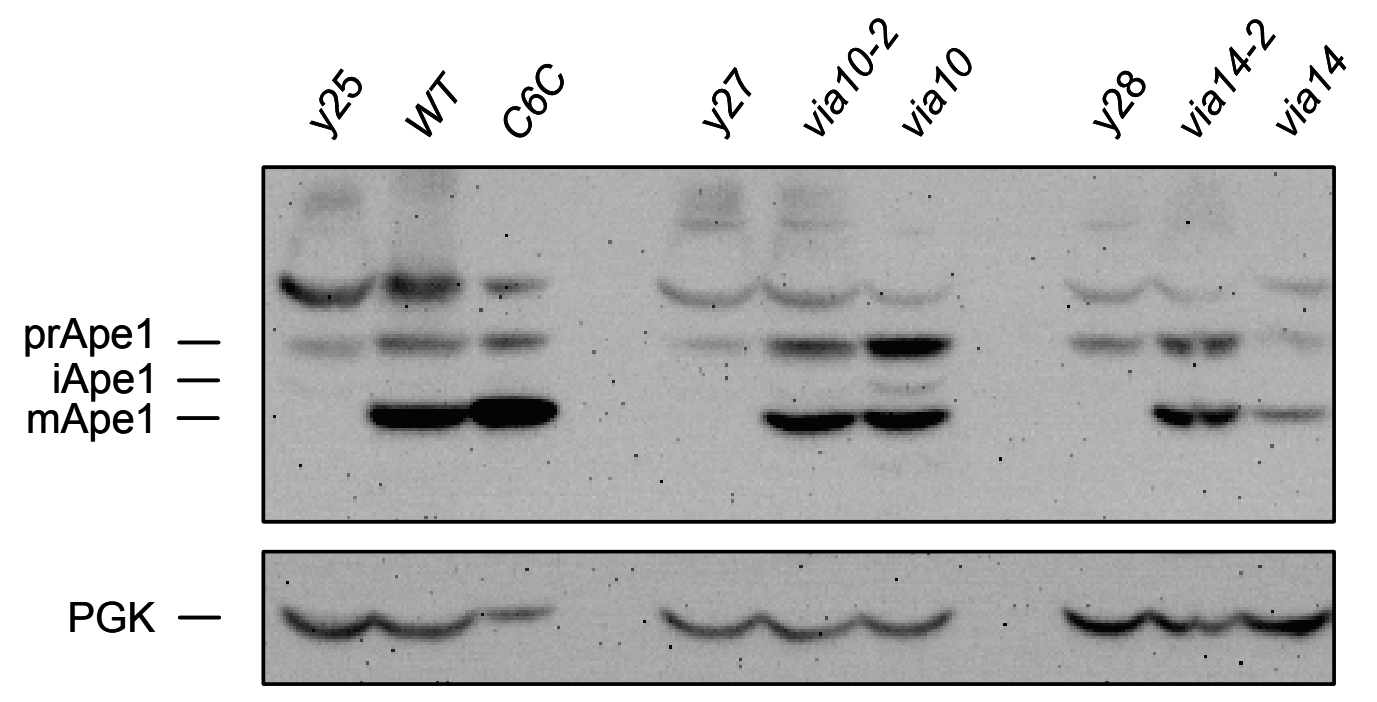

Abb.12: Western Blot-Analyse zum Nachweis der Ape1-Expression nach Integration des Gens in das Hefegenom.

1 OD Zellen der Stämme y25, WT (y96), C6C (y12), y27, via10-2 (y43), via10 (y89), y28, via14-2 (y46), via14 (y91) wurden mittels alkalischer Lyse aufgeschlossen und über ein 10\%-iges Polyacrylamidgel elektrophoretisch aufgetrennt und mit dem „semi dry“ Elektroblot-Verfahren auf eine PVDF-Membran transferiert. Die Membran wurde mit anti-Ape1 Serum inkubiert. Der Nachweis der gebundenen Antikörper erfolgte mit einem Meerrettichperoxidase konjugierten anti-Kaninchen Antikörper und Chemilumineszenz. PGK (45 kDa) diente als Ladekontrolle. 


\subsection{Analyse des ORFs YDR360W}

In der Dissertation von Pasupuleti Naga Rekha (2004) wurde gezeigt, dass der ORF YDR360W (SUVIA1; suppressor of via) die Aktivität der Aminopeptidase 1 in den Mutantenstämmen wiederherstellen konnte, und dass eine Deletion dieses ORFs zu einem Verlust der Ape1-Aktivität führte. Nachdem nun die Ape1 in das Hefegenom integriert wurde, sollten diese Ergebnisse, vor allem in Hinblick auf eine weitere Charakterisierung von YDR360W verifiziert werden.

\subsubsection{Der Einfluss von ORF YDR360W auf die Aktivität der Aminopeptidase 1}

Die Ursprungsmutanten via10 und via14 zeigten eine um $80 \%$, bzw. vollständig reduzierte Aktivität der Aminopeptidase 1 (Andrei-Selmer et al., 2001). Nach der Integration der Aminopeptidase 1 ins Hefegenom wurde die Aktivität der Hefestämme WT, via10-2 und via14-2 in Ape1-Overlay-Assays (3.18) bestimmt. Die gemessene Aktivität des WT-Stammes wurde mit 100\% festgelegt, während die Mutanten via10-2 und via14-2 keine Aktivität der Ape1 zeigten (Abb.13). Daraufhin wurden die zwei Mutanten mit den cen-Plasmiden $p Y X 132-Y D R 360 W$, bzw. $p Y X 141$ YDR360W und dem 2 $\mu$-Plasmid pYX242-YDR360W zur Expression von aminoterminal markierten HA-Fusionsproteinen transformiert. In jeweils acht Einzelklonen wurde anschließend die Ape1-Aktivität bestimmt. Weder die Expression auf einem „single copy“ cen- noch einem „high copy“ $2 \mu$-Plasmid konnten den Verlust der Aminopeptidase 1-Aktivität in den Mutantenstämmen wiederherstellen. Diese Beobachtung, dass Ydr360w keinen Einfluss auf die Ape1-Aktivität hatte, stand im Widerspruch zu vorhergehenden Ergebnissen aus der Dissertation von P.N. Rekha (2004). Ebenso führte die Transformation der Plasmide in die Ursprungsmutanten via10 und via14 zu keiner Reaktivierung des Enzyms. Stattdessen konnte gezeigt werden, dass die Stämme via10 und via10-2 einen hohen Hintergrund, nach Transformation der Leervektoren $p Y X 141$ und pYX242 aufwiesen, der mit der WTAktivität vergleichbar war (Abb13). Bei den Mutantenstämme via14 und via14-2 hingegen wurde keine Leervektor-stimulierte Hydrolase-Aktivität festgestellt. 


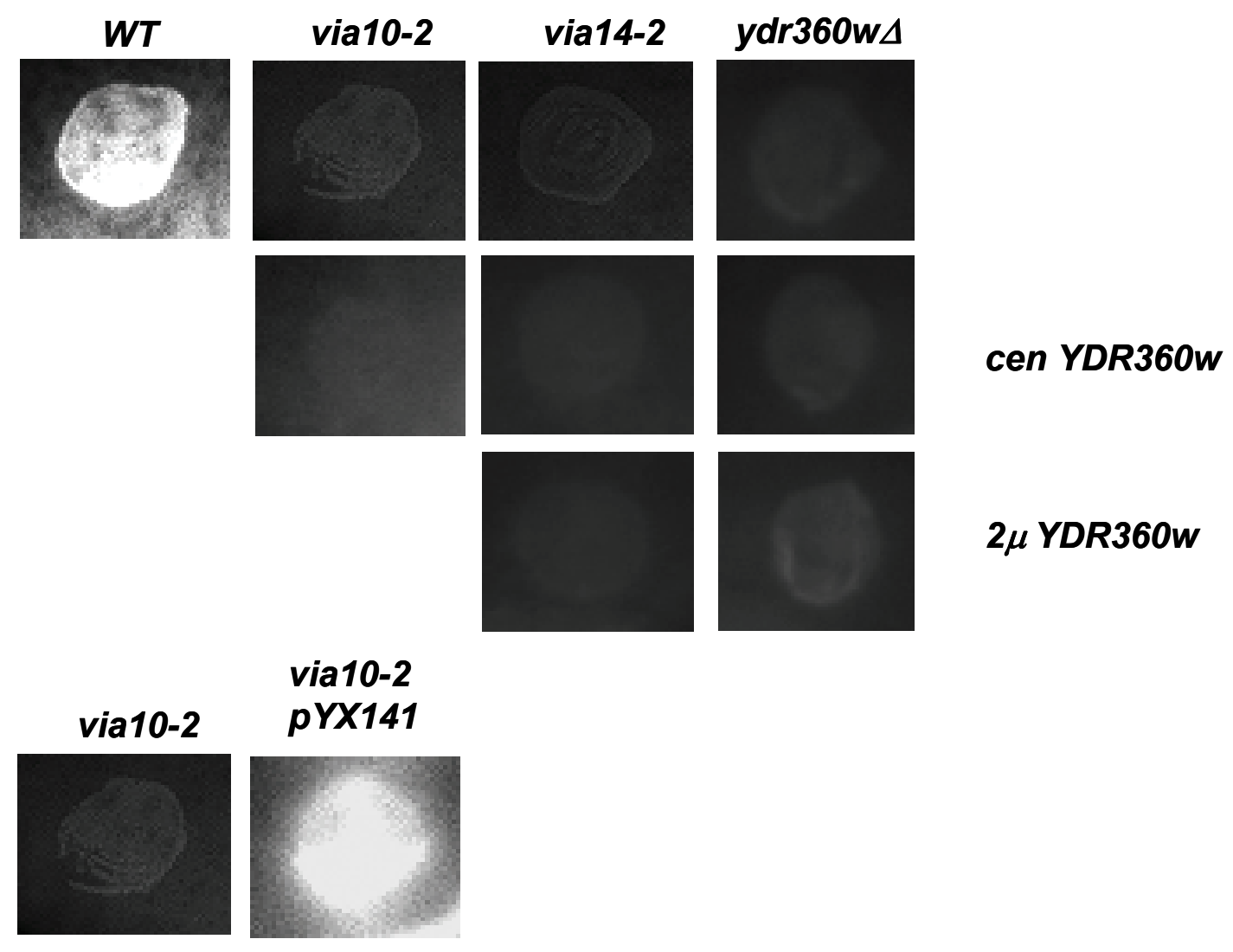

\section{Abb.13: Ape1-Overlay-Assay zur Bestimmung der Aminopeptidase 1-Aktivität.}

Einzelkolonien der Stämme WT (y96), via10-2 (y43), via14-2 (y46) und suvia14 (y10) wurden auf Vollmediumplatten ausgestrichen. Die Stämme via10-2 transf. mit $p Y X 132-Y D R 360 W$, via14-2 transf. mit $p Y X 141-Y D R 360 W$ (y154), via14-2 transf. mit pYX242-YDR360W (y155), ydr360w 4 transf. mit pYX141-YDR360W (y34), suvia14 transf. mit pYX242-YDR360W (y35), via10-2 tranf. mit $p Y X 141$ (y148) wurden auf Tryptophan-, bzw. Leucin-Mangelmedium ausgestrichen. Nach zwei bis drei Tagen Wachstum bei $30^{\circ} \mathrm{C}$ wurden die Zellen auf sterile Rundfilter gestempelt und nach $24 \mathrm{~h}$ Inkubation wurden die Zellen lysiert und mit dem Substrat H-Leucin- $\beta$-Naphtylamid überschichtet. Die Spaltung des Naphtylamids wurde photometrisch bei $365 \mathrm{~nm}$ verfolgt. 


\subsubsection{Transkriptionsstudien der ORFs YDR360W und YDR359C}

Es konnte gezeigt werden, dass die Transformation des Gens YDR360W (SUVIA1) die Aminopeptidase 1-Aktivität weder in den Mutantenstämmen noch im ydr360w 4 Stamm beeinflusste. Die beobachtete, stark reduzierte Ape1-Aktivität des suvia14Stammes (Abb.13) deutete jedoch auf eine Rolle des Genabschnitts um den ORF YDR360W hin (Dissertation P.N. Rekha). Das chromosomale DNA-Fragment, das den Ape1-Reifungsdefekt der via-Mutanten suppremierte, enthielt den putativen ORF YDR360W, sowie 862 bp des Aminoterminus' des 2949 bp großen ORFs YDR359C, die sich um 286 bp teilweise überlappen (Abb.7).

Um zu klären, auf welchem der zwei ORFs der beobachtete Effekt, also die Wiederherstellung der Ape1-Aktivität beruhte, wurde nun deren Transkription mittels Northern Blot-Analysen untersucht. Dazu wurde aus logarithmisch wachsenden und gehungerten Zellen des Stammes SEY6210 Gesamt-RNA isoliert. Diese zwei unterschiedlichen Wachstumsphasen wurden gewählt, um zu überprüfen, ob die ORFs YDR360W und YDR359C eventuell nur zu einem bestimmten Zeitpunkt in der Zelle transkribiert werden oder konstitutiv aktiv sind. Die eingesetzten Sonden entsprachen der gesamten YDR360W-, bzw. der YDR359C-DNA, die sich überlappten und somit jeweils beide Transkripte detektieren sollten (Abb.14A). Abb.14B und $C$ zeigen, dass in ydr3604-und eaf1 $\Delta$-Zellen keine mRNA nachweisbar war, während in YDR360W-überexprimierenden Zellen mehrere Banden zu sehen sind. Sowohl in logarithmisch wachsenden, wie in gehungerten Zellen war ein schwaches Signal auf Höhe der 26S rRNA zu detektieren (Abb.14B). Dieses konnte in Northern Blot-Analysen mit überexprimiertem Eaf1-Protein dem YDR359CTranskript zugeordnet werden (Abb.14C). Nach Überexpression von YDR360W (Abb.14B) konnten keine der Signale unterhalb der $18 S$ rRNA eindeutig der YDR360W-mRNA zugeordnet werden, da diese ebenso nach Überexpression des Proteins Eaf1 detektiert wurden. Dieses Ergebnis wurde 2006 durch eine genomweite Transkriptionsanalyse, unter Anwendung eines „tiling arrays“ (Affimetrix) bestehend aus ca. 6.5 Millionen Oligonukleotiden beider Stränge und einer Überlappung um jeweils 17 Nukleotiden, unterstützt. (Huber et al., 2006; www.ebi.ac.uk/huber-srv/queryGene). In dieser Studie konnte die Transkription von YDR360W in exponetiell wachsenden Zellen ebenfalls nicht gezeigt werden 
(Abb.15). Somit ist davon auszugehen, es sich bei YDR360W mit hoher Wahrscheinlichkeit um einen nicht-proteinkodierenden ORF handelt.

A

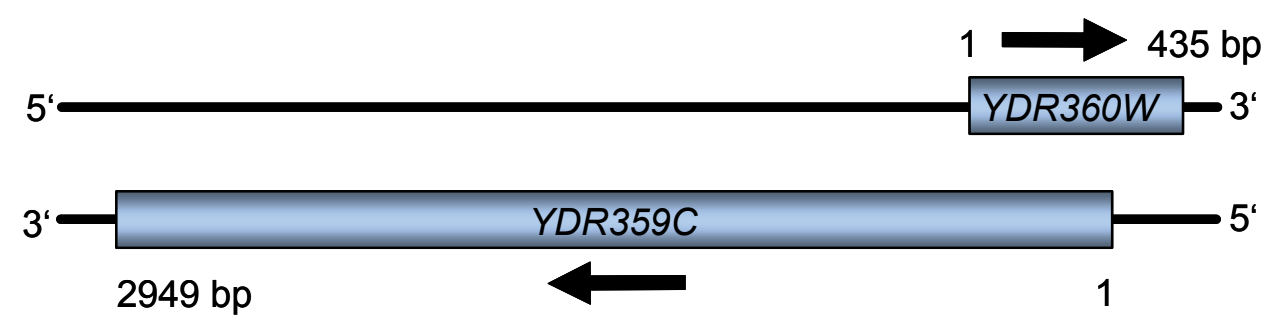

B

C

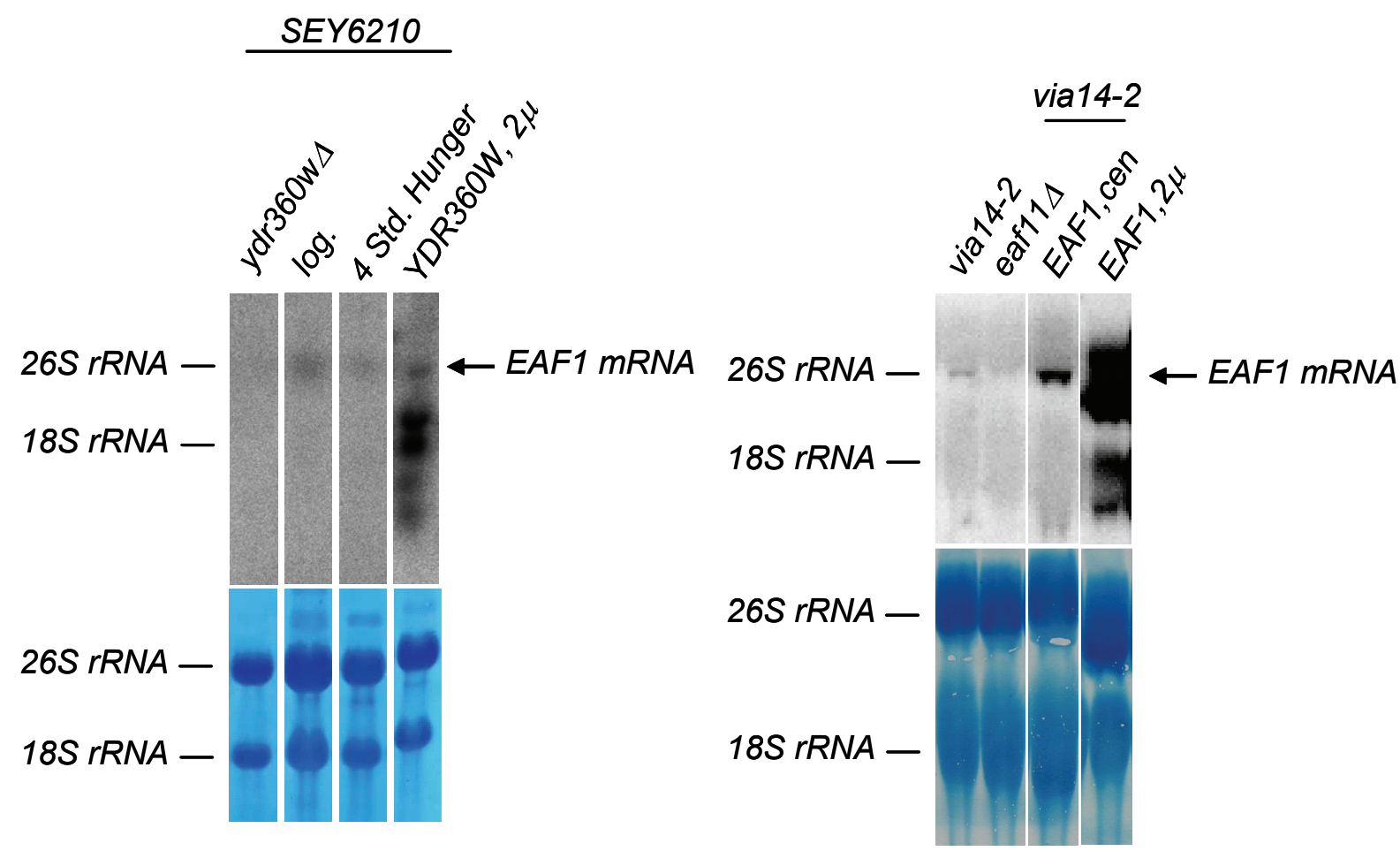

Abb.14: Northern Blot-Analysen zur Überprüfung der Transkiption der ORFs YDR360W und YDR359C.

A Schematische Darstellung der ORFs YDR360W und YDR359C auf Chromosom IV des Hefegenoms. Die Pfeilrichtungen geben die Leserichtung auf Transkriptionsebene an. B Northern Blot-Analyse mit logarithmisch wachsenden $\left(\mathrm{OD}_{600} 1\right)$ und für vier Stunden in Stickstoffmangelmedium gehungerten Zellen. Es wurden $10 \mu \mathrm{g}$ Gesamt-RNA auf eine Nylonmembran transferiert. Die Membran wurde mit einer ${ }^{32} \mathrm{P}$-markierten Sonde des ORFs YDR360W hybridisiert. Die einzelnen Spuren stammten von einer Membran und wurden lediglich in eine gewünschte Reihenfolge gebracht. C Northern Blot-Analyse mit logarithmisch wachsenden Zellen $\left(\mathrm{OD}_{600} 1\right)$. Die ${ }^{32} \mathrm{P}$-markierte Sonde entsprach dem ORF YDR359C (EAF1). Alle Spuren stammten von einer Membran. Die mit Methylenblau gefärbte Nylonmembran zeigt, dass jeweils gleiche Mengen zu $15 \mu \mathrm{g}$ Gesamt-RNA pro Spur aufgetragen wurden. 


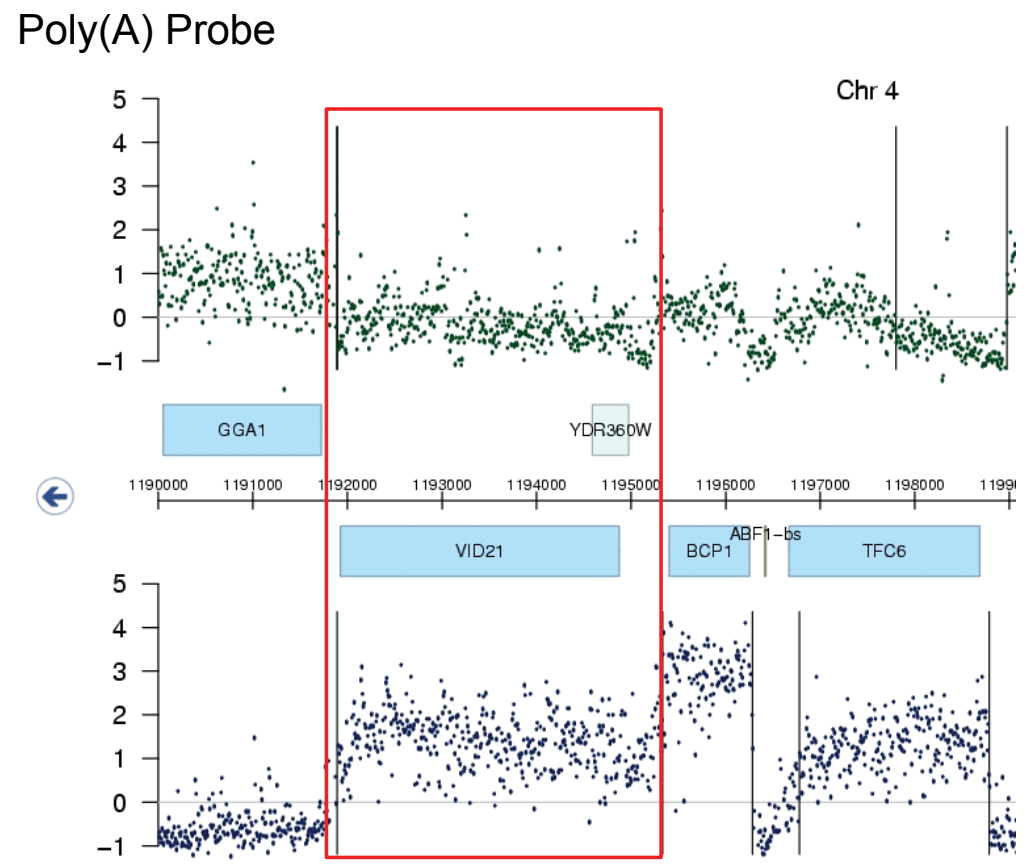

Abb.15: „Tiling array“ in S. cerevisiae.

Die Y-Achse entspricht der Hybridisierungsintensität der cDNA aus poly(A) RNA und die X-Achse den genomischen Koordinaten. Jeder Punkt deckt sich mit einem Oligonukleotid. Der Watson-Strang ist in grün und der Crick-Strang in blau dargestellt. Annotierte ORFs sind mit blauen, fragwürdige ORFs in hellblauen Boxen unterlegt. Die vertikale Linie verweist auf die einzelnen Segmentgrenzen, während die horizontale Linie den Schwellenwert des Hintergrunds anzeigt (Abbildung abgeändert nach www.ebi.ac.uk/huber-srv/queryGene).

\subsection{Analyse des ORFs YDR359C}

Der gefundene Plasmidabschnitt enthielt den zweiten ORF YDR359C nicht komplett, sondern nur 862 bp des Aminoterminus' des 2949 bp großen Proteins, sowie 446 bp der 5'-UTR (untranslated region). Dieser ORF ist verifiziert und kodiert für das nicht essentielle Protein Eaf1 (Esa1-associated factor). Eaf1 ist Teil des HistonAcetyltransferase-Komplexes NuA4 (nucleosome acetyltransferase of $\mathrm{H4}$; Krogan et al., 2004) mit der katalytischen Untereinheit Esa1. In der Literatur wird das Protein auch als Vid21 (vacuole import and degradation) bezeichnet. 


\subsubsection{Der Einfluss des ORFs YDR359C auf die Aktivität der Aminopeptidase 1}

Um zu testen, inwieweit die Eaf1-Proteinexpression die Aktivität der Ape1 beeinflusst, wurde EAF1 zur Markierung mit C-terminalem HA-,tag“ in das pYXVektor-System kloniert. Dazu wurde der Locus YDR359C mittels Polymerasekettenreaktion aus der WT-cDNA amplifiziert und nach Restriktionsenzymverdau mit den Enzymen EcoR I und Hind III in die Vektoren pYX141 und pYX242, bzw. pYX132 kloniert. Diese Konstrukte wurden in die Stämme via10-2 und via14-2 transformiert und in Ape1-Overlay-Assays getestet. Abb.16 zeigt, dass die Expression von Eaf1 den Ape1-Aktivitätsverlust im Stamm via14-2 wiederherstellen konnte. Dabei erreichte die Expression des cen-Plasmids ca. 80\% der Aktivität des $2 \mu$-Plasmids. Die Expression des Proteins im Stamm via10-2 hatte keinen Einfluss auf die Ape1-Aktivität.

Somit konnte gezeigt werden, dass nicht YDR360W, sondern der auf dem CrickStrang liegende ORF YDR359C an der Aktivierung der Aminopeptidase 1 beteiligt ist.

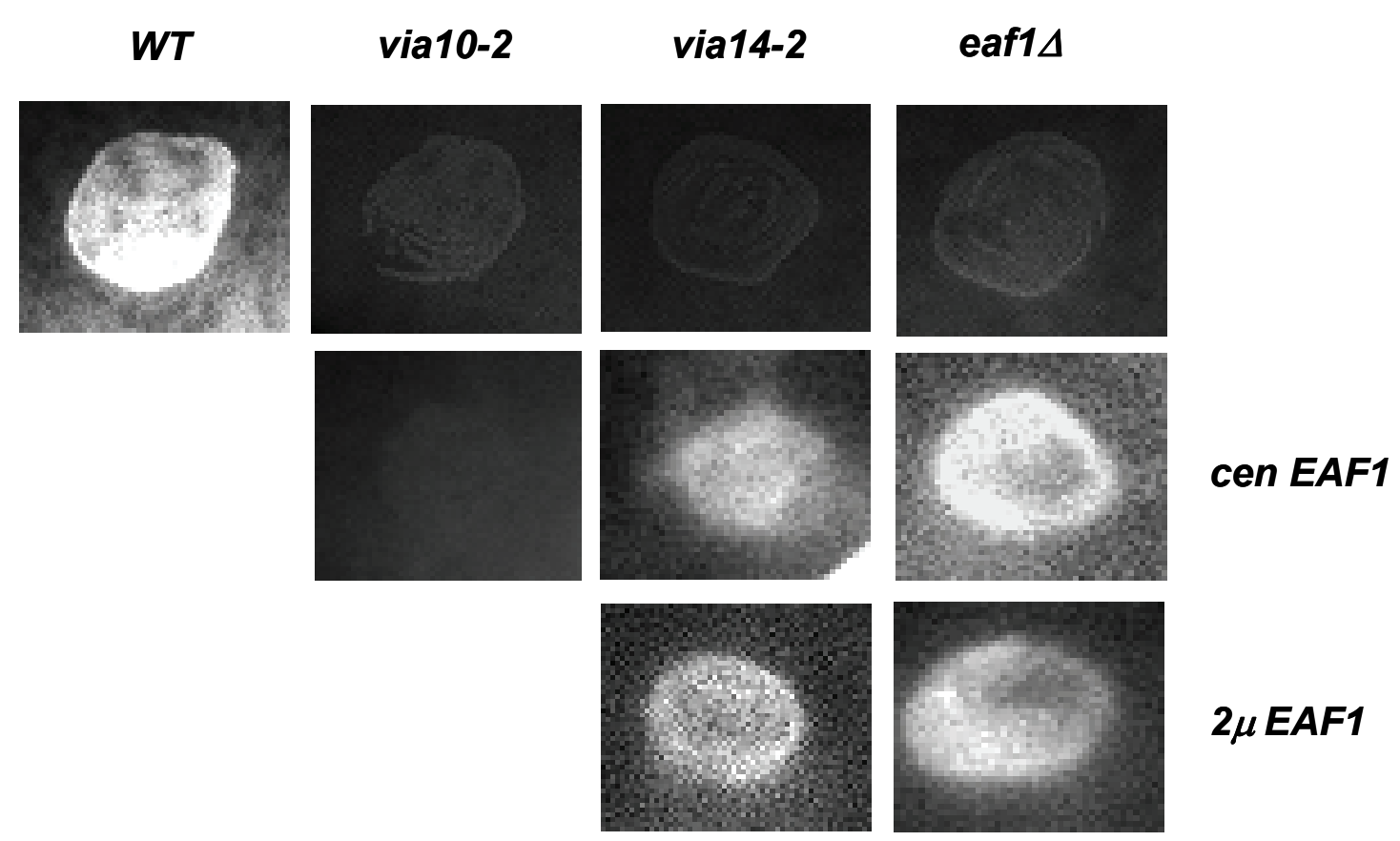

Abb.16: Der Einfluss von Eaf1 auf die Aktivität der Aminopeptidase.

Einzelkolonien der Stämme WT (y96), via10-2 (y43), via14-2 (y46) und eaf1A (y126) wurden auf Vollmediumplatten ausgestrichen. Die Ape1-Aktivität der Stämme via10-2 transf. mit $p Y X 132-$ YDR359C (y234), via14-2 transf. mit $p Y X 141-Y D R 359 C$ (y158), via14-2 transf. mit $p Y X 242-Y D R 359 C$ (y159), eaf14 transf. mit $p Y X 141-Y D R 359 C$ (y170) und eaf1 4 transf. mit $p Y X 242-Y D R 359 C$ (y172) wurde durch Spaltung des Substrats H-Leucin- $\beta$-Naphtylamid photometrisch bei $365 \mathrm{~nm}$ verfolgt. 


\subsubsection{Herstellung von eaf1-Deletionsstämmen}

Um den Aktivierungseffekt von Eaf1 besser zu verstehen, wurde der ORF YDR359C einzeln und zusammen mit ORF YDR360W mittels homologer Rekombination des HIS3-Markergens deletiert. Das Schizosaccharomyces pombe HIS3-Homolog HIS5 ${ }^{+}$ (Erickson und Hannig, 1995) wurde mit 45 bp komplementären 5'- und 3'-Enden der genomischen DNA der ORFs YDR359C, bzw. YDR360W aus dem Plasmid pFA6aHIS3MX6 amplifiziert (Longtine et al., 1998) und in den WT-Stamm (y96) transformiert (3.14.2) (Abb.17). Nach erfolgreicher Integration in das Hefegenom wird der Defekt des his3 31 mutierten Stammes aufgehoben und die Hefen wurden Histidin-prototroph.

Southern Blot-Analysen (3.21) bestätigten die Integration des $\mathrm{HIS5}^{+}$-Gens in den Genlocus YDR359C, bzw. YDR359C und YDR360W. Dazu wurde chromosomale DNA des Wildtypstammes y96 und die der Transformanden mit dem Restriktionsenzym Clal verdaut. Nach erfolgtem Transfer der DNA auf eine Nylonmembran wurde diese entweder mit einem ${ }^{32} \mathrm{P}$-markierten DNA-Fragment des YDR360W- oder des YDR359C-Gens, bzw. HIS5 ${ }^{+}$-Gens hybridisiert. Mit radioaktiv markierten Sonden für das YDR360W- oder das YDR359C-Gen waren im WTStamm eine 1606 bp Bande nachweisbar, die in den Deletionsstämmen fehlte. Umgekehrt lieferte die HIS3-Sonde nur in den integrierten Stämmen ein Signal mit der Größe von 917 bp (Deletion der Loci YDR359C und -360W), bzw. 1063 bp (Deletion des Locus YDR359C) (Abb.17). In dieser Arbeit wurde vorwiegend mit y126 gearbeitet; dieser Stamm wurde zur Vereinfachung mit eaf1 $\triangle$ bezeichnet.

Zur Bestimmung der Ape1-Aktivität wurden Ape1-Overlay-Assays durchgeführt, in denen sowohl die Stämme y206 und 207, als auch eaf1 $\Delta$ eine vollständige Inaktivierung zeigten. In EAF1-Transformanden konnte die Expression des Proteins den Aktivitätsverlust des eaf14-Stammes komplementieren (Abb.16). EAF1 ist kein essentielles Gen, seine Deletion führte allerdings zu einem stark reduzierten Wachstum bei $30^{\circ} \mathrm{C}$ und einem Ausbleiben dessen bei $37^{\circ} \mathrm{C}$. Auch die Mutanten via10-2 und via14-2 konnten bei $37^{\circ} \mathrm{C}$ nicht mehr anwachsen, wobei die Duplikationsrate des Stammes via $10-2$ bei $30^{\circ} \mathrm{C}$ der des WT-Stammes stark ähnelte. Via14-2 zeigte wie eaf1 $\Delta$ eine verlangsamte Anfangsphase nach Überimpfen der in G1-Phase arretierten, stationären Übernachtkultur, erreichte allerdings dieselbe Dichte wie der WT-Stamm (Abb.18). 
A

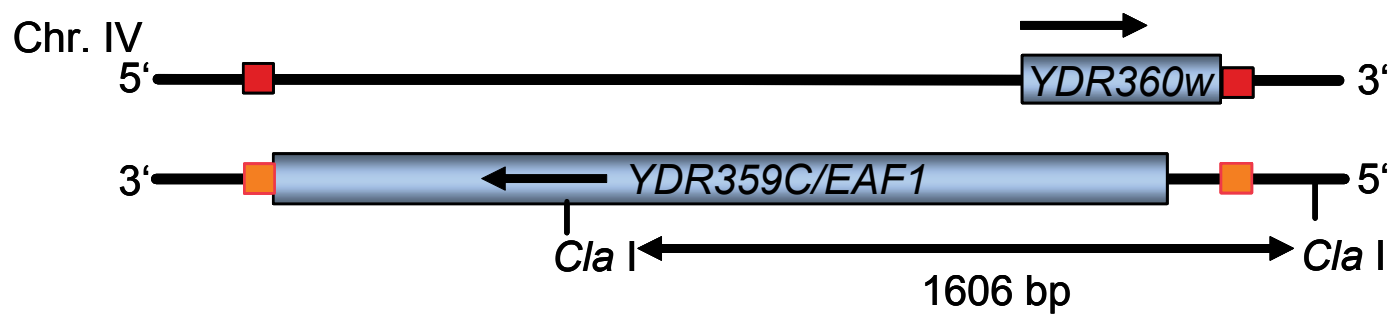

Homologe Rekombination

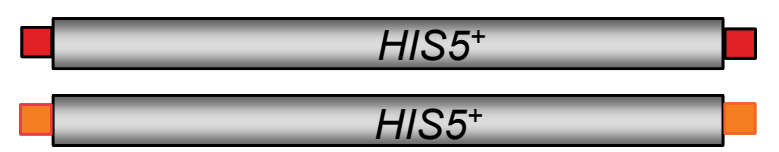

PCR Fragment

Chr. IV

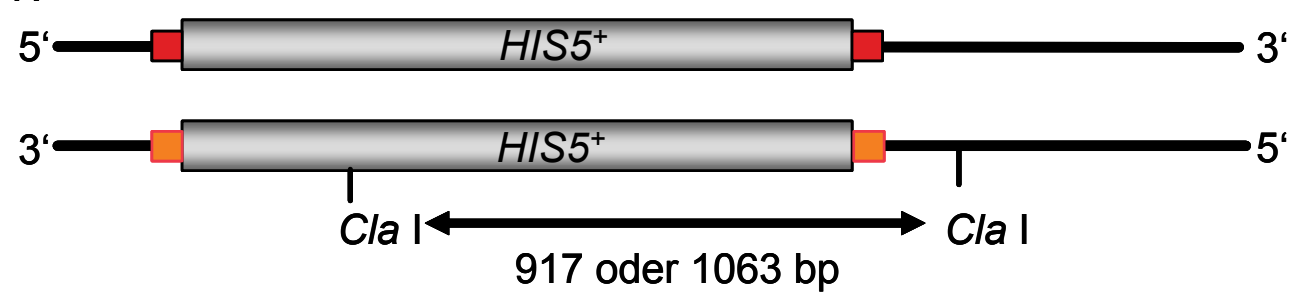

B

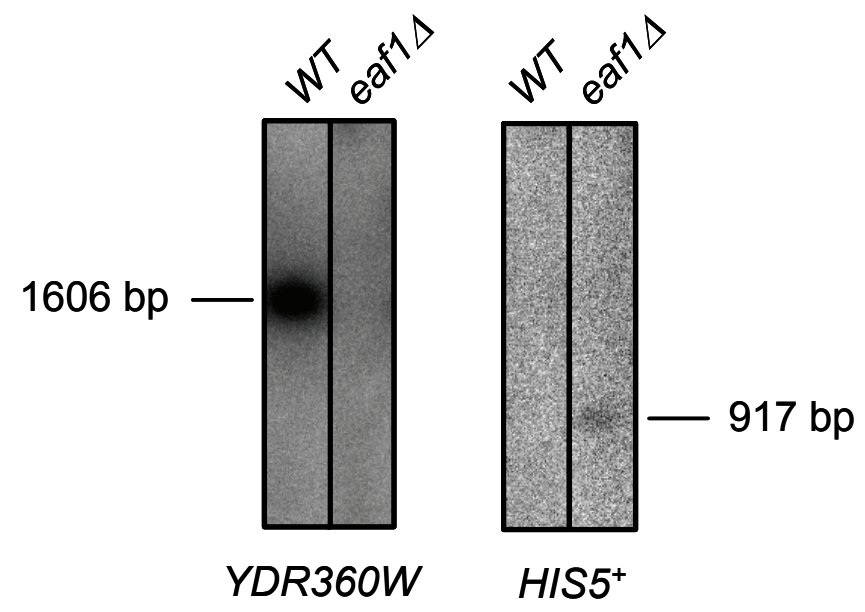

\section{Abb.17: Herstellung der Deletionsstämme eaf1 $\triangle$.}

A $\mathrm{HIS}^{+}$wurde mit 45 bp komplementären Überhängen (rot und orange) zur genomischen DNA am 5'und 3'-Ende der ORFs YDR359C und YDR360W aus dem Plasmid pFA6a-HIS3MX6 amplifiziert. Durch homologe Rekombination integrierte das PCR-Fragment in den Genlocus des Chromosoms IV. B Southern Blot-Analyse zum Nachweis der eaf1-Deletion. Genomische DNA der Stämme WT (y96) und eaf1A (y126) wurde mit dem Restriktionsenzym Cla I verdaut. Die Hybridisierung der Nylonmembran erfolgte mit einem ${ }^{32} \mathrm{P}$-markiertem DNA-Fragment des Gens YDR360W, bzw. HIS5 ${ }^{+}$. 
A
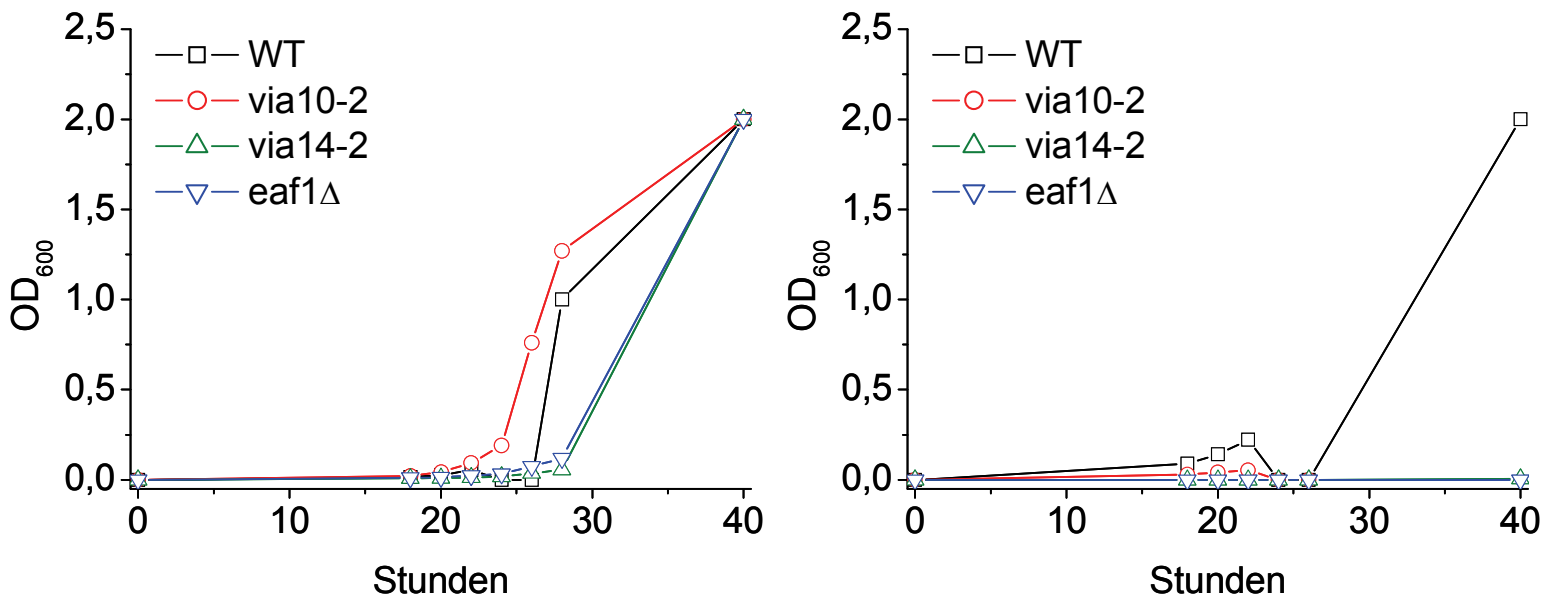

B
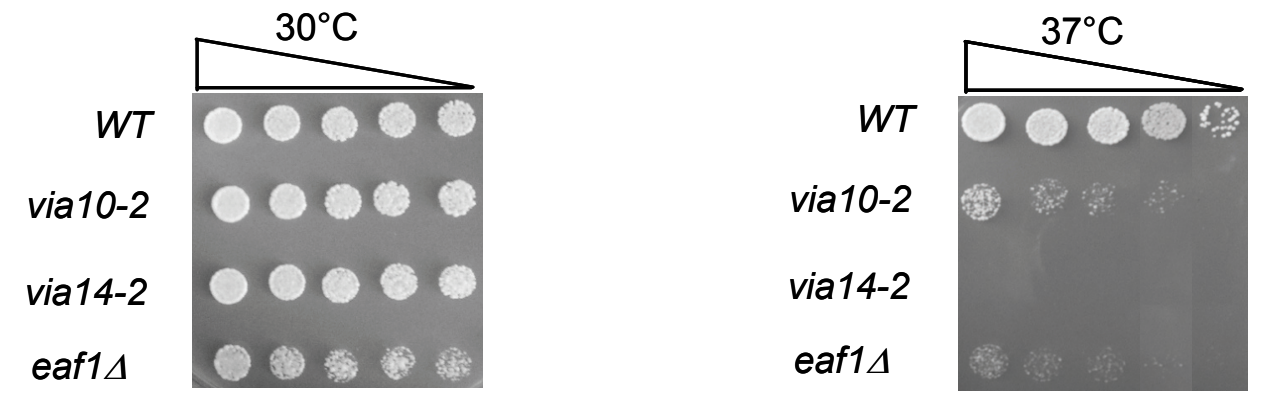

Abb.18: Wachstum der Stämme WT-, via10-2-, via14-2- und eaf1 $\triangle$ bei $30^{\circ} \mathrm{C}$ und $37^{\circ} \mathrm{C}$.

A Stationäre Übernachtkulturen wurden $1: 1000$ in Vollmedium überimpft und 40 Stunden bei $30^{\circ} \mathrm{C}$, bzw. $37^{\circ} \mathrm{C}$ schüttelnd inkubiert. B Stationäre Übernachtkulturen wurden auf eine $\mathrm{OD}_{600}$ von 0.1 in $\mathrm{dH}_{2} \mathrm{O}$ verdünnt, daraus wurde eine fünffach fortlaufende Verdünnung hergestellt, wobei jeweils $5 \mu \mathrm{l}$ Zellsuspension auf den Vollmediumplatten aufgebracht wurden. Die Platten wurden zwei Tage bei $30^{\circ} \mathrm{C}$, bzw. vier Tage bei $37^{\circ} \mathrm{C}$ inkubiert. 


\subsection{Charakterisierung von EAF1 in den Mutantenstämmen}

Wie in Abbildung 16 gezeigt, stellt die Expression von Eaf1 die Aktivität der Aminopeptidase 1 in dem Mutantenstamm via14-2 und Deletionsstamm eaf1 $\Delta$ wieder her. Um zu untersuchen, ob Eaf1 die Ursache des Aktivitätsverlustes der beiden Mutanten ist, wurden die Mutantenstämme via10-2 und via14-2 bezüglich der Expression dieses Genlocus' näher analysiert.

Da kein Antikörper für endogenes Eaf1 zur Verfügung stand, konnte die Expression des Proteins nicht in Western Blot-Analysen nachgewiesen werden. Um Mutationen und ein damit verbundenes Ausbleiben der Expression zu überprüfen, wurde der YDR359C-Locus des WT-, via10-2- und via14-2-Stammes sequenziert. Dazu wurde ihre genomische DNA mit dem Restriktionsenzym Hind III verdaut, um anschließend aus den Genfragmenten, EAF1, inklusive 508 bp der 5'- und 168 bp der 3'-UTR zu amplifizieren. Die Sequenzierung zeigte, dass die Mutantenstämme in dem 3625 bp großen Fragment zwar eine Insertion eines Cytidins an Position -78 vor dem Startcodon aufwiesen, ansonsten aber nicht mutiert waren und deshalb transkribiert werden sollten. Da die zusätzliche Base auch im WT-Stamm vorhanden war, ist davon auszugehen, dass dies keinen Einfluss auf den beobachteten Rückgang der Ape1-Aktivität hatte und entweder stammesspezifisch oder auf einen falschen Eintrag in der veröffentlichten Genomsequenz zurückzuführen ist.

Eine bekannte Funktion von Eaf1 ist seine Beteiligung an der Hyperacetylierung des Histons $\mathrm{H} 4$, d.h. in eaf14-Stämmen ist hyperacetyliertes $\mathrm{H} 4$ kaum mehr nachweisbar (Krogan et al., 2004). Um die Mutanten in Hinblick auf diese beschriebene Funktion hin zu untersuchen, wurden aus den WT-, via10-2-, via14-2- und eaf14-Stämmen Proteinextrakte hergestellt (3.19.3). Nach Auftrennung über ein 15\%-iges Polyacrylamidgel wurden die Proteine auf eine PVDF-Membran im Nassblotverfahren transferiert und mit einem Antikörper gegen hyperacetyliertes Histon H4 für eine Stunde in TBS/Tween inkubiert. Die Detektion der gebundenen Antikörper erfolgt mit einem anti-Kaninchen HRP-konjugiertem Zweitantikörper ebenfalls in TBS/Tween. Wie in Abbildung 19 dargestellt, war die Hyperacetylierung des Histons $\mathrm{H} 4$ in den Mutantenstämmen gegenüber dem Wildtypstamm unverändert deutlich, währenddessen sie im eaf1-Deletionsstamm stark reduziert war. Abhängig von der Expressionsstärke von Eaf1 (cen oder $2 \mu$ ) konnte zunehmend hyperacetyliertes $\mathrm{H} 4$ in dem eaf1 1 -Stamm nachgewiesen werden. 


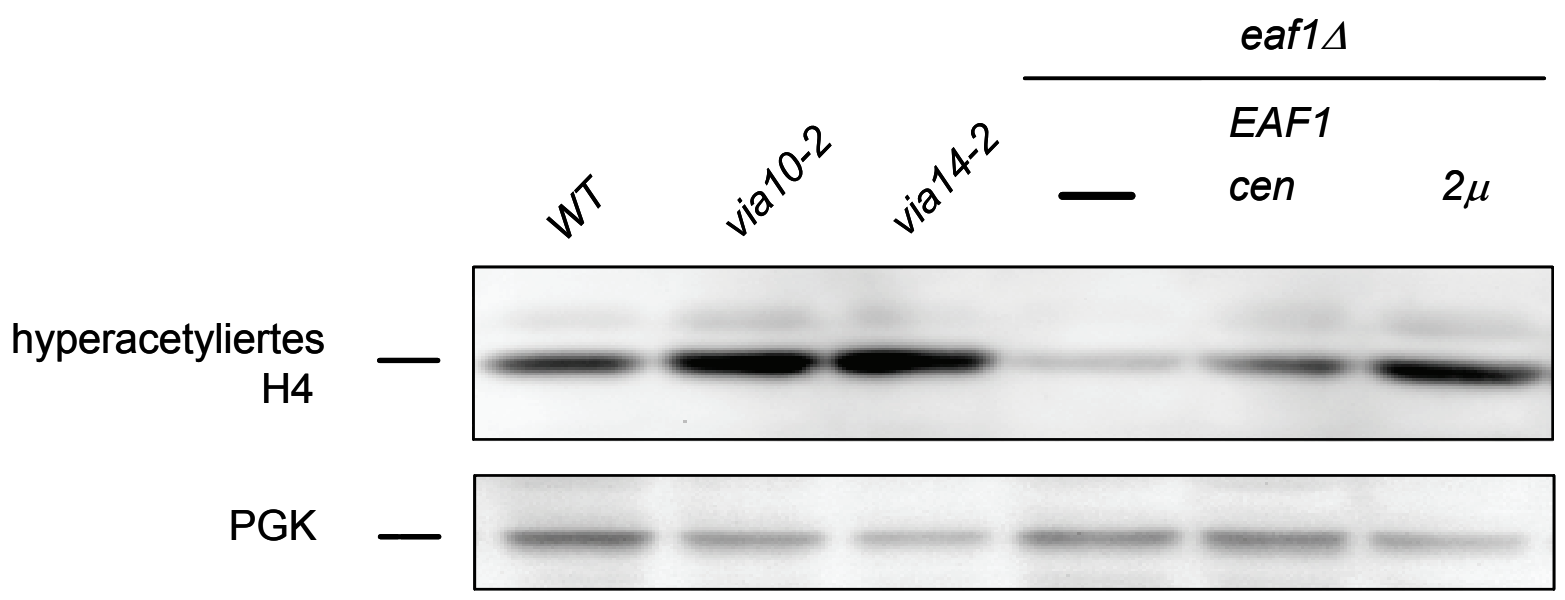

Abb.19: Western Blot-Analyse zur Bestimmung von hyperacetylierten Histon H4.

Ganzzellproteinextrakte aus $W T$, via10-2, via14-2, eaf1A, eaf1 1 transf. mit $p Y X 141-E A F 1$ (y170) und eaf1 $\triangle$ transf. mit $p Y X 242-E A F 1$ (y172) wurden über ein 15\%-iges Polyacrylamidgel separiert und auf eine PVDF-Membran transferiert. Die Membran wurde mit anti-hyperacetylierten H4 Penta Antikörper und anti-PGK als Ladekontrolle inkubiert.

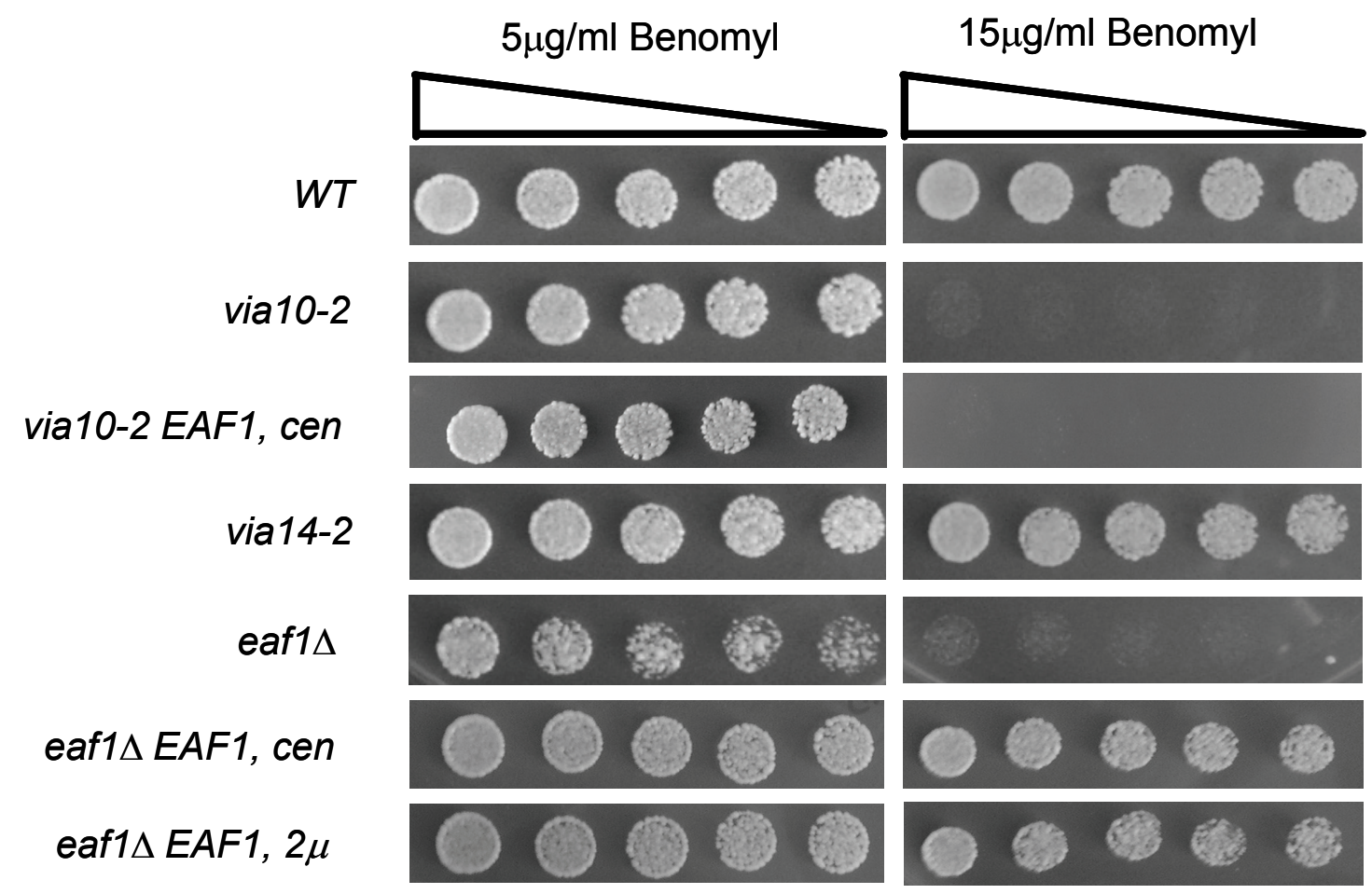

Abb.20: Einfluss von Benomyl auf das Wachstum von WT-, Deletions- und Mutantenstämmen.

Übernachtkulturen der Stämme WT (y96), via10-2 (y43), via10-2 transf. mit pYX141-EAF1 (y156), via14-2 (y46), eaf1 $(\mathrm{y} 126)$, eaf1 $\Delta$ transf. mit $p Y X 141-E A F 1$ (y170), eaf1 $\Delta$ transf. mit $p Y X 242-E A F 1$ (y172) wurden mit $\mathrm{dH}_{2} \mathrm{O}$ auf eine Anfangs- $-\mathrm{OD}_{600}$ von 0.1 verdünnt. Daraus wurde eine fünffach fortlaufende Verdünnung hergestellt, wobei jeweils $5 \mu$ Zellsuspension auf den mit 5 , bzw. $15 \mu \mathrm{g} / \mathrm{ml}$ Benomyl behandelten Vollmediumplatten ausgebracht wurden. Die Platten wurden zwei Tage bei $30^{\circ} \mathrm{C}$ inkubiert. 
Um den Stamm eaf1 $\Delta$ und die zwei Mutanten via10-2 und via14-2 auf einen Defekt in Kinetochor- und Spindel-Kontrollpunkt hin zu untersuchen, wurde ihr Wachstumsverhalten auf Medium mit der Mikrotubuli destabilisierenden Chemikalie Benomyl (Kobor et al., 2004) bestimmt. Dazu wurden die Hefestämme zusammen mit dem WT auf 5, bzw. $15 \mu \mathrm{g} / \mathrm{ml}$ Benomyl enthaltende Vollmediumplatten ausplattiert.

Auf das Wachstumsverhalten des WTs- und via14-2-Stammes zeigte die Chemikalie keinen Einfluss. Die Stämme via10-2 und eaf1 $\Delta$ hingegen zeigten bei einer Konzentration von $5 \mu \mathrm{g} / \mathrm{ml}$ einen leichten Wachstumsdefekt, und konnten bei einer Konzentration von $15 \mu \mathrm{g} / \mathrm{ml}$ nicht mehr anwachsen, was auf einen Defekt der Mikrotubuli hindeutet. Durch Transformation von EAF1 konnte dieser Effekt im Deletionsstamm komplementiert werden, wohingegen die Expression von Eaf1 das Wachstumsverhalten der Mutante via10-2 nicht beeinflusste (Abb.20).

Die Sequenzierung des ORFs YDR359C, Western Blot-Analysen zum Nachweis des hyperacetylierten $\mathrm{H} 4$ und das Wachstum auf Benomyl bestätigten, dass Eaf1 als funktionelles Protein in beiden via-Mutantenstämmen vorlag. 


\subsection{Charakterisierung des Gens EAF1}

\subsubsection{Herstellung von EAF1-Konstrukten}

Der ORF YDR359C (EAF1, VID21) kodiert mit seinen 2949 bp für ein 982 Aminosäure großes Protein mit einem errechneten Molekulargewicht von 112 kDa. Eaf1 ist eine von dreizehn Untereinheiten des Histon-Acetyltransferase-Komplexes NuA4 (nucleosome acetyltransferase of H4) (Krogan et al., 2004). Das Protein besitzt zwei Domänen, eine HSA- (Helicase/SANT-Associated) und eine SANT(Swi3-Ada2-NCoR-TFIIIB) Domäne und C-terminal eine Glutamin (Q)-reiche Region (Doyon und Côté, 2004). Die HSA-Domäne liegt zwischen den Aminosäuren (As) 347 und 418 und entspricht einer potentiellen DNA-Binderegion (Szerlong et al., 2008). SANT-Domänen kommen in einer Vielzahl von Chromatin-Komplexen vor und erkennen die DNA-Sequenz YAAC(G/T)G (Aasland et al., 1996). In Eaf1 liegt dieses Motiv zwischen den Aminosäuren 646 bis 706. Die Funktion der C-terminalen Glutamin-reichen Region ist noch unbekannt. Ihre Deletion zeigt keinen Phänotyp und hat keinerlei Effekt auf die Assemblierung des NuA4-Komplexes (Auger et al., 2008). Eaf1 ist im Kern lokalisiert, ein potentielles Kernlokalisationssignal (NLS; nuclear localization sequence) KKKLK liegt um Aminosäure 100.

Um die Funktion von Eaf1, vor allem in Hinblick auf die Wiederherstellung der Aminopeptidase 1-Aktivität durch das Protein näher zu untersuchen, wurden Verkürzungen hergestellt. Das aminoterminale Fragment des Proteins (1-862 bp) entspricht dem im Komplementationsanalyse gefundenen Genabschnitt (Abb.7). Diese Verkürzung sollte demnach Ape1-Aktivität in dem Stamm via14-2 induzieren können. Ein bis Aminosäure 283 C-terminal verkürztes Fragment enthält alle bekannten Domänen des Proteins (Abb.21). Die Verkürzungen wurden mittels Polymerasekettenreaktion aus dem Konstrukt $p Y X 141-E A F 1$ amplifiziert, mit den Restriktionsenzymen EcoR I und Hind III verdaut und in die Hefevektoren $p Y X 141$, pYX142 und pYX242 kloniert. Zusätzlich wurde die potentielle NLS KKKLK an Position 100 mutiert. Dazu wurden zwei PCRs durchgeführt. Die amplifizierten Fragmente überlappen und sind in ihrer potentiellen NLS-Sequenz mutiert. Beide PCR-Produkte wurden isoliert und für eine neue PCR mit den endständigen 5'- und 3'-Primern eingesetzt. 

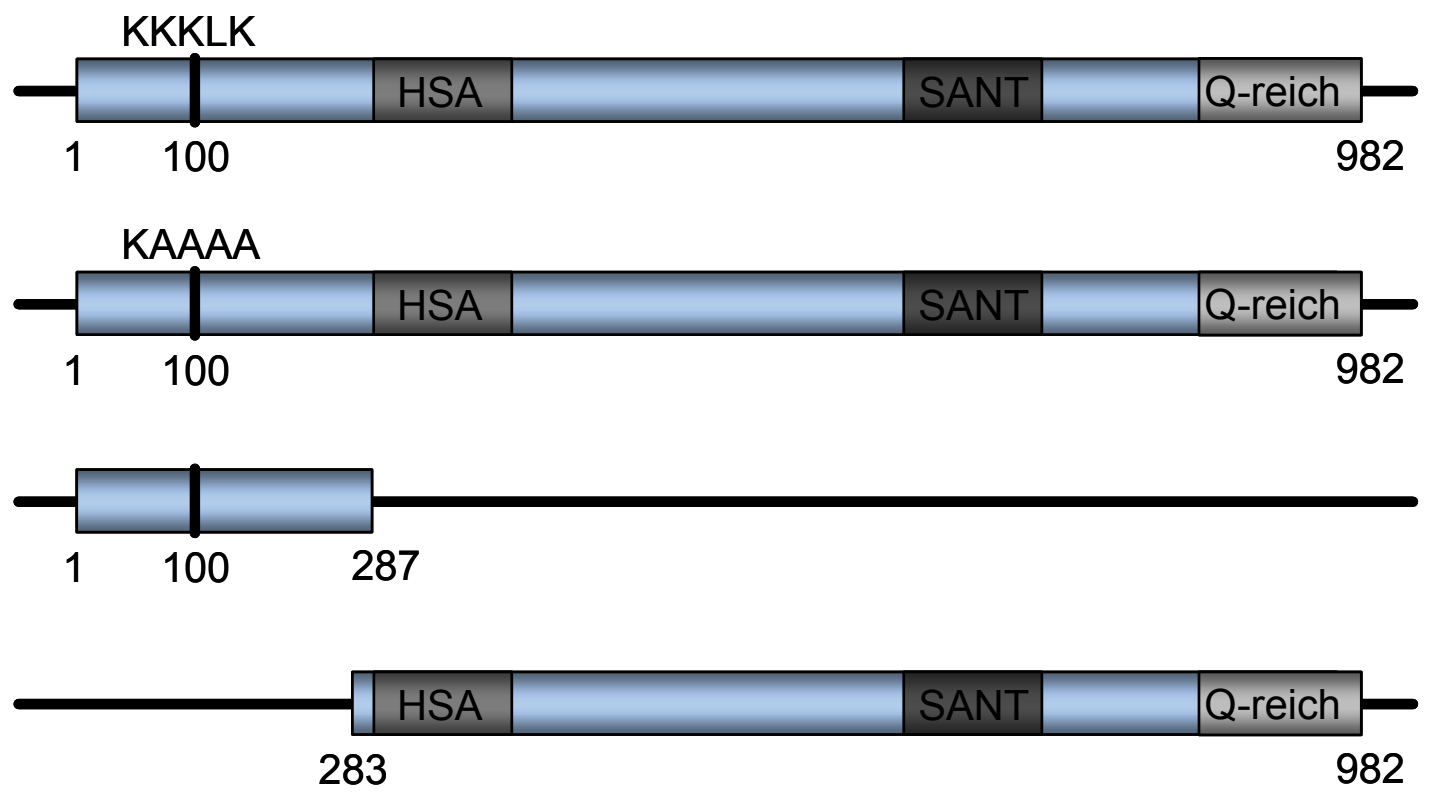

\section{Abb.21: Schematische Darstellung von Eaf1 mit klonierten Verkürzungen.}

Eaf1 besitzt die DNA-bindenden Domänen HSA (As 347-418) und SANT (As 646-706) und eine Glutamin (Q)-reiche Region am C-Terminus. Das potentielle Kernlokalisationssignal KKKLK an Aminosäureposition 100 wurde zu KAAAA mutiert. Es wurden zwei Verkürzungen des Proteins in die Hefevektoren $p Y X 141$ und $p Y X 242$ kloniert: EAF1 1-862 bp (Aminosäuren 1 bis 287), und EAF1 8472946 bp (Aminosäuren 283-982).

\subsubsection{Der Einfluss von EAF1-Verkürzungen auf die Aktivität der Ape1}

Um nun die Funktion von Eaf1 in der Wiederherstellung der Aminopeptidase 1Aktivität zu charakterisieren, wurden die in Abb.21 beschriebenen EAF1-Konstrukte in den Stamm eaf1 $\triangle$ transformiert und in Ape1-Overlay-Assays untersucht. Als Referenzstämme wurden eaf1 $\Delta$ transformiert mit $p Y X 141-E A F 1$, bzw. $p Y X 242-E A F 1$ und eaf1 $\triangle$ transformiert mit Leervektor $p Y X 141$, bzw. $p Y X 242$ auf jeder Platte neben den zu testenden Stämmen ausgestrichen. Somit konnten innerhalb einer Platte die jeweilige Aktivität der getesteten Hefen semi-quantitativ bestimmt werden (Abb.22). Wie bereits erwähnt (4.5.1), sollte die Verkürzung EAF1 1-862 bp in der Lage sein Ape1-Aktivität zu induzieren. Mit dem cen-Konstrukt konnte eine 20\%-ige Aktivität im Vergleich zum vollständigen Protein nachgewiesen werden, mit höherer Expressionsrate $(2 \mu)$ stieg diese Aktivität auf $60 \%$ an. Die N-terminale Verkürzung (847-2946 bp) war geringfügig aktiver, hier entsprach die messbare Ape1-Aktivität bereits bei geringer Expressionsrate (cen) $60 \%$ der Gesamtprotein-Kontrolle. Die 
Mutation des potentiellen Kernlokalisationssignals an Aminosäureposition 100 zeigte gegenüber dem WT-Stamm eine unveränderte Aktivität.

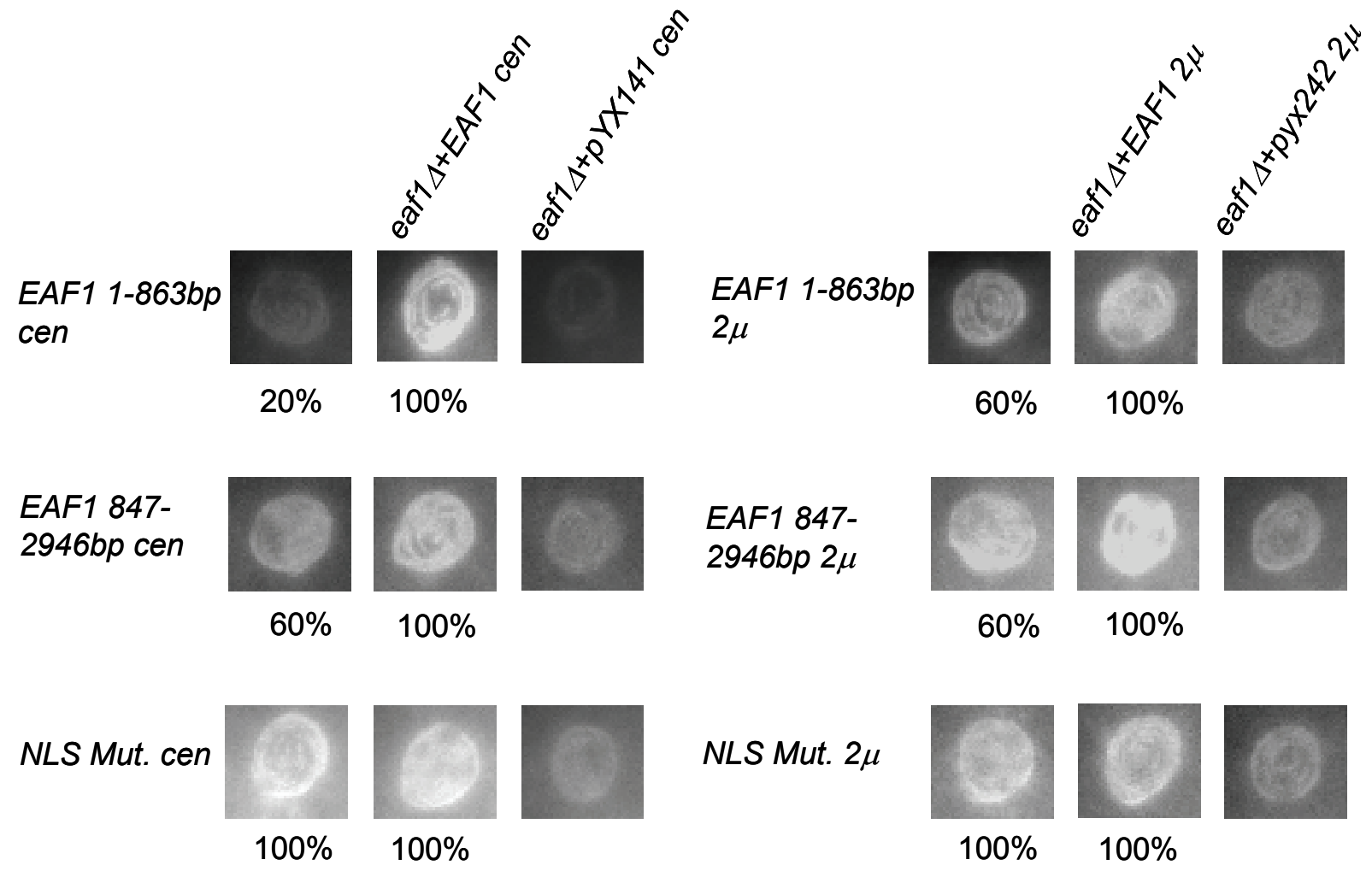

\section{Abb.22: Aminopeptidase 1-Aktivitätsbestimmung in EAF1 transformierten Hefen.}

Aminopeptidase 1-Aktivität wurde durch Spaltung des Substrats H-Leucin- $\beta$-Naphtylamid bei folgenden Stämmen bestimmt und mit den Referenzstämmen eaf1 $\Delta$ transf. mit $p Y X 141-E A F 1$ (y170), bzw. pYX242-EAF1 (y172) als Positivkontrolle und eaf1 4 transf. mit $p Y X 141$ (y162), bzw. $p Y X 242$ (y164) als Negativkontrolle verglichen: eaf1 $\Delta$ transf. mit $p Y X 141-E A F 1$ 1-862 bp (y189); eaf1 4 transf. mit $p Y X 242-E A F 1$ 1-862 bp (y191); eaf1 4 transf. mit pYX141-EAF1 847-2946 bp (y193); eaf1 $\Delta$ transf. mit $p Y X 242-E A F 1$ 847-2946 bp (y195); eaf14 transf. mit $p Y X 141-E A F 1$ NLS Mutation (y197); eaf1 transf. mit $p Y X 242-E A F 1$ NLS Mutation (y199). 


\subsection{Der Einfluss von Eaf1 auf die Expressions- und Transkriptionsrate der Aminopeptidase 1}

Wie in Ape1-Overlay-Assays gezeigt (Abb.16 und Abb.22) erhöht die Expression von Eaf1 die Aktivität der Aminopeptidase 1. Wie aber beeinflusst ein Protein mit beschriebener Kernlokalisation die Aktivität der zytosolischen, bzw. vakuolären Aminopeptidase 1? Wie bereits erwähnt, ist die Ape1-Proteinexpression in den viaMutanten im Vergleich zum WT-Stamm bis zu 50\% reduziert (Abb.12 und AndreiSelmer et al., 2001). Um nun die Ape1-Expressionsrate des eaf1-Deletionsstammes, sowie den Einfluss der Eaf1-Expression auf die Mutanten- und Deletionsstämme zu bestimmen, wurden jeweils 1 OD Zellen logarithmisch wachsender Hefekulturen durch alkalische Lyse aufgeschlossen und die Ape1-Expression mittels Western BlotAnalysen bestimmt. Um sicher zu stellen, dass während des Zellaufschlusses keine Degradation des Ape1-Proteins stattfand, wurde ein pep44-Stamm (y75) als Kontrolle mitgeführt, in dem eine Mutation der Proteinase A die Reifung der prApe1 verhindert.

Wie in Abb.23 A und C gezeigt, war nach Deletion der ORFs YDR359C und YDR360W (eaf1A) die Expression der Aminopeptidase $1 \mathrm{im}$ Vergleich zum WT Stamm um über 50\% reduziert. Die Transformation des EAF1-Gens in Stamm eaf1 $\triangle$ erhöht diese wieder auf über WT-Niveau. Der Anstieg der Ape1-Expressionsrate durch die Eaf1-Expression war in den Mutantenstämmen via10-2 und via14-2 weniger deutlich ausgeprägt und konnte auch auf mRNA-Ebene mittels Northern Blot-Analysen nicht bestätigt werden.

In bis zur stationären Phase $\left(\mathrm{OD}_{600}>2\right)$ gewachsene Hefekulturen kann aufgrund des Transportes durch Autophagocytose untersucht werden, ob die Prozessierung der Aminopeptidase 1 stattfindet, d.h. die prApe1 zur mApe1 reift (Klionsky et al., 1992). Im Vergleich zum Wildtypstamm C6C zeigten die Mutanten via10 und via14 zwar eine geringfügig erhöhte Akkumulation der prApe1, eine Prozessierung des Proteins fand jedoch statt (Andrei-Selmer et al., 2001). Sowohl die Stämme mit integrierter APE1 (WT, via10-2 und via14-2), als auch die Deletion von EAF1 hatte keinen Einfluss auf den Reifungsprozess, d.h. in stationär gewachsenen Zellen konnte ausschließlich die prozessierte mApe1 nachgewiesen werden (Abb.23A).

Um zu überprüfen, ob Veränderungen der Aminopeptidase 1-Level bereits auf transkriptioneller Ebene stattfinden, oder ob es sich um Unterschiede in der Stabilität 
des Proteins nach seiner Synthese handelt, wurden zunächst Northern Blot-Analysen durchgeführt. Dazu wurde isolierte RNA aus logarithmisch wachsenden Hefekulturen der Stämme $W T$, via10-2, via14-2, eaf1 $\Delta$ und eaf1 $\Delta$ transformiert mit EAF1 oder YDR360W über ein Formaldehydgel elektrophoretisch aufgetrennt und mittels dem Kapillarblotverfahren auf eine Nylonmembran transferiert. Die Membran wurde mit einem ${ }^{32} \mathrm{P}$-markierten APE1-Fragment hybridisiert. Die APE1-mRNA migriert auf Höhe der $18 S$ rRNA, was in Hefe einer Größe von 2000 bp entspricht. Als Kontrolle wurde die RNA eines ape14-Stammes verwendet, bei dem kein Signal sichtbar war. Die Stämme via10-2 und eaf1 $\Delta$ zeigten etwas geringere mRNA-Mengen als der WTStamm. Der Stamm via14-2 war in seiner Transkriptionsrate mit dem WT vergleichbar. Nach Transformation von EAF1 in den Deletionsstamm wurde ein Anstieg der APE1-mRNA beobachtet, während die Transformation von YDR360W keinerlei Einfluss auf die Transkriptionsrate hatte. Somit stand in den via-Mutanten und in den eaf1 1 -Stämmen die Transkription des APE1-Gens in direktem Zusammenhang mit der Ape1-Expression. Ob dies auch mit der bereits beschriebenen Aktivität der Aminopeptidase 1 korrelierte, musste noch geklärt werden (graphisch dargestellt in Abb.23C). 
A

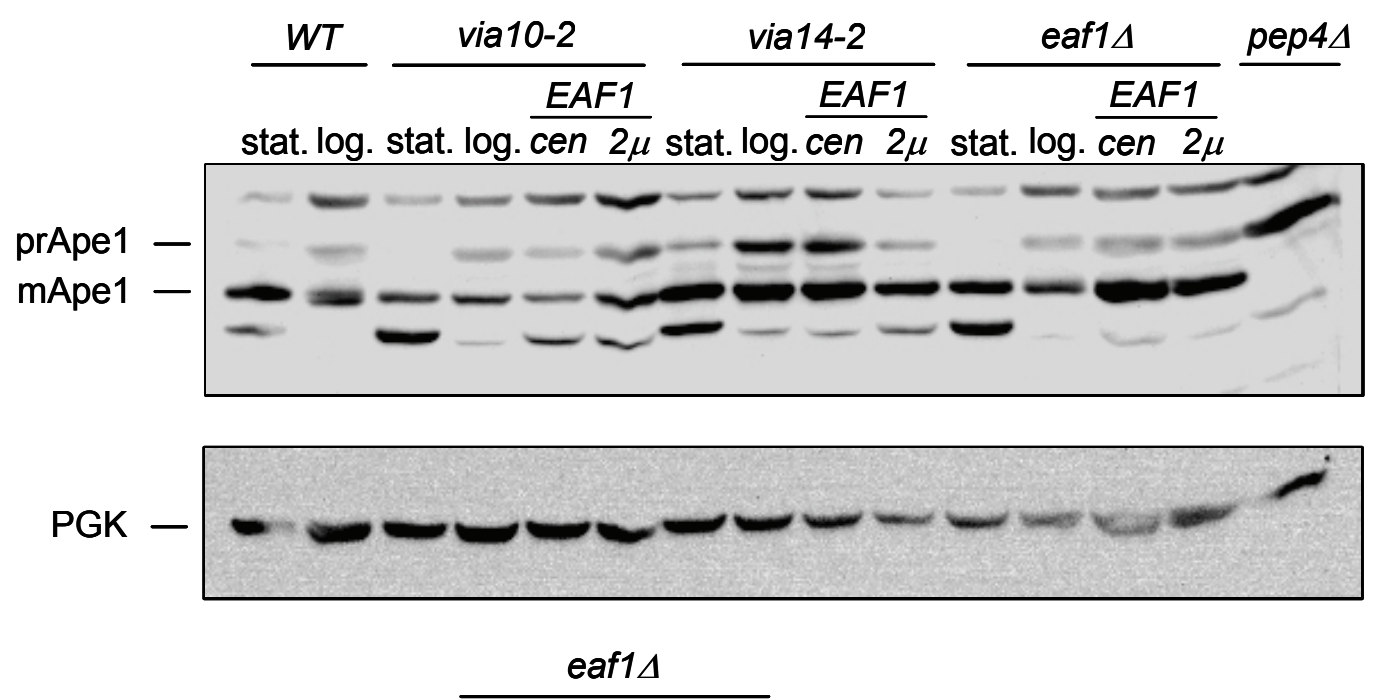

B
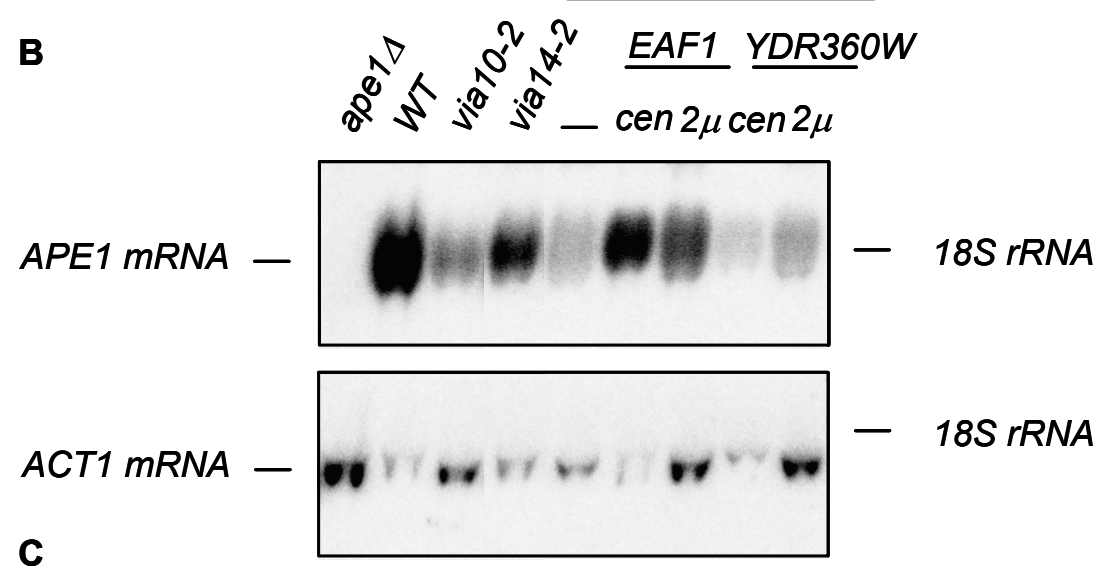

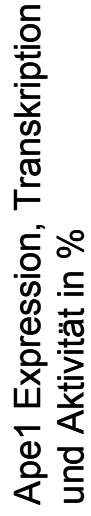

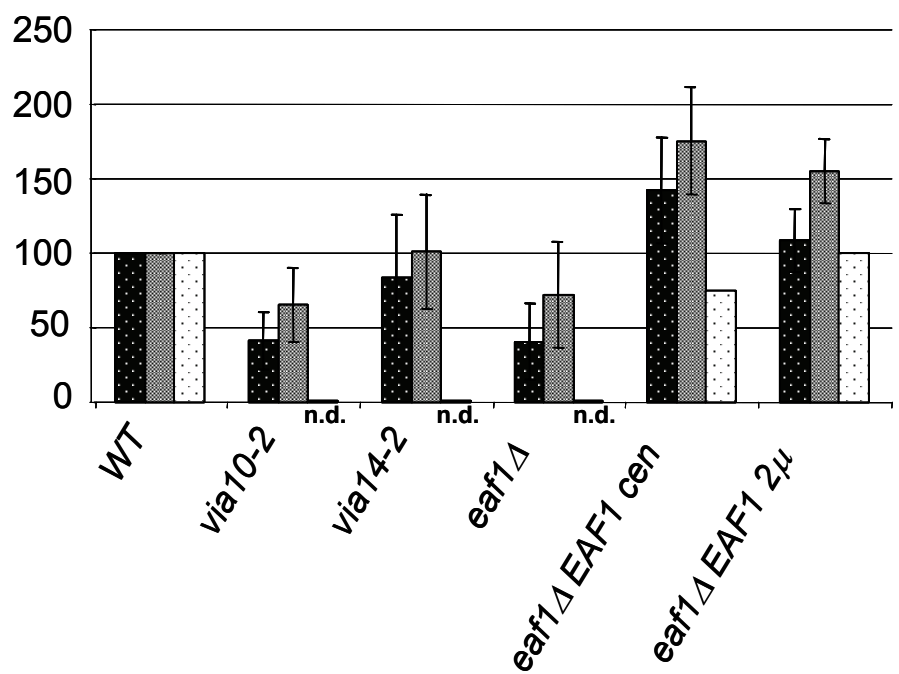

Ape1 Expression

APE1 Transkription

Ape1 Aktivität

Abb.23: Expression und Transkription der Aminopeptidase 1 in Abhängigkeit von Eaf1-

\section{Expression}

A Western Blot-Analyse von Ganzzellproteinextrakten aus stationär $\left(\mathrm{OD}_{600}>2\right)$ und logarithmisch $\left(\mathrm{OD}_{600} 1\right)$ wachsenden Zellen. Jeweils $1 \mathrm{OD}$ Zellen der Stämme WT (y96), via10-2 (y43), via10-2 transf. mit pYX141-EAF1 (y156), via10-2 transf. mit pYX242-EAF1 (y157), via14-2 (y46), via14-2 transf. mit $p Y X 141-E A F 1$ (y158), via14-2 transf. mit $p Y X 242-E A F 1$ (y159), eaf1 $(\mathrm{y} 126)$, eaf1 $\Delta$ transf. mit $p Y X 141-E A F 1$ (y170), eaf1 $\Delta$ transf. mit $p Y X 242-E A F 1$ (y172) und pep4A (y75) als Lyse Kontrolle 
wurden über alkalische Lyse aufgeschlossen, auf einem 10\%-igen Polyacrylamidgel elektrophoretisch aufgetrennt, auf eine PVDF-Membran transferiert und mit anti-Ape1 Serum und anti-PGK inkubiert. B Northern Blot-Analyse der Stämme ape1 $(\mathrm{y} 109), W T$, via10-2, via14-2, eaf1 $\Delta$, eaf1 $\Delta$ transf. mit pYX141-EAF1 (y170), eaf1 1 transf. mit $p Y X 242-E A F 1$ (y172), eaf1 (y166) und eaf1 $\Delta$ transf. mit $p Y X 242-Y D R 360 W$ (y168). Je $20 \mu \mathrm{g}$ RNA wurden auf eine NylonMembran transferiert. Die Membran wurde mit einem ${ }^{32} \mathrm{P}$-markierten APE1-Fragment und nach dessen Entfernung mit einem ${ }^{32} \mathrm{P}$-markierten ACT1-Fragment hybridisiert. C Graphische Darstellung der Ape1-Expression in Western Blot-Analysen $(n=7)$, Transkription durch Northern Blot-Analysen $(n=3)$ und Aktivität bestimmt in Ape1-Overlay-Assays ( $>15)$; n.d. - nicht detektierbar.

\section{7 $\alpha$-Mannosidase-Aktivität im eaf1 $\Delta$-Stamm}

Wie bereits einleitend beschrieben, wird die $\alpha$-Mannosidase (Ams1) zusammen mit der Aminopeptidase 1 über den Cvt-Transportweg in die Vakuole transportiert. Ams1 bindet entweder zeitgleich oder kurz versetzt mit dem Rezeptor Atg19 an die homododecamerisierte Form der Ape1; somit kommt es zur Ausbildung des sog. CvtKomplexes (Abb.3). Die $\alpha$-Mannosidase benötigt dabei die Interaktion mit der Ape1, genauer dem Cvt-Komplex, um in die Vakuole zu gelangen (Shintani et al., 2002). Da in den Mutanten- und eaf1 $\Delta$-Stämmen sowohl die Aktivität, als auch die Expression der Ape1 reduziert war, sollte untersucht werden, ob dies auch die Aktivität der $\alpha$-Mannosidase beeinflusste. Die vakuoläre Ams1-Aktivität ist durch katalytische Spaltung des Substrats 4-Nitrophenyl- $\alpha-D-M a n n o p y r a n o s i d ~ m e s s b a r ~(3.17) . ~ \mathrm{CuSO}_{4}$ in Verbindung mit Triton X-100 hemmt diese Reaktion, was darauf hindeutet, dass das aktive Zentrum des Enzyms auf der Innenseite der Vakuolenmembran liegt (Yoshihisa et al., 1988). Um die Aktivität der $\alpha$-Mannosidase in den Mutanten- und dem Deletionsstamm zu bestimmen, wurden Vakuolen isoliert (3.16) und mit dem Substrat 4-Nitrophenyl- $\alpha-D-M a n n o p y r a n o s i d$ in Anwesenheit von Triton X-100 für zwei bis vier Stunden bei $30^{\circ} \mathrm{C}$ inkubiert. Die katalytische Spaltung des Substrats wurde bei einer Wellenlänge von $400 \mathrm{~nm}$ bestimmt. Zur Auswertung der spezifischen Aktivität wurden die Werte des enzymatisch umgesetzten Substrates der Proben mit Triton X-100 von den Werten mit Triton X-100 und $\mathrm{CuSO}_{4}$ subtrahiert. Die Ams1Aktivität des WT-Stammes wurde jeweils auf 100\% festgelegt. Es zeigte sich, dass die ermittelten Aktivitäten der via-Mutanten und der Deletionsmutante eaf1 $\Delta$ durchschnittlich um $60 \%$, bzw. $70 \%$ geringer waren als die des Wildtyps (Abb.24). 
Dies könnte darauf hindeuten, dass die erniedrigte Ape1-Expressionsrate und eventuell sogar der Verlust der Aminopeptidase 1-Aktivität direkten Einfluss auf die $\alpha-M a n n o s i d a s e a k t i v i t a ̈ t ~ n i m m t$.

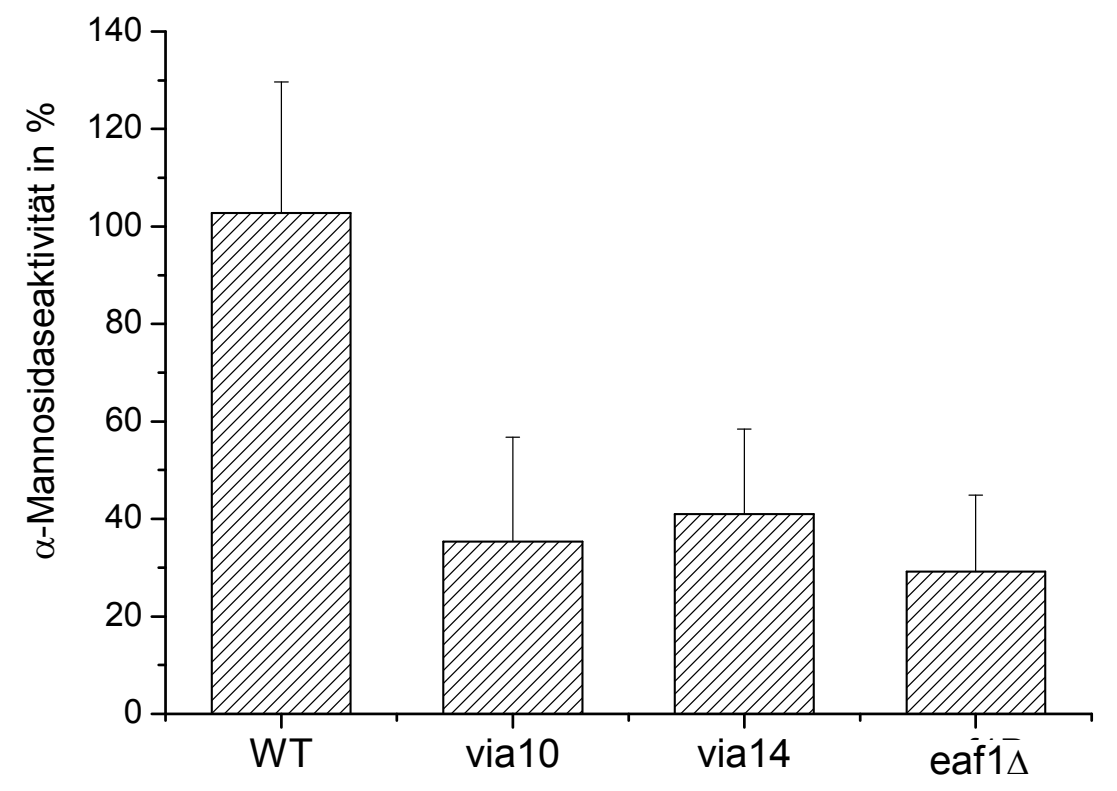

Abb.24: $\alpha$-Mannosidaseaktivität in WT, Mutantenstämmen und Deletionsstamm eaf1 $\triangle$.

Isolierte Vakuolen der Stämme WT (y12 und y96), via10 (y89), via14 (91) und eaf1A (y126) wurden mit dem Substrat 4-Nitrophenyl $\alpha$-D-Mannopyranosid in Anwesenheit von Triton X-100 oder Triton X-100 mit $\mathrm{CuSO}_{4}$ für zwei bis vier Stunden bei $30^{\circ} \mathrm{C}$ inkubiert. Die Auswertung erfolgte photometrisch bei $400 \mathrm{~nm}$.

\subsection{Eaf1 und seine Funktion innerhalb des NuA4-Komplexes}

Eaf1 ist Teil des NuA4-Komplexes und maßgeblich an der Hyperacetylierung des Histons H4 beteiligt (Krogan et al., 2004 und Abb.19). Kobor et al. (2004) beschrieben eine Hypersensitivität von Kinetochor- und Spindel-Kontrollpunkt Mutanten auf die Mikrotubuli destabilisierende Chemikalie Benomyl. Es konnte gezeigt werden, dass diese ebenfalls einen negativen Einfluss auf das Wachstum des eaf1-Deletionsstammes hatte (Krogan et al., 2004 und Abb.20). Außerdem war zu beobachten, dass nach Deletion des EAF1-Gens die Hefezellen temperatursensitiv wurden (Abb.18). Um zu überprüfen, ob dies in einem direkten Zusammenhang mit der Wiederherstellung der Aminopeptidase 1-Aktivität (Abb.16) 
stand, wurden Stämme mit verkürzten EAF1-Konstrukten sowohl auf mit Benomyl behandelten, als auch auf Vollmediumplatten bei $30^{\circ} \mathrm{C}$ und $37^{\circ} \mathrm{C}$ inkubiert (Abb.25A). Es wurde festgestellt, dass der $\mathrm{N}$-terminus des Proteins (EAF1 1-862 bp) vor allem als "single copy“ exprimiertes Protein kaum in der Lage war auf $15 \mu \mathrm{g} / \mathrm{ml}$ Benomyl, bzw. bei $37^{\circ} \mathrm{C}$ zu wachsen. Die N-terminale Verkürzung der Basenpaare 847-2946 hingegen entsprach vor allem bei hoher Expressionsrate $(2 \mu)$ annähernd dem Wachstumsverhalten des kompletten EAF1-Konstruktes. Die Mutation des potentiellen Kernlokalisationssignals hatte keinen Einfluss auf das untersuchte Wachstumsverhalten. Des Weiteren wurde überprüft, inwieweit die verkürzten Eaf1Fragmente in der Lage waren die Hyperacetylierung des Histons 4 zu regulieren. Wie in Abb.25B gezeigt, bedarf es des C-terminalen Teils des Proteins, um sowohl die Hyperacetylierung von $\mathrm{H} 4$, als auch die Expression der Aminopeptidase $1 \mathrm{zu}$ stimulieren.

Das Wachstum der Hefen mit verschiedenen EAF1-Konstrukten auf Benomylhaltigen Vollmediumplatten oder bei $37^{\circ} \mathrm{C}$ und ihre Fähigkeit Histon $\mathrm{H} 4 \mathrm{zu}$ hyperacetylieren, stand in direktem Zusammenhang mit der ermittelten Ape1-Aktivität der Konstrukte in Ape1-Overlay-Assays. Dies ließ vermuten, dass die hier beschriebenen Beobachtungen Teil der Funktionen von Eaf1 innerhalb des NuA4Komplexes sind. 
A

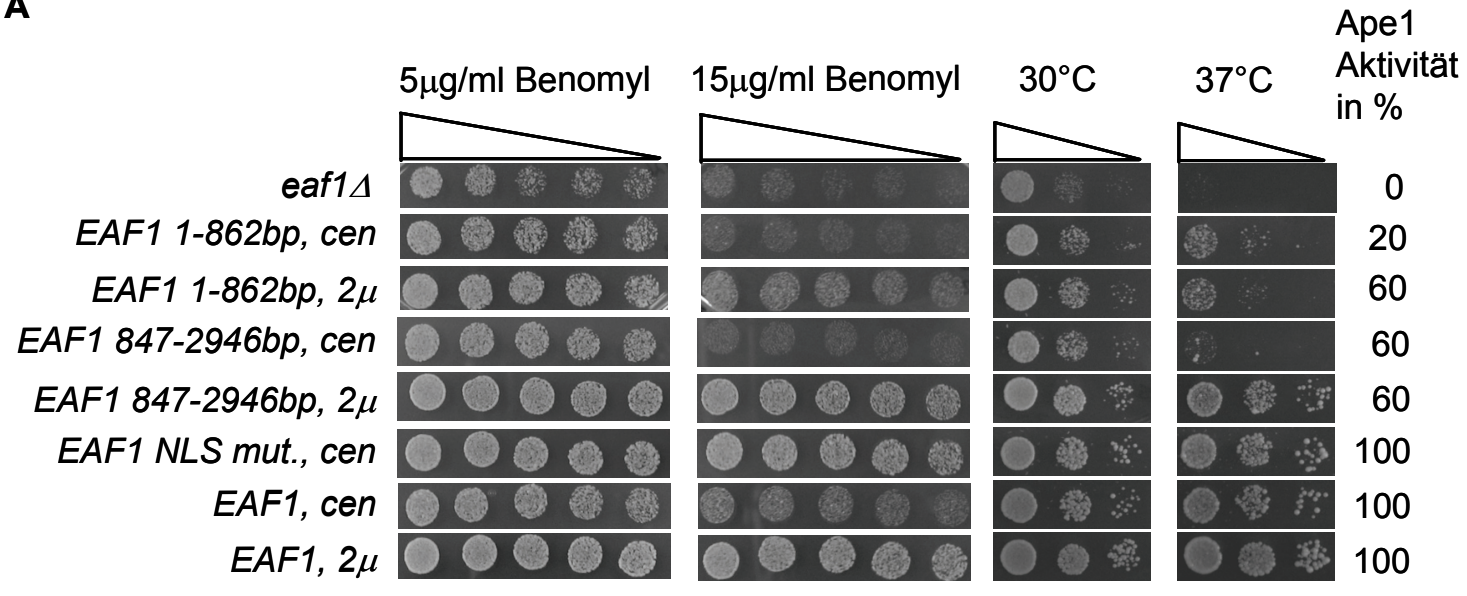

B

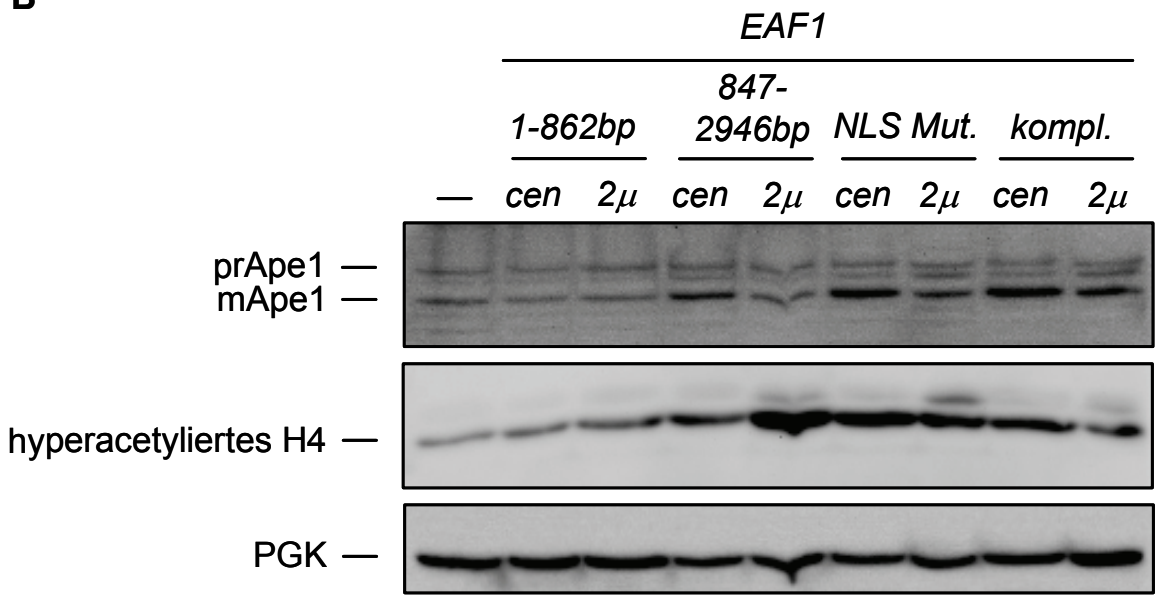

\section{Abb.25: Wachstumsverhalten und Hyperacetylierung von Histon $\mathrm{H} 4$ durch $\mathrm{N}$ - und C-terminale Eaf1-Verkürzung des Stammes eaf1 $\Delta$.}

A Übernachtkulturen der Stämme eaf1 $\triangle$, eaf1 $\Delta$ transf. mit $p Y X 141-E A F 1$ 1-862 bp (y189); eaf1 transf. mit $p Y X 242-E A F 1$ 1-862 bp (y191); eaf1 4 transf. mit $p Y X 141-E A F 1$ 847-2946 bp (y193); eaf1 $\Delta$ transf. mit $p Y X 242-E A F 1$ 847-2946 bp (y195); eaf1 $\Delta$ transf. mit $p Y X 141-E A F 1$ NLS Mutation (y197); eaf1A transf. mit $p Y X 242-E A F 1$ NLS Mutation (y199), eaf1A transf. mit $p Y X 141-E A F 1$ (y170) und eaf1 $\Delta$ transf. $p Y X 242-E A F 1$ (y172) wurden mit $\mathrm{H}_{2} \mathrm{O}$ auf eine Anfangs- $\mathrm{OD}_{600}$ von 0.1 verdünnt. Daraus wurde eine fünffach fortlaufende Verdünnung hergestellt, auf den mit 5 , bzw. $15 \mu \mathrm{g} / \mathrm{ml}$ Benomyl behandelten Vollmediumplatten zwei Tage bei $30^{\circ} \mathrm{C}$ inkubiert. Zur Bestimmung des Wachstumsverhaltens wurden die Übernachtkulturen mit $\mathrm{H}_{2} \mathrm{O}$ auf eine Anfangs- $\mathrm{OD}_{600}$ von 0.1 verdünnt, woraus dann eine 1:10 und 1:100 Verdünnung hergestellt wurde. Die Prozentangaben zur Ape1-Aktivität beziehen sich auf die Prozentangaben in Abbildung 22. B Western Blot-Analysen mit den Eaf1-Verkürzungen. Ganzzelllysate wurden über ein 15\%-iges Polyacrylamidgel elektrophoretisch aufgetrennt und mittels Nassblotverfahren auf eine PVDF-Membran transferiert. Die Membran wurde mit anti-hyperacetylierten H4 Penta, polyklonalem anti-Ape1 und anti-PGK Antikörper inkubiert. 


\subsection{Herstellung weiterer Deletionsmutanten des NuA4-Komplexes}

Der Histon-Acetyltransferase-Komplex NuA4 besteht aus dreizehn Untereinheiten (Abb.26A). Das Protein Esa1 ist die katalytische Untereinheit des Komplexes, das die Acetylierung der Histone $\mathrm{H} 4$ und H2A in Abhängigkeit der beiden Proteine Eaf1 und Yng2 reguliert (Doyon und Côté, 2004, Krogan et al., 2004). Bisher konnte in dieser Arbeit gezeigt werden, dass die Deletion des Proteins Eaf1 zu einem Verlust der Ape1-Aktivität führt.

Neben Eaf1 enthält der NuA4-Komplex sechs weitere nicht-essentielle Proteine (Abb.26A). Um zu untersuchen, ob die Deletion weiterer Untereinheiten ebenfalls zum Verlust der Aminopeptidase 1-Aktivität führt, wurden jeweils die Proteine Yng2 (ORF YHR090C), Yaf9 (ORF YNL107W), Eaf3 (ORF YPR023C), Eaf5 (ORF YEL018W), Eaf6 (ORF YLR082C) und Eaf7 (ORF YNL136W) deletiert. Dazu wurden wie in Kapitel 4.3.2 beschrieben das HIS3-Homolog aus Schizosaccharomyces pombe HIS5 ${ }^{+}$mit 45 bp komplementäre 5'- und 3'-Enden der genomischen DNA der entsprechenden ORFs aus dem Plasmid pFA6a-HIS3MX6 amplifiziert und in den WT-Stamm (y96) transformiert. Nach erfolgreicher Integration mittels homologer Rekombination wurden die Hefestämme Histidin-prototroph. Die Integrationen wurden mit Polymerasekettenreaktion an Ganzzelllysaten überprüft. Zum einen wurden Oligonukleotide eingesetzt, die das jeweilige Gen amplifizierten und somit nur in der WT-Kontrolle ein PCR-Produkt ergaben und zum anderen Oligonukleotide, die ca. 300 bp des Genoms und ca. 700 bp des integrierten Konstrukts amplifizierten und damit nur in den Deletionsstämmen bei korrekter Integration des PCR-Produktes ein Signal ergaben (Abb.26B).

Der Verlust des EAF1-Genes führte zu einem kompletten Verlust der Ape1-Aktivität. Nach Deletion weiterer Untereinheiten des NuA4-Komplexes wurde deren Einfluss auf die Ape1-Aktivität in Overlay-Assays getestet. Die Stämme WT und eaf1 $\Delta$ dienten dabei als Positiv-, bzw. Negativkontrolle. Die Deletionsstämme yng2 $\Delta$, eaf5 $\Delta$, eaf6 $\Delta$ und eaf7 $\Delta$ unterschieden sich nicht in der Ape1-Aktivität vom WT-Stamm. Das Protein Yng2 wird zusammen mit Eaf1 für die Acetylierung des Histons H4 benötigt. Die Transformation des YNG2-Genes in den eaf1 4 -Stamm führte zu keinerlei Aktivitätsgewinn. Bei den Stämmen eaf3 $\Delta$ und yaf9 $\Delta$ war ein Rückgang der Ape1Aktivität um etwa $20 \%$ bis $30 \%$ zu beobachten. Keine der Deletionen führte zu einem Totalverlust der Ape1-Aktivität (Abb.27). Diese deutet auf eine Funktion des Proteins 
Eaf1 außerhalb seiner beschriebenen Rolle als Untereinheit des NuA4-Komplexes hin.

A

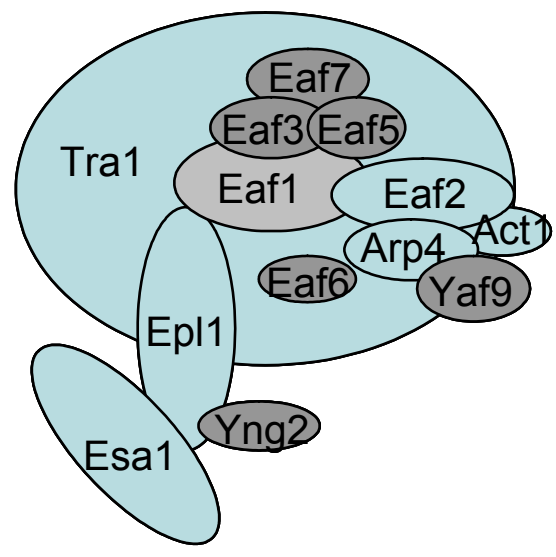

B

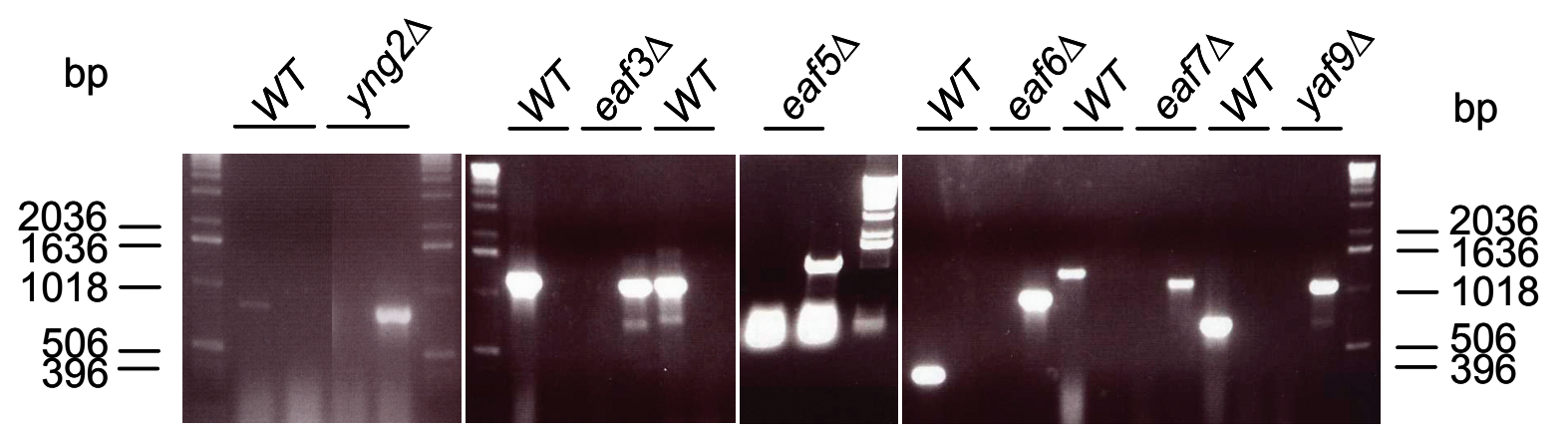

Abb.26: Deletionsstämme des NuA4-Komplexes.

A Schematische Darstellung des aus essentiellen (blau) und nicht-essentiellen (grau) Proteinen zusammengesetzten NuA4-Komplexes (Abbildung abgeändert nach Hancock et al., 2006).

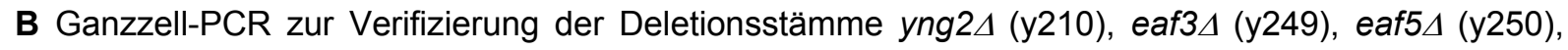
eaf6 4 (y252), eaf7 $(\mathrm{y} 255)$ und yaf9 $\Delta$ (y256). Die DNA des WTs (y96) und der Deletionsstämme wurden jeweils mit den Oligonukleotiden TB90/87 (WT - 849 bp, yng2 - kein Signal (k.S.)) und TB84/56 (WT - k.S., yng2 - ca.700 bp), TB131/132 (WT - 1203 bp, eaf3 - k.S.) und TB128/56 (WT k.S., eaf3 $\Delta$ - ca. 1000 bp), TB127/134 (WT - 1137 bp, eaf5 - k.S.) und TB127/56 (WT - k.S., eaf5 ca. 1000 bp), TB135/136 (WT - 339 bp, eaf6 $\Delta$ - k.S.) und TB141/56 (WT - k.S., eaf6 $\Delta$ - ca. 900 bp), TB137/138 (WT - 1275 bp, eaf7 $\Delta$ - k.S.) und TB130/56 (WT - k.S., eaf7 $\Delta$ - ca. 1000 bp) oder TB139/140 (WT - 682 bp, yaf9 - k.S.) und TB126/56 (WT - k.S., yaf9 - ca. 1000 bp) amplifiziert. 


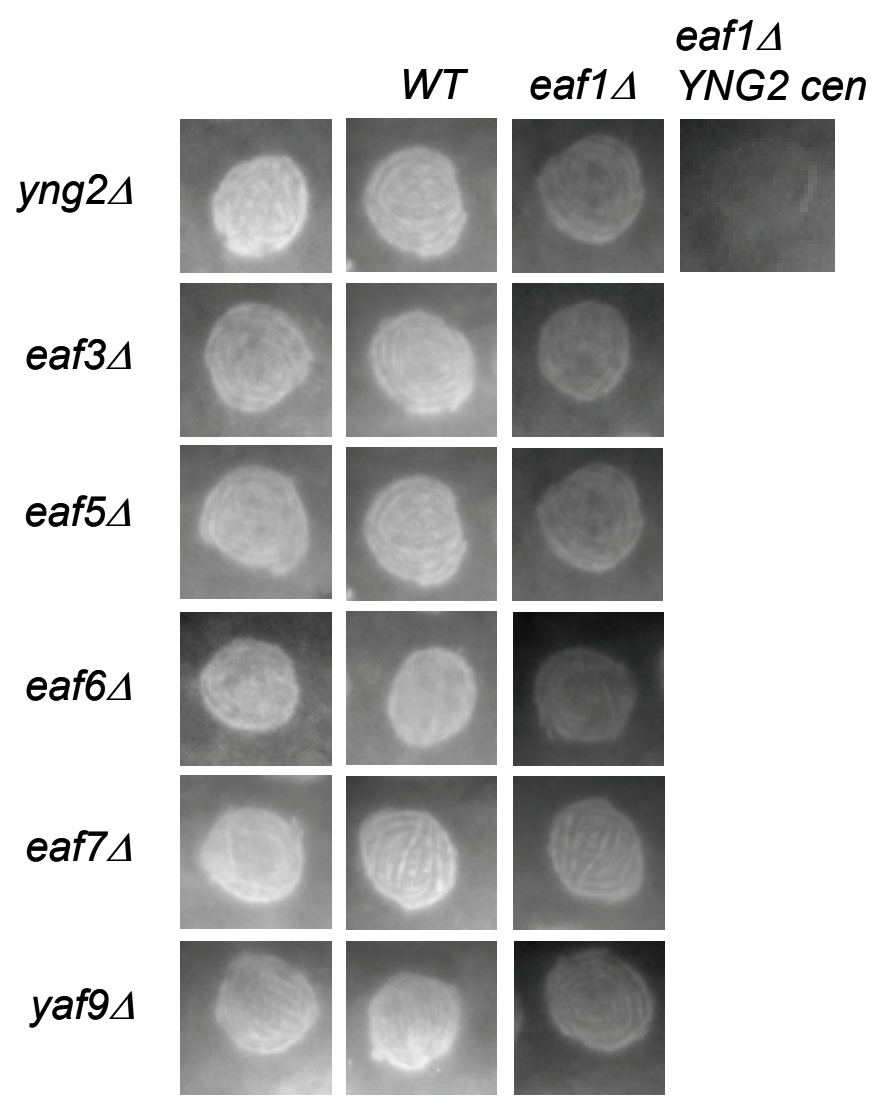

Abb.27: Ape1-Aktivität in Deletionsstämmen des NuA4-Komplexes.

Ape1-Overlay-Assay zur Bestimmung der Aminopeptidase 1-Aktivität durch Spaltung des Substrats $\mathrm{H}$ Leucin- $\beta$-Naphtylamid. Die zu testenden Deletionsstämme befanden sich jeweils mit dem WT (100\% Aktivität) und eaf1 $\Delta$ (keine Aktivität) auf einer Platte.

\subsection{Der Einfluss von Aminopeptidase 1-Überexpression auf die Wiederherstellung der Ape1-Aktivität in eaf1 $\Delta$-Stämmen}

NuA4 ist an der Regulation der Transkription beteiligt. Wir beobachten durch Expression der Untereinheit Eaf1 einen Anstieg der Aminopeptidase 1-Expression und gleichzeitig eine Wiederherstellung ihrer Aktivität in eaf1-Deletionsstämmen und der Mutante via14-2. Um zu klären, ob die Aktivität der Ape1 alleine auf eine erhöhte Expression des Proteins zurückzuführen ist, wurde das Gen APE1 in verschiedenen Hefestämmen überexprimiert und anschließend die Ape1-Aktivität bestimmt. Dazu wurde APE1 mittels Polymerasekettenreaktion aus dem Konstrukt pRS313-APE1 
amplifiziert, mit den Restriktionsenzymen Nco I und Hind III verdaut und die

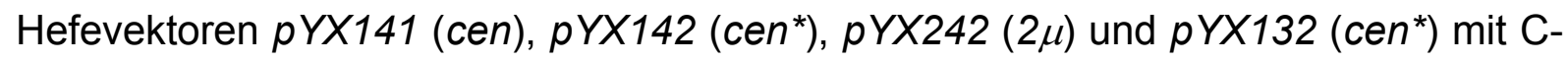
terminalen HA-,tag“" kloniert. Es wurde beobachtet, dass eine C-terminal markierte Aminopeptidase 1 in ihrer Proform akkumuliert, da diese nicht mehr prozessiert werden kann (Daten nicht gezeigt). Folglich wurde durch das Einfügen eines Stopcodons in das verwendete Oligonukleotid TB93 eine Expression des Fusionsproteins verhindert. Die Konstrukte wurden in die Stämme eaf1A, via10-2 und via14-2 transformiert und die Expression der Ape1 in Western Blot-Analysen überprüft (Abb.28A). Die Expressionsraten der mApe1 wurden mit Hilfe des LAS Fuji Bearbeitungsprogramm AIDA quantifiziert. Nach Transformation der Konstrukte wurde eine gleich bleibende (cen), um Faktor zwei (cen*), bzw. um Faktor vier $(2 \mu)$ erhöhte Expression der Ape1 in dem eaf14-Stamm im Vergleich zum WT-Stamm ermittelt. Nach Transformation von EAF1 hingegen ist die mApe1-Expression (cen und $2 \mu$ ) um ca. $20 \%$ gestiegen. In den via-Mutanten wurde die Expressionsrate der mApe1 um Faktor vier (via10-2), bzw. fünf (via14-2) erhöht.

Anschließend wurde mittels Ape1-Overlay-Assays überprüft, ob die so gesteigerte Expression der Aminopeptidase 1 ausreichend ist, um die Aktivität des Enzyms wiederherzustellen (Abb.28B). In eaf1 $\Delta$-Stämmen konnte die Aktivität nach vierfach gesteigerter mApe1-Expression ( $2 \mu$-Vektor) wiederhergestellt werden und, wie bereits in vorhergehenden Versuchen bestätigt (Abb.16), zeigte die Expression von EAF1 (cen) ebenfalls eine deutliche Ape1-Aktivität. In via14-2 führte eine Überexpression der Ape1 ebenfalls zur Wiederherstellung der Ape1-Aktivität, während diese in der Mutante via10-2 keinerlei Einfluss hatte. Dies zeigt, dass zur vollständigen Restauration der Ape1-Aktivität eine vier- bis fünffache Überexpression von Ape1 nötig ist, während die Expression von Eaf1 zu einem Anstieg der Ape1Expression von nur ca. 20\% führt. Dieser ist aber ausreichend, um Ape1-Aktivität zu induzieren. 


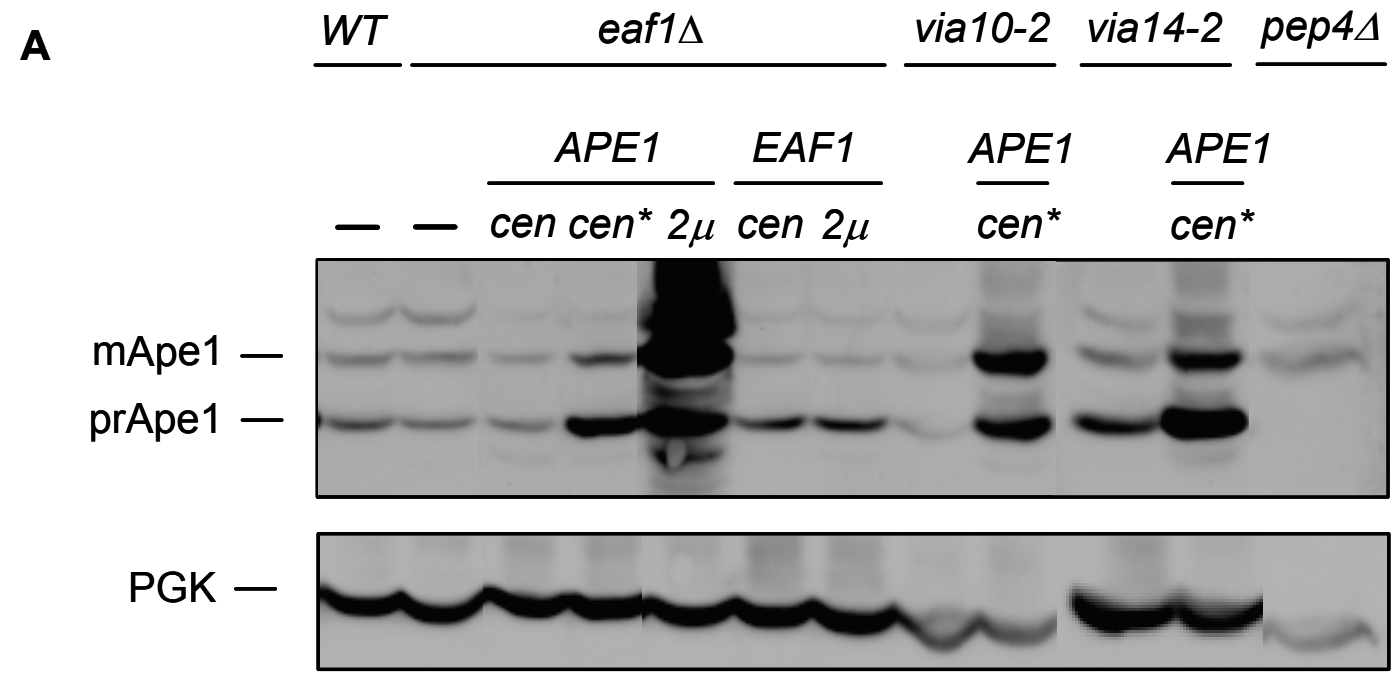

B

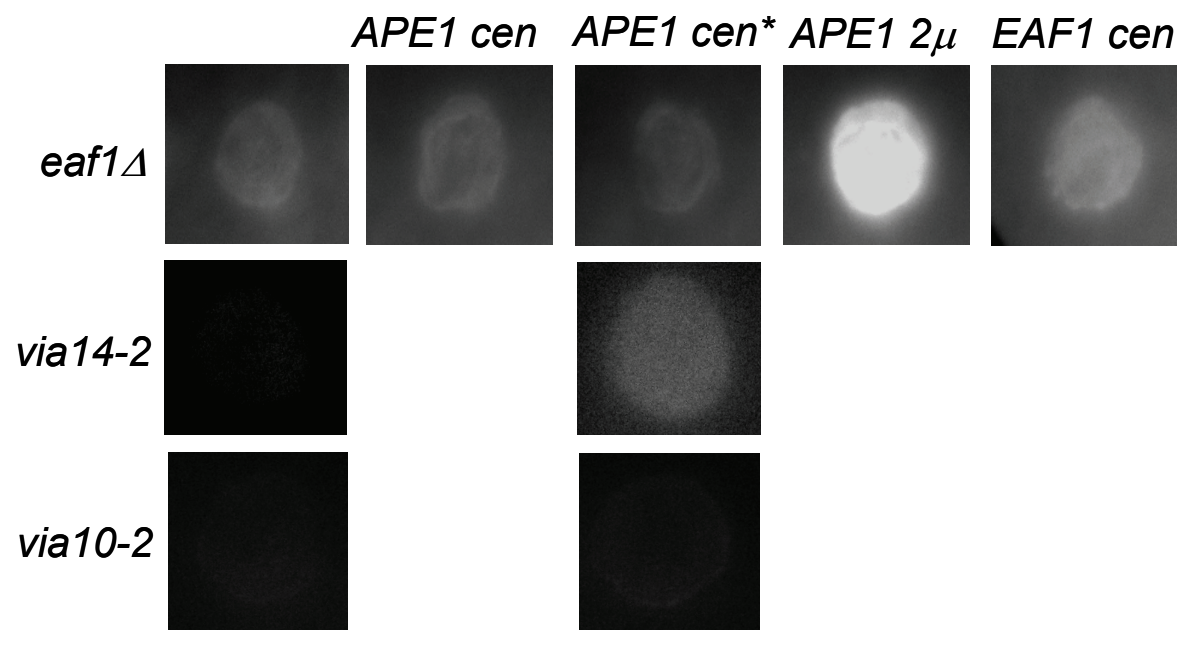

Abb.28: Expression und Aktivität der Aminopeptidase nach Überexpression in den Stämmen eaf14, via10-2 und via14-2.

A Western Blot-Analyse mit Ganzzellproteinextrakten logarithmisch wachsenden Zellen. Jeweils 1 OD Zellen der Stämme $W T$ (y96), eaf1 $(\mathrm{y} 126)$, eaf1 $\Delta$ transf. mit $p Y X 141-A P E 1$, eaf1 $\Delta$ transf. mit pYX142-APE1 (y228), eaf1 $\triangle$ transf. mit $p Y X 242-A P E 1$, eaf1 $\triangle$ transf. mit $p Y X 141-E A F 1$ (y170), eaf1 transf. mit $p Y X 242-E A F 1$ (y172), via10-2 (y43), via10-2 transf. mit $p Y X 132-A P E 1$ (y236), via14-2 (y46), via14-2 transf. mit $p Y X 142-A P E 1$ (y220) und pep4A als Lysekontrolle wurden über alkalische Lyse aufgeschlossen. Nach elektrophoretischer Auftrennung, wurde das 10\%-ige Polyacrylamidgel auf eine PVDF-Membran transferiert und anti-Ape1 Serum und anti-PGK inkubiert. cen - Promotor 786; cen ${ }^{*}$ - Promotor TPI. B Ape1-Overlay-Assay nach Überexpression von Ape1 in den Stämmen eaf14 (y126), via10-2 (y43) und via14-2 (y46). 


\subsection{Eaf1 und Ape1-Interaktionen}

Bisher konnte gezeigt werden, dass die Expression von Eaf1 die Transkription des APE1-Gens und somit dessen Expressionsrate begünstigt, was im Ape1-OverlayAssay zur Wiederherstellung der Ape1-Aktivität führt (Abb.16 und Abb.23). Da eine um Faktor zwei gesteigerte Expressionsrate der Aminopeptidase 1 die Aktivität der Ape1 in dem eaf14-Stamm nicht beeinflusst (Abb.28), ist davon auszugehen, dass der Beitrag von Eaf1 nicht ausschließlich auf einem transkriptionellen Effekt beruht. Im Folgenden sollte geklärt werden, auf welche Weise das Protein Eaf1 die Aktivität der Ape1 induziert.

\subsubsection{Lokalisationsstudien von Eaf1 und Ape1}

Eaf1 wird als Kernprotein beschrieben, während die Aminopeptidase 1 im Zytoplasma synthetisiert und nach ihrer Assemblierung in die Vakuole transportiert wird (Krogan et al., 2004; Frey und Röhm, 1978). Um zu überprüfen, ob diese zwei Proteine trotz ihrer in der Literatur beschriebenen, unterschiedlichen Kompartimentierung interagieren und vielleicht so die Aktivität der Ape1 beeinflussen, wurde eine in situ Immunfluoreszenz durchgeführt. Da bislang Eaf1HA-Fusionskonstrukte in Western Blot-Analysen nicht nachweisbar waren, obwohl die Hefen einen Plasmid-abhängigen Phänotyp zeigten, sollte dieses Experiment mit aminoterminalem statt mit carboxyterminalem markiertem Eaf1 durchgeführt werden. Dazu wurde die HA-,tag“-exprimierende Sequenz des „Yeast two Hybrid“-Vektors pGADT7 mittels Polymerasekettenreaktion amplifiziert und das entstehende PCRProdukt mit den Restriktionsenzymen EcoR I verdaut und in die Vektoren pYX141, 142 und -242 kloniert. Die richtige Orientierung des HA-Fragments wurde durch Sequenzierung bestätigt. Die klonierten Vektoren wurden als $p Y X 141-H A,-142-H A$ und 242-HA bezeichnet. Eaf1 wurde anschließend aus dem $p Y X 141-E A F 1-K o n s t r u k t$ mit C-terminalem Stopcodon amplifiziert, mit den Restriktionsenzymen Apa I und Hind III geschnitten und in die Vektoren $p Y X 141-H A,-142-H A$ und 242-HA kloniert. Der Nachweis der Proteinexpression erfolgte mittels Western Blot-Analyse (Abb.29A). Die HA-Eaf1-Expression unter Verwendung von cen*- und $2 \mu$-Vektoren lieferte ein schwaches, bzw. ein starkes Signal in erwarteter Laufhöhe. Mit dem 
„single copy"-Vektor pYX141-HA war diese wahrscheinlich zu gering, um mit dem anti-HA Antikörper (Roche) detektiert zu werden.

A

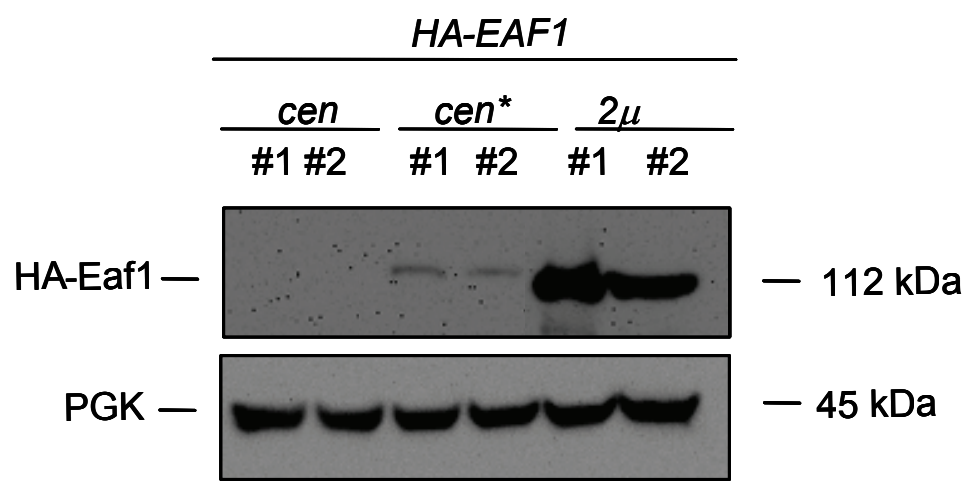

B

DIC

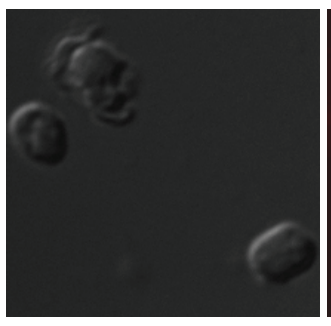

RFP-Ape1

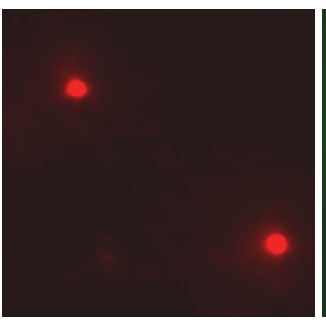

HA-Eaf1

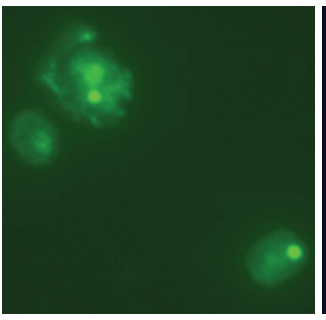

DAPI

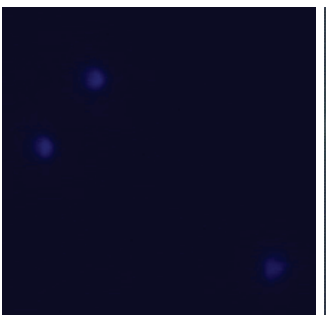

überlagert

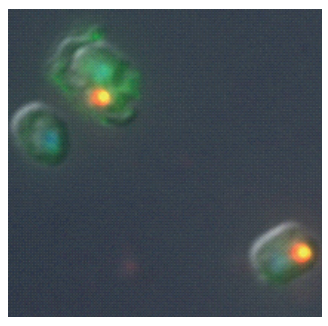

Abb.29: Western Blot-Analyse und in situ Immunfluoreszenz zur Lokalisation von HA-Eaf1.

A Western Blot-Analyse der Stämme WT transf. mit pYX141-HA-EAF1 (cen), pYX142-HA-EAF1 $\left(c^{*}\right)$ und $p Y X 242-H A-E A F 1(2 \mu)$. 1 OD logarithmisch wachsender Zellen wurden über alkalische Lyse aufgeschlossen, über ein 10\%-iges Polyacrylamidgel elektrophoretisch aufgetrennt und auf eine PVDF-Membran transferiert. Die Membran wurde mit anti-HA (1:1000) und anti-PGK (1:5000) Antikörper inkubiert. Der Nachweis der gebundenen Antikörper erfolgte mit HRP-konjugierten antiRatte, bzw. anti-Maus-Antikörpern und Chemilumineszenz. B in situ Immunfluorenzenz des Stammes $W T$ transf. mit $p Y X 142-H A-E A F 1$ und $p R S 313-R F P-A P E 1$. Logarithmisch wachsende Zellen wurden mit anit-HA (1:200) und anti-Ratte Alexa Fluor 488 (1:400) inkubiert.

Für die in situ Immunfluoreszenz wurde HA-EAF1 zusammen mit RFP-APE1 (Konstrukt pRS313-RFP-APE1, freundlicherweise von Michael Thumm zur Verfügung gestellt) in den $W T$-Stamm transformiert. Logarithmisch wachsende Zellen wurden mit anti-HA Antikörper (Roche, 1:200) und danach mit Alexa 488 markierten Zweitantikörper (Molecular Probes, 1:400) inkubiert. HA-Eaf1 konnte wie erwartet im Kern lokalisiert werden; zusätzlich wurde eine Akkumulation des Fusionsproteins im Zytoplasma beobachtet. In 60\% von insgesamt 100 ausgezählten Zellen wurde eine Co-Lokalisation mit dem RFP-Ape1-Signal bestimmt (Abb.29B). RFP-Ape1 sammelt 
sich in logarithmisch wachsenden Zellen am PAS und kann erst in der stationären Phase auch in der Vakuole detektiert werden (Klionsky et al., 1992 und persönliche Korrespondenz mit der Arbeitsgruppe von Prof. Michael Thumm). HA-Eaf1 ist somit sowohl im Kern, als auch am PAS im Zytoplasma zusammen mit dem RFP-Ape1Signal lokalisiert.

\subsection{2 „Yeast two Hybrid“-Interaktionsstudien von Eaf1 und Ape1}

In situ Immunfluoreszenzen haben gezeigt, dass Eaf1 nicht nur im Kern, sondern auch als punktuelle Struktur im Zytoplasma, d.h. in der Umgebung des PAS' lokalisiert ist und dort mit der Aminopeptidase 1 co-lokalisiert. Um zu klären, ob die beiden Proteine auch interagieren, wurden "Yeast two Hybrid“-Studien durchgeführt (Abb.30A).

Für die Expression der Fusionsproteine wurde das Gen APE1 mittels Polymerasekettenreaktion aus dem Plasmid pRS313-APE1 amplifiziert und mit den Restriktionsenzymen Nco I und Sal l, bzw. Sma I und Sal I verdaut und in die DNAbindenden Vektoren $p G B K T 7$ und $p G B T 9$ kloniert. Nach Verdau mit den Enzymen Nco I und Sma I wurde APE1 in den Vektor mit der Aktivierungsdomäne, $p G A D T 7$ kloniert. N- und C-terminale Verkürzungen des Gens EAF1 wurden aus dem Plasmid pYX141-EAF1 amplifiziert und nach Verdau mit den Restriktionsenzymen EcoR I und Sall in die DNA-bindenden Vektoren pGBKT7 und pGBT9 kloniert. Nach dem Verdau mit EcoR I und Sma I wurden die Konstrukte in den Vektor $p G A D T 7$ kloniert (Abb.30B). Die Plasmide wurden in den Hefestamm AH109 transformiert und auf Platten ohne die Aminosäuren Tryptophan und Leucin selektioniert. Um eine potentielle Interaktion der Aminopeptidase 1 mit Eaf1 zu testen, wurde die Transkription der Reportergene HIS3 und $A D E 1$ mittels Selektionsplatten überprüft (Abb.30C). Durch die gezeigte Interaktion der Proteine p53 und SV40-T Antigen wurde die Funktionalität des Versuchs sichergestellt. Nach Expression der Ape1 fusioniert mit der GAL4-Bindedomäne und Eaf1 fusioniert mit der Aktivierungsdomäne konnte kein Wachstum auf Histidin- oder AdeninMangelmedium nachgewiesen werden. Die Reportergene wurden demnach nicht transkribiert, was auf eine fehlende Wechselwirkung der Fusionsproteine schließen ließ. Eine potentielle Interaktion der Proteine sollte auch nach Austausch der Domänen, d.h. bei Expression der Eaf1 mit der DNA-bindenden- und Ape1 mit 
Aktivierungsdomäne getestet werden. Vorversuche zeigten jedoch, dass die Expression Eaf1 mit DNA-bindender Domäne selbstaktivierend wirkte (Abb.30C, rechte Seite). Die Expression der jeweiligen Fusionsproteine wurde mit Western BlotAnalysen überprüft (Daten nicht gezeigt).

Eine direkte Interaktion der Proteine Ape1 und Eaf1 konnte im „Yeast two Hybrid“System nicht gezeigt werden.

A

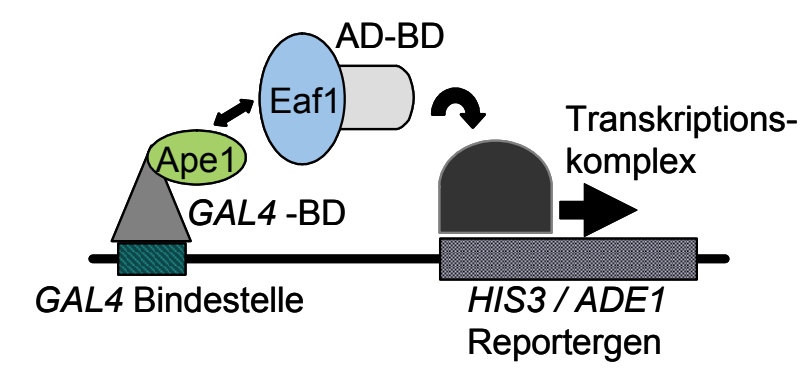

C

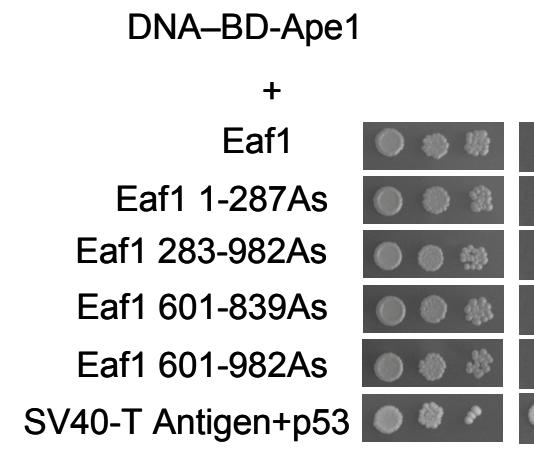

DNA-BD-Ape1

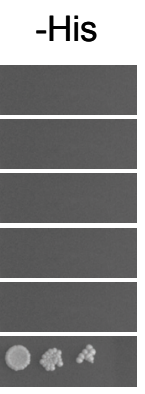

B

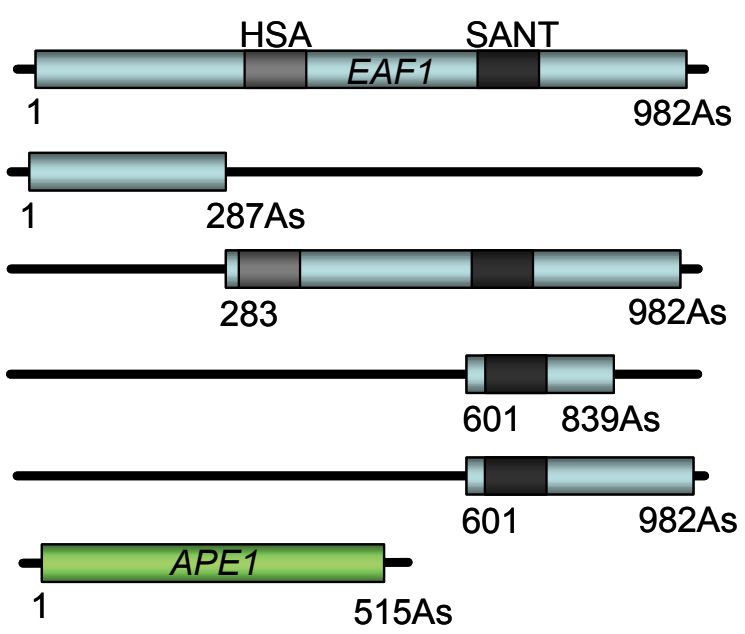

AD-BD-Vektor
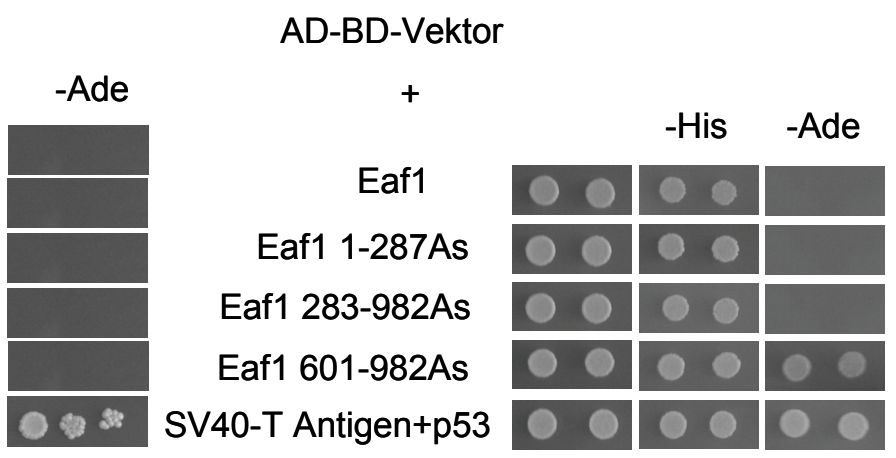

Abb.30: „Yeast two Hybrid“-Studien zur Überprüfung potentieller Interaktion der Proteine Ape1 und Eaf1.

A Schematische Darstellung eines „Yeast two Hybrid“-Experiments. Das Reportergen (hier HIS3 oder $A D E 1)$ wird transkribiert nachdem ein funktioneller Transkriptionsfaktor an die GAL4-Bindestelle der DNA bindet. BD - Bindedomäne; $A D$ - Aktivierungsdomäne. B N- und C-terminale Verkürzungen von EAF1 und APE1, die in die Vektoren $p G B K T 7$ und $p G B T 9$ (beide mit DNA-BD) oder $p G A D T 7$ (AD-BD) kloniert wurden. C Wachstum der Hefestämme AH109 transformiert mit pGBKT7-APE1 und den jeweiligen EAF1-Konstrukten in $p G A D T 7$ auf Tryptophan/Leucin-, Tryptophan/Leucin/Histidin-, bzw. Tryptophan/Leucin/Histidin/Adenin-Mangelmedium (linke Seite) und Wachstum der Hefestämme AH109 transformiert mit pGADT7-Vektor und den jeweiligen EAF1-Konstrukten in pGBT9 auf Tryptophan/Leucin-, Tryptophan/Leucin/Histidin-, bzw. Tryptophan/Leucin/Histidin/AdeninMangelmedium (rechte Seite). 


\subsection{Komplexassemblierung der Aminopeptidase 1 im eaf1 $\Delta$-Stamm}

Die native Konformation der akkumulierten prApe1 ist in den via Mutanten beeinträchtigt, was das Protein sensitiver für Proteasen wie Trypsin oder Proteinase K macht. Während die prApe1 des WT-Stammes erst durch die unspezifischere Proteinase $\mathrm{K}$ in Gegenwart von Detergenz prozessiert wurde, war bei den Mutanten ein Abbau nach Zugabe von Trypsin und Detergenz zu beobachten (Andrei-Selmer et al., 2001). Um zu überprüfen, ob der Ape1-Aktivitätsverlust in den eaf1ム Stämmen auf eine Fehlfaltung, bzw. eine gestörte Komplexassemblierung zurückzuführen ist, wurde die Sensitivität des Proteins auf die Proteasen Trypsin und Proteinase K untersucht (3.22). Dazu wurden logarithmisch wachsende Hefekulturen des WT- und eaf1 1 -Stammes mit Zymolyase 20T sphäroblastiert und anschließend mit DEAE-Dextran lysiert. Um die Vollständigkeit des Lysevorgangs zu überprüfen, wurden die Zelllysate bei $5000 \mathrm{~g}$ zentrifugiert und somit die vakuoläre Fraktion von der zytosolischen getrennt. Bei einer kompletten Lyse der Zellen sollte die Carboxypeptidase $Y$ (CPY) in der Pellet- und die 3-Phosphoglycerat Kinase (PGK) in der Überstand-Fraktion zu finden sein. Ebenso sollte sich die mApe1 im Pellet, also in der noch intakten Vakuole befinden. Wie in Abbildung 31A gezeigt, waren sowohl die CPY als auch die mApe1 in der vakuolären Fraktion enthalten, während PGK überwiegend im Überstand detektiert wurde. Eine wahrscheinliche Erklärung hierfür ist eine unvollständige Lyse der Zellen. Auf eine Verlängerung der Inkubation mit DEAE-Dextran wurde jedoch bewusst verzichtet, da dies zu einer verstärkten Vakuolendegradation führte (Daten nicht gezeigt). Die lysierten Zellen wurden in Abwesenheit von Proteaseinhibitoren mit den Proteasen Trypsin und Proteinase $\mathrm{K}$ mit und ohne Detergenz für 30 Minuten bei $4^{\circ} \mathrm{C}$ verdaut. Anschließend wurde mit Western Blot-Analysen die Sensitivität der Aminopeptidase 1 auf beide Proteasen überprüft. Dabei zeigten sowohl der WT- als auch der eaf1 $\Delta-$ Stamm keine erhöhte Sensitivität auf die Behandlung mit Trypsin oder Proteinase K; nach Zugabe von Proteinase $\mathrm{K}$ und Triton X-100 war in beiden Stämmen eine geringe Prozessierung der prApe1 sichtbar. Die Aminopeptidase 1 reagierte nach Deletion von EAF1 nicht sensitiver auf den Verdau mit Proteasen, wie es in den via-Mutanten beobachtet wurde, was daraus schließen lässt, dass das Protein korrekt gefaltet vorliegt. Dieses wurde mittels einer Auftrennung von Gesamtzelllysat über eine Gelfiltrationssäule (Superdex S200) verifiziert (3.23). In anschließenden Western Blot-Analysen mit anti- 
Ape1 Serum konnte gezeigt werden, dass der homododecamere Komplex und dessen Zwischenstufen in $W T$ - und eaf1 $\Delta$-Stämmen in denselben Fraktionen, d.h. zwischen ca. 600 und $300 \mathrm{kDa}$ und als Monomer bei $50 \mathrm{kDa}$ eluiert (Abb.31B). Auffällig war lediglich eine Reduktion der monomeren Isoform im eaf1 $\Delta$-Stamm. Auch in diesem Experiment ergab sich somit kein Hinweis auf eine fehlerhafte Komplexassemblierung der Ape1 in Abwesenheit von Eaf1.

A

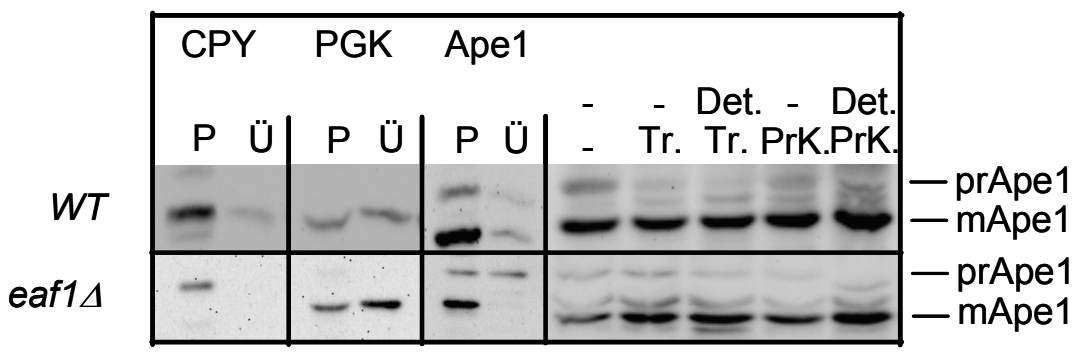

B

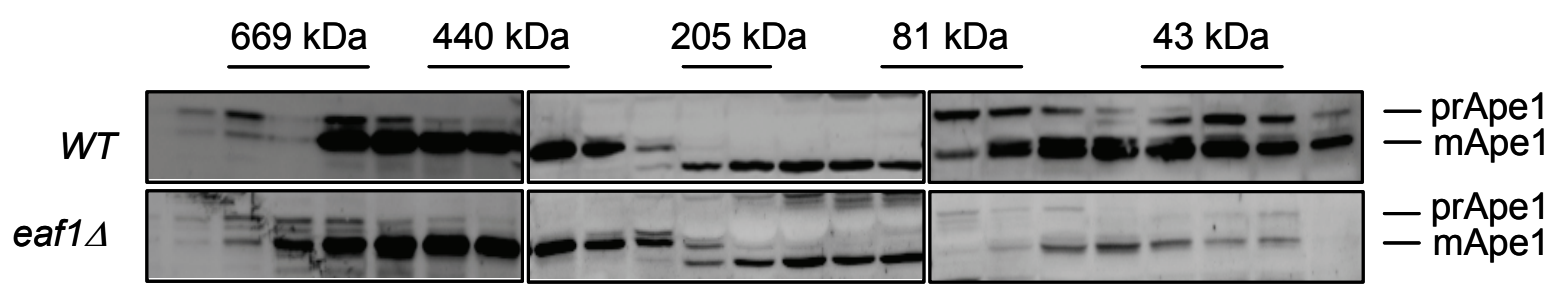
Fraktionen
$14-21$
$22-29$
$30-37$

\section{Abb.31: Die Komplexassemblierung der Aminopeptidase 1 in den Stämmen WT und eaf1 4 .}

A Zellen einer logarithmisch wachsenden Hefekultur der Stämme WT (y96) und eaf1 $\Delta$ (y126) wurden sphäroblastiert und mit DEAE-Dextran lysiert. Zur Subfraktionierung der zytosolischen (Ü) und vakuolären Fraktion $(P)$ wurde das Lysat bei $5000 \mathrm{~g}$ zentrifugiert. Die lysierten Zellen wurden in Abwesenheit (-) und Anwesenheit von Triton X-100 (Det.) mit Trypsin (Tr.) oder Proteinase K (PrK.) inkubiert. Die Zellfraktionen und mit Proteasen behandelten Zellen wurden auf einem 10\%-igen Polyacrylamidgel elektrophoretisch aufgetrennt, auf eine PVDF-Membran transferiert und mit antiCPY, anti-PGK und mit anti-Ape1 Serum inkubiert. B Logarithmisch wachsende Zellen der Stämme $W T$ und eaf1 $\Delta$ wurden mittels Glasperlenaufschluss lysiert. $200 \mu \mathrm{g}$ Gesamtprotein wurde über eine Gelfiltrationssäule in $30 \mu \mathrm{l}$ Fraktionen eluiert. Die Proben wurden mit TCA gefällt und per Western Blot mit anti-Ape1 Serum analysiert. 


\section{Diskussion}

\subsection{Suppression der Ape1-Aktivitätsdefizienz in den Mutanten via10 und via14}

Die Aminopeptidase 1 (Ape1) ist eine Leucin-Exopeptidase, welche die Spaltung aminoterminaler Leucine von Polypeptiden in der Vakuole von Saccharomyces cerevisiae katalysiert. Das Protein wird, wie viele andere Peptidasen, als Vorläuferform im Zytoplasma synthetisiert und oligomerisiert anschließend zu Homododecameren. Diese bilden zusammen mit dem Ape1-Rezeptor Atg19 und der $\alpha$-Mannosidase (Ams1) den sog. Cvt (Cytoplasm to Vacuole Targeting)-Komplex, der in Vesikeln verpackt über den Cvt-Transportweg in die Vakuole transportiert wird. Dort wird unter Abspaltung des Propeptids die prApe1 zur mApe1 („mature“ Ape1) prozessiert (Klionsky et al., 1992). Experimentell kann die Aktivität der Ape1 durch Spaltung des Substrats H-Leucin- $\beta$-Naphtylamid verfolgt werden (3.18).

Um die Biogenese der Ape1-Aktivität besser zu verstehen wurde eine EMSMutagenese an Hefestämmen durchgeführt, die zur Isolierung zweier Mutanten, welche unter logarithmischen und hungerinduzierten Wachstumsbedingungen nur geringe, bzw. keine Ape1-Aktivität zeigten, führte (Andrei-Selmer et al., 2001). Die mit via10 und via14 (via - vacuole import and autophagocytosis) bezeichneten Mutanten zeigten eine verringerte Ape1-Expression und unter logarithmischen Wachstumsbedingungen eine erhöhte Akkumulation der prApe1 im Zytosol. Der Verlust der Ape1-Aktivität, eine fehlerhafte Komplexassemblierung der prApe1 und ihre erhöhte Sensitivität auf Proteasen, ließen auf eine nicht native Konformation des Proteins in den zwei Mutanten schließen (Andrei-Selmer et al., 2001). Zur Identifikation der für diesen Phänotyp verantwortlichen Gene, wurden Komplementationsstudien durchgeführt und ein ca. $1.3 \mathrm{~kb}$ großer Genabschnitt auf Chromosom IV isoliert, der die Aktivität der Ape1 wiederherstellte. Der Genabschnitt beinhaltete den 435 bp großen ORF YDR360W und auf dem Gegenstrang den Aminoterminus (862 bp) des 2949 bp großen ORFs YDR359C, die sich um 286 bp überlappen (Abb.7). In der Dissertation von P.N. Rekha wurde der ORF YDR360W in Hinblick auf die Restauration der Ape1-Aktivität verifiziert. Sequenzvergleiche ergaben, dass dieser ORF in den via-Mutanten intakt war, und das bis dato zu keiner klassifizierten Proteinfamilie gehörende Protein wurde als Suvia1 (suppressor of via) 
bezeichnet. Der N-Terminus des ORFs YDR359C ist Teil des Proteins Eaf1 (Esa1associated factor). Dieses Protein bildet mit zwölf weiteren Untereinheiten den NuA4 (nucleosome acetyltransferase of H4)-Komplex. Seine katalytische Untereinheit Esa1 ist für die Acetylierung des Histons $\mathrm{H} 4$ und der Histon H2A-Variante Htz1 verantwortlich. Weiter reguliert der Komplex eine Vielzahl von zellulären Ereignissen, wie Transkription, DNA-Reparatur und Chromosomen-Segregation (Krogan et al., 2004; Doyon und Côté, 2004; Squatrito et al., 2006; Altaf et al., 2007; Thomas und Voss, 2007).

In dieser Arbeit sollte die Bedeutung der Proteine Suvia1 und Eaf1 für die Biogenese der Ape1 weiter charakterisiert werden.

Das bisher verwendete System zur Untersuchung der Ape1-Aktivität beruhte auf Hefestämmen mit episomalem APE1-Gen auf "single copy“-Plasmiden. Dies hatte vor allem bei der EMS-Mutagenese den großen Vorteil, dass durch sog. Plasmidverlustexperimente und anschließender Retransformation der APE1 ausgeschlossen werden konnte, dass die beobachtete phänotypische Veränderung durch eine Mutation der Ape1 ausgelöst wurde (Andrei-Selmer et al., 2001). Allerdings hatte dieses System den Nachteil, dass episomale Plasmide in unterschiedlichen Kopienzahlen in der Zelle vorlagen, was Aussagen über einen Zusammenhang von exprimierten Proteinmengen und Aktivität verhinderten. Ein weiterer Nachteil war, dass für die Charakterisierung weiterer Gene Doppeltransformationen, verbunden mit der Selektion der Hefestämme auf zwei Auxotrophiemarkern, nötig waren. Vor allem in Ape1-Overlay-Assays (3.18) zur Bestimmung der Ape1-Aktivität wurden große Schwankungen beobachtet, so dass das APE1-Gen jeweils in den URA3-Locus des Ausgangstammes y 25 und den beiden Mutantenstämmen integriert wurde. Die Expression der integrierten APE1 wurde in Western Blot-Analysen (Abb.12) untersucht. Der neu generierte WT-Stamm zeigte gegenüber dem Ursprungsstamm C6C eine um ca. 50\% verringerte Ape1Expression. Dies ließ sich mit der zwei- bis fünffach höheren Kopienzahl des episomalen Plasmids im Stamm C6C erklären. Auch der neu generierte Stamm via10-2 exprimierte geringfügig weniger Ape1 als die Ursprungsmutante via10, was ebenfalls auf die höhere Kopienzahlen des Plasmids zurückzuführen war. Via14-2 dagegen zeigte eine erhöhte Ape1-Expression im Vergleich zu Stamm via14, in welchem die Ape1-Expression nur schwer in Western Blot-Analysen nachzuweisen war (Andrei-Selmer et al., 2001). Es wurde beobachtet, dass die Mutanten via14 und 
via14-2 eine zehnmal geringere Transformationsrate als die WT-Stämme C6C und y96 besaßen, und Versuche Plasmide aus diesen Stämmen zu isolieren, erwiesen sich als sehr schwierig (Daten nicht gezeigt). Es kann nicht ausgeschlossen werden, dass in via14 transformierte episomale Plasmide nicht stabil vererbt werden, während ein Verlust des APE1-Gens nach Integration auszuschließen ist. Dies könnte die beobachteten Schwankungen der Ape1-Expression erklären. Die Ape1Aktivität der beiden WT-Stämme unterschied sich entsprechend ihrer Expressionshöhen und der Kopienzahl des APE1-Gens, d.h. der Stamm C6C war um ca. $50 \%$ aktiver als der neu generierte WT-Stamm (y96). Die Mutante via10-2 zeigte mit integriertem APE1-Gen keine Aktivität mehr, während in via10 noch $20 \%$ der WT-Aktivität zu detektieren war (Andrei-Selmer et al., 2001). Dieser Unterschied ist auch auf die erhöhte Kopienzahl des episomalen APE1-Gens in via10 zurückzuführen. Die Mutanten via14 und via14-2 hatten beide keine messbare Ape1Aktivität. Die hergestellten Hefestämme mit integrierter APE1 erwiesen sich als stabil und lieferten reproduzierbare Ergebnisse, weshalb in dieser Arbeit ausschließlich mit diesen Stämmen gearbeitet wurde.

\subsection{ORF YDR360W hat keinen Einfluss auf die Aminopeptidase 1-}

\section{Aktivität}

In der Dissertation von P.N. Rekha wurde gezeigt, dass die Expression des ORFs YDR360W zur Wiederherstellung der Ape1-Aktivität führte. Diese Daten sollten nun verifiziert und ORF YDR360W näher charakterisiert werden. Nach Transformation von YDR360W-HA in die Mutantenstämme via10-2 und via14-2 und den Deletionsstamm ydr360w $\Delta$ konnte jedoch keine Ape1-Aktivität im Overlay-Assay detektiert werden (Abb.13). Auch die Transformation in die Ursprungsstämme via10 und via14 konnten den Einfluss des Proteins Ydr360w nicht bestätigen. Es wurde stattdessen beobachtet, dass die Vektoren $p Y X 141$ oder $p Y X 242$, die zur Expression von C-terminal HA-markierten Proteinen verwendet wurden in den Mutantenstämmen via10 und via10-2 einen hohen, in seiner Intensität mit dem WTStamm vergleichbaren Hintergrund zeigten. Die verwendeten Vektoren trugen das LEU2-Gen als Selektionsmarker. Bei Verwendung des Vektors $p Y X 132$, welcher an dessen Stelle das TRP1-Gen enthält, war die Hintergrundaktivität gering (Daten nicht 
gezeigt). Somit interferierte höchstwahrscheinlich die Expression des LEU2Auxotrophiemarkers mit dem Substrat $\mathrm{H}$-Leucin- $\beta$-Naphtylamid und verhinderte eine korrekte Bestimmung der Ape1-Aktivität in den Stämmen via10 und via10-2. Dies erklärt zudem, warum die Expression von YDR360W in pYX141 oder -242 ursprünglich zur Identifikation von Suvia1 als verantwortliches Protein für die Wiederherstellung der Ape1-Aktivität im Mutantenstamm via10 führte (Dissertation P.N. Rekha).

In S. cerevisiae gibt es 2997 überlappende ORFs (>100 Codons). Bei ca. 90\% dieser ORFs ist lediglich einer davon proteinkodierend (Cebrat et al., 1998). Wie bereits erwähnt und in Abbildung 7 illustriert, überlappen YDR359C und YDR360W um 286 bp, dies entspricht $66 \%$ des ORFs YDR360W. Da der größere der beiden ORFs eindeutig verifiziert war, sollte nun geklärt werden, ob und wenn ja, zu welchem Zeitpunkt ORF YDR360W in der Zelle transkribiert wird. Es wurden Northern BlotAnalysen mit logarithmisch wachsenden und gehungerten Zellen durchgeführt, die zwar die Transkription des ORFs YDR359C, allerdings nicht die von YDR360W zeigen konnten (Abb.14). 2006 wurde eine Transkriptomanalyse des Genoms von Saccharomyces cerevisiae unter Anwendung eines "tiling arrays" veröffentlicht (Huber et al., 2006). Auch hier konnte die Transkription des ORFs YDR360W nicht bestätigt werden (Abb.15). Zusammenfassend ist deshalb zu schließen, dass es sich bei YDR360W mit sehr hoher Wahrscheinlichkeit um einen nicht-proteinkodierenden ORF handelt. 


\subsection{ORF YDR359C beeinflusst die Aminopeptidase 1-Aktivität}

Um zu überprüfen, ob der zweite, nur partiell vorgefundene ORF YDR359C die Aktivität der Ape1 beeinflusst, wurde das Gen zur Expression mit C-terminalen HA"tag" in die Vektoren $p Y X 141,-132$, und -242 kloniert und anschließend in die Stämme via10-2 (nur pYX132-Konstrukte) und via14-2 transformiert. In Ape1Overlay-Assays konnte gezeigt werden, dass YDR359C die Aktivität der Ape1 im Stamm via14-2 wiederherstellte, wobei die Expression des „single copy“-Plasmids ca. $80 \%$ der Aktivität des "high copy“-Plasmids, welches mit der WT-Aktivität von $100 \%$ vergleichbar war, erreichte. Hingegen führte die Expression des Proteins im Stamm via10-2 zu keiner Wiederherstellung der Ape1-Aktivität (Abb.16). YDR359C kann Ape1-Aktivität demnach nur in der Mutante via14-2, nicht aber in via10-2 induzieren.

Um nun den Verlust des ORFs YDR359C in Hinblick auf die Ape1-Aktivität näher zu untersuchen, wurden Deletionsstämme hergestellt, wobei entweder der ORF YDR359C alleine oder zusammen mit YDR360W durch das Homolog des HIS3Gens aus Schizosaccharomyces pombe ersetzt wurden (Abb.17). Beide Stämme zeigten im Ape1-Overlay-Assay keine Aktivität der Ape1. YDR359C hat folglich direkten Einfluss auf die Funktionalität der Ape1. Dies wurde durch Transformation des YDR359C-HA-Konstrukts bestätigt, welches die Aktivität abhängig von der jeweiligen Expressionsstärke komplementieren konnte (Abb.16).

\subsubsection{Eaf1 suppremiert den Aktivitätsverlust im Mutantenstamm via14-2}

Als nächstes sollte geklärt werden, wie dieser ORF den Aktivitätsverlust der beiden Mutantenstämmen via10-2 und vor allem via14-2 beeinflusste. Sequenzvergleiche von Mutantenstämmen und WT-Stamm zeigten keine Unterschiede, weshalb davon auszugehen ist, dass der ORF YDR359C in den Mutantenstämmen intakt ist und deshalb transkribiert werden sollte. Eine definitive Aussage über die Proteinexpression ließ sich aber mangels eines Eaf1-Antikörpers nicht machen.

Krogan et al. (2004) beschreiben einen direkten Einfluss von Eaf1 auf die Hyperacetylierung des Histons H4. In Abb.19 gezeigten Versuchen wurde die Funktionalität des Proteins in den Mutantenstämmen daraufhin untersucht. Es konnte 
kein Rückgang der $\mathrm{H} 4$ Hyperacetylierung festgestellt werden, es war im Gegenteil sogar ein Anstieg im Vergleich zum WT-Stamm zu beobachten (Abb.19). Die Acetylierung von Histonen wird mit transkriptioneller Aktivierung in direkten Zusammenhang gebracht. Dabei führt die Acetylierung der Lysin-Reste am Aminoterminus der Histone $\mathrm{H} 3$ und $\mathrm{H} 4$ zu der Neutralisation ihrer positiven Ladung, was mit einer Verringerung der DNA-Affinität einhergeht und somit zur Dekompaktierung des Chromatins beiträgt (Vettese-Dadey et al., 1996; Grunstein, 1997). Die gesteigerte H4 Hyperacetylierung in den Mutantenstämmen lässt sich, mit den durch ungerichtete EMS-Mutagenese entstandenen multiplen Mutationen und der damit erhöhten Transkriptionaktivität in diesen Hefen erklären. Sowohl eine Vielzahl von Kinetochore- und Spindelkontrollpunkt-Mutanten, als auch der eaf1AStamm reagieren hypersensitiv auf die Mikrotubuli destabilisierende Chemikalie Benomyl (Kobor et al., 2004; Krogan et al., 2004). Die Mutante via14-2 zeigte in Anwesenheit von Benomyl keinerlei Wachstumsveränderungen, wohingegen in via10-2 zwar ein Defekt der Mikrotubulistabilität beobachtet wurde, dieser jedoch Eaf1-unabhängig war. Daraus lässt sich schlussfolgern, dass Eaf1 zwar die Ape1Aktivität des Mutantenstammes via14-2 wiederherstellen kann, dieser Effekt allerdings nicht auf die Komplementation eines mutierten EAF1-Gens zurückzuführen ist, sondern es sich hierbei um einen Suppressor-Phänotyp handelt.

\subsubsection{Analyse von Eaf1-Domänen für die Induktion der Ape1-Aktivität}

Eaf1 ist ein $112 \mathrm{kDa}$ großes Protein mit zwei beschriebenen Domänen und einem Motiv: einer HSA- (Helicase/SANT-Associated), einer SANT- (Swi3-Ada2-NCoRTFIIIB)-Domäne und einer Glutamin-reichen Region. Um den Einfluss verschiedener Abschnitte des Eaf1-Proteins auf die Ape1-Aktivität zu untersuchen, wurden aminound carboxyterminale Verkürzungen hergestellt (Abb.21) und in Overlay-Assays getestet (Abb.22).

Es konnte gezeigt werden, dass der Hauptanteil des Ape1-Aktivitätsgewinns durch den C-Terminus des Proteins induziert wurde. Dieser Teil des Proteins beinhaltete alle Domänen und sollte demnach funktionell dem Gesamtprotein weitestgehend entsprechen. Allerdings konnte auch der wesentlich kleinere $\mathrm{N}$-Terminus (Aminosäuren 1 bis 287) Ape1-Aktivität wiederherstellen (Abb.22). Zum einen erklärt dieser Befund weshalb das Gen im Komplementationsscreen gefunden wurde, da 
der identifizierte Genabschnitt nur diesen Teil des Proteins beinhaltete (Abb.7). Zum anderen wiederum ist es erstaunlich, dass beide, $\mathrm{N}$ - und $\mathrm{C}$-terminale Verkürzungen Ape1-Aktivität induzieren. Diese Beobachtung könnte ein Hinweis darauf sein, dass die Aminopeptidase 1 und Eaf1 nicht direkt interagieren, sondern Eaf1 als Teil eines Komplexes wirkt und Proteinfragmente Komplexpartner binden oder blockieren.

\subsubsection{Der Einfluss von Eaf1 innerhalb des NuA4-Komplexes}

Eine beschriebene Funktion des Proteins Eaf1 innerhalb des NuA4-Komplexes ist die Hyperacetylierung von Histon H4. Außerdem führt die Deletion des Genlocus YDR359C zu einer Hypersensitivität auf die mikrotubulidestabilisierende Chemikalie Benomyl (Krogan et al., 2004 und Kapitel 4.4). Nachdem gezeigt wurde, dass die Eaf1 N- und C-terminalen Verkürzungen die Ape1-Aktivität wiederherstellen, sollte überprüft werden, ob der Rückgewinn der Aktivität in Zusammenhang mit den Funktionen des Proteins als Teil des Kernkomplexes stehen (4.8). Es wurde beobachtet, dass der Aminoterminus mit den Aminosäuren 1 bis 287 im Vergleich zum Deletionsstamm die Hyperacetylierung von H4 kaum steigern konnte. Zusätzlich hatte die Expression dieses Fragmentes keinen Einfluss auf die Ape1-Expression und das Wachstum der Hefen auf $15 \mu \mathrm{g} / \mathrm{ml}$ Benomyl-haltigen Vollmediumplatten war vor allem unter „single copy“-Expressionsbedingungen mit dem des eaf1 1 -Stammes vergleichbar. Dieses C-terminal verkürzte, niedrigexprimierte Konstrukt war allerdings, wenn auch nicht in vollem Maße in der Lage Ape1-Aktivität zu komplementieren. Die N-terminale Verkürzung (Aminosäuren 283 bis 981), welches einen wesentlich stärkeren Einfluss auf die Ape1-Aktivität hatte, zeigte auch eine gesteigerte H4 Hyperacetylierung, verbunden mit einem Anstieg der Ape1Expression und unter starken Expressionsbedingungen $(2 \mu)$ normales Wachstum unter Einfluss von Benomyl oder erhöhter Temperatur (Abb.25). Dies deutete darauf hin, dass der durch die Eaf1-Verkürzungen induzierte Rückgewinn der Ape1-Aktivität möglicherweise in direktem Zusammenhang mit der beschriebenen Funktion des Proteins innerhalb des NuA4-Komplexes steht. Die Mutation des potentiellen Kernlokalisationssignals scheint keinen Einfluss, weder auf das Wachstumsverhalten, auf die Expression der Ape1 oder die Hyperacetylierung von H4, noch auf die Wiederherstellung der Ape1-Aktivität zu nehmen. Jedoch könnte das Protein ein zweites Signal am C-terminus besitzen und somit auch nach 
Mutation des $\mathrm{N}$-terminus nicht beeinträchtigt sein oder Eaf1 gelangt mittels eines anderen Proteins in den Kern und benötigt somit das eigene Kernlokalisationssignal nicht. In situ Immunfluoreszenzen und Zellfraktionierungen könnten zur Klärung der Lokalisation des Proteins und seiner Verkürzungen abschließend beitragen.

\subsubsection{Eaf1 induziert die Aminopeptidase 1-Transkription und -Expression}

Bis jetzt konnten wir unsere Beobachtung, dass zum einen die Deletion des Genlocus' YDR359C zu einem Verlust der Ape1-Aktivität führte, und dass zum anderen nach Transformation von YDR359C/EAF1 Ape1-Aktivität in dem Mutantenstamm via14-2 und in der Deletionsmutante wiederhergestellt, bzw. komplementiert wurde, nicht auf eine konkrete Funktion des Proteins Eaf1 zurückführen. Western und Northern Blot-Analysen zeigten, dass die Stämme via102 und eaf1 $\triangle$ eine um 40 bis $60 \%$ geringere APE1-Transkription und Ape1-Expression im Vergleich zum WT- oder via14-2-Stamm aufwiesen (4.6). Nach Transformation von EAF1 wurde schon unter niedrigen Expressionsbedingungen (cen) ein Anstieg der Ape1-Expression bis zu 40\% im Vergleich zum WT beobachtet, welcher in direktem Zusammenhang mit der Transkription des APE1-Gens stand (Abb.23C). Die Transformation von EAF1 in die beiden Mutantenstämme via10-2 und via14-2 führten allerdings nur zu einer geringen Steigerung der Ape1-Expression (Abb.23A), was auf RNA-Ebene verifiziert wurde. Da in diesen Zellen das endogene Eaf1Protein nicht mutiert und somit funktionell ist, resultierte eine Überexpression des Proteins in einen milderen Phänotyp, im Vergleich mit dem Deletionstamm eaf1 $\triangle$. Der NuA4-Komplex ist an der Genregulation beteiligt und wird an Promotorregionen verschiedener, stark transkribierter Gene rekrutiert (Robert et al., 2004). Sollte der Einfluss des Proteins Eaf1 auf die Ape1-Aktivität ausschließlich in Zusammenhang mit dem NuA4-Komplex stehen, könnten Chromatin Immunopräzipitation (ChIP) Assays Aufschluss geben, ob sich der Komplex in der Promotorregion des APE1Gens befindet und dessen Transkription reguliert. Zur Durchführung dieses Versuches, bei dem die Protein-DNA-Interaktion über Co-Immunopräzipitation nachgewiesen wird, wurde das Protein mit N-terminalem HA-,tag" kloniert und die Expression mit anti-HA Antikörpern in Western Blot-Analysen überprüft (Abb.29A), zusätzlich wurden Eaf1-spezifische Peptidantikörper hergestellt, die zur Zeit getestet werden. 
Wie einleitend beschrieben, wird neben der Ape1 auch die $\alpha$-Mannosidase (Ams1) über den Cvt-Transportweg in die Vakuole transportiert. Dabei benötigt die Ams1 die Interaktion mit seinem Cargo-Protein Ape1 und deren Rezeptor Atg19 (Thumm, 2002; Abb.3). In dieser Arbeit sollte nach beobachtetem Rückgang der Ape1-Aktivität und -Expression, der Einfluss der Ape1 auf die Aktivität der vakuolären $\alpha$-Mannosidase untersucht werden (4.7). Sowohl in den beiden Mutantenstämmen via10 und via14 als auch in dem Deletionsstamm eaf1 $\Delta$ wurde ein Rückgang der Ams1-Aktivität um mindestens $50 \%$ im Vergleich zu den WT-Stämmen C6C und y96 beobachtet. In den Mutantenstämmen und dem Deletionsstamm ist die Ape1Expression reduziert. Wirkt sich dieser Rückgang an Ape1 auf den Transport von Ams1 aus, würde dieses Ergebnis in Einklang mit dem beschriebenen Modell, nämlich dass das Protein Ape1 für den Transport der Ams1 essentiell ist, stehen. Der Verlust der Ape1-Aktivität könnte auch einen negativen Einfluss auf die Ams1Aktivität haben, dies konnte allerdings nicht abschließend geklärt werden. Stattdessen stellt sich die Frage, ob die beobachtete Reduktion der Ams1-Aktivität auf die reduzierte Ape1-Expression und somit auf einen eingeschränkten Transport zurückzuführen ist, oder ob die Expression der Ams1 selbst reduziert war. Dies konnte abschließend nicht geklärt werden, da für Expressionsstudien an Ams1 kein endogener Antikörper zur Verfügung stand und eine Quantifizierung der Proteinexpression aufgrund von drei Ams1-Isoformen erschwert ist (Yoshihisa und Anraku, 1989). In diesem Fall würden eventuell Northern Blot-Analysen klären, ob der beobachtete Rückgang der Ams1-Aktivität in direktem Zusammenhang mit der Ape1-Expression steht.

\subsubsection{Auswirkung einer Ape1-Überexpression auf die Ape1-Aktivität}

Sollte der Einfluss des Proteins Eaf1 auf eine reduzierte APE1-Transkription und somit -Expression, also auf den Einfluss des NuA4-Komplex zurückzuführen sein, müsste die Expression der Ape1 alleine schon in der Lage sein, Ape1-Aktivität in den Stämmen via14-2 und eaf1A zu induzieren. In Ape1-Overlay-Assays ließ sich allerdings beobachten, dass erst eine um 400\%, bzw. 500\% (2 $\mu)$ gesteigerte Ape1Expression die Ape1-Aktivität wiederherstellen konnte, während nach Transformation des EAF1-Gens im Deletionsstamm eaf1A, bzw. im Stamm via14-2 ein Anstieg der 
Ape1-Expression um maximal 20\% im Vergleich zum $W T$ zu beobachten war, die ebenfalls Ape1-Aktivität induzierte (Abb.28). Dies führte zu dem Schluss, dass zum einen die Ape1-Expressionshöhe die Aktivität der Ape1 beeinflusst und dass zum anderen das Protein Eaf1 nicht nur die Expression reguliert, sondern darüber hinaus eventuell an der Stabilität oder der Faltung der Ape1, die sich dann positiv auf die Aktivität des Proteins auswirkt, beteiligt ist.

\subsection{Weitere NuA4-Deletionsmutanten haben keinen Einfluss auf die} Aktivität der Ape1

Der NuA4-Komplex besteht aus dreizehn Untereinheiten, sechs davon sind essentiell, inklusive der Acetyltransferase Esa1, und sieben werden für das Überleben der Zelle nicht benötigt (Doyon und Côté, 2004; Abb.26A). Zur Verifizierung unserer Hypothese, dass zwar Eaf1 die Aktivität der Ape1 beeinflusst, dies aber nicht nur auf einen transkriptionellen Effekt zurückzuführen ist, wurden die sechs verbleibenden nicht-essentiellen Untereinheiten Yng2, Eaf3, Eaf5, Eaf6, Eaf7 und Yaf9 jeweils im WT-Stamm deletiert und die Ape1-Aktivität bestimmt. Durch Deletion der Proteine Yng2, Eaf5, Eaf6 und Eaf7 war die Ape1-Aktivität nicht beeinflusst. Die Deletion der Gene EAF3 und YAF9 führten jeweils zu einem geringen Rückgang (20, bzw. 30\%) der Ape1-Aktivität im Vergleich zum WT-Stamm (Abb.27), ein kompletter Verlust wurde bei keinem der getesteten Stämme beobachtet. Auch die Transformation des YNG2-Gens in den eaf14-Stamm hatte keinen Einfluss auf die Aminopeptidase 1. Yng2 interagiert direkt mit Eaf1 und ist ebenfalls an der Hyperacetylierung der Histone $\mathrm{H} 4$ und H2A beteiligt (Krogan et al., 2004). Diese Daten unterstreichen erneut, dass der beobachtete Effekt, der totale Rückgang der Ape1-Aktivität, zwar in direktem Zusammenhang mit Eaf1, möglicherweise aber nicht zwangsläufig mit Eaf1 als Bestandteil des NuA4Komplexes steht. Die Reduktion der Aktivität nach Deletion der Gene EAF3 und YAF9 könnte eher darauf hindeuten, dass diese Proteine mit Eaf1 interagieren und unabhängig von NuA4 die Ape1-Aktivität regulieren. Eine Interaktion dieser drei Proteine konnte mit TAP-,tag“" markiertem Esa1 jedenfalls nicht ausgeschlossen werden (Mitchell et al., 2008). 


\subsection{HA-Eaf1 co-lokalisiert mit der Ape1 im Zytoplasma}

Der Nachweis der Eaf1-Expression in Western Blot-Analysen gestaltete sich schwierig. Das Protein wurde bis dato in $p Y X$-Hefevektoren exprimiert (3.5), die das Protein C-terminal mit einem HA-,tag“ fusionierten, deren Expression aber nur phänotypisch oder auf transkriptioneller Ebene nachweisbar waren. Auch der Austausch des einfachen HA-,tags" mit einem dreifachen führte zu keinem positiven Ergebnis, so dass die Vermutung nahe liegt, dass der exprimierte HA-,tag“ unter Umständen maskiert und deshalb in Western Blot-Analysen nicht nachweisbar ist. Dies ist allerdings eher unwahrscheinlich, da die Proteinproben denaturiert waren und somit alle Peptide frei zugänglich sein sollten. Auch könnte der C-Terminus aus noch unbekannten Gründen nach Expression des Proteins abgespalten werden und deshalb von Antikörpern nicht mehr detektiert werden. Da die carboxyterminale Fusion eines „tags" nicht den gewünschten Erfolg brachte, wurden die Vektoren mit aminoterminalen HA-,tags“ versehen. Die Expression von HA-Eaf1 konnte dann sowohl in Western Blot-Analysen, als auch in in situ ImmunfluoreszenzExperimenten nachgewiesen werden (Abb.29). Dabei konnte gezeigt werden, dass HA-Eaf1 nicht nur im Kern, sondern auch als punktuelle Struktur im Zytoplasma zusammen mit RFP-Ape1 co-lokalisiert. RFP-Ape1 befindet sich in logarithmisch wachsenden Zellen am PAS und kann erst in der stationären Phase in der Vakuole nachgewiesen werden (Klionsky et al., 1992). Diese Beobachtungen müssen nun weiter verifiziert werden, indem zum einen HA-Eaf1-Verkürzungen auch auf ihre zelluläre Verteilung hin untersucht werden, sowohl in in situ Immunfluoreszenzen, als auch in Zellfraktionierungsexperimenten. Die Detektion von HA-Eaf1 im Zytoplasma, genauer am PAS könnte auch auf eine Akkumulation des Proteins durch dessen Überexpression in der Hefezelle zurückzuführen sein. Western Blot-Analysen zeigten allerdings keine starke Expression des Proteins. Ein Vergleich mit endogenen Proteinmengen war bisher mangels Antikörper jedoch nicht möglich. Aus diesem Grund wurden Peptid-Antikörper generiert, die momentan getestet werden. Eine Überexpression von Eaf1 und somit die Gefahr Artefakte in Hinblick der zellulären Verteilung des Proteins zu riskieren, würde sich auch durch Integration eines "tags“ vor das Startcodon des Genlocus YDR359C reduzieren. 
Die Co-Lokalisation von RFP-Ape1 und HA-Eaf1 müsste zum einen in eaf14- und ape1A-Stämmen untersucht werden, um den Einfluss der jeweiligen endogenen Proteine zu minimieren, und zum anderen in einem atg194-Stamm. Atg19 ist der Ape1-Rezeptor, der nach Synthese und Oligomerisierung der Ape1 bindet und somit die Rekrutierung der Cvt-Vesikel in die Vakuole reguliert (Thumm, 2002). Bei Verlust von Atg19 akkumuliert die Ape1 am PAS und wird unter logarithmischen Wachstumsbedingungen nicht mehr in die Vakuole transportiert. Deshalb eignet sich dieses System um eine Abhängigkeit von HA-Eaf1-Lokalisation und -Prozessierung vom Cvt-Transportweg zu testen. Eine direkte Interaktion von Eaf1 und Ape1 konnte bis jetzt in "Yeast two Hybrid"-Studien nicht nachgewiesen werden (Abb.30). Das Exprimieren beider Gene als HA- oder Myc-,tag"-Fusionsproteine, könnte deren Faltung negativ beeinflusst haben (4.10), so dass eine mögliche Interaktion mit diesem System nicht nachgewiesen werden kann. Außerdem könnten auch die in der Hefe endogen exprimierten Proteine Ape1 und Eaf1 den Nachweis stören. Nachdem jetzt ein funktioneller "tag“ zur Verfügung steht, sollten CoImmunopräzipitationen weitere Hinweise auf eine mögliche direkte Interaktion der Proteine Eaf1 und Ape1 geben, bzw. zur Identifikation noch unbekannter Interaktionspartner führen.

\subsection{Die Komplexassemblierung der Ape1 wird durch Deletion von} EAF1 nicht beeinträchtigt

Da in den via-Mutanten die Komplexassemblierung der prApe1 beeinträchtig war, was die Mutantenstämme sensitiver auf die Behandlung mit Proteasen reagieren ließ (Andrei-Selmer et al., 2001), sollte nun untersucht werden, ob die Deletion des Proteins Eaf1 und der damit verbundene Verlust der Ape1-Aktivität auf einen Defekt der Ape1-Komplexassemblierung, d.h. einer nicht nativen Konformation des Proteins zurückzuführen war. Die Sensitivität der Stämme WT und eaf1 $\Delta$ wurde jeweils mit den Proteasen Trypsin und Proteinase K in An- und Abwesenheit des Detergenz Triton X-100 in sog. Protease Sensitivitäts-Assays getestet (Abb.31A). Die Aminopeptidase 1 beider Stämme wurde erst nach Zugabe der unspezifischen Proteinase $\mathrm{K}$ und Triton $\mathrm{X}-100$ geringfügig prozessiert, was auf korrekt gefaltetes Protein in WT- und eaf1A-Stämmen zurückzuführen ist. Zusätzlich wurde die intakte 
Komplexassemblierung der Ape1 in Gelfiltrationsexperimenten verifiziert, in denen zu beobachten war, dass das Protein in WT- und eaf1A-Stämmen in den gleichen Fraktionen eluierte (Abb.31B). Der beobachtete Rückgang der monomeren Isoform der Ape1 im eaf1 1 -Stamm lässt sich mit der bereits beschriebenen reduzierten Expressionshöhe des Proteins im Vergleich zum WT erklären. Schlussfolgernd ist zu sagen, dass nach Deletion des EAF1-Gens die Ape1-Expression zwar reduziert ist, die Deletion aber nicht deren Synthese und die anschließende Oligomerisierung und Prozessierung beeinflusst. Dennoch besitzt der unter diesen Bedingungen gebildete Ape1-Komplex keine enzymatische Aktivität.

\subsection{Ausblick}

Mit Eaf1 wurde hier ein Protein isoliert, das maßgeblich an der Aktivierung der vakuoläre Aminopeptidase 1 beteiligt ist. Zum einen führte die Expression des Eaf1HA Konstrukts zur Wiederherstellung der Ape1-Aktivität in der Mutante via14-2, zum anderen resultiert die Deletion des EAF1-Gens in einem kompletten Verlust der Ape1-Aktivität und einer Reduktion der Ape1-Expression. In der Literatur wird die Funktion von Eaf1 vor allem als Teil des Acetyltransferase-Komplexes NuA4 beschrieben, wo es zusammen mit dem Protein Yng2 an der Hyperacetylierung des Histons $\mathrm{H} 4$ beteiligt ist (Krogan et al., 2004). Außerdem wird dem Protein eine exklusive Rolle im Zusammenhalt und der Assemblierung durch unabhängige Interaktionen mit funktionellen Teilkomplexen von NuA4 zugeschrieben (Auger et al., 2008; Mitchell et al., 2008). Ob der beobachtete Effekt, also der Einfluss von Eaf1 auf die Aktivität der Aminopeptidase 1 auf eine dem NuA4-Komplex unabhängige Funktion zurückzuführen ist, konnte hier nicht abschließend geklärt werden.

Die Tatsache, dass sowohl die $\mathrm{N}$ - als auch die C-terminalen Verkürzungen von Eaf1 Ape1-Aktivität induzieren konnten, spricht für eine komplexgebundene Funktion des Proteins. Da diese Verkürzungen funktionell in Hinblick auf die Hyperacetylierung von $\mathrm{H} 4$, der Expression des APE1-Gens und dem Wachstum der Hefen auf Benomyl-haltigem Medium und der erhöhten Temperatur von $37^{\circ} \mathrm{C}$ in direktem Zusammenhang mit beschriebenen Aufgaben des NuA4 korrelierten, deutet auf eine Beteiligung dieses Komplexes hin. Andererseits zeigte sich, dass erst eine massive Überexpression der Ape1 ihren Aktivitätsverlust ausgleicht, während eine unter 
Beteiligung von Eaf1 induzierte viel geringere Ape1-Expression schon ausreichte, denselben Effekt zu erzielen. Zudem führten die Deletionen der verbleibenden nichtessentiellen Proteine des NuA4 zu keinem, bzw. nur sehr mildem Phänotyp. Dies spricht zum einen wieder für eine Funktion des Eaf1 unabhängig des NuA4Komplexes, könnte allerdings zum anderen auch das oben genannte Model unterstützen, dass Eaf1 das zentrale Element für den Zusammenhalt und die Assemblierung des Komplexes darstellt. So wurde anhand von TAP-markiertem Esa1-Protein gezeigt, dass die jeweilige Eliminierung der Proteine Eaf3, Eaf5, Eaf6, Eaf7 und Yaf9 keinen Einfluss auf die Assoziation der verbleibenden Untereinheiten hatte, während die Deletion von Eaf1 zu einem dramatischen Rückgang der Komplex-Integrität führte und nur die Bindung der Proteine Epl1 und Yng2 an Esa1TAP nachweisbar war (Mitchell et al., 2008).

Die Lokalisation des Proteins außerhalb des Nukleus' und dessen eventuelle CoLokalisation mit RFP-Ape1 sprechen ebenfalls für eine Kern-unabhängige Funktion des Proteins, allerdings nicht zwangsläufig unabhängig vom NuA4-Komplex. Neuesten Studien einer genomweiten „synthetically lethal“ (SL) „synthetic genetic array" (SGA)-Analyse belegen, dass der NuA4-Komplex unter Umständen nicht nur, wie bisher angenommen, an nukleären Vorgängen beteiligt ist, sondern beispielsweise auch beim Proteintransport, genauer dem vesikulären Transport, bei der Stress-Antwort, der Arginin-Biosynthese und der Ubiquitinierung eine Rolle spielt (Mitchell et al., 2008). Es bleibt allerdings zu klären, ob diese Beobachtungen auf transkriptionelle Effekte oder - eher unwahrscheinlich - auf direkte Interaktionen des NuA4-Komplexes zurückzuführen sind. Aufgrund der großen Vielfalt der gefundenen zellbiologischen Prozesse, könnte der hier beobachtete Effekt, die Wiederherstellung der Ape1-Aktivität in Abhängigkeit des Proteins Eaf1, sowohl auf Eaf1 alleine, als auch auf eine noch nicht bekannte Funktion des NuA4-Komplexes zurückzuführen sein.

Zukünftige Experimente, wie z. B. ChIP-Assays könnten einen potentiellen Einfluss des Proteins auf die Transkription des APE1-Gens klären. Zudem würden Zellfraktionierungsexperimente und in situ Immunfluoreszenzen mit verschiedenen Deletionsmutanten Aufschluss über die Lokalisation und Prozessierung des HAEaf1-Proteins geben. Mit Co-Immunopräzipitationen könnte eine mögliche Interaktion mit der Ape1 untersucht werden und eventuell neue Interaktionspartner identifiziert werden. Außerdem würde ein Komplementationsscreen mit den Stämmen eaf1 $\Delta$ und 
via10-2, zum einen zur Klärung der Funktion von Eaf1 beitragen und zum anderen zur Identifikation der „VIA“-Gene führen, die für den Mutantenphänotyp direkt verantwortlich sind. 


\section{Literaturverzeichnis}

Aasland R, Stewart AF, Gibson T (1996) The SANT domain: a putative DNAbinding domain in the SWI-SNF and ADA complexes, the transcriptional co-repressor N-CoR and TFIIIB. Trends Biochem Sci. 21(3):87-8 Review

Abeliovich H, Dunn WA Jr, Kim J, Klionsky DJ (2000) Dissection of autophagosome biogenesis into distinct nucleation and expansion steps. J Cell Biol. 151(5):1025-34

Abeliovich H, Zhang C, Dunn WA Jr, Shokat KM, Klionsky DJ (2003) Chemical genetic analysis of Apg1 reveals a non-kinase role in the induction of autophagy. Mol Biol Cell. 14(2):477-90

Adachi W, Suzuki NN, Fujioka Y, Suzuki K, Ohsumi Y, Inagaki F (2007) Crystallization of Saccharomyces cerevisiae aminopeptidase 1, the major cargo protein of the Cvt pathway. 63(3):200-3

Altaf M, Saksouk N, Côté J (2007) Histone modifications in response to DNA damage. Mutat Res. 618(1-2):81-90 Review

Ammerer G, Hunter CP, Rothman JH, Saari GC, Valls LA, Stevens TH (1986) PEP4 gene of Saccharomyces cerevisiae encodes proteinase A, a vacuolar enzyme required for processing of vacuolar precursors. Mol Cell Biol. 6(7):2490-9

Andrei-Selmer C, Knüppel A, Satyanarayana C, Heese C, Schu PV (2001) A new class of mutants deficient in dodecamerization of aminopeptidase 1 and vacuolar transport. J Biol Chem. 276(15):11606-14

Auger A, Galarneau L, Altaf M, Nourani A, Doyon Y, Utley RT, Cronier D, Allard S, Côté J (2008) Eaf1 is the platform for NuA4 molecular assembly that evolutionarily links chromatin acetylation to ATP-dependent exchange of histone $\mathrm{H} 2 \mathrm{~A}$ variants. $\mathrm{Mol}$ Cell Biol. 28(7):2257-70

Baba M, Takeshige K, Baba N, Ohsumi Y (1994) Ultrastructural analysis of the autophagic process in yeast: detection of autophagosomes and their characterization. J Cell Biol. 124(6):903-13

Bankaitis,VA, Johnson, LM and Emr, SD (1986) Isolation of yeast mutants defective in protein targeting to the vacuole. Proc Natl Acad Sci USA 83(23): 90759079

Botstein D, Fink GR (1988) Yeast: an experimental organism for modern biology Science 240(4858):1439-43

Broach JR, Strathern JN, Hicks JB (1979)Transformation in yeast: development of a hybrid cloning vector and isolation of the CAN1 gene.Gene. 8(1):121-33 
Cereghino JL, Marcusson EG, Emr SD (1995) The cytoplasmic tail domain of the vacuolar protein sorting receptor Vps10p and a subset of VPS gene products regulate receptor stability, function, and localization. Mol Biol Cell 6(9):1089-102

Cebollero E, Gonzalez R. (2007) Autophagy: from basic research to its application in food biotechnology. Biotechnol Adv. 25(4):396-409 Review

Cebrat S, Mackiewicz P, Dudek MR (1998) The role of the genetic code in generating new coding sequences inside existing genes. Biosystems. 45(2):165-76

Chang YH, Smith JA (1989) Molecular cloning and sequencing of genomic DNA encoding aminopeptidase I from Saccharomyces cerevisiae. $J$ Biol Chem. 264(12):6979-83

Ciehanover A, Hod Y, Hershko A (1978) A heat-stable polypeptide component of an ATP-dependent proteolytic system from reticulocytes. Biochem Biophys Res Commun. 81(4):1100-5

Cooper AA, Stevens TH (1996) Vps10p cycles between the late-Golgi and prevacuolar compartments in its function as the sorting receptor for multiple yeast vacuolar hydrolases. J Cell Biol. 133(3):529-41

Cowles CR, Snyder WB, Burd CG, Emr SD (1997) Novel Golgi to vacuole delivery pathway in yeast: indentification of a sorting determinant and required transport component EMBO J. 16:2769-2782

Cuervo AM, Dice JF (1998) Lysosomes, a meeting point of proteins, chaperones, and proteases.J Mol Med. 76(1):6-12 Review

Cueva R, García-Alvarez N, Suárez-Rendueles $\mathbf{P}$ (1989) Yeast vacuolar aminopeptidase yscl. Isolation and regulation of the APE1 (LAP4) structural gene. FEBS Lett. 259(1):125-9

Darsow T, Katzmann DJ, Cowles CR, Emr SD (2001) Vps41p function in the alkaline phosphatase pathway requires homo-oligomerization and interaction with AP-3 through two distinct domains. Mol Biol Cell 12(1):37-51

Deloche O, Yeung BG, Payne GS, Schekman R (2001)Vps10p transport from the trans-Golgi network to the endosome is mediated by clathrin-coated vesicles. Mol Biol Cell 12(2):475-85

Dice JF (1990) Peptide sequences that target cytosolic proteins for lysosomal proteolysis. Trends Biochem Sci. 15(8):305-9 Review

Doyon Y, Côté J (2004) The highly conserved and multifunctional NuA4 HAT complex. Curr Opin Genet Dev. 14(2):147-54 Review

Epple UD, Suriapranata I, Eskelinen EL, Thumm M (2001) Aut5/Cvt17p, a putative lipase essential for disintegration of autophagic bodies inside the vacuole.J Bacteriol. 183(20):5942-55 
Erickson FL, Hannig EM (1995) Characterization of Schizosaccharomyces pombe his1 and his5 cDNAs. Yeast 11(2):157-67

Foreman PK, Davis RW (1994) Cloning vectors for the synthesis of epitope-tagged, truncated and chimeric proteins in Saccharomyces cerevisiae. Gene 144(1):63-8

Frey J, Röhm KH (1978) Subcellular localization and levels of aminopeptidases and dipeptidase in Saccharomyces cerevisiae. Biochim Biophys Acta. 527(1):31-41

Goffeau A, Barrell BG, Bussey H, Davis RW, Dujon B, Feldmann H, Galibert F, Hoheisel JD, Jacq C, Johnston M, Louis EJ, Mewes HW, Murakami Y, Philippsen P, Tettelin H, Oliver SG (1996) Life with 6000 genes. Science 274(5287):546, 563-7 Review

Grunstein M (1997)Histone acetylation in chromatin structure and transcription. Nature 389(6649):349-52. Review

Hancock LC, Behta RP, Lopes JM (2006) Genomic analysis of the Opi-phenotype. Genetics 173(2):621-34

Harding TM, Morano KA, Scott SV, Klionsky DJ (1995) Isolation and characterization of yeast mutants in the cytoplasm to vacuole protein targeting pathway.J CellBiol. 131(3):591-602

Hartley JL, Gregori TJ (1981) Cloning multiple copies of a DNA segment. Gene 13(4):347-53

Hashimoto C, Cohen RE, Zhang WJ, Ballou CE (1981) Carbohydrate chains on yeast carboxypeptidase $Y$ are phosphorylated. Proc Natl Acad Sci USA 78(4):2244-8

Hasilik A, Tanner W (1978) Biosynthesis of the vacuolar yeast glycoprotein carboxypeptidase $\mathrm{Y}$. Conversion of precursor into the enzyme.

Eur J Biochem. 85(2):599-608

Hemmings BA, Zubenko GS, Hasilik A, Jones EW (1981) Mutant defective in processing of an enzyme located in the lysosome-like vacuole of Saccharomyces cerevisiae. Proc Natl Acad Sci U S A. 78(1):435-9

Hong E, Davidson AR, Kaiser CA (1996) A pathway for targeting soluble misfolded proteins to the yeast vacuole. J Cell Biol. 135(3):623-33

Huber W, Toedling J, Steinmetz LM (2006) Transcript mapping with high-density oligonucleotide tiling arrays. Bioinformatics 22(16):1963-70

Hutchins MU, Veenhuis M, Klionsky DJ (1999) Peroxisome degradation in Saccharomyces cerevisiae is dependent on machinery of macroautophagy and the Cvt pathway. J Cell Sci. 112 (22):4079-87

Jones EW, Webb GC, Hiller MA (1997) Biogenesis and function of the yeast vacuole. molecular biology of the yeast Saccharomyces cerevisiae Vol. III. Cold Spring Harbor, New York: Cold Spring Harbor Laboratory Press, p 363- 469 
Kabeya Y, Kamada Y, Baba M, Takikawa H, Sasaki M, Ohsumi Y (2005) Atg17 functions in cooperation with Atg1 and Atg13 in yeast autophagy. Mol Biol Cell. 16(5):2544-53

Kabeya Y, Kawamata T, Suzuki K, Ohsumi Y (2007) Cis1/Atg31 is required for autophagosome formation in Saccharomyces cerevisiae. Biochem Biophys Res Commun. 356(2):405-10

Kamada Y, Funakoshi T, Shintani T, Nagano K, Ohsumi M, Ohsumi Y (2000) Tormediated induction of autophagy via an Apg1 protein kinase complex. $J$ Cell Biol. 150(6):1507-13

Kawamata T, Kamada Y, Suzuki K, Kuboshima N, Akimatsu H, Ota S, Ohsumi M, Ohsumi Y (2005) Characterization of a novel autophagy-specific gene, ATG29 Biochem Biophys Res Commun. 338(4):1884-9

Kihara A, Noda T, Ishihara N, Ohsumi Y (2001) Two distinct Vps34 phosphatidylinositol 3-kinase complexes function in autophagy and carboxypeptidase Y sorting in Saccharomyces cerevisiae. J Cell Biol. 152(3):519-30

Kim J, Huang WP, Klionsky DJ (2001) Membrane recruitment of Aut7p in the autophagy and cytoplasm to vacuole targeting pathways requires Aut1p, Aut2p, and the autophagy conjugation complex. J Cell Biol. 152(1):51-64

Kim J, Huang WP, Strømhaug PE, Klionsky DJ (2002) Convergence of multiple autophagy and cytoplasm to vacuole targeting components to a perivacuolar membrane compartment prior to de novo vesicle formation. J Biol Chem 277:763-73

Kim J, Scott SV, Oda MN, Klionsky DJ (1997) Transport of a large oligomeric protein by the cytoplasm to vacuole protein targeting pathway. J Cell Biol. 137(3):609-18

Kirisako T, Baba M, Ishihara N, Miyazawa K, Ohsumi M, Yoshimori T, Noda T, Ohsumi Y (1999) Formation process of autophagosome is traced with Apg8/Aut7p in yeast. J Cell Biol. 147(2):435-46

Kirisako T, Ichimura Y, Okada H, Kabeya Y, Mizushima N, Yoshimori T, Ohsumi M, Takao T, Noda T, Ohsumi Y (2000) The reversible modification regulates the membrane-binding state of Apg8/Aut7 essential for autophagy and the cytoplasm to vacuole targeting pathway. J Cell Biol. 151(2):263-76

Klionsky DJ, Cregg JM, Dunn WA Jr, Emr SD, Sakai Y, Sandoval IV, Sibirny A, Subramani S, Thumm M, Veenhuis M, Ohsumi Y (2003) A unified nomenclature for yeast autophagy-related genes. Dev Cell. 5(4):539-45

Klionsky DJ, Cueva R, Yaver DS (1992) Aminopeptidase I of Saccharomyces cerevisiae is localized to the vacuole independent of the secretory pathway. $J$ Cell Biol. 119(2):287-99 
Kobor MS, Venkatasubrahmanyam S, Meneghini MD, Gin JW, Jennings JL, Link AJ, Madhani HD, Rine J (2004) A protein complex containing the conserved Swi2/Snf2-related ATPase Swr1p deposits histone variant H2A.Z into euchromatin. PLoS Biol. 2(5):E131

Krogan NJ, Baetz K, Keogh MC, Datta N, Sawa C, Kwok TC, Thompson NJ, Davey MG, Pootoolal J, Hughes TR, Emili A, Buratowski S, Hieter P, Greenblatt JF (2004) Regulation of chromosome stability by the histone H2A variant Htz1, the Swr1 chromatin remodeling complex, and the histone acetyltransferase NuA4. Proc Natl Acad Sci USA. 101(37):13513-8

Kuma A, Mizushima N, Ishihara N, Ohsumi $\mathbf{Y}$ (2002) Formation of the approximately 350-kDa Apg12-Apg5.Apg16 multimeric complex, mediated by Apg16 oligomerization, is essential for autophagy in yeast. J Biol Chem. 277(21):18619-25

Kunau, W.-H., Bühne, S., Moreno de la Garza, M., Kionka, C., Mateblowski, M., Schultz-Borchard, U. und Thieringer, R. (1988) Comparative enzymology of $B$ oxidation. Biochem. Soc. Trans. 16:418-420

Laemmli, UK (1970) Cleavage of Structural Proteins during the Assembly of the Head of Bacteriophage T4 Nature 227, $680-685$

Lang T, Reiche S, Straub M, Bredschneider M, Thumm M (2000) Autophagy and the cvt pathway both depend on AUT9. J Bacteriol 182:2125-33

Levine B, Kroemer G (2008) Autophagy in the pathogenesis of disease. Cell 132(1):27-42 Review

Longtine MS, McKenzie A 3rd, Demarini DJ, Shah NG, Wach A, Brachat A, Philippsen P, Pringle JR (1998) Additional modules for versatile and economical PCR-based gene deletion and modification in Saccharomyces cerevisiae. Yeast 14(10):953-61

Matile P, Cortat M, Wiemken A, Frey-Wyssling A (1971) Isolation of glucanasecontaining particles from budding Saccharomyces cerevisiae. Proc Natl Acad Sci USA. 68(3):636-40

Metz G, Röhm KH. (1976) Yeast aminopeptidase I. Chemical composition and catalytic properties. Biochim Biophys Acta. 429(3):933-49

Moehle CM, Dixon CK, Jones EW (1989) Processing pathway for protease B of Saccharomyces cerevisiae. J Cell Biol. 108(2):309-25

Min, T., Burley, S., Shapiro, L Crystal structrue of putative aminopeptidase 2 from Pseudomonas Aeruginosa, wird veröffentlicht

Mitchell L, Lambert JP, Gerdes M, AI-Madhoun AS, Skerjanc IS, Figeys D, Baetz K (2008) Functional dissection of the NuA4 histone acetyltransferase reveals its role as a genetic hub and that Eaf1 is essential for complex integrity. Mol Cell Biol. 28(7):2244-56 
Mortimore GE, Lardeux BR, Adams CE (1988) Regulation of microautophagy and basal protein turnover in rat liver. Effects of short-term starvation.

J Biol Chem. 263(5):2506-12

Nakamura N, Matsuura A, Wada Y, Ohsumi Y (1997) Acidification of vacuoles is required for autophagic degradation in the yeast, Saccharomyces cerevisiae.

J Biochem. 121(2):338-44

Nasmyth KA, Tatchell K (1980) The structure of transposable yeast mating type loci. Cell 19(3):753-64

Nice DC, Sato TK, Strømhaug PE, Emr SD, Klionsky DJ (2002) Cooperative binding of the cytoplasm to vacuole targeting pathway proteins, Cvt13 and Cvt20, to phosphatidylinositol 3-phosphate at the pre-autophagosomal structure is required for selective autophagy. J Biol Chem. 277(33):30198-207

Noda T, Ohsumi Y (1998) Tor, a phosphatidylinositol kinase homologue, controls autophagy in yeast. J Biol Chem. 273(7):3963-6

Oda MN, Scott SV, Hefner-Gravink A, Caffarelli AD, Klionsky DJ (1996) Identification of a cytoplasm to vacuole targeting determinant in aminopeptidase I.J Cell Biol. 132(6):999-1010

Piper RC, Bryant NJ, Stevens TV (1997) The membrane protein alkaline phosphatise is delivered to the vacuole by a route that is distinct form the VPSdependent pathway J. Cell Biol. 138:531-545

Powell B, Graham LA, Stevens TH (2000) Molecular characterization of the yeast vacuolar H+-ATPase proton pore.J Biol Chem. 275(31):23654-60

Reggiori F, Klionsky DJ (2005) Autophagosomes: biogenesis from scratch? Curr Opin Cell Biol 17:415-22

Reggiori F, Shintani T, Nair U, Klionsky DJ (2005) Atg9 cycles between mitochondria and the pre-autophagosomal structure in yeasts. Autophagy 1(2):101-9

Robert F, Pokholok DK, Hannett NM, Rinaldi NJ, Chandy M, Rolfe A, Workman JL, Gifford DK, Young RA (2004) Global position and recruitment of HATs and HDACs in the yeast genome. Mol Cell 16(2):199-209

Robinson JS, Klionsky DJ, Banta LM, Emr SD (1988) Protein sorting in Saccharomyces cerevisiae: isolation of mutants defective in the delivery and processing of multiple vacuolar hydrolases. Mol Cell Biol. 8(11):4936-48

Schlumpberger M, Schaeffeler E, Straub M, Bredschneider M, Wolf DH, Thumm M (1997) AUT1, a gene essential for autophagocytosis in the yeast Saccharomyces cerevisiae. J Bacteriol. 179(4):1068-76

Scott SV, Hefner-Gravink A, Morano KA, Noda T, Ohsumi Y, Klionsky DJ (1996) Cytoplasm-to-vacuole targeting and autophagy employ the same machinery to deliver proteins to the yeast vacuole. Proc Natl Acad Sci U S A. 93(22):12304-8 
Scott SV, Nice DC 3rd, Nau JJ, Weisman LS, Kamada Y, Keizer-Gunnink I, Funakoshi T, Veenhuis M, Ohsumi Y, Klionsky DJ (2000) Apg13p and Vac8p are part of a complex of phosphoproteins that are required for cytoplasm to vacuole targeting. J Biol Chem. 275(33):25840-9

Seguí-Real B, Martinez M, Sandoval IV (1995) Yeast aminopeptidase I is posttranslationally sorted from the cytosol to the vacuole by a mechanism mediated by its bipartite N-terminal extension. EMBO J. 14(22):5476-84

Shintani T, Huang WP, Stromhaug PE, Klionsky DJ (2002) Mechanism of cargo selection in the cytoplasm to vacuole targeting pathway. Dev Cell 3(6):825-37

Sikorski RS, Hieter PA (1989) System of shuttle vectors and yeast host strains designed for efficient manipulation of DNA in Saccharomyces cerevisiae. Genetics 122(1):19-27

Squatrito M, Gorrini C, Amati B (2006) Tip60 in DNA damage response and growth control: many tricks in one HAT. Trends Cell Biol. 16(9):433-42 Review

Strømhaug PE, Reggiori F, Guan J, Wang CW, Klionsky DJ (2004) Atg21 is a phosphoinositide binding protein required for efficient lipidation and localization of Atg8 during uptake of aminopeptidase I by selective autophagy. Mol Biol Cell. 15(8):3553-66

Suzuki K, Kirisako T, Kamada Y, Mizushima N, Noda T, Ohsumi Y (2001) The pre-autophagosomal structure organized by concerted functions of $A P G$ genes is essential for autophagosome formation. EMBO J 20:5971-81

Szerlong H, Hinata K, Viswanathan R, Erdjument-Bromage H, Tempst P, Cairns BR (2008) The HSA domain binds nuclear actin-related proteins to regulate chromatin-remodeling ATPases. Nat Struct Mol Biol. Apr 13

Takeshige K, Baba M, Tsuboi S, Noda T, Ohsumi Y (1992) Autophagy in yeast demonstrated with proteinase-deficient mutants and conditions for its induction.

J Cell Biol. 119(2):301-11

Tanida I, Mizushima N, Kiyooka M, Ohsumi M, Ueno T, Ohsumi Y, Kominami E (1999) Apg7p/Cvt2p: A novel protein-activating enzyme essential for autophagy. Mol Biol Cell. 10(5):1367-79

Teichert U, Mechler B, Müller H, Wolf DH (1989) Lysosomal (vacuolar) proteinases of yeast are essential catalysts for protein degradation, differentiation, and cell survival.J Biol Chem. 264(27):16037-45

Teter SA, Eggerton KP, Scott SV, Kim J, Fischer AM, Klionsky DJ (2001) Degradation of lipid vesicles in the yeast vacuole requires function of Cvt17, a putative lipase. J Biol Chem. 276(3):2083-7

Thomas T, Voss AK (2007) The diverse biological roles of MYST histone acetyltransferase family proteins. Cell Cycle. 6(6):696-704 Review 
Thumm M (2002) Hitchhikers guide to the vacuole-mechanisms of cargo sequestration in the Cvt and autophagic pathways. Mol Cell 10(6):1257-8

Thumm M, Egner R, Koch B, Schlumpberger M, Straub M, Veenhuis M, Wolf DH (1994) Isolation of autophagocytosis mutants of Saccharomyces cerevisiae. FEBS Lett. 349(2):275-80

Thumm M, Wolf DH (1998) From proteasome to lysosome: studies on yeast demonstrate the principles of protein degradation in the eukaryote cell. Adv Mol Cell Biol A. J. Rivett. Greenwich: JAI Press, 27:41-67

Tsukada M, Ohsumi Y (1993) Isolation and characterization of autophagy-defective mutants of Saccharomyces cerevisiae.FEBS Lett. 333(1-2):169-74

Trumbly RJ, Bradley G (1983) Isolation and characterization of aminopeptidase mutants of Saccharomyces cerevisiae. J. Bacteriol. 156:36-48

van den Hazel HB, Kielland-Brandt MC, Winther JR (1996) Review: biosynthesis and function of yeast vacuolar proteases. Yeast 12:1-16

Vettese-Dadey M, Grant PA, Hebbes TR, Crane- Robinson C, Allis CD, Workman JL (1996) Acetylation of histone H4 plays a primary role in enhancing transcription factor binding to nucleosomal DNA in vitro. EMBO J. 15(10):2508-18

Wach A, Brachat A, PöhImann R, Philippsen P (1994) New heterologous modules for classical or PCR-based gene disruptions in Saccharomyces cerevisiae.

Yeast 10(13):1793-808

Yen WL, Legakis JE, Nair U, Klionsky DJ (2007) Atg27 is required for autophagydependent cycling of Atg9. Mol Cell Biol 18:581-93

Yoshihisa T, Anraku Y (1989) Nucleotide sequence of AMS1, the structure gene of vacuolar alpha-mannosidase of Saccharomyces cerevisiae. Biochem Biophys Res Commun. 163(2):908-15

Yoshihisa T, Anraku Y (1990) A novel pathway of import of alpha-mannosidase, a marker enzyme of vacuolar membrane, in Saccharomyces cerevisiae. J Biol Chem. 265(36):22418-25

Yoshihisa T, Ohsumi Y, Anraku Y (1988) Solubilization and purification of alphamannosidase, a marker enzyme of vacuolar membranes in Saccharomyces cerevisiae. J Biol Chem. 263(11):5158-63

Young AR, Chan EY, Hu XW, Köchl R, Crawshaw SG, High S, Hailey DW, Lippincott-Schwartz J, Tooze SA (2006) Starvation and ULK1-dependent cycling of mammalian Atg9 between the TGN and endosomes. J Cell Sci. 119(18):3888-900 


\section{Anhang}

\subsection{Saccharomyces cerevisiae-Stämme}

\begin{tabular}{|c|c|c|c|}
\hline Stamm & Synonym & Genotyp & Referenz \\
\hline y10 & suvia 4 & $\begin{array}{l}\text { Mat } \alpha \text {, ura3 } \triangle 0 \text {, his341, leu2-3, -112, trp1-289, ade2-101, } \\
\text { lap1, lap2, lap3, lap4;YDR360W::kanMX4; transf. mit } \\
\text { pRS313-APE1 }\end{array}$ & P.N. Rekha \\
\hline $\mathrm{y} 12$ & $\mathrm{C6C}$ & $\begin{array}{l}\text { Mat } \alpha \text {, ura3-52, his341, leu2-3, -112, trp1-289, ade2- } \\
\text { 101, lap1, lap2, lap3, lap4; transf. mit pRS313-APE1 }\end{array}$ & $\begin{array}{l}\text { Andrei-Selmer } \\
\text { et al., } 2001\end{array}$ \\
\hline y25 & & $\begin{array}{l}\text { Mato; ura3-52; his341; leu2-3, -112; trp1-289; ade2- } \\
\text { 101; lap1; lap2 ;lap3; lap4 }\end{array}$ & diese Arbeit \\
\hline y26 & $y d r 360 w \Delta$ & $\begin{array}{l}\text { Mato, ura340, his341, leu2-3, -112, trp1-289, ade2-101, } \\
\text { lap1, lap2, lap3, lap4;YDR360W::kanMX4 }\end{array}$ & diese Arbeit \\
\hline $\mathrm{y} 27$ & & $\begin{array}{l}\text { Mata; ura3-52; his341; leu2-3, -112; trp1-289; ade2-101; } \\
\text { lap1; lap2 ;lap3; lap4 EMS Mutagenese }\end{array}$ & diese Arbeit \\
\hline y28 & & $\begin{array}{l}\text { Mato; ura3-52; his341; leu2-3, -112; trp1-289; ade2- } \\
\text { 101; lap1; lap2 ;lap3; lap4 EMS Mutagenese }\end{array}$ & diese Arbeit \\
\hline y34 & & $\begin{array}{l}\text { Mat } \alpha \text {; ura3 } \Delta 0 \text { his3 } 41 \text {, leu2-3, -112, trp1-289, ade2-101, } \\
\text { lap1, lap2, lap3, lap4;YDR36OW::kanMX4; transf. mit } \\
\text { pRS313-APE1 und pYX141-YDR360W }\end{array}$ & diese Arbeit \\
\hline y35 & & $\begin{array}{l}\text { Mat } \alpha \text {; ura3 } \Delta 0 \text { his3 } 41 \text {, leu2-3, -112, trp1-289, ade2-101, } \\
\text { lap1, lap2, lap3, lap4;YDR36OW::kanMX4; transf. mit } \\
\text { pRS313-APE1 und pYX242-YDR360W }\end{array}$ & diese Arbeit \\
\hline y43 & via10-2 & $\begin{array}{l}\text { Mata, ura3::pRS306-APE1, his341, leu2-3, -112, trp1- } \\
\text { 289, ade2-101, lap1, lap2, lap3, lap4, EMS Mutagenese }\end{array}$ & diese Arbeit \\
\hline y46 & via14-2 & $\begin{array}{l}\text { Mat } \alpha, \text { ura3::pRS306-APE1, his341, leu2-3, -112, trp1- } \\
\text { 289, ade2-101, lap1, lap2, lap3, lap4, EMS Mutagenese }\end{array}$ & Arbeit \\
\hline y89 & via10 & $\begin{array}{l}\text { Mata; ura3-52; his341; leu2-3, -112, trp1-289; ade2-101; } \\
\text { lap1; lap2; lap3; lap4; EMS Mutagenese; transf. mit } \\
\text { pRS313-APE1 }\end{array}$ & $\begin{array}{l}\text { Andrei-Selmer } \\
\text { et al., } 2001\end{array}$ \\
\hline y70 & SEY6210 & $\begin{array}{l}\text { Mat } \alpha \text {; ura3-53; his3- } \Delta 200 ; \text { leu2-3,-112; trp1- } 4901 \text {;suc2- } \\
\Delta 9 \text {; lys2-801 }\end{array}$ & $\begin{array}{l}\text { Robinson et al., } \\
1988\end{array}$ \\
\hline y71 & SEY6211 & $\begin{array}{l}\text { Mata; ura3-53; his3- } 4200 ; \text { leu2-3,-112; trp1- } 4901 \text {;suc2- } \\
\Delta 9 \text {; lys2-801 }\end{array}$ & $\begin{array}{l}\text { Robinson et al., } \\
1988\end{array}$ \\
\hline y72 & $11-17$ & $\begin{array}{l}\text { Mat } \alpha \text {; ura3-52; his341; leu2-3,-112; trp1- } \\
\text { 289,lap1;lap2;lap3;lap4 }\end{array}$ & D.H. Wolf \\
\hline y75 & pep4A & $\begin{array}{l}\text { Mata; his341; leu2 } \Delta 0 ; \text { met15 } 40 \text {; ura3 } \Delta 0 ; \\
\text { YPL154C::kanMX4 }\end{array}$ & Euroscarf \\
\hline y82 & $\begin{array}{r}\text { ydr360w } \\
\text { (Original) }\end{array}$ & 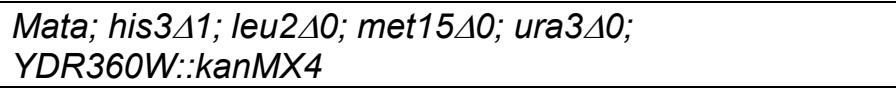 & Euroscarf \\
\hline y87 & C6A & $\begin{array}{l}\text { Mata, ura3-52, his341, leu2-3, -112, trp1-289, ade2-101, } \\
\text { lap1, lap2, lap3, lap4; transf. mit pRS313-APE1 }\end{array}$ & $\begin{array}{l}\text { C. Andrei- } \\
\text { Selmer }\end{array}$ \\
\hline y91 & via14 & $\begin{array}{l}\text { Mato, ura3-52, his3 1, leu2-3, -112, trp1-289, ade2- } \\
\text { 101, lap1, lap2, lap3, lap4, EMS Mutagenese, transf. mit } \\
\text { pRS313-APE1 }\end{array}$ & $\begin{array}{l}\text { Andrei-Selmer } \\
\text { et al., } 2001\end{array}$ \\
\hline y93 & YR320 & Mat $\alpha$, his1-123; Mat $\alpha$-Testerstamm & M.Thumm \\
\hline y94 & YR312 & Mata,his1-123; Mata-Testerstamm & M.Thumm \\
\hline y96 & WT & $\begin{array}{l}\text { Mat } \alpha \text {; ura3::pRS306-APE1; leu2-3, -112; trp1-289; } \\
\text { ade2-101; lap1; lap2; lap3; lap4 }\end{array}$ & diese Arbeit \\
\hline y109 & ape14 & 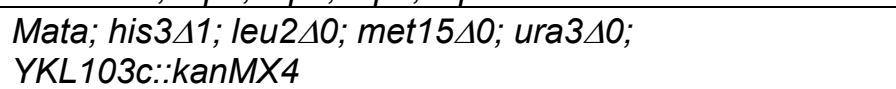 & Euroscarf \\
\hline y126 & eaf1A & $\begin{array}{l}\text { Mat } \alpha \text {; ura3::pRS306-APE1; leu2-3, -112; trp1-289; } \\
\text { ade2-101; lap1; lap2; lap3; lap4; YDR359C und } \\
\text { YDR360W::HIS3MX6 }\end{array}$ & diese Arbeit \\
\hline y143 & BY4741 & MATa; his3 $\Delta 1$; leu2 $\Delta 0 ;$ met15 $\Delta 0$; ura3 $\Delta 0$ & Euroscarf \\
\hline
\end{tabular}




\begin{tabular}{|c|c|c|}
\hline y148 & $\begin{array}{l}\text { Mata, ura3::pRS306-APE1, his341, leu2-3, -112, trp1- } \\
\text { 289, ade2-101, lap1, lap2, lap3, lap4, EMS Mutagenese; } \\
\text { pYX141 }\end{array}$ & diese Arbeit \\
\hline y149 & $\begin{array}{l}\text { Mata, ura3:: pRS306-APE1, his341, leu2-3, -112, trp1- } \\
\text { 289, ade2-101, lap1, lap2, lap3, lap4, EMS Mutagenese; } \\
\text { pYX242 }\end{array}$ & diese Arbeit \\
\hline y150 & $\begin{array}{l}\text { Mata, ura3::pRS306-APE1, his341, leu2-3, -112, trp1- } \\
\text { 289, ade2-101, lap1, lap2, lap3, lap4, EMS Mutagenese; } \\
\text { pYX141-YDR360W }\end{array}$ & diese Arbeit \\
\hline y151 & $\begin{array}{l}\text { Mata, ura3::pRS306-APE1, his341, leu2-3, -112, trp1- } \\
\text { 289, ade2-101, lap1, lap2, lap3, lap4, EMS Mutagenese; } \\
\text { pYX242-YDR360W }\end{array}$ & diese Arbeit \\
\hline y152 & $\begin{array}{l}\text { Mat } \alpha \text {, ura3::pRS306-APE1, his341, leu2-3, -112, trp1- } \\
\text { 289, ade2-101, lap1, lap2, lap3, lap4, EMS Mutagenese; } \\
\text { transf. mit pYX141 }\end{array}$ & diese Arbeit \\
\hline y153 & $\begin{array}{l}\text { Mat } \alpha \text {, ura3::pRS306-APE1, his3A1, leu2-3, -112, trp1- } \\
\text { 289, ade2-101, lap1, lap2, lap3, lap4, EMS Mutagenese; } \\
\text { transf. mit pYX242 }\end{array}$ & diese Arbeit \\
\hline y154 & $\begin{array}{l}\text { Mat } \alpha, \text { ura3::pRS306-APE1, his341, leu2-3, -112, trp1- } \\
\text { 289, ade2-101, lap1, lap2, lap3, lap4, EMS Mutagenese; } \\
\text { transf. mit pYX141-YDR360W }\end{array}$ & diese Arbeit \\
\hline y155 & $\begin{array}{l}\text { Mat } \alpha, \text { ura3::pRS306-APE1, his3 } 1 \text { 1, leu2-3, -112, trp1- } \\
\text { 289, ade2-101, lap1, lap2, lap3, lap4, EMS Mutagenese; } \\
\text { transf. mit } p Y X 242-Y D R 360 W\end{array}$ & diese Arbeit \\
\hline y156 & $\begin{array}{l}\text { Mata, ura3::pRS306-APE1, his341, leu2-3, -112, trp1- } \\
\text { 289, ade2-101, lap1, lap2, lap3, lap4, EMS Mutagenese; } \\
\text { transf. mit pYX141-EAF1 }\end{array}$ & diese Arbeit \\
\hline y157 & $\begin{array}{l}\text { Mata, ura3::pRS306-APE1, his341, leu2-3, -112, trp1- } \\
\text { 289, ade2-101, lap1, lap2, lap3, lap4, EMS Mutagenese; } \\
\text { transf. mit pYX242-EAF1 }\end{array}$ & diese Arbeit \\
\hline y158 & $\begin{array}{l}\text { Mat } \alpha, \text { ura3::pRS306-APE1, his341, leu2-3, -112, trp1- } \\
\text { 289, ade2-101, lap1, lap2, lap3, lap4, EMS Mutagenese; } \\
\text { transf. mit pYX141-EAF1 }\end{array}$ & diese Arbeit \\
\hline y159 & $\begin{array}{l}\text { Mat } \alpha, \text { ura3::pRS306-APE1, his341, leu2-3, -112, trp1- } \\
\text { 289, ade2-101, lap1, lap2, lap3, lap4, EMS Mutagenese; } \\
\text { transf. mit pYX242-EAF1 }\end{array}$ & diese Arbeit \\
\hline y162 & $\begin{array}{l}\text { Mat } \alpha \text {; ura3::pRS306-APE1; leu2-3, -112; trp1-289; } \\
\text { ade2-101; lap1; lap2; lap3; lap4; YDR359C und } \\
\text { YDR360W::HIS3MX6; transf. mit pYX141 }\end{array}$ & diese Arbeit \\
\hline y164 & $\begin{array}{l}\text { Mat } \alpha \text {; ura3::pRS306-APE1; leu2-3, -112; trp1-289; } \\
\text { ade2-101; lap1; lap2; lap3; lap4; YDR359C und } \\
\text { YDR360W::HIS3MX6; transf. mit pYX242 }\end{array}$ & diese Arbeit \\
\hline y166 & $\begin{array}{l}\text { Mato; ura3::pRS306-APE1; leu2-3, -112; trp1-289; } \\
\text { ade2-101; lap1; lap2; lap3; lap4; YDR359C und } \\
\text { YDR360W::HIS3MX6; transf. mit pYX141-YDR360W }\end{array}$ & diese Arbeit \\
\hline y168 & $\begin{array}{l}\text { Mat } \alpha \text {; ura3::pRS306-APE1; leu2-3, -112; trp1-289; } \\
\text { ade2-101; lap1; lap2; lap3; lap4; YDR359C und } \\
\text { YDR360W::HIS3MX6; transf. mit pYX242-YDR360W }\end{array}$ & diese Arbeit \\
\hline y170 & $\begin{array}{l}\text { Mat } \alpha \text {; ura3::pRS306-APE1; leu2-3, -112; trp1-289; } \\
\text { ade2-101; lap1; lap2; lap3; lap4; YDR359C und } \\
\text { YDR360W::HIS3MX6; transf. mit pYX141-EAF1 }\end{array}$ & diese Arbeit \\
\hline y172 & $\begin{array}{l}\text { Mat } \alpha \text {; ura3::pRS306-APE1; leu2-3, -112; trp1-289; } \\
\text { ade2-101; Iap1; lap2; lap3; lap4; YDR359C und } \\
\text { YDR360W::HIS3MX6; transf. mit pYX242-EAF1 }\end{array}$ & diese Arbeit \\
\hline y189 & $\begin{array}{l}\text { Mat } \alpha \text {; ura3::pRS306-APE1; leu2-3, -112; trp1-289; } \\
\text { ade2-101; lap1; lap2; lap3; lap4; YDR359C und } \\
\text { YDR360W::HIS3MX6; transf. mit pYX141-EAF1 1-862 } \\
\text { bp }\end{array}$ & diese Arbeit \\
\hline
\end{tabular}




\begin{tabular}{|c|c|c|c|}
\hline$y 191$ & & $\begin{array}{l}\text { Mat } \alpha \text {; ura3::pRS306-APE1; leu2-3, -112; trp1-289; } \\
\text { ade2-101; lap1; lap2; lap3; lap4; YDR359C und } \\
\text { YDR360W::HIS3MX6; transf. mit pYX242-EAF1 1- } \\
\text { 862bp }\end{array}$ & diese Arbeit \\
\hline y193 & & $\begin{array}{l}\text { Mat } \alpha \text {; ura3:: pRS306-APE1; leu2-3, -112; trp1-289; } \\
\text { ade2-101; lap1; lap2; lap3; lap4; YDR359C und } \\
\text { YDR360W::HIS3MX6; transf. mit pYX141-EAF1 847- } \\
2946 \text { bp }\end{array}$ & diese Arbeit \\
\hline y195 & & $\begin{array}{l}\text { Mat } \alpha \text {; ura3:: pRS306-APE1; leu2-3, -112; trp1-289; } \\
\text { ade2-101; lap1; lap2; lap3; lap4; YDR359C und } \\
\text { YDR360W::HIS3MX6; transf. mit pYX242-EAF1 847- } \\
2946 \text { bp }\end{array}$ & diese Arbeit \\
\hline y197 & & $\begin{array}{l}\text { Mat } \alpha \text {; ura3::pRS306-APE1; leu2-3, -112; trp1-289; } \\
\text { ade2-101; lap1; lap2; lap3; lap4; YDR359C und } \\
\text { YDR360W::HIS3MX6; transf. mit pYX141-EAF1 NLS } \\
\text { Mutation }\end{array}$ & diese Arbeit \\
\hline y199 & & $\begin{array}{l}\text { Mato; ura3:: pRS306-APE1; leu2-3, -112; trp1-289; } \\
\text { ade2-101; lap1; lap2; lap3; lap4; YDR359C und } \\
\text { YDR360W::HIS3MX6; transf. mit pYX242-EAF1 NLS } \\
\text { Mutation }\end{array}$ & diese Arbeit \\
\hline y206 & & $\begin{array}{l}\text { Mat } \alpha \text {; ura3::pRS306-APE1; leu2-3, -112; trp1-289; } \\
\text { ade2-101; lap1; lap2; lap3; lap4; YDR359C::HIS3MX6; } \\
\text { Klon \#1 }\end{array}$ & diese Arbeit \\
\hline y207 & & $\begin{array}{l}\text { Mat } \alpha \text {; ura3::pRS306-APE1; leu2-3, -112; trp1-289; } \\
\text { ade2-101; lap1; lap2; lap3; lap4; YDR359C::HIS3MX6; } \\
\text { Klon \#4 }\end{array}$ & diese Arbeit \\
\hline$y 210$ & yng24 & $\begin{array}{l}\text { Mat } \alpha \text {; ura3::pRS306-APE1; leu2-3, -112; trp1-289; } \\
\text { ade2-101; lap1; lap2; lap3; lap4; YHRO90C::HIS3MX6; } \\
\text { Klon \#5 }\end{array}$ & diese Arbeit \\
\hline$y 213$ & AH109 & $\begin{array}{l}\text { Mat } \alpha \text {, trp1-901, leu2-3, 112, ura3-52, his3-200, gal4A, } \\
\text { gal80A, LYS2::GAL1 UAS-GAL1 TATA-HIS3, MEL1, } \\
\text { GAL2 LAS-GAL2 } \text { TATA }_{\text {TADE2, URA3::MEL1 }} \text { UAS-MEL1 } \text { TATA- }^{-} \\
\text {lacZ }\end{array}$ & Clontech \\
\hline$y 220$ & & $\begin{array}{l}\text { Mat } \alpha \text {, ura3::pRS306-APE1, his3A1, leu2-3, -112, trp1- } \\
\text { 289, ade2-101, lap1, lap2, lap3, lap4, EMS; transf. mit } \\
\text { pYX142-APE1 }\end{array}$ & diese Arbeit \\
\hline$y 228$ & & $\begin{array}{l}\text { Mat } \alpha \text {; ura3::pRS306-APE1; leu2-3, -112; trp1-289; } \\
\text { ade2-101; lap1; lap2; lap3; lap4; YDR359C und } \\
\text { YDR360W::HIS3MX6; transf. mit pYX142-APE1 }\end{array}$ & diese Arbeit \\
\hline$y 234$ & & $\begin{array}{l}\text { Mata, ura3::pRS306-APE1, his341, leu2-3, -112, trp1- } \\
\text { 289, ade2-101, lap1, lap2, lap3, lap4, EMS Mutagenese; } \\
\text { transf. mit } p Y X 132-Y D R 360 W\end{array}$ & diese Arbeit \\
\hline$y 236$ & & $\begin{array}{l}\text { Mata, ura3::pRS306-APE1, his341, leu2-3, -112, trp1- } \\
\text { 289, ade2-101, lap1, lap2, lap3, lap4, EMS Mutagenese; } \\
\text { transf. mit } p Y X 132-A P E 1\end{array}$ & diese Arbeit \\
\hline$y 249$ & eaf3 $\Delta$ & $\begin{array}{l}\text { Mat } \alpha \text {; ura3::pRS306-APE1; leu2-3, -112; trp1-289; } \\
\text { ade2-101; lap1; lap2; lap3; lap4; YPRO23C::HIS3MX6 }\end{array}$ & diese Arbeit \\
\hline$y 250$ & eaf5 $\Delta$ & $\begin{array}{l}\text { Mat } \alpha \text {; ura3::pRS306-APE1; leu2-3, -112; trp1-289; } \\
\text { ade2-101; lap1; lap2; lap3; lap4; YEL018W::HIS3MX6 }\end{array}$ & diese Arbeit \\
\hline$y 252$ & eaf6 $\Delta$ & $\begin{array}{l}\text { Mat } \alpha \text {; ura3:: pRS306-APE1; leu2-3, -112; trp1-289; } \\
\text { ade2-101; lap1; lap2; lap3; lap4; YJR082C::HIS3MX6 }\end{array}$ & diese Arbeit \\
\hline y255 & eaf7 $\Delta$ & $\begin{array}{l}\text { Mat } \alpha \text {; ura3::pRS306-APE1; leu2-3, -112; trp1-289; } \\
\text { ade2-101; lap1; lap2; lap3; lap4;YNL136W::HIS3MX6 }\end{array}$ & diese Arbeit \\
\hline$y 256$ & yaf9 $\Delta$ & $\begin{array}{l}\text { Mat } \alpha \text {; ura3::pRS306-APE1; leu2-3, -112; trp1-289; } \\
\text { ade2-101; lap1; lap2; lap3; lap4;YNL107W::HIS3MX6 }\end{array}$ & diese Arbeit \\
\hline
\end{tabular}

Nicht alle in dieser Arbeit verwendeten Hefestämme wurden in die Stammsammlung aufgenommen. Einige Stämme, wie beispielsweise die für in situ Immunfluoreszenzen wurden für die jeweiligen Experimente immer neu transformiert. Die hier in grau aufgeführten Hefestämme werden in der Arbeit nur erwähnt, aber in Abbildungen nicht direkt aufgeführt. 


\subsection{Oligonukleotide}

7.2.1 Oligonukleotide für Klonierungen in die Hefevektoren pYX141, 142, 242 und 132

\begin{tabular}{|c|c|c|}
\hline $\begin{array}{l}\text { 5'-Primerl } \\
\text { 3'-Primer }\end{array}$ & Sequenz & Funktion \\
\hline $\begin{array}{l}\text { TB22/ } \\
\text { TB29 }\end{array}$ & $\begin{array}{l}\text { 5'-CGCGAATTCATGATGGGAGTCGCAGCTG-3' } \\
\text { 5'-CGCAAGCTTGAAGGGATAAGGA-3' }\end{array}$ & $\begin{array}{l}\text { Amplifikation des } \\
\text { YDR360W- } \\
\text { Fragments }\end{array}$ \\
\hline $\begin{array}{l}\text { TB34/ } \\
\text { TB35 }\end{array}$ & $\begin{array}{l}\text { 5'-CGCGAATTCATGTCCTCACGTCCAAGT-3' } \\
\text { 5'-CGCAAGCTTTTGTTTTTGGAACCT-3' }\end{array}$ & $\begin{array}{l}\text { Amplifikation des } \\
\text { EAF1-Fragments }\end{array}$ \\
\hline $\begin{array}{l}\text { TB34/ } \\
\text { TB66 }\end{array}$ & $\begin{array}{l}\text { 5'-CGCGAATTCATGTCCTCACGTCCAAGT-3' } \\
\text { 5'-TTATTAAATTTACATCCGCCGCTGCCGCTTTTGTTA } \\
\text { TGGGAGT-3' }\end{array}$ & $\begin{array}{l}\text { Amplifikation des } \\
\text { EAF1-Fragments } \\
\text { bp 1-322 zur } \\
\text { Mutation der } \\
\text { potentiellen NLS }\end{array}$ \\
\hline $\begin{array}{l}\text { TB65/ } \\
\text { TB35 }\end{array}$ & $\begin{array}{l}\text { 5'-ACTCCCATAACAAAAGCGGCAGCGGCGGATGTAAAT } \\
\text { TTAATAA-3' } \\
\text { 5'-CGCAAGCTTTTGTTTTTGGAACCT-3' }\end{array}$ & $\begin{array}{l}\text { Amplifikation des } \\
\text { EAF1-Fragments } \\
\text { bp } 279-2946 \text { zur } \\
\text { Mutation der } \\
\text { potentiellen NLS }\end{array}$ \\
\hline $\begin{array}{l}\text { TB34/ } \\
\text { TB67 }\end{array}$ & $\begin{array}{l}\text { 5'-CGCGAATTCATGTCCTCACGTCCAAGT-3' } \\
\text { 5'-CGCAAGCTTTAAGGGCAAAGCCTGGG-3' }\end{array}$ & $\begin{array}{l}\text { Amplifikation des } \\
\text { EAF1-Fragments } \\
\text { bp 1-862 }\end{array}$ \\
\hline $\begin{array}{l}\text { TB68/ } \\
\text { TB35 }\end{array}$ & $\begin{array}{l}\text { 5'-CGCGAATTCATGCAGGCTTTGCCCTTAG-3' } \\
\text { 5'-CGCAAGCTTTTGTTTTTGGAACCT-3' }\end{array}$ & $\begin{array}{l}\text { Amplifikation des } \\
\text { EAF1-Fragments } \\
\text { bp 847-2946 }\end{array}$ \\
\hline $\begin{array}{l}\text { TB91/ } \\
\text { TB93 }\end{array}$ & $\begin{array}{l}\text { 5'-CGCCCATGGAGGAACAACGTGAAAT-3' } \\
\text { 5'-CGCAAGCTTTCACAACTCGCCGAAT-3' }\end{array}$ & $\begin{array}{l}\text { Amplifikation des } \\
\text { APE1-Fragments }\end{array}$ \\
\hline $\begin{array}{l}\text { TB90/ } \\
\text { TB87 }\end{array}$ & $\begin{array}{l}\text { 5'-CGCCCATGGATCCAAGTTTAGTTTTA-3' } \\
\text { 5'-CGCAAGCTTGTTACGTTTTCTT-3' }\end{array}$ & $\begin{array}{l}\text { Amplifikation des } \\
\text { YNG2-Fragments }\end{array}$ \\
\hline
\end{tabular}

7.2.2 Oligonukleotide zur Klonierung der Hefevektoren pYX-HA141, 142 und 242

\begin{tabular}{|l|l|l|}
\hline $\begin{array}{l}\text { 5'-Primerl } \\
\text { 3'-Primer }\end{array}$ & Sequenz & Funktion \\
\hline TB120/ & 5'-CGCGAATTCGCCGCCATCATGGAG-3' & $\begin{array}{l}\text { Amplifikation des } \\
\text { TB121 }\end{array}$ \\
& 5'-CGCGAATTCGGCCTCCATGGCCA-3' & pGKT7 \\
\hline TB122/ & 5'-CGCGAATTCGCCGCCATGGAGTAC-3' \\
TB123 & 5'-CGCGAATTCACTGGCCTCCATGGC-3' & $\begin{array}{l}\text { Amplifikation des } \\
\text { HA-Tags aus } \\
\text { pGADT7 }\end{array}$ \\
\hline
\end{tabular}

\subsubsection{Oligonukleotide für Klonierungen in die Hefevektoren pYX-HA141, 142} und 242

\begin{tabular}{|c|c|c|}
\hline $\begin{array}{l}\text { 5'-Primerl } \\
\text { 3'-Primer }\end{array}$ & Sequenz & Funktion \\
\hline $\begin{array}{l}\text { TB45/ } \\
\text { TB124 }\end{array}$ & $\begin{array}{l}\text { 5'-CGCGGGCCCTGTCCTCACGTCCAAGT-3' } \\
\text { 5'-CGCAAGCTTTCATTGTTTTTGGAACCT-3' }\end{array}$ & $\begin{array}{l}\text { Amplifikation des } \\
\text { EAF1-Fragments }\end{array}$ \\
\hline $\begin{array}{l}\text { TB45/ } \\
\text { TB125 }\end{array}$ & $\begin{array}{l}\text { 5'-CGCGGGCCCTGTCCTCACGTCCAAGT-3' } \\
\text { 5'-CGCAAGCTTTCATAAGGGCAAAGCCTGGG-3' }\end{array}$ & $\begin{array}{l}\text { Amplifikation des } \\
\text { EAF1-Fragments } \\
\text { bp 1-862 }\end{array}$ \\
\hline $\begin{array}{l}\text { TB143/ } \\
\text { TB124 }\end{array}$ & $\begin{array}{l}\text { 5'-CGCGGGCCCTGCAGGCTTTGCCCTTAG-3' } \\
\text { 5'-CGCAAGCTTTCATTGTTTTTGGAACCT-3' }\end{array}$ & $\begin{array}{l}\text { Amplifikation des } \\
\text { EAF1-Fragments } \\
\text { bp 847-2946 }\end{array}$ \\
\hline
\end{tabular}




\subsubsection{Oligonukleotide für Klonierungen in „Yeast two Hybrid“-Vektor pGADT7}

\begin{tabular}{|c|c|c|}
\hline $\begin{array}{l}\text { 5'-Primerl } \\
\text { 3'-Primer }\end{array}$ & Sequenz & Funktion \\
\hline $\begin{array}{l}\text { TB34/ } \\
\text { TB98 }\end{array}$ & $\begin{array}{l}\text { 5'-CGCGAATTCATGTCCTCACGTCCAAGT-3' } \\
\text { 5'-CGCGAGCTCTCATTGTTTTTGGAACCTTTG-3' }\end{array}$ & $\begin{array}{l}\text { Amplifikation des } \\
\text { EAF1-Fragments }\end{array}$ \\
\hline $\begin{array}{l}\text { TB34/ } \\
\text { TB99 }\end{array}$ & $\begin{array}{l}\text { 5'- CGCGAATTCATGTCCTCACGTCCAAGT-3' } \\
\text { 5'-CGCGAGCTCTCATAAGGGCAAAGCCTGGG-3' }\end{array}$ & $\begin{array}{l}\text { Amplifikation des } \\
\text { EAF1-Fragments } \\
\text { bp 1-862 }\end{array}$ \\
\hline $\begin{array}{l}\text { TB68/ } \\
\text { TB98 }\end{array}$ & $\begin{array}{l}\text { 5'-CGCGAATTCATGCAGGCTTTGGCCTTAG-3' } \\
\text { 5'-CGCGAGCTCTCATTGTTTTTGGAACCTTTG-3' }\end{array}$ & $\begin{array}{l}\text { Amplifikation des } \\
\text { EAF1-Fragments } \\
\text { bp 847-2946 }\end{array}$ \\
\hline $\begin{array}{l}\text { TB97/ } \\
\text { TB98 }\end{array}$ & $\begin{array}{l}\text { 5'-CGCGAATTCCTTGAGCGTCAATTGATTGAC-3' } \\
\text { 5'-CGCGAGCTCTCATTGTTTTTGGAACCTTTG-3' }\end{array}$ & $\begin{array}{l}\text { Amplifikation des } \\
\text { EAF1-Fragments } \\
\text { bp 1803-2946 }\end{array}$ \\
\hline $\begin{array}{l}\text { TB101/ } \\
\text { TB102 }\end{array}$ & $\begin{array}{l}\text { 5'-CGCCCATGGAGGAACAACGTGAAATACTG-3', } \\
\text { 5'-CGCCCCGGGTCACAACTCGCCGAATTCAT-3' }\end{array}$ & $\begin{array}{l}\text { Amplifikation des } \\
\text { APE1-Fragments }\end{array}$ \\
\hline
\end{tabular}

\subsubsection{Oligonukleotide für Klonierungen in „Yeast two Hybrid“-Vektoren pGBT9 und pGBKT7}

\begin{tabular}{|c|c|c|}
\hline $\begin{array}{l}\text { 5'-Primerl } \\
\text { 3'-Primer }\end{array}$ & Sequenz & Funktion \\
\hline $\begin{array}{l}\text { TB34/ } \\
\text { TB95 }\end{array}$ & $\begin{array}{l}\text { 5'-CGCGAATTCATGTCCTCACGTCCAAGT-3' } \\
\text { 5'-CGCGTCGACTCATTGTTTTTGGAACCTTTG-3' }\end{array}$ & $\begin{array}{l}\text { Amplifikation des } \\
\text { EAF1-Fragments }\end{array}$ \\
\hline $\begin{array}{l}\text { TB34/ } \\
\text { TB96 }\end{array}$ & $\begin{array}{l}\text { 5'-CGCGAATTCATGTCCTCACGTCCAAGT-3' } \\
\text { 5'-CGCGTCGACTCATAAGGGCAAAGCCTGGG-3' }\end{array}$ & $\begin{array}{l}\text { Amplifikation des } \\
\text { EAF1-Fragments } \\
\text { bp 1-862 }\end{array}$ \\
\hline $\begin{array}{l}\text { TB68/ } \\
\text { TB95 }\end{array}$ & $\begin{array}{l}\text { 5'-CGCGAATTCATGCAGGCTTTGCCCTTAG-3' } \\
\text { 5'- CGCGTCGACTCATTGTTTTTGGAACCTTTG-3' }\end{array}$ & $\begin{array}{l}\text { Amplifikation des } \\
\text { EAF1-Fragments } \\
\text { bp 847-2946 }\end{array}$ \\
\hline $\begin{array}{l}\text { TB97/ } \\
\text { TB95 }\end{array}$ & $\begin{array}{l}\text { 5'-CGCGAATTCCTTGAGCGTCAATTGATTGAC-3' } \\
\text { 5'- CGCGTCGACTCATTGTTTTTGGAACCTTTG-3' }\end{array}$ & $\begin{array}{l}\text { Amplifikation des } \\
\text { EAF1-Fragments } \\
\text { bp 1803-2946 }\end{array}$ \\
\hline $\begin{array}{l}\text { TB105/ } \\
\text { TB103 }\end{array}$ & $\begin{array}{l}\text { 5'-CGCCCCGGGGGAGGAACAACGTGAAATACTG-3' } \\
\text { 5'-CGCGTCGACTCACAACTCGCCGAATTCAT-3' }\end{array}$ & $\begin{array}{l}\text { Amplifikation des } \\
\text { APE1-Fragments }\end{array}$ \\
\hline $\begin{array}{l}\text { TB101/ } \\
\text { TB103 }\end{array}$ & $\begin{array}{l}\text { 5'-CGCCCATGGAGGAACAACGTGAAATACTG-3' } \\
\text { 5'-CGCGTCGACTCACAACTCGCCGAATTCAT-3' }\end{array}$ & \\
\hline
\end{tabular}

\subsubsection{Oligonukleotide zur Verifizierung der Deletionsstämme}

\begin{tabular}{|c|c|c|}
\hline $\begin{array}{l}\text { 5'-Primerl } \\
\text { 3'-Primer }\end{array}$ & Sequenz & Funktion \\
\hline $\begin{array}{l}\text { TB90/ } \\
\text { TB87 }\end{array}$ & $\begin{array}{l}\text { 5'-CGCCCATGGATCCAAGTTTAGTTTTAA-3' } \\
\text { 5'-CGCAAGCTTGTTACGTTTTCTT-3' }\end{array}$ & $\begin{array}{l}\text { Amplifikation des } \\
\text { ORFs YHRO9OC }\end{array}$ \\
\hline $\begin{array}{l}\text { TB84/ } \\
\text { TB56 }\end{array}$ & $\begin{array}{l}\text { 5'-AAGAAGGATATGCAAGTTTATATTGGACAACA } \\
\text { TAACCAATAGAAGATGCGGATCCCCGGGTTAATTAA -3' } \\
\text { 5'-CCACGGACAGCACCCATTGC-3' }\end{array}$ & $\begin{array}{l}\text { Amplifikation des } \\
\text { deletierten ORFs } \\
\text { YHRO9OC }\end{array}$ \\
\hline $\begin{array}{l}\text { TB131/ } \\
\text { TB132 }\end{array}$ & $\begin{array}{l}\text { 5'-CGCGGGCCCTCGTTGATTTGGAGCAGGAA-3' } \\
\text { 5'-CGCAAGCTTTCACATACCTAAAGCCACTCCTTCG-3' }\end{array}$ & $\begin{array}{l}\text { Amplifikation des } \\
\text { ORFs YPRO23C }\end{array}$ \\
\hline $\begin{array}{l}\text { TB128/ } \\
\text { TB56 }\end{array}$ & $\begin{array}{l}\text { 5'-CTTCACCAACTCCGATATA-3' } \\
\text { 5'-CCACGGACAGCACCCATTGC-3' }\end{array}$ & $\begin{array}{l}\text { Amplifikation des } \\
\text { deletierten ORFs } \\
\text { YPRO23C }\end{array}$ \\
\hline $\begin{array}{l}\text { TB127/ } \\
\text { TB134 }\end{array}$ & $\begin{array}{l}\text { 5'-GTCTCATCAATTTGTTTGTAG-3' } \\
\text { 5'-CGCAAGCTTTCACTCTAGTGCTCTTCTCA-3' }\end{array}$ & $\begin{array}{l}\text { Amplifikation des } \\
\text { ORFs YELO18W }\end{array}$ \\
\hline $\begin{array}{l}\text { TB125/ } \\
\text { TB56 }\end{array}$ & $\begin{array}{l}\text { 5'-CGCAAGCTTTCATAAGGGCAAAGCCTGGG-3' } \\
\text { 5'-CCACGGACAGCACCCATTGC-3' }\end{array}$ & $\begin{array}{l}\text { Amplifikation des } \\
\text { deletierten ORFs } \\
\text { YEL018W }\end{array}$ \\
\hline
\end{tabular}




\begin{tabular}{|l|l|l|}
\hline $\begin{array}{l}\text { TB135/ } \\
\text { TB136 }\end{array}$ & $\begin{array}{l}\text { 5'-CGCGGATCCTACTGATGAGCTGAAAAGT -3' } \\
\text { 5'-CGCAAGCTTTCAGTCGTTTTGTGATTGGCC-3' }\end{array}$ & $\begin{array}{l}\text { Amplifikation des } \\
\text { ORFs YLR082C }\end{array}$ \\
\hline TB141/ & $\begin{array}{l}\text { 5'-GTGAAGACGAGGATGATGA-3' } \\
\text { TB56 }\end{array}$ & $\begin{array}{l}\text { Amplifikation des } \\
\text { deletierten ORFs } \\
\text { YLRO82C }\end{array}$ \\
\hline $\begin{array}{l}\text { TB137/ } \\
\text { TB138 }\end{array}$ & $\begin{array}{l}\text { 5'-CGCGGATCCTGTAGTACATTGGACA-3' } \\
\text { 5'-CGCAAGCTTTCATTTTTTATTTCGTAGCCTGC-3' }\end{array}$ & $\begin{array}{l}\text { Amplifikation des } \\
\text { ORFs YNL136W }\end{array}$ \\
\hline $\begin{array}{l}\text { TB130/ } \\
\text { TB56 }\end{array}$ & $\begin{array}{l}\text { 5'-TTGGCATTATCTCTGTATT-3' } \\
\text { 5'-CCACGGACAGCACCCATTGC-3' }\end{array}$ & $\begin{array}{l}\text { Amplifikation des } \\
\text { deletierten ORFs } \\
\text { YNL136W }\end{array}$ \\
\hline $\begin{array}{l}\text { TB139/ } \\
\text { TB140 }\end{array}$ & $\begin{array}{l}\text { 5'-CGCGGATCCTGCTCCGACAATAAGCAAAAG-3' } \\
\text { 5'-CGCAAGCTTTCAACTTCCGTTAATGGCTTC-3' }\end{array}$ & $\begin{array}{l}\text { Amplifikation des } \\
\text { ORFs YNL107W }\end{array}$ \\
\hline $\begin{array}{l}\text { TB126/ } \\
\text { TB56 }\end{array}$ & $\begin{array}{l}\text { 5'-GACCTGTAACCATGTCTGGC-3' } \\
\text { 5'-CCACGGACAGCACCCATTGC-3' }\end{array}$ & $\begin{array}{l}\text { Amplifikation des } \\
\text { deletierten ORFs } \\
\text { YNL107W }\end{array}$ \\
\hline
\end{tabular}

\subsubsection{Oligonukleotide für Sequenzierungen}

\begin{tabular}{|l|l|l|}
\hline Primer & Sequenz & Funktion \\
\hline $\begin{array}{l}\text { pYX } \\
\text { Sequ.141 }\end{array}$ & 5'-GGTGTGCTTTACGAACAGCGCTGG-3' & $\begin{array}{l}\text { Sequenziert vor } \\
\text { MCS von } p \text { YX141 }\end{array}$ \\
\hline $\begin{array}{l}\text { pYX } \\
\text { Sequ.242 }\end{array}$ & 5'-GCTTAAATCTATAACTACA-3' & $\begin{array}{l}\text { Sequenziert vor } \\
\text { MCS von } p \text { YX142 } \\
\text { und 242 }\end{array}$ \\
\hline TB39 & 5'-GCCACTTGAGTCAACTATGG-3' & $\begin{array}{l}\text { Sequenziert EAF1 } \\
\text { von bp 500 }\end{array}$ \\
\hline TB40 & 5'-TAAGAAGACTTGGATTATGG-3' & $\begin{array}{l}\text { Sequenziert EAF1 } \\
\text { von bp 1000 }\end{array}$ \\
\hline TB41 & 5'-ATTGACACCAAGTTACTTCT-3' & $\begin{array}{l}\text { Sequenziert EAF1 } \\
\text { von bp 1500 }\end{array}$ \\
\hline TB42 & 5'-CAATTGGGAATTGATTAGTG-3' & $\begin{array}{l}\text { Sequenziert EAF1 } \\
\text { von bp 2000 }\end{array}$ \\
\hline TB45.1 & 5'-CCAATACCTTCAAATGGC-3' & $\begin{array}{l}\text { Sequenziert EAF1 } \\
\text { von bp 2526 }\end{array}$ \\
\hline TB108 & 5'-GCGCCGGTGATGCCGGCCACGAT-3' & $\begin{array}{l}\text { Sequenziert } \\
\text { YEp13; Lybarger } \\
\text { et al., 1999 }\end{array}$ \\
\hline TB109 & 5'-CTACTTGGAGCCACTATCGACTAC-3' & $\begin{array}{l}\text { Sequenziert } \\
\text { YEp13; Lybarger } \\
\text { et al., 1999 }\end{array}$ \\
\hline
\end{tabular}

\subsubsection{Oligonukleotide zur Amplifikation des $\mathrm{HIS5}^{+}$-Gens aus pFA6a-HIS3MX6}

\begin{tabular}{|c|c|c|}
\hline $\begin{array}{l}\text { 5'-Primerl } \\
\text { 3'-Primer }\end{array}$ & Sequenz & Funktion \\
\hline $\begin{array}{l}\text { TB32/ } \\
\text { TB31 }\end{array}$ & $\begin{array}{l}\text { 5'-TTACAGAGAACAGAGTGTTACGCCAACATACTAAACCAGA } \\
\text { GAAGTATGCGGATCCCCGGGTTAATTAA-3' } \\
\text { 5'-TGCGGCGTAACTACAAAATTTCTGGTTCTTCCCCCTTTCGA } \\
\text { ACCGTTAGAATTCGAGCTCGTTTAAAC-3' }\end{array}$ & $\begin{array}{l}\text { Zur Deletion von } \\
\text { YDR360W und } \\
\text { YDR359C }\end{array}$ \\
\hline $\begin{array}{l}\text { TB32/ } \\
\text { TB33 }\end{array}$ & $\begin{array}{l}\text { 5'-TTACAGAGAACAGAGTGTTACGCCAACATACTAAACCAGA } \\
\text { GAAGTATGCGGATCCCCGGGTTAATTAA-3' } \\
\text { 5'-TTATTTAGAGACATCATAATCAAAAGTACAGTTTCCGCCTC } \\
\text { AAAGTTAGAATTCGAGCTCGTTTAAAC-3' }\end{array}$ & $\begin{array}{l}\text { Zur Deletion von } \\
\text { YDR359C }\end{array}$ \\
\hline
\end{tabular}




\begin{tabular}{|c|c|c|}
\hline $\begin{array}{l}\text { TB84/ } \\
\text { TB85 }\end{array}$ & $\begin{array}{l}\text { 5'-AAGAAGGATATGCAAGTTTATATTGGACAACATAACCAATAG } \\
\text { AAGATGCGGATCCCCGGGTTAATTAA-3' } \\
\text { 5'-TAGTGTAAATGAGGTCATTCAGTCTCAAAAAGGTATTTTTGTT } \\
\text { CATTAGAATTCGAGCTCGTTTAAAC -3' }\end{array}$ & $\begin{array}{l}\text { Zur Deletion von } \\
\text { YHRO9OC }\end{array}$ \\
\hline $\begin{array}{l}\text { TB18/ } \\
\text { TB19 }\end{array}$ & $\begin{array}{l}\text { 5'-ACATTACTTGTGACCACCTATTTACGGCATCACAAAGAAAG } \\
\text { CGAGATGCGGATCCCCGGGTTAATTAA-3' } \\
\text { 5'-TACTATGGCTGTTATGAAAATACCGTTGTTCCGGGTGCAGTG } \\
\text { ATCTTAGAATTCGAGCTCGTTTAAAC-3' }\end{array}$ & $\begin{array}{l}\text { Zur Deletion von } \\
\text { YNL107W }\end{array}$ \\
\hline $\begin{array}{l}\text { TB112/ } \\
\text { TB113 }\end{array}$ & $\begin{array}{l}\text { 5'-TCTGTGAGGCCTCGTCACTGGATTTACCCTATTGAAGAA } \\
\text { CGTATAATGCGGATCCCCGGGTTAATTAA-3' } \\
\text { 5'-AAGAACTAAATACTAGAAATAATCCCAAGCTAG } \\
\text { AATATAAACGTCTTAGAATTCGAGCTCGTTTAAAC-3' }\end{array}$ & $\begin{array}{l}\text { Zur Deletion von } \\
\text { YPRO23C }\end{array}$ \\
\hline $\begin{array}{l}\text { TB116/ } \\
\text { TB117 }\end{array}$ & $\begin{array}{l}\text { 5'GATACTTCTGCGTGCCGGAGTAACCAGAATCAAAGGAACGCA } \\
\text { TAGATGCGGATCCCCGGGTTAATTAA-3' } \\
\text { 5'-AATGTTACAAGACTTTAGATTTTCGAAGTGTCGCCTACTATCT } \\
\text { CCTTAGAATTCGAGCTCGTTTAAAC-3' }\end{array}$ & $\begin{array}{l}\text { Zur Deletion von } \\
\text { YEL018W }\end{array}$ \\
\hline $\begin{array}{l}\text { TB114/ } \\
\text { TB115 }\end{array}$ & $\begin{array}{l}\text { 5'TTTCCATCATCTTTCCGTTTGTTACCAACCTACGCCTAGAAGA } \\
\text { AAATGCGGATCCCCGGGTTAATTAA-3' } \\
\text { 5'-TTTTAGAGCGGTCAAGCAACGTAAATACCAACGTGTGCTATC } \\
\text { GCATTAGAATTCGAGCTCGTTTAAAC-3' }\end{array}$ & $\begin{array}{l}\text { Zur Deletion von } \\
\text { YLR082C }\end{array}$ \\
\hline $\begin{array}{l}\text { TB110/ } \\
\text { TB111 }\end{array}$ & $\begin{array}{l}\text { 5'-TAGAAGTTGCTAGCTGCTAGTGAAGAAAAGGGAATCGTGG } \\
\text { ATGTGATGCGGATCCCCGGGTTAATTAA-3' } \\
\text { 5'-GGAACGGATGAGCGTTTATTATCGCGATCTATATATGAGC } \\
\text { AGTGATTAGAATTCGAGCTCGTTTAAAC -3' }\end{array}$ & $\begin{array}{l}\text { Zur Deletion von } \\
\text { YNL136W }\end{array}$ \\
\hline
\end{tabular}

\subsubsection{Oligonukleotide zur Amplifikation von Sonden-DNA}

\begin{tabular}{|l|l|l|}
\hline $\begin{array}{l}\text { 5'-Primerl } \\
\text { 3'-Primer }\end{array}$ & Sequenz & Funktion \\
\hline TB20/ & $\begin{array}{l}\text { 5'-CTGGAGTTAGTTGAAGCATTAGGTC-3' } \\
\text { 5'-CCAACAATAATAATGTCAGATCC-3' }\end{array}$ & $\begin{array}{l}\text { Amplification des } \\
\text { URA3-Fragments } \\
\text { aus pRS306 }\end{array}$ \\
\hline $\begin{array}{l}\text { TB27/ } \\
\text { TB28 }\end{array}$ & $\begin{array}{l}\text { 5'-TGAGAGTTGCCCCAGAAGA-3' } \\
\text { 5'-TCAATACCGGCAGATTCCA-3' }\end{array}$ & $\begin{array}{l}\text { Amplification des } \\
\text { ACT1-Fragments } \\
\text { aus genomischer } \\
\text { DNA }\end{array}$ \\
\hline $\begin{array}{l}\text { TB36/ } \\
\text { TB35 }\end{array}$ & $\begin{array}{l}\text { 5'-CGCGGATCCATGTCCTCACGTCCAAGT-3' } \\
\text { 5'-CGCAAGCTTTTGTTTTTGGAACCT-3' }\end{array}$ & $\begin{array}{l}\text { Amplification des } \\
\text { EAF1-Fragments } \\
\text { aus genomischer } \\
\text { DNA }\end{array}$ \\
\hline $\begin{array}{l}\text { TB22/ } \\
\text { TB29 }\end{array}$ & $\begin{array}{l}\text { 5'-CGCGAATTCATGATGGGAGTCGCAGCTG-3' } \\
\text { 5'-CGCAAGCTTGAAGGGATAAGGA-3' }\end{array}$ & $\begin{array}{l}\text { Amplification des } \\
\text { YDR360W- } \\
\text { Fragments aus } \\
\text { PYX141- } \\
\text { YDR360W }\end{array}$ \\
\hline TB55/ & & $\begin{array}{l}\text { Amplification des } \\
\text { HIS5'-Fragments } \\
\text { TB56 }\end{array}$ \\
& 5'-CTGTTCAGGAGCGCAAGGCGTT-3' & HIS3MX6- \\
\hline
\end{tabular}





\section{Danksagung}

Ein herzlicher Dank geht an Prof. Kurt von Figura für die Betreuung dieser Arbeit.

Prof. Gerhard Braus möchte ich für seine Bemühungen als Korreferent danken.

Vielen Dank an Prof. Peter Schu für die Bereitstellung des interessanten, herausfordernden Themas. Danke für Deine Diskussionsbereitschaft und Unterstützung in den letzten drei Jahren und dass Du mir die Freiheit gegeben hast, meinen eigenen Ideen nachzugehen.

Neben Prof. Peter Schu, möchte ich auch den zwei weiteren Mitgliedern meines Thesis Committees, Prof. Michael Thumm und Prof. Gerhard Braus für die Anregungen und wertvollen Vorschläge bezüglich meines Projektes herzlich danken.

Es war ein großes Privileg dem Graduiertenkolleg 521 unter Leitung von Prof. Detlef Doenecke anzugehören. Ich möchte vor allem inm und allen beteiligten Doktoranden für ihre große Hilfsbereitschaft, Organisation der lehrreichen Seminare und die gute Zeit danken.

In diesen drei Jahren hatte ich viel Glück mit meinen Kollegen und möchte deshalb den „übrig gebliebenen“ der Biochemie II, Rosi, Tanja, Anika, Petra, Yvonne, Jörn, Sebastian, Evelyn, Katrin, Nicole, Ellen, Markus, Florian, Martina, Matthias, Tobias, Ina, Klaus und Torben für das kollegiale Klima, ihre Freundschaft und hilfreichen, wissenschaftlichen Diskussionen danken. Vor allem Olaf, Jutta, Karthik und Jenny haben dazu beigetragen, dass die Arbeit viel Spaß gemacht hat. Bei Karthik und Jenny möchte ich mich zusätzlich für den regen wissenschaftlichen Austausch, ihr Interesse und leckeres indisches Essen und Kuchen bedanken.

Ein riesengroßer Dank geht an meine Familie. An meine Eltern Marianne und Helmut und meiner Schwester Katrin für ihre ständige, liebevolle Unterstützung, an meinen Mann Guido, der mich immer bestärkt und mir Kraft gibt und an meinen Sohn Felix, der in den letzten Jahren toll mitgearbeitet hat und uns beiden somit ermöglichte, berufstätig zu sein. 



\section{Lebenslauf}

\section{Persönliche Angaben}

Staatsangehörigkeit: deutsch

Geburtsort: Nürnberg

Geburtsdatum: 30.05.1974

\section{Schulische Ausbildung}

1980-1984 Grundschule Schwaig b. Nürnberg

1984-1986 Hauptschule Schwaig b. Nürnberg

1986-1990 Veit-Stoss Realschule, Nürnberg

1990-1994 Peter-Vischer Gymnasium, Nürnberg

Wissenschaftliche Ausbildung

1995-2001 Studium: Diplom-Biologie an der Friedrich-Alexander-Universität, Erlangen-Nürnberg

Hauptfach: Biochemie

2000-2001 Diplomarbeit an der Friedrich-Alexander-Universität, Erlangen-Nürnberg Thema: Zellzyklusregulierte Transkription in Saccharomyces cerevisiae: Identifikation regulatorischer Domänen von Swi6

2005-2008 Dissertation an der Georg-August-Universität, Göttingen

Thema: Charakterisierung der Eaf1-Funktion für die Biogenese der Aminopeptidase 1

\section{Sonstige Berufserfahrung}

2001-2003 University of Manchester, Manchester (UK)

Research Assistant (zytologische und biochemische Charakterisierung von Integrinen in Zusammenarbeit mit Sanofi-Pharma, Frankfurt) 